NAT'L INST. OF STAND \& TECH

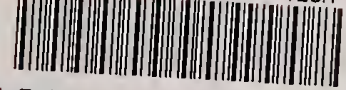

A 737070645

A1120? 206453 

. 





\section{A】l】03 073206}

NAT'L INST OF STANDARDS \& TECH RIIC.

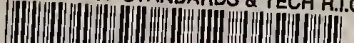

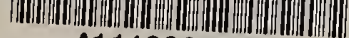

A11103073206

(n)

QC100.U57 NO.586, 1980 Csearch and innove

$\Rightarrow$ F

NBS SPECIAL PUBLICATION 586

U.S. DEPARTMENT OF COMMERCE / National Bureau of Standards

National Bureau of Standards

Library, E-01 Admin. Bldg.
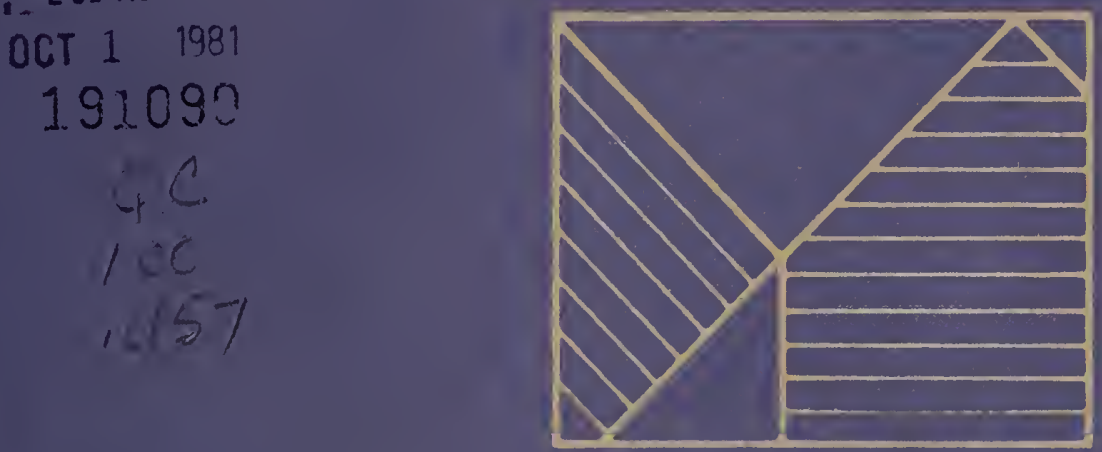

Research and Innovation in the Building Regulatory Process 


\section{NATIONAL BUREAU OF STANDARDS}

The National Bureau of Standards' was established by an act of Congress on March 3, 1901. The Bureau's overall goal is to strengthen and advance the Nation's science and technology and facilitate their effective application for public benefit. To this end, the Bureau conducts research and provides: (1) a basis for the Nation's physical measurement system, (2) scientific and technological services for industry and government, (3) a technical basis for equity in trade, and (4) technical services to promote public safety. The Bureau's technical work is performed by the National Measurement Laboratory, the National Engineering Laboratory, and the Institute for Computer Sciences and Technology.

THE NATIONAL MEASUREMENT LABORATORY provides the national system of physical and chemical and materials measurement; coordinates the system with measurement systems of other nations and furnishes essential services leading to accurate and uniform physical and chemical measurement throughout the Nation's scientific community, industry, and commerce; conducts materials research leading to improved methods of measurement, standards, and data on the properties of materials needed by industry, commerce, educational institutions, and Government; provides advisory and research services to other Government agencies; develops, produces, and distributes Standard Reference Materials; and provides calibration services. The Laboratory consists of the following centers:

\section{Absolute Physical Quantities ${ }^{2}$ - Radiation Research - Thermodynamics and}

Molecular Science - Analytical Chemistry - Materials Science.

THE NATIONAL ENGINEERING LABORATORY provides technology and technical services to the public and private sectors to address national needs and to solve national problems; conducts research in engineering and applied science in support of these efforts; builds and maintains competence in the necessary disciplines required to carry out this research and technical service; develops engineering data and measurement capabilities; provides engineering measurement traceability services; develops test methods and proposes engineering standards and code changes; develops and proposes new engineering practices; and develops and improves mechanisms to transfer results of its research to the ultimate user. The Laboratory consists of the following centers:

Applied Mathematics - Electronics and Electrical Engineering ${ }^{2}$ - Mechanical

Engineering and Process Technology ${ }^{2}$ - Building Technology - Fire Research -

Consumer Product Technology — Field Methods.

THE INSTITUTE FOR COMPUTER SCIENCES AND TECHNOLOGY conducts research and provides scientific and technical services to aid Federal agencies in the selection, acquisition, application, and use of computer technology to improve effectiveness and economy in Government operations in accordance with Public Law 89-306 (40 U.Ś.C. 759), relevant Executive Orders, and other directives; carries out this mission by managing the Federal Information Processing Standards Program, developing Federal ADP standards guidelines, and managing Federal participation in ADP voluntary standardization activities; provides scientific and technological advisory services and assistance to Federal agencies; and provides the technical foundation for computer-related policies of the Federal Government. The Institute consists of the following centers:

Programming Science and Technology-Computer Systems Engineering.

'Headquarters and Laboratories at Gaithersburg, MD, unless otherwise noted; mailing address Washington, DC 20234.

${ }^{2}$ Some divisions within the center are located at Boulder, CO 80303. 


\section{Research and Innovation in the Building Regulatory Process}

Proceedings of the Fourth

NBS/NCSBCS Joint Conference

Held in St. Louis, Missouri

on September 11, 1979, in conjunction

with the Twelfth Annual Meeting of the

National Conference of States on Building

Codes and Standards (NCSBCS), Inc.

Sandra A. Berry, Editor

Building Economics and Regulatory

Technology Division

Center for Building Technology

National Engineering Laboratory

National Bureau of Standards

Washington, D.C. 20234

\section{Sponsored by}

U.S. Department of Commerce

National Bureau of Standards

and

National Conference of States on

Building Codes and Standards (NCSBCS), Inc.

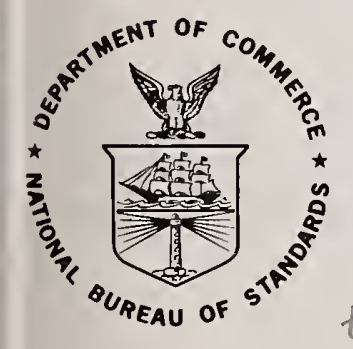

U.S. DEPARTMENT OF COMMERCE, Philip M. Klutznick, Secretary

Luther H. Hodges, Jr., Deputy Secretary

Jordan J. Baruch, Assistant Secretary for Productivity, Technology and Innovation

NATIONAL BUREAU OF STANDARDS, Ernest Ambler, Director

Issued June 1980 
Library of Congress Catalog Card Number: 80-600080

\section{National Bureau of Standards Special Publication 586}

Nat. Bur. Stand. (U.S.), Spec. Publ. 586, 261 pages (June 1980)

CODEN: XNBSAV 
The National Bureau of Standards (NBS) and the National Conference of States on Building Codes and Standards, Inc. (NCSBCS), developed and carried out this Fourth Annual NBS-NCSBCS Joint Conference on Research and Innovation in the Building Regulatory Process. The Conference was held on September 11, 1979, in conjunction with the Twelfth Annual Meeting of NCSBCS in St. Louis, Missouri.

The Joint conference provided an opportunity for researchers from industry, universities, public interest groups, and government to interact with state and local building regulatory officials and code administrators. In addition, it provided a forum for the exchange of research findings and for the reporting of innovative practices among regulatory agencies.

The proceedings include the seventeen papers presented at the various technical sessions, the opening remarks, and the Keynote Address. In addition, two papers are included which were not presented (denoted by an asterisk in the table of contents) at the actual conference.

\section{ACKNOWLEDGEMENTS}

The editor expresses appreciation for the assistance and cooperation of the following NCSBCS State Delegates and staff members of the Building Economics and Regulatory Technology Division at NBS who served as moderators to the technical sessions.

\section{NCSBCS Delegates}

Mr. Trevor Jacobson (Oregon)

Mr. Jack Kerin (California)

Mr. Joseph Cirillo (Rhode Island)
NBS Stafó

Mr. Charles T. Mahiffey

Mr. Thomas K. Faison

Mr. Patrick W. Cooke

In addition, appreciation is expressed to members of the National conference of States on Building codes and Standards staff for their assistance in carrying out the Fourth Annual NBS-NCSBCS Joint Conference on Research and Innovation in the Building Regulatory Process. 
The following list of conversion factors for the most frequently used quantities in building design and construction may be used.

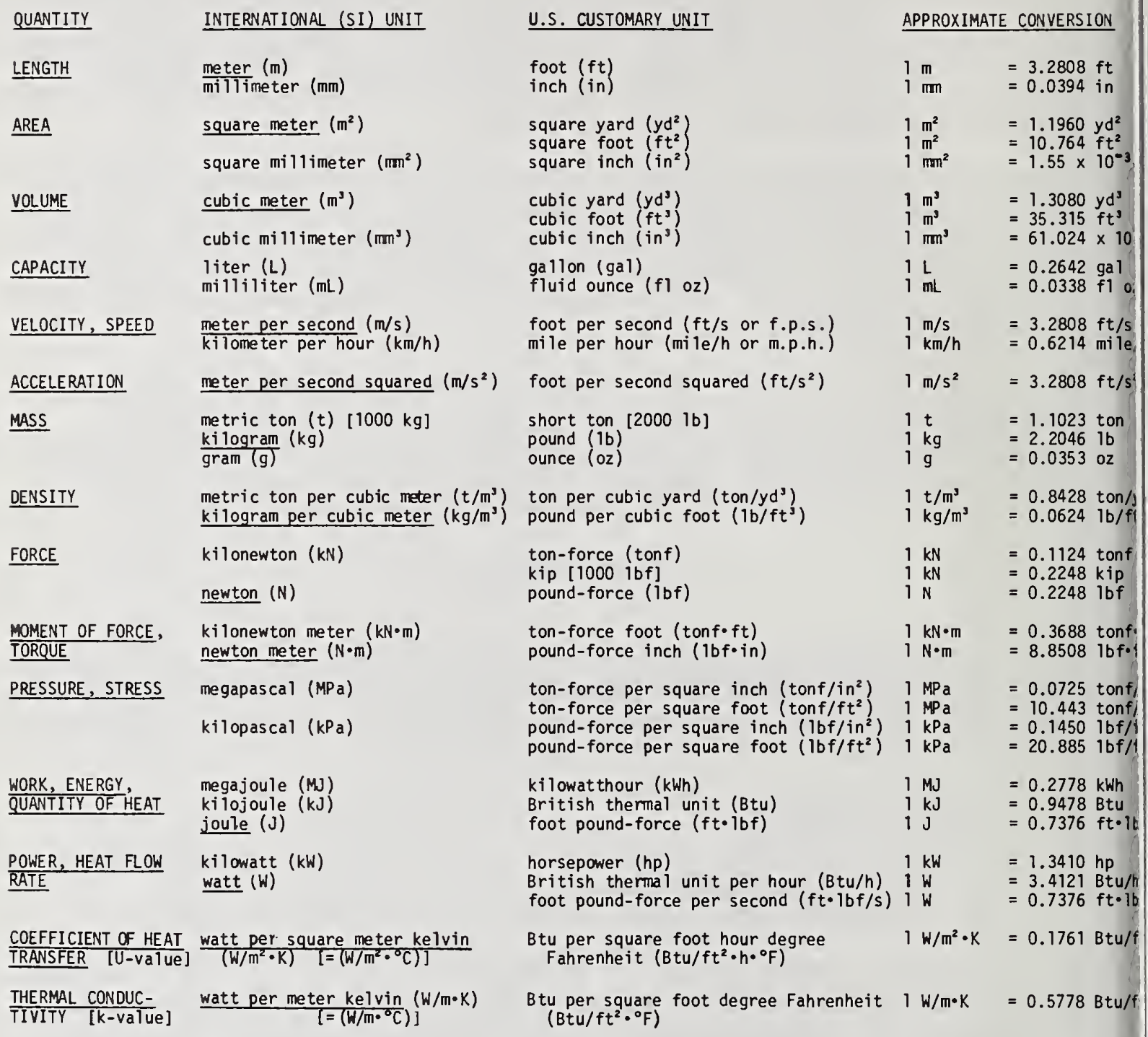

NOTES: (1) The above conversion factors are shown to three or four places of dectmals.

(2) Unprefixed SI units are underlined. (The kilogram, although prefixed, is an SI base unit.)

REFERENCES: NBS Guidelines for the Use of the Metric System, LC1056, Revised August 1977;

The Metr1c System of Measurement, Federal Register Not1ce of October 26, 1977, LC 1078, Revised November NBS Special Publication 330, "The International System of Un1ts (SI)," 1977 Edition;

NBS Technical Note 938, "Recommended Practice for the Use of Metric (SI) Units In Building Design and Construction," Revised edition June 1977;

ASTM Standard E621-78, "Standard Practice for the Use of Metric (SI) Units 1n Buflding Des1gn and Construction," (based on NBS TN 938), March 1978;

ANSI Z210.1-1976, "American Nat1onal Standard for Metric Practice;" also 1ssued as ASTM E380-76 ${ }^{\varepsilon}$, or IEEE Std.268-1976. 
Page

PREFACE...................................

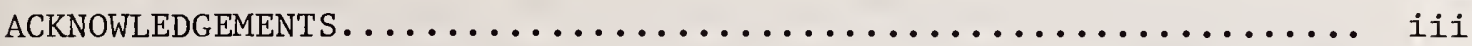

SI CONVERSION............................ iv

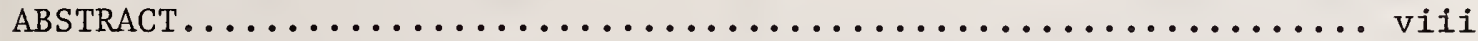

\section{OPENING SESSION}

WELCOME.................................. 1

Willard E. Bryant

Maryland Department of Economic and Community Development

INTRODUCTION TO CONFERENCE....................

Thomas K. Faison

National Bureau of Standards

KEYNOTE ADDRESS - "CHALLENGES IN BUILDING REGULATION".....

Rudard A. Jones

University of Illinois at Urbana Champaign

SESSION 1A - ISSUES IN BUILDING CODE ENFORCEMENT............

Moderator: Charles T. Mahaffey, NBS

DEVELOPMENT FEE SCHEDULE SURVEY..................

Deborah D. Fontaine

Orange County Chapter Building Industry Association

Duncan M. Coffey

Californians for an Environment of Excellence, Full

Employment and a Strong Economy through Planned

Development (C.E.E.E.D.)

*CRITERION FOR THE THERMAL INSULATION QUALITY OF A BUILDING..

J. Uyttenbroeck

Brussels, Belgium

A REPORT: INDIANA BUILDING CODE ENFORCEMENT SURVEY-1979...

David L. Bills

State of Indiana

SESSION 1B - LEGAL, POLITICAL AND EDUCATIONAL ASPECTS OF CODE

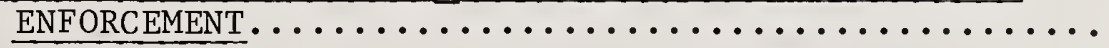

Moderator: Trevor Jacobson, NCSBCS

LEGAL RELATIONS AND CONSIDERATIONS FOR CODE OFFICIALS

AND DESIGN PROFESSIONALS....................

John R. Groves, Jr.

State of Kentucky

THE EFFECTS OF CIVIL SERVICE, UNIONS, STATUTORY LAW AND

ECONOMICS ON SYSTEMS DEVELOPMENT IN MUNICIPAL REGULATORY

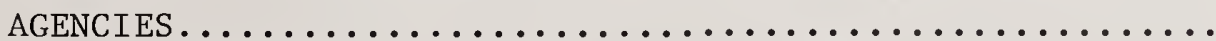

Norton S. Remmer

City of Worcester, Massachusetts 
LICENSING OF BUILDING CODE OFFICIALS: THE EDUCATIONAL

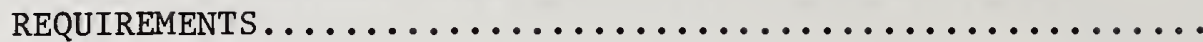

Kenneth Albert

New Jersey Institute of Technology

SESSION 2A - STUDIES DEALING WITH HOUSING CODES.

Moderator: Thomas K. Faison, NBS

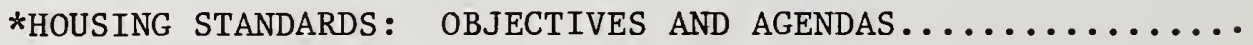

Danie1 L. Schodek

Harvard University

HOUSING STANDARDS:

THEIR DERIVATION AND RATIONALE........

Urs P. Gauchat

Harvard University

COMPARATIVE ANALYSIS OF PROVISIONS IN HOUSING CODES

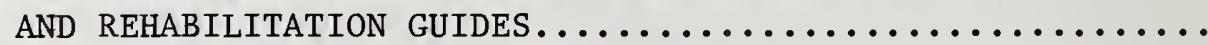

Patrick W. Cooke

National Bureau of Standards

PROBLEMS IN HOUSING CODE ENFORCEMENT: A FOCUS ON THE

BUDGET .

Carol B. Meeks

NYS College of Human Ecology, Cornell University

SESSION 2B - ENERGY CONSERVATION AND THE BUILT ENVIRONMENT......

Moderator: Jack Kerin, NCSBCS

DEVELOPMENT AND EVALUATION OF SOLAR STANDARDS AND

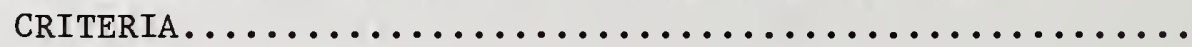

Robert D. Dikkers

National Bureau of Standards

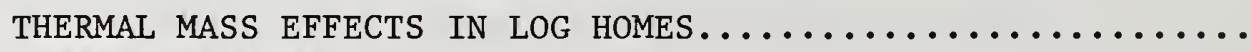

William Magruder and

Steven Winter

Steven Winter Associates, Inc.

ANALYSIS OF CODE RELATED RESPONSES FROM THE

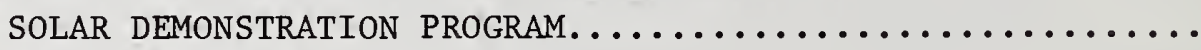
Joseph Greenberg

National Bureau of Standards

SESSION 3A - DESIGN CONSIDERATIONS AND THEIR IMPACT ON

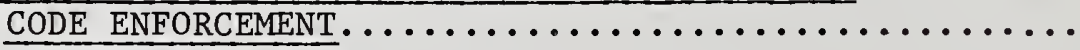

Moderator: Joseph A. Cirillo, NCSBCS

CONTRACTING FOR VALUE MANAGEMENT DURING DESIGN.......... 189 Donald E. Parker

General Services Administration 
BUILDING RECERTIFICATION AND DADE COUNTY, FLORIDA........ 197 Ralph Warburton

University of Miami

COMPUTER-AIDED DESIGN REVIEW: PREDICTING THE EMERGENCY

EGRESS POTENTIAL OF PROPOSED BUILDINGS............. 205

Fred I. Stahl

National Bureau of Standards

SESSION 3B - INNOVATIVE REGULATORY APPROACHES FOR METRICATION, INSULATION STANDARDS, AND CLIMATIC CONDITIONS....... 225

Moderator: Patrick W. Cooke, NBS

METRICATION--AN OPPORTUNITY FOR THE HARMONIZATION OF

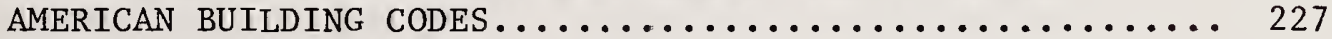

Hans J. Milton

Technical Consultant to the Center for Building Technology

National Bureau of Standards

SETTING FORMALDEHYDE STANDARDS.................... 253

Richard L. Meyer

State of Wisconsin

SNOW - WIND - ICE, ITS CHANGING EFFECT ON BUILDING

CONSTRUCTION................................ 259

Charles V. Opdyke

State of Michigan 
The Proceedings of the Fourth Annual NBS-NCSBCS Joint Conference on Research and Innovation in the Building Regulatory Process contain nineteen technical papers, the opening remarks and Keynote Address. The subject matter covered in these Proceedings includes:

- Issues in Building Code Enforcement;

- Legal, Political and Educational Aspects of Code Enforcement;

- Studies Dealing with Housing Codes;

- Energy Conservation and the Built Environment;

- Design Considerations and Their Impact on Code Enforcement; and,

- Innovative Regulatory Approaches for Metrication, Insulation Standards, and Climatic Conditions.

Key Words: Buildings; building code enforcement; design; energy conservation; housing codes; regulatory approaches. 


\section{WELCOME}

by

Willard E. Bryant

Maryland Department of Economic and Community Development National Conference of States on Building Codes and Standards, Inc.

Welcome attendees to the Fourth Annual NBS-NCSBCS Joint Conference on Research and Innovation in the Building Regulatory Process. The purpose of the Conference is to inform and assist policy decision makers in the building regulatory area through meaningful research findings and innovative administrative procedures. Researchers from industry, universities, public interest groups, and government have the opportunity to interact with State and local building regulatory officials and code administrators.

The subjects covered at this Conference can provide useful areas of study for the various standing committees, ad hoc committees and subcommittees of the National Conference of States on Building Codes and Standards, Inc. (NCSBCS). The presentations do have a direct bearing on the activities of the committees and can provide topics for further discussion. This Conference will also broaden the technical knowledge and expertise of all the attendees.

The building regulatory process in this nation is the primary mechanism for the regulation of safety and health in and around buildings. The process of regulating building construction and occupancy is diverse and decentralized. As a result, there is a need for the establishment of a more systematic understanding of the building regulatory process and a need to further identify the relationship between regulation and technical innovation.

This joint venture by NBS and NCSBCS further strengthens the bond between the two organizations and is just one of many ways the two organizations cooperate as stated in the Memorandum of Understanding between NBS and NCSBCS.

The topics to be covered are:

- Issues in Building Code Enforcement

- Lega1, Politica1, and Educationa1 Aspects of Code Enforcement

- Studies Dealing with Housing Codes

- Energy Conservation and the Built Environment

- Design Considerations and Their Impact on Code Enforcement

- Innovative Regulatory Approaches for Metrication, Insulation Standards, and Climatic Conditions

This Conference should continue to be as successful as the past three. I thank each one of you for attending with a special thanks to those making presentations and the session moderators. 



\title{
INTRODUCTION TO CONFERENCE
}

\author{
by \\ Thomas K. Faison \\ Building Economics and Regulatory Technology Division, CBT \\ National Bureau of Standards
}

$\mathrm{Mr}$. James G. Gross, who was to have made the introductory remarks is unable to be here today, but he sends his best wishes for a successful conference.

It is indeed a pleasure and an opportunity for me to be here and participate in this Fourth Annual Joint Conference. The preceding three conferences have been very successful in establishing a precedent and the opportunity to share experiences and present new ideas related to research and innovation in the building regulatory process. The scope of each of the conferences, including this one, has been broad; covering several major issues relating to and frequently impacting upon the regulatory process.

During the past several years, there has been considerable study of the impact of building codes upon the cost of construction. There have been implied and direct statements that some code requirements have a tendency to drive costs upward and tend to stifle innovation, thus prohibiting the use of more cost effective materials. The recent study which resulted in the U.S. Department of Housing and Urban Development (HUD) document, "Final Report of the Task Force on Housing Costs," alludes to building regulations being a factor in not allowing more cost effective materials and innovative building techniques. The Center for Building Technology at NBS has recently made an initial effort at developing a methodology for assessing code provisions with regard to benefits and cost. Expansion and refinement of this methodology for cost-benefit analysis will be of value in future prioritization of building code related research.

One of the major efforts of NBS is to address these code related issues from a technical approach to determine the technical rationale for the requirements and establish the technical performance base from which realistic criteria can be developed or for the modification of existing frovisions so that they are more responsive to current needs. In today's sessions we will be looking at administrative procedures, energy conservation and new energy usage, standards development, housing codes, and opportunities for improvement in these and other related topics. We should have very interesting presentations and challenging discussion periods throughout the day. 
During the past year, NBS has had the opportunity to work closely with organizations such as NCSBCS, the model building code organizations, National Institute of Building Sciences (NIBS), and particularly with the State of Massachusetts in the development of Article 22 of the Massachusetts Building Code as it relates to rehabilitation of older buildings. NBS and NCSBCS are jointly sponsoring a conference on rehabilitation in December of this year. This conference is to be held at the Jack Tar Hotel in San Francisco, California on December 10-11, 1979. The general topics of the rehabilitation conference include: Building Code Development and Enforcement; Seismic Considerations and Solutions; Legal Implications; Economic Approaches; and Energy Conservation. Literature announcing the conference is available.

We have also worked with the Council of American Building Officials (CABO) and the U.S. Department of Energy in providing technical support for the development of provisions to be included in the Document for Code Officials on Solar Heating and Cooling of Buildings. This effort, a first of its kind, is seeking to follow the consensus process from its inception to the final acceptance by the American National Standards Institute (ANSI) as a consensus document. CABO recently received accreditation by ANSI as fulfilling the requirements to develop consensus standards.

NBS looks forward to working with NCSBCS, providing technical assistance where possible, and cooperating in the sponsorship of conferences such as this one. 
Keynote Address

\title{
CHALLENGES IN BUILDING REGULATION
}

\author{
by \\ Rudard A. Jones \\ Research Professor of Architecture \\ Director, Small Homes Council- \\ Building Research Council \\ University of Illinois at Urbana-Champaign
}

I am very happy to have the opportunity to participate in this NBS/ NCSBCS research conference by presenting the Keynote Address. When I was invited to make this talk, there was no mention of any requirements or limitations; therefore, I have chosen to use this occasion as an opportunity to present some personal thoughts on the "state-ofthe-art" of building regulation and to express some opinions as to some of the challenges we are now facing and will have to face in the future.

I say "we" because, although I am not on the firing line administering building regulation, my work at the University of Illinois is certainly related to building process and building quality. As some of you may know, when the University of Illinois' Small Homes Council was founded in 1944, the Board of Trustees of the University charged the Council to "keep abreast" of all that is "new" and "inform the public impartially." It further said that the Council should "cooperate with industry." Accordingly, I feel knowledge of on-going activities in building regulation is a part of my duties, and of other Council staff members too.

In addition, I have had a long-time personal interest in the development of standards in the building area. For these reasons I feel I can say "we" without being too presumptuous.

I must also emphasize that this presentation today is the expression of a purely personal viewpoint. I am not wearing my American Society for Testing and Materials (ASTM) hat; I am not wearing my National Institute of Building Sciences (NIBS) hat--nor my Building Research Advisory Board (BRAB) hat--nor my University hat. In fact, I come to you without any hat on my head whatsoever.

Building regulation is not static. We continually face new and expanding challenges. It seems to me that one of the most difficult challenges we face is that of coping with the tremendous expansion of the number of agencies that are intervening in the building regulation system. 
The Federal presence seems to increase constantly. For example, there are now six Federal agencies that are setting standards, or rules, or regulations, on insulation. These are the Department of Housing and Urban Development, the Department of Commerce, the Department of Energy, the Consumer Products Safety Commission, the Federal Trade Commission, and the Environmental Protection Administration.

The most serious Federal challenge to the building regulation system as it functions today is the proposal of the Federal Trade Commission (FTC) to regulate the operations of the voluntary standards writing organizations.

As you well know, building regulations rely heavily on voluntary standards developed by other organizations such as the American Society for Testing and Materials (ASTM) and the National Fire Protection Association (NFPA). In my opinion, the voluntary standards system, as exemplified by ASTM, is working quite well and is performing a real service to this country.

I submit that two of the major thrusts of the FTC are contradictory. On the one hand they profess to be concerned about the development of standards that will assure products of adequate quality. On the other hand they are concerned that standards will not restrain trade. I suggest that any decent standard will create restraint of trade. That is what we want to do; that is, we try to eliminate a poor product from the marketplace. It is important to have both things; that is, you cannot have completely unlimited trade and quality products at the same time. The two goals are not compatible.

I further submit that the procedures proposed by the FTC staff would be cumbersome and cause delay in the standards writing process while at the same time they would set up a development schedule which could not be achieved by the voluntary system. I believe the proposed ruling would greatly curtail the effectiveness of the voluntary system and might eventually lead to its dissolution.

In case you feel that I am unduly biased in this matter, read what the Executive Director of the National Conference of States on Building Codes and Standards, Inc. (NCSBCS) had to say in the July 1979 NCSBCS Newsletter.

All the pro and con testimony on the proposed FTC rule is now on the record; let us hope the FTC will decide not to issue the proposed rule, or any other rule which will hamper the effectiveness of the voluntary standards system.

The FTC situation points up an overall basic challenge: "How do we preserve the prerogatives of the individual States, but, at the same time, achieve a reasonable harmonization of building regulations?" This is a difficult task, but members of NCSBCS are well aware of their success in the development of reciprocity with respect to the examination of mobile homes. We should also be aware of the attempt that is 
being made to harmonize the building codes of the European Economic Community. The more successfully we meet this challenge, the better we shall be able to resist the federalization of building regulations.

Part of our problem in achieving harmonization of our codes is the problem of language and vocabulary. We need to put aside our parochial differences and develop a common language in order that we may communicate more readily. At the present time NIBS is initiating an effort to develop a broad consensus on the meaning of some terms used in connection with building regulations. For example, we need to develop and use clear definitions as to what is meant by standards, model codes, codes of practice, specifications, etc. In this way we can expedite and clarify communications between the various segments of the regulation process.

Another major challenge that we are facing relates to the scope of building regulations. How do we handle the expanding role of building regulations? We all know that our regulations are based on the idea of protecting health, safety, and welfare. (In my classes at the University I substitute the term "well being" for "welfare," inasmuch as the term "welfare" has an entirely different connotation today than it did when the idea was originally expressed.) There are two facets of this expanding role. One of them has to do with a much higher degree of protection and the other has to do with the broadening of the groups that are to be protected.

Somehow or other we have to make a better assessment of the real benefit of some of the protective measures that are being added to building codes. In this respect we are beginning to hear about cost/benefit assessments of new measures. This is a step in the right direction, but it is not easily accomplished. For example, on the economic side we can estimate some dollar costs of some of the new devices that are required for the building. On the other hand, we cannot very well assess the cost to society of pricing housing out of the marketplace. And, of course, it is very difficult and no one really wants to put a dollar value on a human life. Nevertheless, we should take a good look at some of the regulations that are proposed as life-saving measures, and try to make a reasonable judgment as to their cost and their effectiveness. The Center for Building Technology (CBT) at the National Bureau of Standards has demonstrated one technique for this type of evaluation with its study on the cost benefit ratio of the use of ground-fault-interruptors in housing. Committee E6 of ASTM has embarked on the development of some standard practices for performing these types of economic evaluations.

A big part of the problem of expansion of the role of the building code is related to the term "welfare." Originally, we were concerned with the well being of the occupants of the house; this has been expanded to include concern for the neighborhood and the city. The latest expansion has to do with some of our societal objectives. The matter 
of energy conservation falls into this category. The proposed and existing regulations for energy conservation stem from an objective of our society as a whole rather than coming from protection of the individual housing consumer.

The matter of elimination of architectural barriers to the physically handicapped, particularly wheelchair users, is an example of our concern for the welfare of a special group of people. All of us can agree that such provisions are desirable, but how far do we go? A few years ago it was proposed that all housing should be designed and built to accommodate paraplegics. The reasoning was expressed in the statement, "I want to be able to visit all my friends."

In one of the hearings I testified against this pointing out that some features necessary to the handicapped would affect the general population adversely. For example, a kitchen that is suitable for a wheelchair user is not suitable for others. Both populations cannot be served by the same solution.

I also pointed out that economic considerations would effectively eliminate the two-story house as a housing form, because it would require an elevator or an extensive ramp system to accommodate persons confined to a wheelchair. In these days, when land costs are a problem, and higher density housing seems to be one of our better solutions, we cannot afford to rule out multi-level houses. Needless to say, I felt quite uncomfortable in presenting this testimony before an audience which included a number of handicapped persons. Issues such as these are charged with emotion, but we must try to evaluate them objectively.

Another challenge which we face with respect to the expanding scope of building codes and building regulations relates to the pressure that seems to be increasing for the inclusion of items which I am inclined to classify as "consumer protection items." We are beginning to see some effort to include in building codes durability requirements for certain mechanical systems, as well as efficiency requirements for these systems. I believe that we must look very carefully at such requirements before we decide the building code is the proper place for this type of protection.

The last challenge that I want to speak about relates more directly to research activities. Most of us are in agreement that fundamentally the idea of performance standards and codes is a good one. At the same time we must recognize that the administration and the use of such standards is difficult, unless we have a satisfactory means of assessing the performance. This means that a great many more test methods and other types of evaluating procedures must be devised. There is ample room for expansion of research in this area. Furthermore, for the purposes of building regulation it is necessary for us to develop much more satisfactory means of predicting performance. This is particularly 
well illustrated by the problems which are being encountered in developing a performance code with respect to energy use. If the performance code is to specify energy use in tarms of the amount of energy that a building will use during a given period of time, we must have some means of predicting from the plans and drawings of that building the amount of energy that it will use. Such a system is not as yet perfected, and until it is perfected, the use of performance energy codes of this nature will not be feasible.

These are only a few specific reminders of the expanding challenges that are constantly arising in building regulation. I would have liked to comment on consumer participation as well as on the regulation of rehabilitation, but time constraints prevented this.

Thank you for giving me the opportunity to make these comments. 

SESSION $1 \mathrm{~A}$ - ISSUES IN BUILDING CODE ENFORCEMENT

\author{
Moderator: Charles T. Mahaffey \\ Building Economics and Regulatory \\ Technology Division \\ Center for Building Technology, NEL \\ National Bureau of Standards \\ Washington, D.C.
}




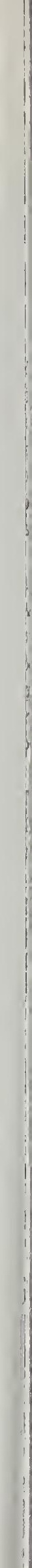




\author{
by \\ Deborah D. Fontaine \\ Orange County Chapter Building Industry Association \\ Irvine, California \\ and \\ Duncan M. Coffey \\ Californians for an Environment of Excellence, Ful1 Employment \\ and a Strong Economy through Planned Development (C.E.E.E.D.)
}

In January of 1971 , due to the rising costs of housing and the insufficient supply of affordable housing in Orange County, California, the Board of Supervisors passed a policy which mandated builders to provide $25 \%$ of all new homes at affordable prices. Because of the high cost of land, the escalating costs of labor and materials, and the delays in the governmental processing, this task will not be easily attained.

As a result, the Orange County Chapter of the Building Industry Association--a trade association comprised of over 600 companies bound together by the common desire to improve working, business, and profit conditions in the building industry--with CEEED--a coalition of taxpayers, property owners, business and organized labor supporting property rights, land use and free enterprise--joined efforts to research a development fee schedule.

This schedule incorporates 38 development fees which highlight the major building, engineering and planning requirements needed for approval by the local governments.

The study is based upon a hypothetical "model" consisting of 50 detached single-family, wood framed dwellings, situated on a 10 acre parcel of land, resulting in a density of 5 units per acre. In order the achieve an accurate study, 3 sized model units were researched. They are as follows:

$\begin{array}{cccccc}\begin{array}{c}\text { Square Footage } \\ \text { Living Area }\end{array} & \begin{array}{c}\text { Square Footage } \\ \text { Garage }\end{array} & \text { Bedrooms } & \text { Baths } & \text { Sales Price } \\ 1,300 & 400 & & 2 & 2 & \$ 70,000 \\ 1,500 & 400 & & 3 & 2 & \$ 90,000 \\ 2,000 & 400 & 4 & 2-1 / 2 & \$ 110,000\end{array}$

In addition to the above criteria, a supplemental study will be completed and accompany the original study. The second study will focus on affordable housing and in particular, the effect of the County's new housing element policy, The two studies will analyze development fee costs for low cost/higher density units compared to high priced/lower density units. Also, single-family versus multi-family, attached versus detached and greater versus reduced square footage living area, will be considered.

Key Words: Affordable housing; development fee; planning cost;

Proposition 13. 
On June 6, 1978, California voters approved the passage of Proposition 13, the Jarvis Gann Amendment. The main purpose of this initiative was to alleviate escalating property taxes. State and local governmental agencies were faced with the problem of funding essential services formerly covered by property tax revenues.

In the face of this decline in tax revenues, builders and developers in California have experienced a $225 \%$ increase in development fees which have been imposed at the city and county levels.

In January of this year, as a result of rising housing costs and an insufficient supply of affordable housing in Orange County, the Board of Supervisors passed a resolution under the state housing element which required builders to provide $25 \%$ of all new homes at affordable prices. Because of the high cost of land, escalating costs of labor and materials, and delays in governmental processing, this goal will not be easily attained.

Orange County is the first county in California to comply with the State's mandatory housing element and its plan is being viewed by many as the prototype for affordable housing. Not only are state authorities closely monitoring the results of this program, but national attention as well is being focused on the plan.

As a result, the Orange County Chapter of the Building Industry Association, a trade association which is comprised of over 600 firms bound together by a common desire to improve working, business and profit conditions in the building industry, in conjunction with Californians for Environment, Employment, Economy and Development (C.E.E.E.D.), joined efforts to research a development fee schedule.

Our project involved detailed research on thirty-eight categories of development fees assessed by the County of Orange, as well as the twentysix cities under its jurisdiction.

These fees highlight many of the major building, engineering and planning requirements needed for approval by the local governmental agencies.

The study was based on a hypothetical "model" consisting of fifty detached, single family, wood-framed dwellings, situated on a ten acre parcel of land, resulting in a density of five units per acre. In order to achieve an accurate study, three sized model units were researched. A 1300 square foot two bedroom-two bath home, selling for $\$ 70,000$; a 1500 square foot three bedroom-two bath home, selling for $\$ 90,000$; and a 2000 square foot home with four bedrooms-two and one half baths, selling for $\$ 110,000$.

As evidenced by the attached criteria key, it is important that other information be taken into consideration, in addition to the physical characteristics. These include, but are not limited to an assumed value of one gross acre of land being $\$ 100,000$ and a predetermined per lot improvement cost. 
In accumulating the information, we personally visited each city to acquire current and correct data. We then formulated each city's input and returned the format to the appropriate city or county official for their review.

However, because of frequent changes in fees, this analysis provides only a partial comparison. A number of jurisdictions were in the process of reviewing their fees at the time of the survey and a few substantial increases may have occurred subsequent to the survey. These increases are not reflected in the analysis.

After the cities reviewed and returned the information, it was converted to a cost per lot breakdown for the fifty units in the hypothetical project.

We then compared our findings to a 1975 Board of Supervisors survey which was researched by California State University at Fullerton. Some of the findings of this comparison for a 1300 square foot home are as follows:

1. When averaging the 1975 study, the total development fees ranged from $\$ 847.00$ for the City of Seal Beach to $\$ 2,030$ for the City of Laguna Beach. The average total development fee per city was $\$ 1,127.87$.

2. When averaging the 1979 study, the fees range from $\$ 1,260$ for the City of La Habra to $\$ 7,382$ for the City of San Clemente. The average total development fee per city was $\$ 3,437.31$.

3. When comparing the 1975 study to the 1979 study, the percentage increases in total development fees ranged from $33 \%$ for the City of La Habra, to the City of Irvine with a $551 \%$ increase. The average total development fee percentage increase per city was $205 \%$.

We have chosen the City of San Clemente to illustrate some of the trends in the specific fee areas. The following breakdown is based upon the 1979 fees for a 1300 square foot home as shown on the development fee schedule.

For a 1300 square foot home, the City of San Clemente assesses charges of \$825.69 for building fees. These fees include building permits, plan checks, electrical permits and plumbing permits. Under engineering fees, flood and drainage, engineering and inspection, grading and inspection, and sewer fees have been taken into consideration to arrive at a total of $\$ 1,759.50$. When determining the planning fees, it is important to remember that all fees listed may not be applicable for any one project. However, for our purposes, all will be taken into consideration. Planning fees include conditional use permit fees, processing fees for environmental impact reports which are required by California law, as well as zone changes, variances and numerous other categories. The planning fees for the City of San Clemente total $\$ 4,796.76$. This extremely high 
planning cost can be attributed to the park-in-lieu fee which is $\$ 3,538.00$ per unit and an assessed school fee of $\$ 1,200$ per unit.

In summary, the City of San Clemente charges a $\$ 7,381.89$ per unit for building, engineering and planning fees. When using the $\$ 7,381.89 \mathrm{fig}-$ ure, the total amount that the builder/developer must pay to the City of San Clemente for our hypothical project will be $\$ 369,094.50$. Please keep in mind that the fees referenced are by no means the total fees required by the agency, rather, they are some of the major fees only.

There have been frequent changes in fee structures throughout the County since June 1978. In addition to the consistent fees which each jurisdiction assesses, a few cities have enacted new fees such as an energy fee, a library fee, a seismic fee, an agricultural preserve fee and new bedroom taxes.

Alfred Gobar \& Associates, Inc., a well respected residential marketing firm in Southern California, recently completed their "Concise Factors for Housing Cost Increases in Orange County" which was prepared for C.E.E.E.D. In their report, they conclude that fees have increased annually over $30 \%$ since 1975 . Therefore, the median rate of increase for fees surpassed the rate of increase in home prices in the twentyseven jurisdictions studied.

The study has just been printed and it is in the process of being distributed to county and city governmental agencies, in addition to any interested parties within the building industry. 
DEVELOPM

\begin{tabular}{|c|c|c|}
\hline CITY & \begin{tabular}{|c|} 
BLILOIHS: \\
PERMIT \\
1300 SI.FT.
\end{tabular} & $\begin{array}{c}\text { PLQR } \\
\text { CHECK } \\
1300 \text { SO.FT. }\end{array}$ \\
\hline ANAHE IM & 272.79 & 175.18 \\
\hline BREA & 162.73 & 94.20 \\
\hline BUENA PARK & 381.59 & 238.70 \\
\hline COSTA MESA & 156.78 & 77.00 \\
\hline CYPRESS & 199.20 & 83.00 \\
\hline $\begin{array}{l}\text { FOUNTAIN } \\
\text { VALLEY }\end{array}$ & 156.68 & 77.00 \\
\hline FULLERTON & 185.60 & 83.00 \\
\hline $\begin{array}{l}\text { GAROEN } \\
\text { GRDVE }\end{array}$ & 181.50 & 112.75 \\
\hline $\begin{array}{l}\text { HUNTINGTON } \\
\text { BEACH }\end{array}$ & 177.60 & 88.80 \\
\hline IRVINE & $\$ 43.65$ & 103.80 \\
\hline LA HABRA & $260.50 * *$ & $130.25 * *$ \\
\hline LAGUNA BEACH & $345.00 * \star$ & 207.00 ** \\
\hline LA PALMA & $187.00^{* *}$ & 93. $50 * *$ \\
\hline LOS ALAMITOS & 220.50 & 143.33 \\
\hline MEINPORT BEACH & 228.00 & 148.20 \\
\hline ORANGE & 157.00 & 77.00 \\
\hline PLACENTIA & 166.80 & 81.00 \\
\hline SAR CLEMENTE & 640.19 & 87.50 \\
\hline $\begin{array}{l}\text { SAN JUAN } \\
\text { CAPISTRANO }\end{array}$ & 1261.00 & 425.75 \\
\hline SANTA ANA & 177.60 & 88.80 \\
\hline SEAL BEACH & $235.50 * *$ & $117.75 * *$ \\
\hline STARITON & 192.57 & $94.5 n$ \\
\hline TUSTIN & S95.67 & 81.00 \\
\hline VILLA PARK & 188.00 & 110.00 \\
\hline WESTIHINSTER & 191.00 & 94.50 \\
\hline YORBA LINOA & 258.57 & 127.50 \\
\hline COUNTY & 188.00 & 111.00 \\
\hline
\end{tabular}

* All Planning Fees may not be applicab * Oata not confirmed by City 




\section{CRITERION FOR THE THERMAL INSULATION \\ QUALITY OF A BUILDING \\ by \\ J. Uyttenbroeck \\ Belgian Building Research Institute \\ Brussels, Belgium}

In an effort to conserve energy in Belgium, the Belgian Standardization Institute has published a draft of a proposed standard for thermal insulation of a building. The concept and methodology is described in this paper.

The global thermal insulation value, $U_{m}$, varies as a function of the ratio of volume of the building to the exposed area of the building (V/A). The relationships are simple and the implementation, through legislation and enforcement, is relatively straight-forward.

Key Words: Heat loss; standard; thermal insulation; U-value. 
With the world shortage of fuels and the costs of fuel steadily increasin. there is need to establish limits for heat loss from heated building spaces. In Belgium and other European countries, attempts have been made to address this problem. The methodology for the Belgian thermal insulation standard for buildings is described here.

\section{DEFINITIONS}

\section{Mean U-value of a Building}

The overall or mean U-value of a building " $\mathrm{U}_{\mathrm{m}}$ " can be defined by the following expression:

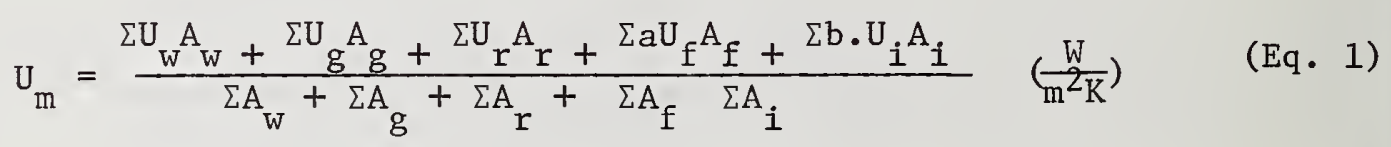

In this expression

$U_{W}, U_{g}, U_{r}, U_{f}, U_{i}$ are the U-values of

- the external walls (w)

- the glazed areas in the building enclosures ( $g$ )

- the roofs ( $r$ )

- the inferior* floors (f) and parts of the walls in contact with the earth

- the interior walls between the building and unheated rooms or spaces of other buildings (i);

$A_{W}, A_{g}, A_{r}, A_{f}, A_{i}$ are the areas $\left(m^{2}\right)$ of the above mentioned bưilding êlements;

$\mathrm{a}$ and $\mathrm{b}$ are reduction factors.

In the Belgian proposal

$a=1$ for inferior floors above the open air

$a=2 / 3$ for inferior floors above non-heated spaces or rooms and for walls in contact with the earth

$a=1 / 3$ for inferior floors directly on the ground

$\mathrm{b}=2 / 3$ for interior separation elements between the building being considered and non-heated spaces or rooms of another building.

*The term "inferior" refers to transmission paths to the earth. 


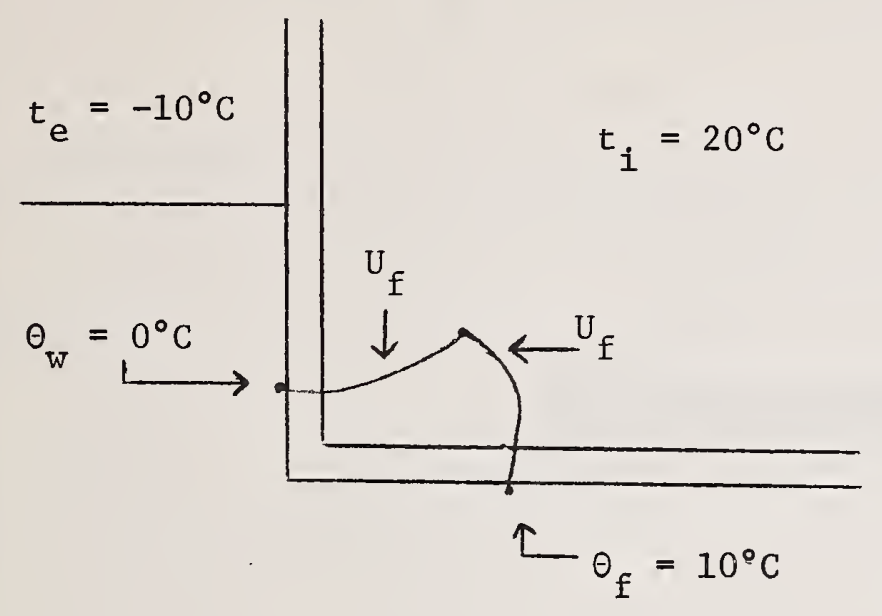

Figure 1: Illustration of Intermediant Heat Flow Paths

It must be noted that the $U_{f}$-values of floor above are the U-values between the interior space of the heated building and the underside of the floor or the earthside of the wall.

This approach, as illustrated in Figure 1 , is based on the approximation that a normal interior temperature in the heated building is $t_{i}=20^{\circ} \mathrm{C}$, and the basic outdoor temperature is $t_{e}=-10^{\circ} \mathrm{C}$ (for the greater part of Belgium), which gives a total $\Delta t$ of $30 \mathrm{~K}$. The temperature on the outside of a wall in contact with the earth is considered to be $\theta_{\mathrm{W}}=0^{\circ} \mathrm{C}$ and on the underside of the floor $\theta_{\mathrm{f}}=+10^{\circ} \mathrm{C}$.

\section{Total Heat Loss Area of a Building A}

The total heat loss area of a building is given by the sum of terms of expression (1):

$$
A=\sum A_{W}+\sum A_{g}+\sum A_{r}+\sum A_{f}+\sum A_{i} \quad\left(m^{2}\right)
$$

The heat loss area of a building does not always correspond with the visible building envelope. For example, in the case of a building where the insulation is placed on the attic floor, the roof area to be taken into account is of course the area of this attic floor and not the area of the uninsulated roof. 


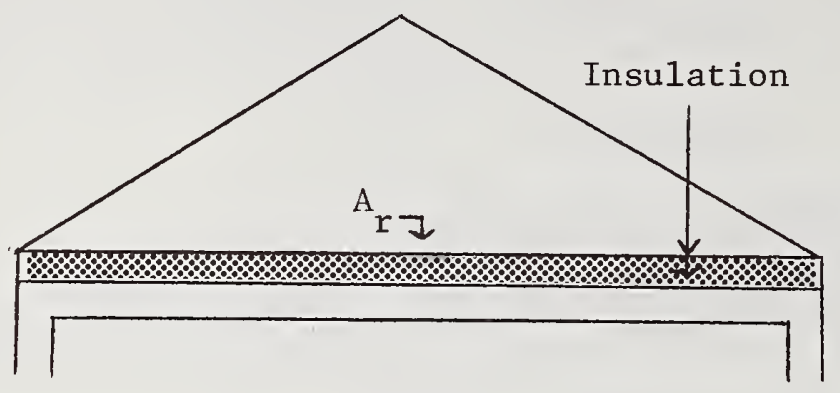

Figure 2: Illustration of Heat Flow Through the Ceiling Area Rather than the Gross Area of the Roof.

\section{Volume of a Building: V}

The volume of a building is the total volume ( $\mathrm{m}^{3}$ ) included in the heat loss area $A$ of the building and sometimes by some interior walls between the building being considered and normally heated rooms or spaces of another building.

\section{BASIS OF A CRITERION}

\section{Unique Requirement}

An acceptable basis for a criterion of the thermal insulation of a building seems to be that an allowance be established for each cubic meter of the heated (protected or insulated) volume of the building so that a given amount of energy that may be consumed to neutralize the transmission losses of the building.

For a building with a global $U_{m}$ value $\left(W / m^{2} \mathrm{~K}\right)$ and with a total heat loss area $A\left(\mathrm{~m}^{2}\right)$ the transmission heat losses per $\mathrm{K}$ are

$$
\mathrm{U}_{\mathrm{m}} \cdot \mathrm{A} \quad(\mathrm{W} / \mathrm{K})
$$

And, the transmission losses per $\mathrm{K}$ and per $\mathrm{m}^{3}$ are

$$
\mathrm{U}_{\mathrm{m}} \cdot \frac{\mathrm{A}}{\mathrm{V}}=\mathrm{C} \quad\left(\mathrm{W} / \mathrm{m}^{3} \mathrm{~K}\right)
$$


If the above expression is limited to a given constant value $\mathrm{C}$, an expression of equilateral hyperbole is arrived at

$$
\mathrm{U}_{\mathrm{m}} \cdot \frac{\mathrm{A}}{\mathrm{V}}=\mathrm{C} \quad\left(\mathrm{W} / \mathrm{m}^{3} \mathrm{~K}\right)
$$

The expression (2) is represented in Figure 3.

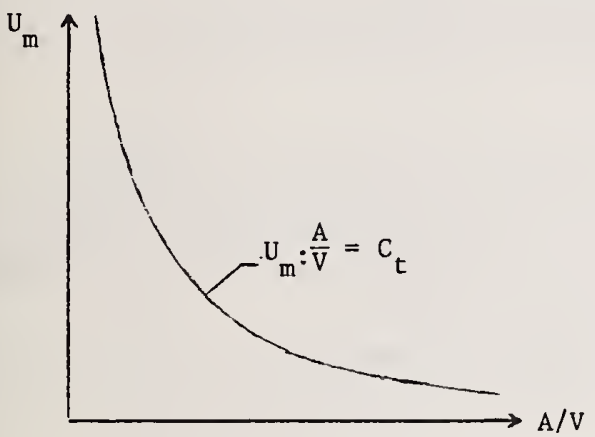

Figure 3: Global $\mathrm{U}_{\mathrm{m}}$ Represented as a Function of the Area to Volume Equation 2 can also be written as

$$
\mathrm{U}_{\mathrm{m}}=\mathrm{C} \cdot \frac{\mathrm{V}}{\mathrm{A}} \quad\left(\mathrm{W} / \mathrm{m}^{2} \mathrm{~K}\right)
$$

This is the expression of a straight line passing through the origin of a diagram giving $\mathrm{U}_{\mathrm{m}}$ as a function of V/A (Figure 4).

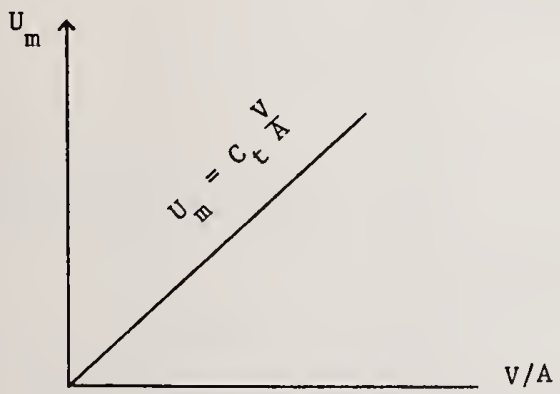

Figure 4: Global $U_{m}$ As a Function of Volume-Area Ratio 


\section{Practical Limitation of the Basic Criterion}

The logical criterion as proposed above cannot be adopted for all kinds of buildings. Indeed, as can be seen (Figure 3 or 4), such a simple requirement will lead to requirements which would be too strict for independent houses or in general for constructions with a high value of $\mathrm{A} / \mathrm{V}$ (Figure 3 ) or with a low value of V/A (Figure 4 ).

A unique requirement shall also lead to a very poor insulation for buildings with a low A/V value (or a high V/A value).

So it seems necessary to adapt this simple requirement by fitting the equilateral hyperbole or by adopting a straight line which cuts the $U_{m}$ axis in a point situated above the origin. It seems also logical to $\mathrm{m}$ limit the fitted curve or the straight line by two constant values for small values of $(A / V)$ and for great values for $(A / V)$.

A general form of the requirement can be shown as in Figures $5 a$ and $5 b$.

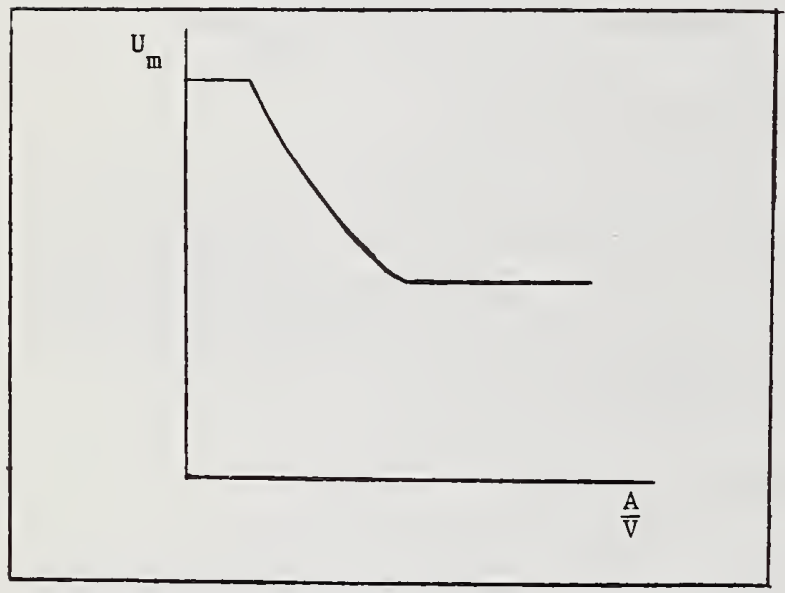

Figure 5a

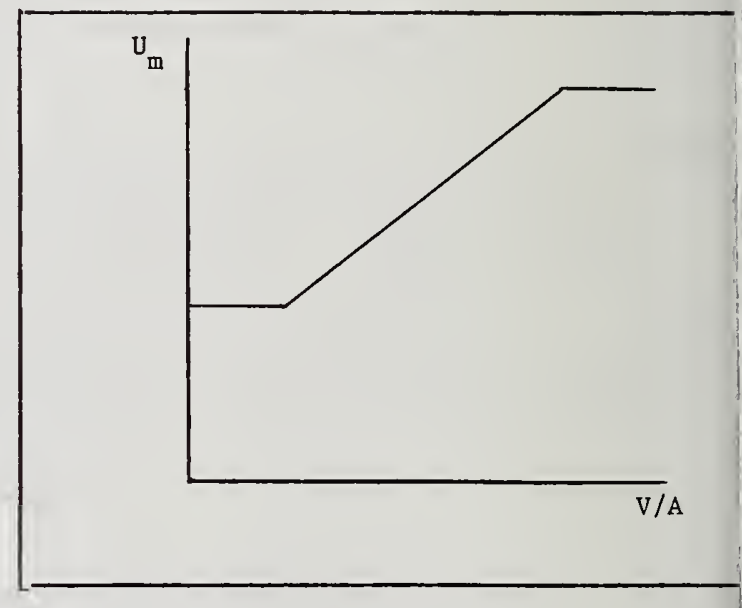

Figure 5b

Constant Values of $U_{m}$ Established for the Extreme Regions of the Curves 
In a study (*) made on request of the European Communities the opportunity was taken to make a comparison between the different regulations on the thermal insulation of buildings (transmission losses only). In this study, translations of these different regulations were made in a common language, through the use of a diagram giving the maximum allowed $U_{m}$ value as a function of the term $A / V$.

The result of this study is represented in Figure 6. As illustrated, most of the national requirements represented more or less follow the philosophy which has been described above.

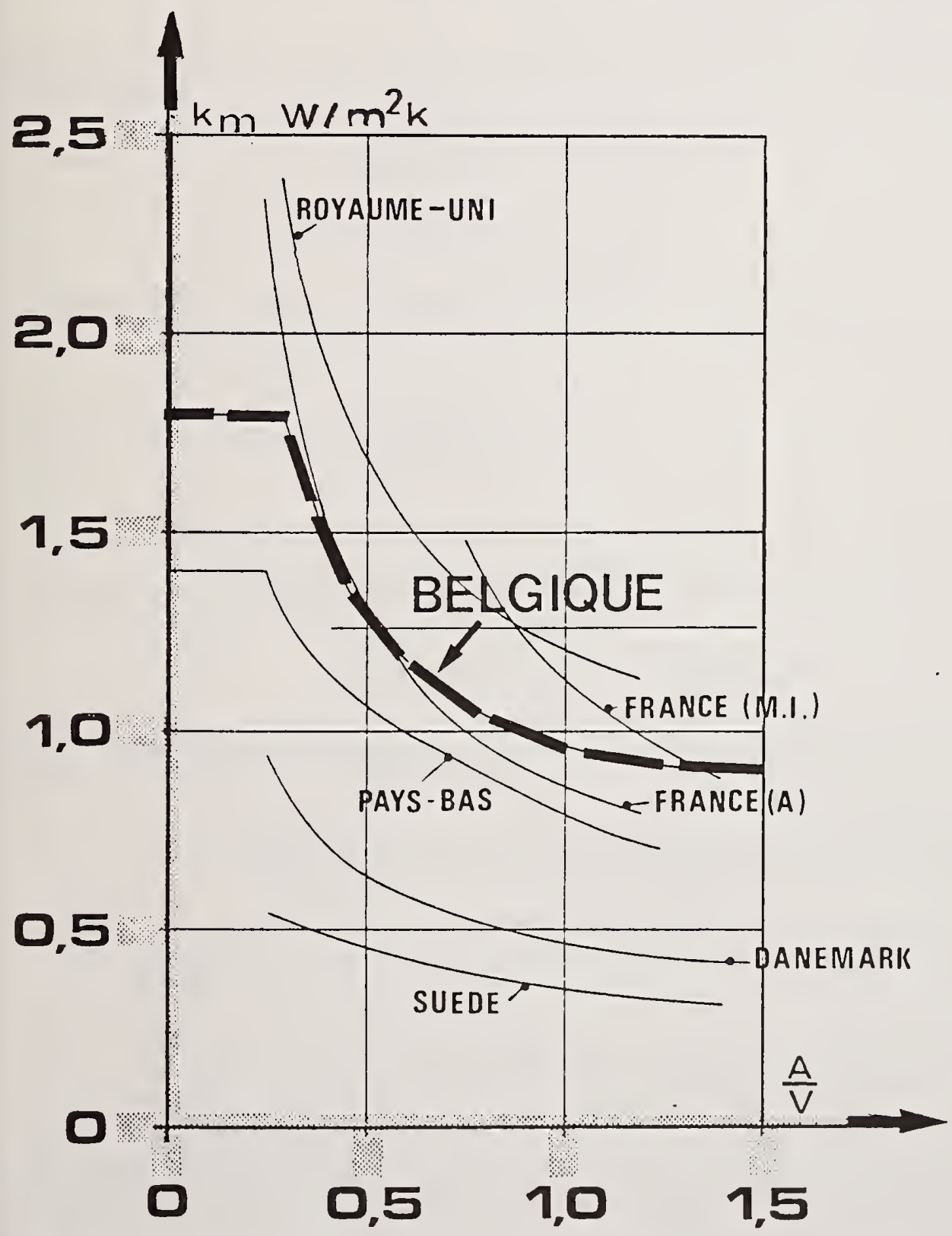

Figure 6: Comparison of Several European Thermal Insulation Standards 
For the practical use of the proposed requirement it seems to be easier to adopt a requirement under the form of a straight line rather than under the form of a curve.

So, we propose that the presentation in a $\left(U_{-}-V / A\right)$ diagram form (see Figure 5b) be accepted. In such a diagram the requirement will be represented by a straight line which will be completely defined by the slope $(B)$ of the straight line and by the value of $U_{m}$ corresponding to $\mathrm{V} / \mathrm{A}=0\left(\mathrm{U}_{\mathrm{mo}}\right) \cdot \quad$ (See Figure 7.$)$

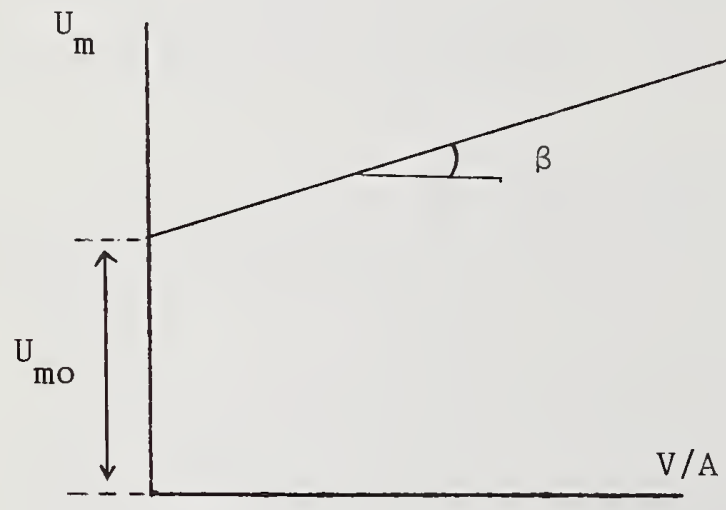
Figure 7: $\mathrm{U}_{\mathrm{m}}$ is a Linear Function of $\mathrm{V} / \mathrm{A}$, the Slope of Which is
Determined by $\beta$

Significance of the Slope $\beta$ and of the $U$ mo Value

Consider a building with overall dimensions

$\mathrm{L}$ length (m)

B depth (m)

$\mathrm{H}$ height (m)

The included volume is

$$
V=L B H \quad\left(m^{3}\right)
$$

The total heat loss area $\mathrm{A}$ equals

$$
A=2(\mathrm{LB}+\mathrm{BH}+\mathrm{LH}) \quad\left(\mathrm{m}^{2}\right)
$$


Let us indicate the window area as a fraction $\alpha$ of the total floor area. So if $h$ is the height of one story ( $h=$ free height between two floors + the thickness of one floor), we can say that the total floor area equals

$$
\frac{\mathrm{H}}{\mathrm{h}} \cdot \mathrm{LB} \quad\left(\mathrm{m}^{2}\right)
$$

And, the window area can thus be given by

$$
\alpha \cdot \frac{\mathrm{H}}{\mathrm{h}} \cdot \mathrm{LB} \quad\left(\mathrm{m}^{2}\right)
$$

Transmission heat losses per $\mathrm{K}$. The transmission heat losses are equal to the sum of

- transmission losses through the vertical walls

$$
\mathrm{U}_{\mathrm{W}}\left(2 \mathrm{LH}+2 \mathrm{BH}-\alpha \frac{\mathrm{H}}{\mathrm{h}}: \mathrm{BL}\right) \quad\left(\frac{\mathrm{W}}{\mathrm{K}}\right)
$$

- transmission losses through the windows

$$
\mathrm{U}_{\mathrm{g}} \cdot \frac{\alpha}{\mathrm{h}} \cdot \mathrm{HLB}
$$

- transmission losses through the roof

$$
\mathrm{U}_{\mathrm{r}} \cdot \mathrm{L} \cdot \mathrm{B}
$$

- transmission losses through the inferior floor

$$
\begin{array}{r}
\mathrm{U}_{\mathrm{f}} \cdot \mathrm{a} \mathrm{LB} \quad \text { (with } \mathrm{a}=1 \text { or } 2 / 3 \text { or } 1 / 3 \\
\text { in the Belgian proposal) }
\end{array}
$$

Global U-value of the building $\mathrm{U}_{\mathrm{m}}$. With the definition given above we come to

$$
\mathrm{U}_{\mathrm{m}}=\frac{\mathrm{U}_{\mathrm{W}}\left(2 \mathrm{LH}+2 \mathrm{BH}-\alpha \frac{\mathrm{H}}{\mathrm{h}} \cdot \mathrm{BL}\right)+\mathrm{U}_{\mathrm{g}} \frac{\alpha}{\mathrm{h}} \cdot \mathrm{HLB}+\mathrm{U}_{\mathrm{r}} \cdot \mathrm{LB}+\mathrm{aU}_{\mathrm{f}} \cdot \mathrm{LB}}{\mathrm{A}}
$$

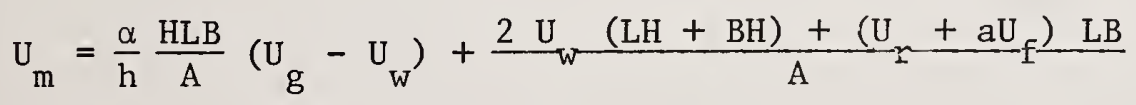

$$
\mathrm{U}_{\mathrm{m}}=\frac{\alpha}{\mathrm{h}}\left(\mathrm{U}_{\mathrm{g}}-\mathrm{U}_{\mathrm{W}}\right) \frac{\mathrm{V}}{\mathrm{A}}+{\frac{2 \mathrm{U}}{\mathrm{w}}(\mathrm{LH}+\mathrm{BH})+\left(\mathrm{U}+\mathrm{aU}_{\mathrm{f}}\right) \mathrm{LB}}_{\mathrm{f}}
$$

Discussion of the Equation 4. The last term of the expression (Eq.4) is the mean U value of the building, considering the building without wind ows. 
Of course, this last term depends upon the shape of the building but only in the case where the $U$ values of the walls $\left(U_{W}\right)$, the roof $\left(U_{r}\right)$ and the floor $\left(\mathrm{aU}_{\mathrm{f}}\right)$ are very different.

If we consider all of these opaque walls the same $U$ value, the last term of the expression (Eq. 4) is actually the common $U$ value.

So we can say that for a given building this last term represents the insulation value of the opaque parts of the building, and we can write the expression (Eq. 4) as follows

$$
\mathrm{U}_{\mathrm{m}}=\frac{\alpha}{\mathrm{h}}\left(\mathrm{U}_{\mathrm{g}}-\mathrm{U}_{\mathrm{w}}\right) \frac{\mathrm{V}}{\mathrm{A}}+\mathrm{U}_{\mathrm{mo}}
$$

Approximately, the expression (Eq. 4) is a linear expression between $\mathrm{U}_{\mathrm{m}}$ and $\mathrm{V} / \mathrm{A}$.

The slope $\beta$ of the straight line depends on the window percentage $\alpha$ and on the insulation value of the windows $\left(U_{g}-U_{W}\right)$.

The term $U$ remains constant for the insulation of all the opaque parts of the building.

Proposition of requirements. With the knowledge of the preceding paragraph we can now propose reasonable requirements.

Indeed, a requirement as indicated by the straight line 1 (Figure 8) is a requirement which is very strict for the opaque building elements $\left(U_{\text {mo }}=\right.$ small) but which is not strict at all for the glazed area $(\beta=$ high $)$

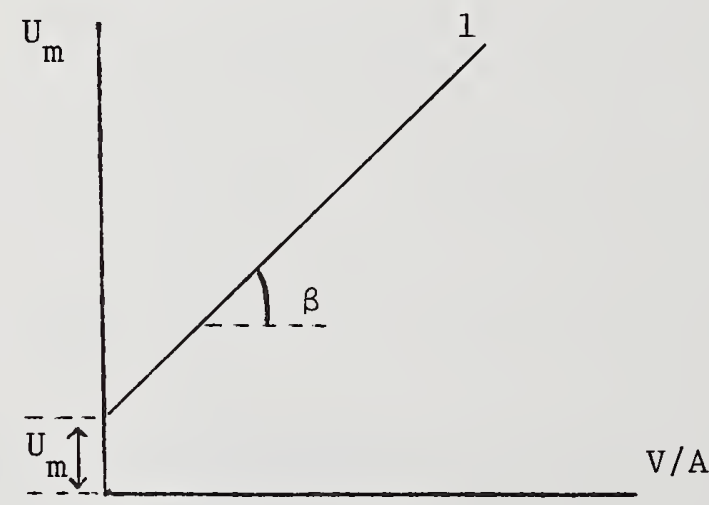

Figure 8: Very Strict Requirement for Opaque Building Elements 
A requirement as indicated by line 2 (Figure 9) is not strict for the opaque walls but is very strict for the glazed area $(\beta=$ small).

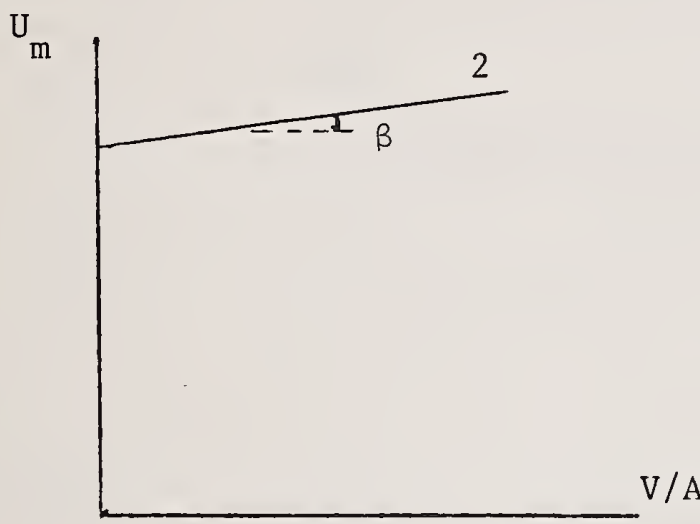

Figure 9: Very Strict Requirements for Glazed Areas

Thanks to these considerations it is now possible to accept a basic requirement in a reasonable way.

As an example, one country could require that for all future buildings it will be necessary that opaque walls have at least a U-value $\left(\mathrm{U}_{\mathrm{mo}}=1 \mathrm{~W} / \mathrm{m}^{2} \mathrm{~K}\right)$ and that the window area of single glazed windows $\left(\mathrm{U}^{\mathrm{mo}}=5.5 \mathrm{~W} / \mathrm{m}^{2} \mathrm{~K}\right)$ must be limited at $\alpha=25$ percent of the total floor area. That means that the straight line corresponding to these hypotheses is given by

$$
\mathrm{U}_{\mathrm{m}}=\frac{\alpha}{\mathrm{h}}\left(\mathrm{U}_{\mathrm{g}}-\mathrm{U}_{\mathrm{w}}\right) \cdot \frac{\mathrm{V}}{\mathrm{A}}+\mathrm{U}_{\mathrm{mo}}
$$

If we accept $h=2.8 \mathrm{~m}$

$$
\mathrm{U}_{\mathrm{m}}=\frac{0.25}{2.8}(5.5-1) \frac{\mathrm{V}}{\mathrm{A}}+1
$$

Or, $\mathrm{U}_{\mathrm{m}}=0.40 \frac{\mathrm{V}}{\mathrm{A}}+1$

of course, this line does not represent a very well insulated building, but it can be useful to accept such a basic line corresponding, for instance, to the insulation of buildings prior to the energy crisis. 
New Belgian standard on the thermal insulation of buildings. In 1979, the Belgian Standardization Institute (IBN) published a draft for a new standard NBN B62-301, "Level of the global thermal insulation of a buflding."

The proposed standard indicates only the way to compute and to indicate the global thermal insulation level or quality of a building. It, thus, does not indicate requirements.

This standard has defined in the $\left(U, \frac{V}{A}\right)$ graph (Figure 10) a basic reference-line given by the following coordinates:

$$
\begin{array}{ll}
\text { for } V / A<1 & U_{\mathrm{m}}=1 \mathrm{~W} / \mathrm{m}^{2} \mathrm{~K} \\
\text { for } 1 \leqslant \mathrm{~V} / \mathrm{A} \leqslant 3 & U_{\mathrm{m}}=0.5(\mathrm{~V} / \mathrm{A}+1) \mathrm{W} / \mathrm{m}^{2} \mathrm{~K} \\
\text { for } \mathrm{V} / \mathrm{A}>3 & \mathrm{U}_{\mathrm{m}}=2 \mathrm{~W} / \mathrm{m}^{2} \mathrm{~K}
\end{array}
$$

The degree of insulation corresponding to this basic line is indicated by the solid line $\mathrm{K} 100$.

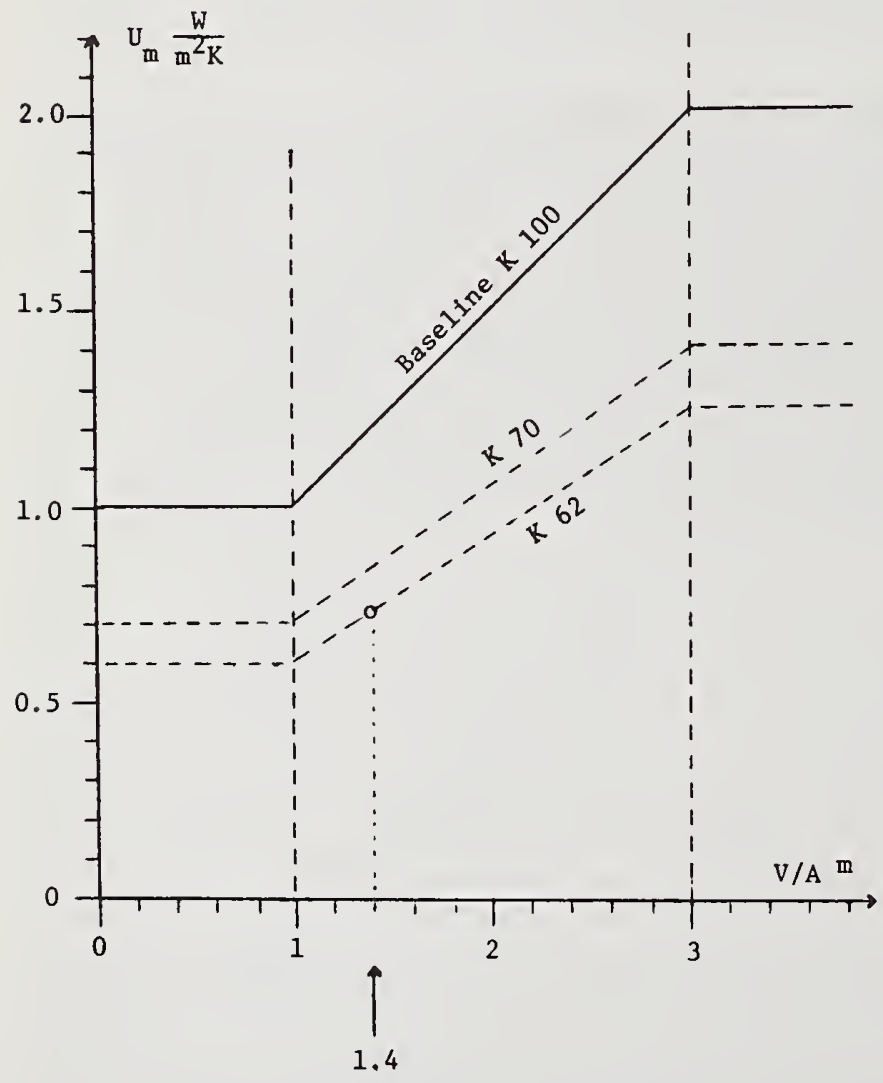

Figure 10: A Proposed Method of Selecting Global Thermal Insulation Values 
Other lines can be determined as shown in Figure 10. For example, the line $\mathrm{K} 90$ is given by the broken line passing through $U_{\mathrm{m}}=0.9$ for $\mathrm{V} / \mathrm{A}=1$ and through $\mathrm{U}_{\mathrm{m}}=1.8$ for $\mathrm{V} / \mathrm{A}=3$. The line $\mathrm{K} 90$ is taken to be a value of 90 percent of that of the baseline $\mathrm{K} 100$. Thus, the insulation requirements can be varied for geographic areas where the climatic conditions may be more or less severe than the cases stated in this paper.

It is anticipated that using this standard the task of legislating thermal requirements of buildings is a relatively simple matter. Indeed, with the selection of one value, for example $\mathrm{K} 70$, the required insulation level of buildings can be indicated.

This requirement takes into account all of the transmission losses of a building and also of the shape of the building.

For builders and manufacturers the standard makes it possible to indicate very precisely the insulation level of their buildings.

* G. Carpentier and J. Uyttenbroeck (C.S.T.C.), December 1975, (XII/839/75-E): Comparison of thermal insulation regulations in the member countries of the E.E.C. (Report I). 



\author{
A REPORT \\ INDIANA BUILDING CODE ENFORCEMENT SURVEY \\ 1979 \\ by \\ David L. Bills \\ Director of Code Enforcement \\ Administrative Building Council \\ State of Indiana
}

This survey of Indiana cities, towns, and counties was undertaken by the Division of Code Enforcement of the Indiana Administrative Building Council. Its purpose was to determine the status and effectiveness of local building code administration and enforcement agencies. Its findings will be used to provide guidance and priority to state level programs to encourage the development and advancement of local building regulatory agencies, which is a statutory mission of the Division.

The survey measured manpower resources and productivity; inspection frequency; building permit fees; inspector training, and the status of local ordinances pertaining to adoption of the statewide building code, establishment of building departments, and regulation of unsafe buildings.

The survey results depict the condition of statewide building regulation in a rural, small community environment with traditional political influence on local governmental operations and services.

Key Words: Building departments; building inspection; code administration; Indiana building code enforcement; local government; political appointments; survey of local building departments. 
The small town building department seems to have received little attention in the various independent studies, periodical literature, or texts of the building code administration and enforcement organizations and agendas - public or private. The voice of the grass roots building official, as a combination administrator, plan reviewer, inspector, complaint investigator, and consultant to the community he serves, is seldom heard; except to complain that he is overworked, underpaid, and unappreciated. One of these voices in California suggested that $85 \%$ of all local building departments in the United States were basically a one-man operation (Ref. 1). If this were true, perhaps a better understanding of the personnel, capability, performance and political environment of the small building department would be useful to the policy makers, code publishers, and related associations in the building regulatory field. For this purpose, the Indiana Building Code Enforcement Survey was undertaken.

\section{BACKGROUND}

A brief explanation of the Indiana code administration establishment will provide the basis and format for the survey. The Indiana Administrative Building Council is established and empowered to promulgate a mandatory statewide building code. Its adoption, with some amendment, of a group of Uniform codes published by the International Conference of Building Officials (ICBO), is typizal of procedures used by other states with similar laws. Perhaps atypical, however, are two statutory provisions. The statute does not impose a duty on local government to establish a building department or to hire inspectors: it simply states that local executive officers (all elected officials) have a responsibility to enforce the promulgated rules and regulations of the Administrative Building Council. The second provision establishes the office of the State Building Commissioner, and creates operating divisions at the state level. The Plan Review Division must check plans for all buildings except one and two family dwellings and farm buildings. Local building departments, thereby relieved of that traditional duty, are not obligated to provide staff or funds for that purpose. The Code Enforcement Division provides assistance to local government in the establishment and improvement of building departments. It employs thirteen regional code administrators to deliver direct support to local building officials in the form of advice, on-the-job training, and field inspection. These thirteen employees provided the manpower vital to the execution of this survey.

\section{METHODOLOGY}

In the summer of 1978, the Director of Code Enforcement developed a two-page survey form designed to record a number of facts about local building departments. It was decided to survey all counties, cities, and incorporated towns with an objective of $100 \%$ coverage. Also, the survey would utilize a direct interview technique. The survey results, 
therefore, would not be based on a sample of voluntary responses to a questionnaire. The survey form was tested in 26 jurisdictions with each regional code administrator performing two interviews - one county and one city. Completed forms, interviewer comments, and reactions were analyzed. A revised survey form, written instructions, and tabulation procedures were prepared for initiation of the full survey in May 1979.

The entire project was to be an in-house task with no outside resources or funds required, except for the use of a summer employee college student to assist in tabulation. The survey was completed in July 1979.

\section{THE COUNTY BUILDING DEPARTMENT}

There are 92 counties in Indiana. Marion County, which is merged with the city of Indianapolis for building regulation purposes, was excluded from the survey because of its highly urban character. It was felt that its inclusion in either county (or city) statistical summaries would distort the intended portrayal of typical Indiana communities. Also, the nearly exact central location of Marion County suggested a division of the state into four geographical quadrants (Fig. 1) for the purpose of regional analysis of survey results. Such analysis is not included in this report in the belief it is of lesser general interest. Data from the remaining 91 counties, therefore, represents a $100 \%$ coverage of that level of government.

Only 30 counties have adopted the current statewide building code, but 35 have established building departments by act of local ordinance; with 30 of these adopting the current statewide building code and five continue to enforce superseded codes. On1y 12 counties have ordinances specifically designed to regulate unsafe buildings for which separate statutory authority is available. The typical county building department employs two full-time technical personnel, usually a building commissioner and an inspector. Both perform inspection duty which occupies $52 \%$ of their time. They average about 3 inspections for each job covered by a building permit. The building permit for a detached single family dwelling (1500 square feet, $\$ 25,000$, less lot) costs about $\$ 41.00$ which includes electrical, plumbing, and mechanical work as well. The chief building official has served less than five years in the department. Four out of ten of these personnel are political appointees of a Board of County Commissioners. Their average annual salary is $\$ 10,500$. Only $18 \%$ of the building departments have in-house training programs. Just over one-third of all technical personnel are members of the Indiana Association of Building Officials (IABO). Some counties have additional part-time inspectors, but on the basis of full-time code enforcement personne1, there are only 3 for every 100,000 residents living in unincorporated (and almost all rural) areas in counties. 


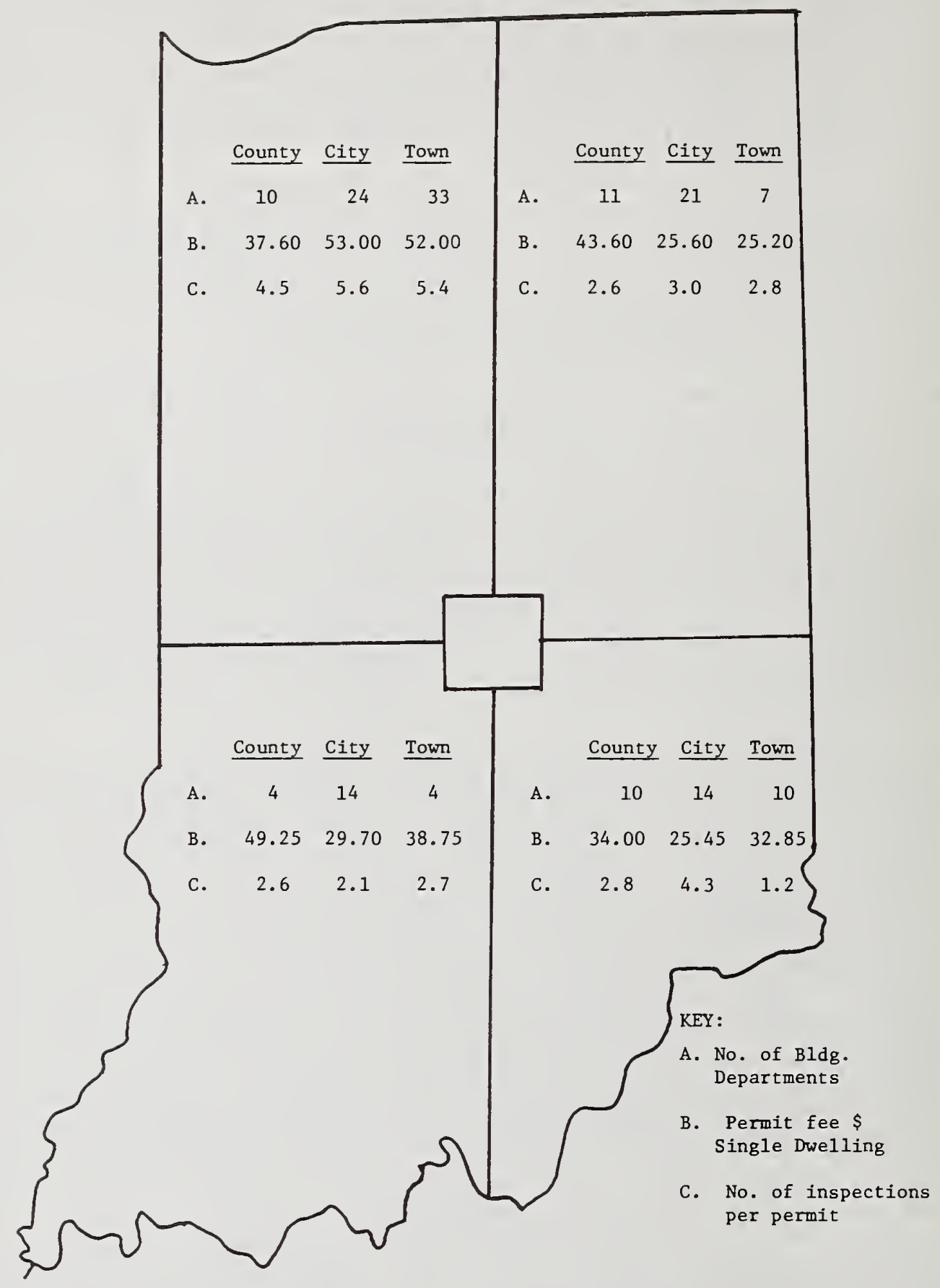

Figure 1: Geographical Quadrants 
There are 112 Indiana cities excluding Indianapolis and four separate cities within Marion County. Survey data was collected for 104 cities of which 61 have populations of less than 10,000, but more that 2000 . There were 73 city building departments of which 51 have ordinances adopting the current statewide code. The remaining 22 cities either enforce superseded state codes, or continue to enforce pre-1971 building ordinances never repealed after the effective date of the statewide building codes. Reflecting a more urban environment, 54 cities have ordinances to regulate unsafe buildings by means of condemnation or other abatement procedure. The average city building department has about three full-time technical personnel, of which one is likely to be an electrical or plumbing inspector. They have about five years experience on the job and perform almost four inspections per building permit for new construction. The single family dwelling permit costs $\$ 33.50$, and a few cities require separate electrical, plumbing, and mechanical permits. Inspection and travel time account for about $50 \%$ of their time, and another $32 \%$ is spent on administration and general public assistance duties. Only $17 \%$ of these departments have in-house training programs. The chief building officials work in a highly political environment where $73 \%$ of them are direct appointees of Mayors. There is no civil service organization in any of the cities surveyed. The chief building official earns about $\$ 10,400$ annually. Cities have about 1.3 full-time technical personnel per 10,000 residents which seems to be a more favorable ratio than that of counties. However, a few large cities with more complete technical staffs tend to improve the overall ratio to some degree. Even though city building departments seem better staffed in relation to population served, the survey finds only 15 of 61 cities with population of 10,000 or less with at least one ful1-time building inspector, and 31 of 104 cities with no building department at a11.

\section{THE TOWN BUILDING DEPARTMENT}

Indiana's 428 incorporated towns yielded 313 survey reports. Interviewers mostly found themselves talking with town clerk-treasurers, many of whom work part-time and at irregular hours. The 115 missing reports represent the interviewer's knowledge that there was either no building department to survey or that a part-time inspector could not be located during normal business hours because he was employed full-time in a business or on a farm. A survey coverage of $73 \%$ was considered acceptable, considering the effort that would be required to achieve a very small amount of additional significant data. We found only $54(17 \%)$ towns with ordinances that established a building department, of which 34 were using the statewide building code. Surprisingly, 32 towns had ordinances to regulate unsafe buildings. Only 23 towns had full-time technical personnel with a numerical average of 1.2 persons. Clearly, these are the "oneman shows" that code administrators speak of when considering the small community. These officials averaged less than four years on the job. Their productivity equaled their county colleagues with about 3 inspections per building permit, which took half of their workday. The new 
house building permit cost $\$ 37.20$. A ratio of full-time inspectors per 10,000 population was not calculated because it would be statistically meaningless, considering the small population of any town, and the fact that existing inspectors operate only within their town limits. One can be sure, however, that the ratio is much smaller than that of counties, on a statewide basis. Data on average annual salary was unreliable or unavailable. Some part-time inspectors were paid token amounts to offset transportation expenses with the understanding that most of their service was donated; much the same as the practice for small town elected officials. Typically, $68 \%$ of the full-time inspectors were political appointees of the elected Town Board of Trustees. Considering that only 23 of 423 Indiana towns are served with full-time building inspectors and only 31 more with part-time inspectors, one must conclude that most construction in towns is completely unregulated.

\section{FINDINGS}

Analysis of the survey data resulted in a number of conclusions presented here in a sequence following that of the Statistical Summary (Fig. 2). Occasional references are made to the comprehensive 1970 survey and report of city building departments by Field and Ventre (Ref. 2). That report noted that data was lacking on cities with populations less than 10,000. Generally, the conclusions of this report, while much smaller in scope of subject matter, are consistent with their research results.

\section{A. Personne1:}

In 117 building departments with full-time technical personnel, averages ranked: 3 in cities, 2 in counties, and 1 in towns. Only three cities had 10 or more. There was one such person (inspector) for each 12,500 Indiana residents on a statewide basis. Their average building department service was about four and one-half years.

\section{B. Ordinances:}

Less than $30 \%$ of all jurisdictions have ordinances which adopt the current statewide building code. Many ordinances are out of date or obsolete. Forty percent of all jurisdictions have established building departments with cities having the highest proportion at $70 \%$. Separate ordinances to regulate unsafe buildings follow the same frequency pattern between the three levels of local government. A1though enabling legislation exists to form joint building departments among the three levels of government, it is not commonly employed. Promotion of this procedure is a major goal of the state Division of Code Enforcement.

\section{Productivity:}

Ratios of inspections performed per building permit were consistent with an average of 3.3. Given the traditional foundation, framing, and final inspections for light frame construction, performance would 
1. PERSONNEL

Number per building department

Number per 10,000 population

Years of experience on job

3. BUILDING DEPARTMENT ORDINANCES

Percent adopting state building code

Percent establishing Building Official

Percent regulating unsafe buildings

Single dwelling building permit fee (\$)

\section{$\therefore$ PRODUCTIVITY}

No. inspections per building permit

Percent of time spent on inspection

D. TRAINING

Percent with in-house program

No. of outside training experiences

2. PROFESSIONAL MEMBERSHIPS

Indiana Assoc. of Building Officials

Other national associations.

APPOINTMENT SOURCE

Percent of political appointments

SALARY

Average annual salary ( $\$ \underline{000})$

\begin{tabular}{|c|c|c|c|}
\hline COUNTY & CITY & TOWN & STATEWIDE \\
\hline 2.0 & 2.9 & 1.2 & 2.03 \\
\hline 0.3 & 1.3 & - & 0.8 \\
\hline 4.7 & 5.0 & 3.7 & 4.45 \\
\hline 32 & 49 & 8 & 29.3 \\
\hline 38 & 70 & 13 & 40 \\
\hline 13.5 & 52 & 7 & 24.2 \\
\hline 41.10 & 33.50 & 37.20 & 37.30 \\
\hline 3.1 & 3.7 & 3.0 & 3.3 \\
\hline 52 & 48 & 51 & 50 \\
\hline 18 & 17 & 0 & 11.7 \\
\hline 49 & 67 & 26 & 142 \\
\hline 33 & 50 & 7 & 90 \\
\hline 21 & 22 & 3 & 46 \\
\hline 40.5 & 73 & 68 & 60.5 \\
\hline 10.5 & 10.4 & - & 10.45 \\
\hline
\end{tabular}

Figure 2: Statistical Summary 
seem to meet only minimum required levels as advocated by model building codes. Additional inspection tasks necessary to implement an energy conservation code may well establish an increased workload. A showing that only $50 \%$ of available manpower is spent on inspection and travel is not surprising to the knowledgeable building official. Administrative tasks, such as record keeping, special reports, and inspection scheduling, consume about $15 \%$ of his time with another $10 \%$ devoted to direct public contacts to render advice and assistance. Study and training to remain current in a rapidly changing building technology requires most of his remaining productive time. Note that plan review tasks are limited to dwellings because of the mandatory state level plan review for public buildings mentioned earlier.

\section{Training:}

County and city building departments reported little formal in-house training, which would normally be the predominant method. Greater reliance is placed on individual study and on-the-job training. The thirteen regional code administrators of the state's Division of Code Enforcement attempt to provide "one-on-one" training experiences for local inspectors. Two state electrical specialists of the Division perform the same function. The survey found that there were 142 instances where local inspectors attended a group training activity outside of their jurisdiction. This is significant in planning regional training seminars, because the prospect of attracting a reasonable number of attendees is small. In fact, only 46 of the reported instances occurred in the southern half of the state over a period of 12 months. As a consequence, the annual training school of the Indiana Association of Building Officials is probably the only group training effort that has a reasonable chance of success. Any substantial registration fee for a group training program almost guarantees its failure, because very few jurisdictions will reimburse building officials for such expenses.

\section{E. Professional Memberships:}

The survey attempted to measure participation in recognized associations of building officials and inspectors. Of $294 \mathrm{full-time} \mathrm{local} \mathrm{building}$ officials and inspectors, 90 were members of their state association (IABO), and 46 reported membership in ICBO, IAEI (International Association of Electrical Inspectors), NFPA (National Fire Protection Association), NACA (National Academy of Code Administration), or other related organizations. Professional recognition did not seem to be a motivating force among Indiana building officials; which is understandable in view of evidence that job security in a political environment is not assured by peer group association or recognition. 


\section{F. Political Appointments:}

Over $60 \%$ of full-time building officials and inspectors are political appointees. This is not to say that whole building departments are always wiped out with a shift in political affiliation of the executive branch of local government, but the possibility exists, and unfortunately, becomes a reality too often. In this climate, as noted in the Field and Ventre report, local building officials who survive must be politically adaptive. There is probably no greater impediment to impartial, competent, and professional building code administration and enforcement than the patronage system of appointment, so traditional with Indiana politicians.

\section{G. Salary:}

Annual salaries for full-time technical personnel averaged at $\$ 10,450$. Field and Ventre reported chief building official's salaries for cities having populations between 10,000 and 29,000 to have a mean of $\$ 9,786$. That was in 1970. If Indiana building officials feel underpaid, they seem to deserve sympathy in 1979. Future proposals for mandatory state examination and certification of building inspectors, if enacted, may provide the basis for equitable compensation for qualified and competent personnel.

\section{CONCLUSION}

The Indiana Building Code Enforcement Survey of 1979 will serve as a useful tool to impress upon local elected officials the needs for improved and effective code administration and enforcement. Growing consumer demands for quality, and now, energy efficiency, in their buildings are being heard by local officials. More and more Indiana communities are "getting the message" and are acting to fulfill their legal responsibilities for public safety, health, and welfare in building construction and maintenance. We believe the Indiana condition is typical of rural America, and that condition is not clearly understood by the established model code publishers, the national associations of code administrators, or Federal agencies regulating the construction industry. We Hoosiers hope this report will provide a measure of enlightenment.

\section{ACKNOWLEDGEMENTS}

The assistance of Tim Madden, a sophomore at Indiana Central University, in the tabulation of incoming data, correlation, and totalling was invaluable. Typing and proofreading by our Division secretary, Vera Rothenbush, was equally essential to the preparation of the report. Their assistance is deeply appreciated, as is that of our thirteen code administrators who became survey interviewers for the Summer of 1979. 


\section{REFERENCES}

1. Letter of April 18, 1978, by Wallace H. Byron, Building Official, City of Campbe11, California.

2. "Local Regulation of Building: Agencies, Codes, and Politics," Charles G. Field and Francis T. Ventre, Center for Urban Studies of the Massachusetts Institute of Technology and Harvard University. 
SESSION 1B - LEGAL, POLITICAL, AND EDUCATIONAL ASPECTS OF CODE ENFORCEMENT

\author{
Moderator: Trevor Jacobson \\ Administrator, Building Codes Division \\ Department of Commerce \\ 401 Labor and Industries Building \\ Salem, Oregon
}



LEGAL RELATIONS AND CONSIDERATIONS FOR CODE

OFFICIALS AND DESIGN PROFESSIONALS

\author{
by \\ John R. Groves, Jr. \\ Deputy Commissioner \\ Department of Housing, Buildings and Construction \\ Frankfort, Kentucky
}

In the last several years, the number of statutes, ordinances, and the volume of case law affecting architects and engineers has increased dramatically. The changing legal responsibilities of architects and engineers has been a matter of great concern to individuals in those professions. Professional liability insurance, negligence, statutes of limitation, reasonable care, duty, contract relationships, and numerous other subjects have moved to the forefront of continuing education efforts for registered design professionals. During this process, code officials as well have found themselves increasingly involved with sometimes complex legal considerations. Code officials, in particular, have moved out of the shelter of freedom from liability based on government immunity into a legal posture in some ways similar to that of design professionals. This has been intensified by the often overlapping relationship between registered design professionals and code officials in the administration of a variety of codes.

In the past, programs and articles on this subject have often taken an approach of admonishment rather than education. Code officials and design professionals have been told that caution and self-protection are emerging as the basis for the conduct of day-to-day affairs. This concept has been further supported with numerous cases and incidents involving property damage, personal injury or death and resulting in the legal determination of extremely large monetary judgments. While this process may have a dramatic impact, it often ignores the need to continue a normal professional relationship placing basic competency as the fundamental principle directing those concerned. Certainly lawsuits illustrating a variety of problems confronting both design professionals and building officials will continue. The notion, however, that judgment, common sense and risk can or should be eliminated from the construction and code administration process is in practice unrealistic. The legal education of parties to the process cannot seek to eliminate every possible misfortune which could befall those involved. To attempt to do so would cause the entire process to grind to a halt.

Based on the premise that scare tactics are not the appropriate vehicle for the legal education of code officials and design professionals, this paper will proceed to discuss a number of current legal developments of interest to both. The goal will be to help in establishing prudent but 
sensible ways of discharging professional obligations and enforcing laws, codes and ordinances in a manageable and professional manner. Inherent in the process will be the translation of basic legal concepts into workable professional practice techniques and procedures.

Key Words: Appeals process; architect; certification; checklists; code official; consultant; engineer; equivalent life safety; municipal attorney; product endorsement; professional liability; variances 


\section{INTRODUCTION}

The potential for catastrophic professional liability is no stranger to design professionals in the United States. All licensed professionals to some degree share this common status. While professional liability has had its impact in the fields of medicine, law, engineering and architecture, it has moved more slowly to encompass building code officials. Nevertheless, case law is beginning to reflect the existence of serious potential liability issues for code administrators.

In the last several years, many regional and national meetings of code officials have included seminars on legal aspects of code enforcement. These programs have typically concentrated on the personal liability potential of public officials charged with code enforcement. Those sessions have done much to inform code administrators as to liability problems and to identify particular areas where liability problems have greater frequency. Often, however, those same programs have achieved another purpose. Depending on the manner of presentation, the resulting actions for code officials has been akin to establishing a military defensive perimeter. Code officials, with good cause, have started to feel a strangle-hold brought about in part by legal actions resulting in professional liability against code officials based on loss of property or life or both. It is little wonder that the outcome has often been a form of paranoia which is then reflected in day-to-day practices at the local level. Such is not all together bad. As with other reactions, however, if the changes are extreme in nature, the effect on the conduct of daily business can be unnecessarily restrictive. They can lead to a self-perpetuating condition which restrains and burdens the normally acceptable and reasonable ways of doing business as between code officials and those whom they serve. This paper is directed to the notion that while liability problems exist and must be researched and discussed; the application of the results of those efforts must be undertaken in a reasonable way and in the context of building code administration on a day-to-day basis.

Code officials are by no means free from liability. But the general rule followed by most courts is not to hold code officials liable for actions undertaken in good faith and to the best of the code official's judgment and ability, even when those acts may have included an element of negligence. This standard varies from jurisdiction to jurisdiction. The fundamental preventive action for code officials, to be discussed further, is to talk with the municipal attorney in the local jurisdiction to determine what protection is afforded by local ordinance or state statutes and what the history of liability for design professionals and code officials has been in that particular jurisdiction.

Most courts still hold to the policy that the building code official is an advisor. Further, he (or she) is not responsible for giving professional information in the same way as a registered design professional. The code official must exercise his best judgment and must give it free from any personal or self-interest. Beyond that, any individual code 
official's standard of acceptable professional performance is generally a measure of his actions against those in the same profession having the same degree of experience and exposure to the building code enforcement process. Many other factors may also be considered. The above will suffice as a point of departure, however discussions as to the "discretionary" or "ministerial" nature of the actions of code officials, and derivatives, will not be considered in this paper, those having been addressed in an earlier NBS publication and other writings.

\section{THE CERTIFICATION PROCESS}

Many building officials are seeking to establish or are involved in code certification processes to certify their own competency. It is felt, and rightfully so, that the process of certification should upgrade the knowledge and ability of the officials concerned. Also, certification is a means of establishing categories of qualifications for salary purposes. Certification is in many ways a desirable goal. If properly undertaken, it can lead to a high-level of training and competency. Also, certification programs can establish minimum qualifications necessary for building code officials or any sub-categories within the broader classification of building code administration.

Certification, however, must be undertaken with caution. With the status of certification also comes a status and level of professionalism which the law recognizes. That status may be legally treated as a level of knowledge and performance which the building official should have achieved by virtue of fulfilling the requirements of a certification process.

This means that if the certification process becomes simply a label and the educational and training requirements are minimized or not rigidly enforced, a "certified" building code official may find that his expected level of performance may be far greater than his actual abilities. An individual so "certified" may be expected in legal terms to perform in a way in which is realistically impossible. Thus, certification becomes a double-edged sword; on the one hand it can benefit the code official through the establishment of categories which will promote advancement and salary improvement. At the same time it can create a level of professionalism and competency against which the actions of that individual will be measured in a legal dispute.

Certification must be recognized as a process confirming a significant legal status. It should never be discouraged. Conversely, it should never be undertaken in anything less than a very serious and carefully designed manner which will establish a level of professionalism which the law will require of a person so certified.

Certification programs take many forms. They may be administered at the municipal or the state level or through a national model code organization. Any certification process must show a documented attainment of a degree of knowledge and ability by those recéiving certification status. To do less is not only a disservice to the public served by the building 
official, but may lead to personal liability for the building code official who is expected to perform in a way in which he or she is simply not capable of doing.

\section{COORDINATING WITH THE MUNICIPAL ATTORNEY}

One important step. for any building code official is the development of a strong working relationship with the local municipal attorney. This relationship should be termed an alliance of sorts and serves at least two purposes.

First, the municipal attorney can provide preventive legal advice by establishing basic ground rules as to how complaints from those in disagreement with the building code official can be processed. Second, there should be a procedure as to how and when the building code official is to present to the municipal attorney questions on legal interpretations of the building code.

The code official must establish a strong working relationship with the municipal attorney. This should include periodic (meaning regularly scheduled) contact with the municipal attorney. A continuing dialogue on small or seemingly inconsequential problems may pay large dividends. The discussion of a legal strategy which will give the building code official the basis for cautious but effective day-to-day operations is a must. Furthermore, those discussions should be undertaken in a climate of conflict/liability avoidance rather than in the midst of a crisis where legal action appears imminent.

Each building code official should arrange to meet with the municipal attorney for a short period at least once every month. An informal luncheon meeting can sometimes defuse problems which if not given legal attention may lead to complications for both the code official and municipal attorney.

\section{DEVELOPING OFFICE POLICIES}

In discussions with the municipal attorney, the building code official should freely describe daily routines and how problems are normally dealt with. Such discussion should also concentrate on office policies, written or unwritten, which may be included in the enforcement of the local building code. These last two items are important because of the need to give legal status to those practices which may otherwise be not legally enforceable if brought to a court of law. To say that a certain practice is "office policy" is often an invitation for legal action to determine just how legally supportable that policy may be. The need to reduce policies to writing and to then see that they are followed in a consistent manner cannot be overly stressed. If brought to litigation, a given office practice or procedure may be given legal recognition by a court simply because it has been applied in a consistent manner over a long period of time. This is not the recommended method of testing the legality of a policy, however. Even though the history of application 
combined with the reasonable nature of the policy when taken together may result in favor of the building code official, it must first be shown that the policy was known to all who were responsible for its enforcement, and must have been applied consistently to all concerned. This is obviously more burdensome than incorporating that policy into a law, regulation or ordinance before a lawsuit develops.

The establishment of reasonable consistent written policies in itself reduces the potential for liability. The tendency toward arbitrary decision making is minimized with the establishment of written policy. The result will benefit the entire building inspection staff.

\section{THE APPEALS PROCESS}

Another step which can be integrated into day-to-day operations and which will assist in minimizing the code officials potential for liability is the establishment of an appeals board or committee at the local level. Unfortunately, it is becoming increasingly evident that private citizens are reluctant to become involved in the appeals process where the possibility of personal liability for their actions is present. Nonetheless, there is much precedent for the establishment of such committees. When properly constituted by professionally trained and informed persons, successful challenges against those holdings become more difficult. of course when an appeals committee reflects arbitrary or self--serving interests in rendering decisions, those actions should be legally cha1lenged. Where an appeals committee exists the code official has a final option which in effect removes the ultimate decision and possibility of personal liability from his shoulders.

Many code officials are often less than enthusiastic about appeals bodies. This skepticism is usually based on the lack of technically trained individuals serving on those bodies. Where an appeals body is not in existence but contemplated, careful attention should be given to the credentials of the board members. The experience requirements should be written into statutes or regulations. Conversely, for boards which are already in existence, the need to convince the appointing authority of the necessity for competently trained members is essential. Also, as stated above, when an issue is given thorough analysis by a technically experienced code committee, the resulting decision is also less prone to produce liability than if non-professional and non-trained individuals make the decision based on a gut reaction or best judgment under the circumstances.

This should encourage the code officials to take two steps; (1) to seek the creation of an appeals committee, and (2) to be prepared to convince not only the appointing authority, but potential members of the committee as to the legal significance of appointing qualified members to the board. 


\section{VARIANCES VS. EQUIVALENT LIFE SAFETY}

Probably every building code official has used the terms waiver and variance. This is common nomenclature but it is often dangerous. Whether a decision is reached by an individual building official or members of an appeals board, that decision should never be in terms of a variance or waiver which imply that an otherwise legal requirement is being either ignored or overlooked, and that nothing is being substituted in place thereof.

Better terminology and the better practice is to use the term "equivalent life safety." Documentation should then indicate that where a particular provision of the building code may not have been fully met, there is another factor present which off-sets the absence of that particular requirement and which results in equivalent life safety for building inhabitants. The possibility of substitutions to achieve equivalent life safety usually exists. However, the need to make sure that the intent of the building code is met regardless of what particular technical provisions are used is absolutely crucial. The importance of this practice should also extend to the conversational language used by field inspectors and code officials. The use of waiver and variance should be strongly discouraged. Code officials should speak in terms of equivalent life safety documenting with correspondence the steps taken to ensure that an equivalent standard has been achieved.

\section{CHECKLISTS}

While many building code officials are reluctant to do so, the use of checklists in plan review and field inspections can be a helpful procedure. Many building code officials are hesitant to use checklists, feeling that their experience and ability to perceive and detect deficiencies during an inspection process should override the use of a checklist. That argument also states that following a checklist puts blinders on the code official and does not allow him to approach problems with an open mind. On the other hand one of the most significant and reoccurring problems encountered in the building inspection process, whether in plan review or field inspection, is that of finding code discrepancies at points in the construction process after which the initial plan review has taken place.

Often design professionals, after having their plans reviewed, are told that new and additional requirements which were not brought up prior to construction will not be made a requirement. The requirements for construction changes to comply with later imposed code provisions can sometimes spell catastrophe for a building owner who is financing construction on a very limited budget. Also it can be embarrassing to the design professional who, while retaining ultimate liability for code compliance, has relied greatly on the code official to review the construction documents and to identify the major code discrepancies which may be present on the construction drawings. 
Obviously, if the project is not constructed in conformity with the drawings and if that departure from the drawings represents a code deficiency, then neither the architect nor the owner can be held to blame if the change took place without their knowledge. In those instances the contractor must be notified through the owner of the problem and instructed to make necessary corrections. The architect should also be informed by the code official of these actions.

When required code provisions are made known to the owner after construction has started and after the architect and owner have been lead, during the plan review process, to believe that code compliance has been satisfied, both resentment of and embarrassment to the building code official may result for not having identified that code provision early in the process. The need for careful training of code officials, continuing education and double checking of drawings can do much to minimize this situation. In addition, the addition of the checklist in the plan review process can also do much to eliminate oversights. The code official should seek to write or adopt an already available checklist and integrate it as soon as possible into the plan review process.

The same use of a checklist also applies to field inspection. Many local jurisdictions do not become involved in detailed plan review. There, the process of building code enforcement takes place primarily through field inspection. Where that is true, a field inspection checklist should be utilized for every inspection. In this way not only is a record available reflecting the results of each field inspection, but the field inspector is given a format which will enable all code compliance matters to be considered and reviewed without reliances upon memory. The need for a checklist is well established in other technical fields as necessary even for those very experienced practitioners. The senior airline pilot with several thousand hours will use a pre-flight checklist just as the student pilot. No less should be true of the building code official. Technical provisions of building codes are often complex and lengthy. A checklist adapted to meet the local needs and to be used as a document to record the results of plans review and field inspections can be of great help in increasing efficiency and minimizing liability in the building code enforcement process.

In very complex buildings where many technical provisions of the building code may be brought into play, it is not unreasonable to require two experienced members of the building code staff to conduct the plan review. This, with the use of a checklist, can minimize the possibility of an overlooked code requirement.

The above items pertaining to plan review take special significance where the building owner does not retain the service of a design professional during the construction process. Once the drawings have been reviewed and deficiencies identified, it is the contractual duty of the contractor to construct the building in accordance with the drawings as approved. With no design professional present during construction, the code official has an increased dual responsibility. The first is a thorough plan review. The second is to conduct field inspections to 
determine that the building is in fact being constructed in accordance with the drawings as approved. In many buildings, particularly those of a residential or light construction type, the complexity of field inspection is relatively minor. On larger buildings, however, where significant structural, heating, cooling and ventilating matters are concerned, and when an architect or engineer may not be present to oversee construction, careful inspection by the building code official takes on greater significance. Based on local ordinance or state law, building code officials may be able to compel the use of a registered design professional during construction. Most states do not give this kind of authority to building code officials on a statewide basis, however. Conversely, many larger cities do allow the building official this discretion. Also, apart from requirements of the building official, several states now require architects to conduct inspections during construction on buildings for which the architect is required by 1 aw to prepare the drawings and specifications. The plan reviewer should determine as early in the process as possible whether or not an architect or engineer will conduct inspections during the construction process. Where a design professional is present or available during construction, code related problems which do arise can usually be solved quickly.

As a further note, where it appears that the owner may not be planning to use an architect during the construction process, the building official should not hesitate to discuss with the owner the advantages of retaining a design professional for inspections. Most experienced building code officials can cite many examples where the presence of a design professional on the job site during construction could have lessened code related problems which arose during the construction process. When an architect is retained by the owner for inspection during construction, his duty is to represent the owner as an agent. The architect inspects to discover departures in construction from the working drawings. The presence of a design professional is a form of insurance policy for both the owner and the code official. The code official should make this point forcefully to owners who feel that the use of design professionals during the construction process is an unnecessary expenditure.

\section{CODE OFFICIALS AS CONSULTANTS}

Al1 states require architects and engineers to pass a registration exam. While building code officials may also be subject to some certification process, there are few states which require a professional license for building code officials. The legal result has been to create a greater standard of care to be exacted from architects and engineers, who by their training and education are legally held to a high standard of performance.

Because building code officials are not licensed, their legal standard of care is not the same as architects and engineers. However, building code officials may be certified and that certification process may affect the legal standard of care which is applied to them. Even upon becoming certified, however, a building code official is still not 
subject to the same legal standard of care as a professionally licensed architect or engineer. Case law, for the most part, still assigns the responsibility for code compliance to the architect or engineer. In practice this means the design professional must establish code complianct in the drawings which he prepared and for which he is responsible. Many design professionals will consult closely with code officials in this process. Code officials are almost always glad to assist in this process whether it be formally as with a plan review or informally based on a meeting at the job site. Nonetheless, regardless of the experience of the code official and the lack of experience of the design professional, the law will in most cases require the design professional to take ultimate responsibility for code compliance in building construction.

Where an architect or engineer is not involved in the process the degree of potential liability for the code official increases. In those instances where no design professional is present, the code official is usually working directly with the owner or contractor. Whether working with owner or architect, however, the code official should avoid a posture of consultant. The line between what constitutes a consultant and what constitutes a building code official who advises as to the requirements of the building code is a narrow and often nebulous one. Nonetheless, building code officials must resist the impulse to suggest solutions to building code problems where the solutions are architectural or construction in nature. Building code officials should limit their discussions to written provisions of the code and leave the means and the specific solutions for satisfying those provisions to the design professional. When a building code official starts delineating the requirements for proprietary materials or methods of construction, the possibility for liability against the code official increases dramatically.

The practice of checking plans and indicating on the drawings areas which require corrections is also one which should be avoided by the code official. Where discrepancies are found in the plan review, those discrepancies should be reduced to references to technical provisions of the building code. The solution as to how those references are to be addressed should be left to the design professional or the individual preparing the drawings for the owner. Building officials should strongly resist the urge to "mark up" sets of drawings which are then returned to the submitter. It is understandable that the non-complex nature of many buildings lends itself to the code official making corrections on the drawings which can then easily be followed by the builders and which will assure the building code official compliance with the applicable codes. The point should still be remembered, however, that the building code official is not the author of the drawings. To show changes on the drawings is the responsibility of the designer and carries legal implications which the code official should not presume, and which may, if undertaken, reduce the designer's legal responsibility.

In correspondence and in conversation, the building code official should indicate clearly that while the building code official is making a review of the drawings to the best of his ability, the design professional and 
the owner retain the ultimate responsibility in every case to conform the building to the requirements of the building code. In practice, this simply means that if the building official makes an oversight, while he may be embarrassed and while the owner may be enraged because of the additional costs, the building official is nonetheless not the architect nor owner and is not therefore the person who is ultimately responsible for compliance with the codes.

Building officials should be viewed as advisors to the design professional who are giving guidance to the best of their professional ability but who are public employees, not in the private sector and who are not realizing a business profit. The building official is in the public sector and is giving his best advice on behalf of the public for the protection of the public, and will, therefore, be comparatively insulated from liability resulting from the risk undertaken by design professionals in the private sector. Of course, when building code officials are guilty of acts of gross negligence, they too should be subject to liability.

As the building code official is undertaking his work to the best of his ability, the expectations from architects and engineers should only be to the extent of their best ability. It is tempting for building code officials to require from architects and engineers written certificates of compliance with the codes. Frequently that language will be in the form of an affidavit or a letter in which the design professional is required to certify that the building as constructed meets all building code requirements.

This requirement for certification has potentially damaging legal implications for the design professional. An architect or engineer cannot guarantee his work to be totally free from error. Statements of performance should only require language indicating that the professional services rendered are to the professional's best ability and knowledge. To do otherwise places the design professional in a legally dangerous position of having given a warranty for his performance. If warranty language is used, the design professional may be unable to legally protect himself by showing that any mistakes which resulted were reasonable. The use of language which is warranty or guaranty in nature may further preclude the design professional from using a reasonable mistake argument to counter charges of negligence. As the building code official can perform only to the best of his ability, no more should be expected from the registered architect or engineer.

\section{PROJECT CLOSEOUT PROCEDURES}

Regardless of the type of plan review or field inspection process utilized on the local level, each office of building inspection should develop a closeout process for each project. Whether the process involves the issuance of an occupancy permit, final inspection certificate or some other method, a final statement of inspection and code compliance should be issued by the building inspection official. By so 
doing, the building official indicates that the building has been constructed in a manner satisfying the minimum requirements of the building code and is safe for occupancy by the public. It also establishes and documents a point in time at which the building has been declared reasonably safe for occupancy under the terms of the building code.

In many instances, buildings can be brought to a point of substantial completion and are, for all practical purposes, safe for occupancy. Because several items may not have been completed, however, the structure will not, in fact, be in compliance with the building code and cannot be described as such. Many local jurisdictions will use the device of a temporary occupancy permit or a similar measure to permit occupancy in all or part of the building under these circumstances. That temporary occupancy permit takes into account the need to complete one or more outstanding discrepancies in the building. The building official in his judgment may properly feel that a building can be occupied without the completion of these items. Yet to ensure that those items will be completed in a reasonable period of time, a final occupancy certificate should not be issued until all items are completed.

For legal purposes, a temporary occupancy permit should only be issued when accompanied by an agreed order. An agreed order is a legal agreement in which the building owner states by a certain time he will complete the outstanding items and that if he does not do so, he will be subject to immediate court action. That agreed order, in effect, becomes a legal document which a court of law can enforce immediately. The presence of an agreed order is a form of incentive for the owner to complete outstanding deficiencies at the earliest possible time.

\section{ENDORSEMENTS OF PRODUCTS AND MATERIALS}

Finally, it is not unusual for code officials, expecially on the state level to be asked to certify certain materials as having met their requirements. Frequently, manufacturers of certain items will refer to the approval of certain State Fire Marshals in promoting their material. This is a practice which the code official should avoid under all circumstances. The code official should establish testing criteria which will allow for the use of materials under the building code. Most of the model building codes will accept test results from agencies such as Factory Mutua1, Underwriters' Laboratories and many others. Once these results are made available and once they are indicated as having satisfied the requirements of the building code, then a local official may accept their use. At no time, however, should the building code official give a product endorsement or product recommendation.

\section{A FINAL WORD}

The continuing need for professionalism and consistency of performance (at a high level) are fundamental ingredients in building code administration. As the process of code administration becomes more technically 
complex and demanding, so also will the need for adopting anti-liability procedures. This paper has sought to identify several of those practices which should, if implemented, reduce the potential for liability while allowing the code official to proceed with the business at hand in a thorough but expeditious manner. 

THE EFFECTS OF CIVIL SERVICE, UNIONS, STATUTORY LAW AND ECONOMICS ON SYSTEMS DEVELOPMENT IN MUNICIPAL REGULATORY AGENCIES

by

Norton S. Remmer, Commissioner

Department of Code Inspection Worcester, Massachusetts

In 1973, the City Council of Worcester, Massachusetts voted to create a new Department of Code Inspection which would incorporate all the responsibilities for administration and enforcement of code and regulatory activities in the City in one Department under one administrative head.

The initial concept was to include building and trade inspection, construction inspection, zoning, housing, fire prevention, weights and measures, environmental inspection, subdivision, license board and license commission inspections.

The plan was to proceed forward in three phases:

1. The immediate incorporation of building, zoning and housing responsibilities into the new department from the department of public works and department of public health, respectively.

2. The integration of administrative processes for the building, housing and zoning responsibilities and the development of necessary procedures for the incorporation of the additional functions and responsibilities.

3. The incorporation of the additional functions and responsibilities over a period of time and systematic development of the administrative programs for integrating the functions.

It became apparent early in the process that the ability to pass home rule ordinances had no relationship with the ability to implement the ordinance due to union considerations, civil service requirements and over-riding statutory requirements. The attempted implementation of an idealized system of management and organization required many modifications and trade-offs to try to accommodate the constraints of law, budget and time which developed. Even the determination of the sequence of many of the steps became a crucial factor in trying to organize such an integrated regulatory system.

While the process is still continuing, the lessons already learned about the limitations imposed on the creation of an idealized system are important, and the questions for the future of such efforts, especially in Massachusetts and states with similar situations are important to consider.

Key Words: Code administration agencies; civil service; idealized system; reorganization 


\section{PURPOSE}

The purpose of this paper is to describe a reorganization which took place in Worcester, Massachusetts, which created the Department of Code Inspection, and the problems and complications of such a process when subject to the constraints of civil service regulations, union rules and agreements statutory requirements and budgeting limitations. The paper is not intende as a guide to others in reorganizing under similar circumstances, since it would be impossible to account for all the variations in law and regulation which might come into play. It is presented as a documentary of the proces as it occurred with the hope that by having a detailed reference of such a process many of the issues which evolved can be anticipated by others, and the time and effort considerably reduced.

\section{INTRODUCTION}

On many occasions organizations decide to reorganize aspects of their functional structure for various reasons. Often, in private industry, the reorganization is a response to a need which is ultimately related to improved sales and/or profits. In government, the need to reorganize can be created by many factors. Some of these factors can be easily identified such as mandatory legislation, change in emphasis in public policy or public service programs and response to social influences and physical changes In the case of government the result of reorganization tends to reflect a re-allocation of limited resources to either legally mandated requirements or needs which have developed a new emphasis.

The need for reorganization in this case could be categorized under three headings; efficiency, service and modernization. Since the change was the result of a local ordinance and not a state or Federal mandate, and the need for reorganization was not a response to what was considered a critical issue, time was not an essential factor.

Worcester is an older industrial city in central Massachusetts with a population of about 180,000 . The building stock is old, with many of the typical New England "three decker" three family dwellings. The city has" a large college population of over 25,000 students.

The inspection responsibilities for the city were divided among many departments. By state statute housing inspection responsibility was vested under the authority of the Board of Health. Building inspection and zoning authority was vested in the Superintendent of Buildings within the Department of Public Works. Plumbing and elevator inspections were administered by the Superintendent of Buildings. Wiring inspections were under the authority of the Department of Street Lights and Wiring in the Department of Public Works. In addition, fire prevention inspections are under the authority of the Fire Department, a subdivision inspection under the authority of the Department of Land Use Control. Also there are other related inspection activities which were considered in the initial evaluation of reorganization. On June 24, 1975, the City Council passed an 
ordinance, to become effective Ju1y 1, 1975, establishing a Department of Code Inspection including the position of Commissioner, and providing for very broad general powers (see Appendix 1). In September 1976 the Commissioner was hired and given the responsibility of creating the new Department. The timetable established was as follows:

1976-1977: To work out the details for the transfer of the Bureau of Buildings and the Health Department housing inspection section to the Code Inspection Department effective July 1, 1977.

1977-1978: To work out the details for the appropriate location of the Department of Public Works wire inspection, zoning, subdivision inspection and Conservation Commission inspections effective July 1, 1978.

1978-1979: To prepare the appropriate procedures for the coordination of all remaining inspection activities with the Commissioner of Public Health and Fire Chief and other appropriate officials.

\section{BACKGROUND}

Civil Service: A11 the permanent positions within the Department of Code Inspection, except for that of Commissioner, are civil service positions. A11 the personnel transferred to the Department were in civil service positions, with the exception of five individuals funded under a blockgrant funded project. The special constraints created by Civil Service were as follows:

1. Al1 job titles and descriptions must be taken from the state uniform job listing and coding catalog. In cases where there is no title and/or description suitable, a new title and description must be subject to an application and approval process. The approval is based on an evaluation of the proposed table of organization. The process time can take from six months to one year.

2. Filling a11 positions which represent promotions are subject to competitive examinations limited to departmental personnel who have appropriate qualifications for such promotion.

3. Any individual who had a permanent civil service position prior to October 1967 had the right to refuse to be transferred.

Union: All the personnel, except for clerical, transferring to the Department, who were non-supervisory, were required to be members of the union. At the time of initial Department creation and reorganization, there were only two positions which were not in the union, one of which was Commissioner. The policies proposed by the union in representing its members in the reorganization were as follows:

1. Because the housing inspection unit positions were generally at a lower level than building inspection, all promotions related to housing inspection or administration should be limited to personnel transferred as housing inspectors. 
2. A separation of responsibilities should be maintained. For example, only building officials could have any zoning authority, even though the Commissioner has the power to delegate zoning enforcement authority to anyone in the Department.

Statutory Law: State law establishes the Board of Health as the authority for enforcing the state laws empowering the enforcement of the uniform mandatory state housing code.

Budget and Economics: The policy established for the creation of the Department was that whatever reorganization took place relative to positions and salaries would result in no net change in salary budget. In other words, if re-gradings were proposed, other positions would have to be either eliminated or down-graded so that the net effect was no change in salary budget.

\section{PROCESS}

\section{Personne1 Transfer:}

1. Housing Inspection - Budgeted positions were transferred by City Council vote to the new Department. By the authority vested in the City. Manager, personnel, except those in permanent positions prior - .to October 1967, could be transferred at his discretion to another Department. The budgeted positions were allocated by the Department of Public Health to the new Department and removed from the budget of the Department of Public Health.

The Department of Public Health is a much larger Department than the Department of Code Inspection. Personnel transferred out of Public Health would have had the opportunity for advancement into many supervisory level civil service positions available within that Department. Therefore, as the result of negotiations with the union, the Department of Public Health made available a full sequence of three promotional positions covering the three sequentially higher promotional grades existing above entry level. Therefore, out of a total of 15 inspector positions transferred, 4 were above entry level.

2. Building Inspection - Building inspection positions, including plumbing and gasfitting and elevator inspection, and also clerical staff, were transferred as a single entity without any changes by vote of City Council.

3. Wiring Inspection - Wiring inspection was separated from the former Bureau of Street Lights and Wires and four positions were transferred with three permanent civil service incumbents.

Budget and Equipment Transfer: Budgets for ordinary maintenance and capital equipment had to be negotiated with the Departments transferring personnel since the basic assumption was that budgets transferred would reduce the original Department's budget by an equal amount so there was no net change. Ultimately, however, there was an overall increase in 
ordinary maintenance budget since it became readily apparent that it was necessary to provide new services, materials and equipment which duplicated that available in the other Departments but no longer available to the new Department.

\section{NEEDS}

The creation of the Department of Code Inspection established new supervisory responsibilities and required a new management super-structure. With many separate regulatory responsibilities in one Department, one of the earliest objectives was to establish the organization and systems necessary to supervise each responsibility, to coordinate responsibilities and to train personnel for these responsibilities. As an example, it was necessary to establish a system of reporting and coordinating housing, zoning, electrical, and plumbing complaints relative to the same address. This required a supervisory position which did not exist within the positions transferred. As another example, all court actions relative to enforcement of any of the codes or regulations would have to be coordinated through a single position, and a system would have to be established for reporting information and collecting it. There were many systems which had to be changed or created and many responsibilities which had to be created or reassigned. Figure 1 of Appendix 2 shows the original organization. It can be said that most of the needs for an efficiently functioning Department in terms of positions, organization, systems and responsibilities, were anticipated with reasonable accuracy, prior to the creation of the Department.

\section{PROBLEMS}

1. One of the major problems encountered resulted from the position adopted by local and state personnel agencies that no action could be considered until all administrative steps and been formally accomplished. This meant, for instance, that it was not possible to anticipate the date of transfer of the Department personnel and positions by initiating action to change positions, job descriptions and responsibilities prior to the formal creation of the Department. As a result, only after all personnel and positions had officially been transferred could any changes be made. The need for new responsibilities and systems was immediate, as soon as the Department started to function. The final results of this situation were as follows :

a. Personnel had to be assigned on a temporary basis to specialized assignments while waiting for approval of their transfer, on a provisional basis to the supervisory positions which were available. In many cases both civil service regulations and union agreements had to be tacitly ignored.

b. Some individuals had to be transferred to new positions several times when positions were eliminated, consolidated or changed in responsibility. 
c. Some personnel had to be trained for positions on a provisional basis with the expectation that the position, which was subject to a Civil Service Examination, would be permanently filled by others.

2. Because of civil service restrictions, the continuing use of prior job descriptions, and union involvement, the use of qualified personnel in new or changed responsibilities has not yet been fully effected. Promotions could only be effected on a sequential basis, which meant, in especially two cases, that individuals highly qualified for supervisory positions for which there were no available candidates would require a process of sequential upgrading, through competitive examinations to permanently fill the designed position. In the process of creating two new supervisory positions there was the uncertainty of obtaining approval during the six months and nine months required for two positions.

3. Creating new supervisory positions and changing positions at lower levels required approvals from the city personnel office, approvals of job descriptions, titles and grades from the state civil service office, and finally approval of the modification in the salary budget by the City Council. The process was sequential based on the approval of each prior agency and in most cases has taken approximately two years. During the approvals process all developments in the Department had to be tentative, subject to the possibility that the lack of an approval at any point would require either an appeal or revisions to many elements of the reorganization.

4. The transfer of authority for administration and enforcement of the Housing Code required a statutory amendment by the legislature. This process required a full year to become effective and considerable time and effort for lobbying.

\section{RECOMMENDATIONS}

Based on the experience in Worcester the recommendations which follow are intended to apply as generally as possible. It is recognized that there are legal and statutory requirements which vary from area to area and any program might have to be tailored to accommodate specific local constraints

1. It is essential that as early as possible in the process of designing a reorganization, all the applicable local procedures and forms should be cataloged - completely, accurately and preferably shown in some type of flow chart.

2. The basic changes of personnel in terms of numbers and positions should be identified as early as possible and firm commitments made concerning transfers of personnel, equipment, and budgets. Any agreements with personnel or unions should be established as early as possible and made firm. 
3. Based on the two preceeding steps, a proposed Table of Organization should be drawn up. In the case of Worcester, the first three steps should have been accomplished in time to allow a full year prior to the anticipated effective date of the creation of the Department.

4. The Table of Organization should reflect, as accurately as possible, the personnel needs for the implementation of administrative systems and enforcement functions.

5. Based on the Table of Organization, all the forms necessary for effecting the changes should be completed. In the case of Worcester, this would have required making many presumptions. However, from experience, it is usually relatively easy to alter existing documents as the situation changes.

6. The method and requirements for effecting promotions within the system should be clearly identified and the sequence of steps necessary to accomplish the promotion identified.

7. Probably the most effective method of dealing with the entire process of reorganization would be to have individuals appointed who are responsible for liaison in the process. In Worcester's case, one individual from the personnel department should have been appointed to help develop the necessary material, one from the City Manager's office, one from each department affected and if possible, one at the state level. Idea11y, the package of materials necessary for reorganization should have been prepared cooperatively to be available upon legal creation of the Department, so that all administrators would know their role and responsibilities in effecting a rapid and efficient transition. 
Code Inspection Department

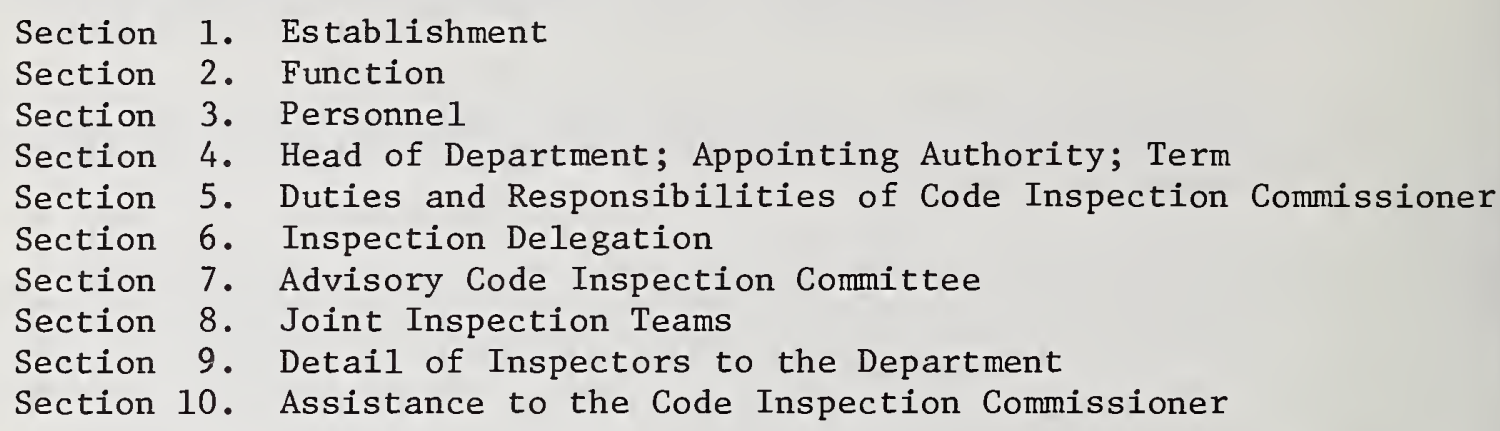

Section 1. Establishment: Under the authority of the General Laws, Chapter 43, Section 5, there is hereby established a Code Inspection Department (hereafter referred to as "Department") under the jurisdiction of the City Manager.

Section 2. Function: It shall be the function of the Department to coordinate code inspection services required of the code agencies of the City.

Section 3. Personnel: The Department shall consist of a Commissioner of Code Inspection and such other personnel as the City Council, with the advice of the City Manager, shall from time to time authorize.

Section 4. Head of Department; Appointing Authority; Term: The Department shall be headed by the Commissioner who shall be appointed by and shall serve at the pleasure of the City Manager.

Section 5. Duties and Responsibilities of Code Inspection Commissioner: It shall be the duty and responsibility of the Commissioner:

a. To prepare the plans and objectives of the Department.

b. To prepare and organize the inspectional program.

c. To train departmental personnel in inspection techniques and methods.

d. To supervise and coordinate the activities of the inspection personnel of the Department.

e. To prepare and to maintain a current library of applicable code inspection laws, including any amendments thereto.

f. To maintain a complete record of all inspections conducted by the Department. 
g. To receive and investigate complaints of alleged violations of laws pertaining to agencies serviced by this Department.

h. To coordinate the Department's inspection activities with other agencies.

i. Upon request of a code agency to review and investigate the factual basis for the issuance of permits and to make recommendations to the requesting agencies.

j. To perform departmental duties in conformance with the requirements of State and local codes.

k. To administer the Department.

1. To perform such other duties that may be prescribed by law.

Section 6. Inspection Coordination: The Commissioner, under the direction of the City Manager, shall perform such inspectional duties as may be lawfully delegated to him by the several departments, boards and commissions of the City, including but not limited to the Commissioner of Public Health, the Commissioner of Public Works, the Planning Board, the Conservation Commission, the Chief of Police, and the Chief of Fire. Said inspections shall be conducted in accordance with the requirements of the delegating authority and the applicable code.

Section 7. Advisory Code Inspection Committee: There shall be within the Department an Advisory Code Inspection Committee consisting of the Commissioner, the Commissioner of Public Health, the Commissioner of Public Works, the Planning Director, the Chairman of the Conservation Commission, the Chief of Police and the Chief of Fire. The Commissioner shall be the Chairman of the Committee. The Chairman of the Executive Committee on Housing shall serve on the Committee ex officio.

The Committee sha11 review the inspectional activities of the City and assist in the coordination of such activities. The Committee shall establish a liaison system between the various inspectional agencies of the City to ensure coordination and avoidance of duplication of inspections.

The Committee shall annually issue a report on the inspection activities of the City. 
Section 8. Joint Inspection Teams: The Commissioner, with the approval of the City Manager, may establish joint inspection teams that may include inspectional personnel from other city agencies. Said teams may handle joint inspection of an area falling within the delegation of the participating agencies.

Section 9. Detail of Inspectors to the Department: Any department, board or commission, with the approval of the City Manager, may assign personnel to perform inspectional duties to the Department. During the period of such assignment, the person assigned sha11 be under the supervision and direction of the Commissioner.

Section 10. Assistance to the Code Commissioner: All inspectors, assign personnel, and other personnel of the Department shall perform their duties prescribed by law under the direction and supervision of the Commissioner. 
Appendix 2-Figure 1

Table of Organization
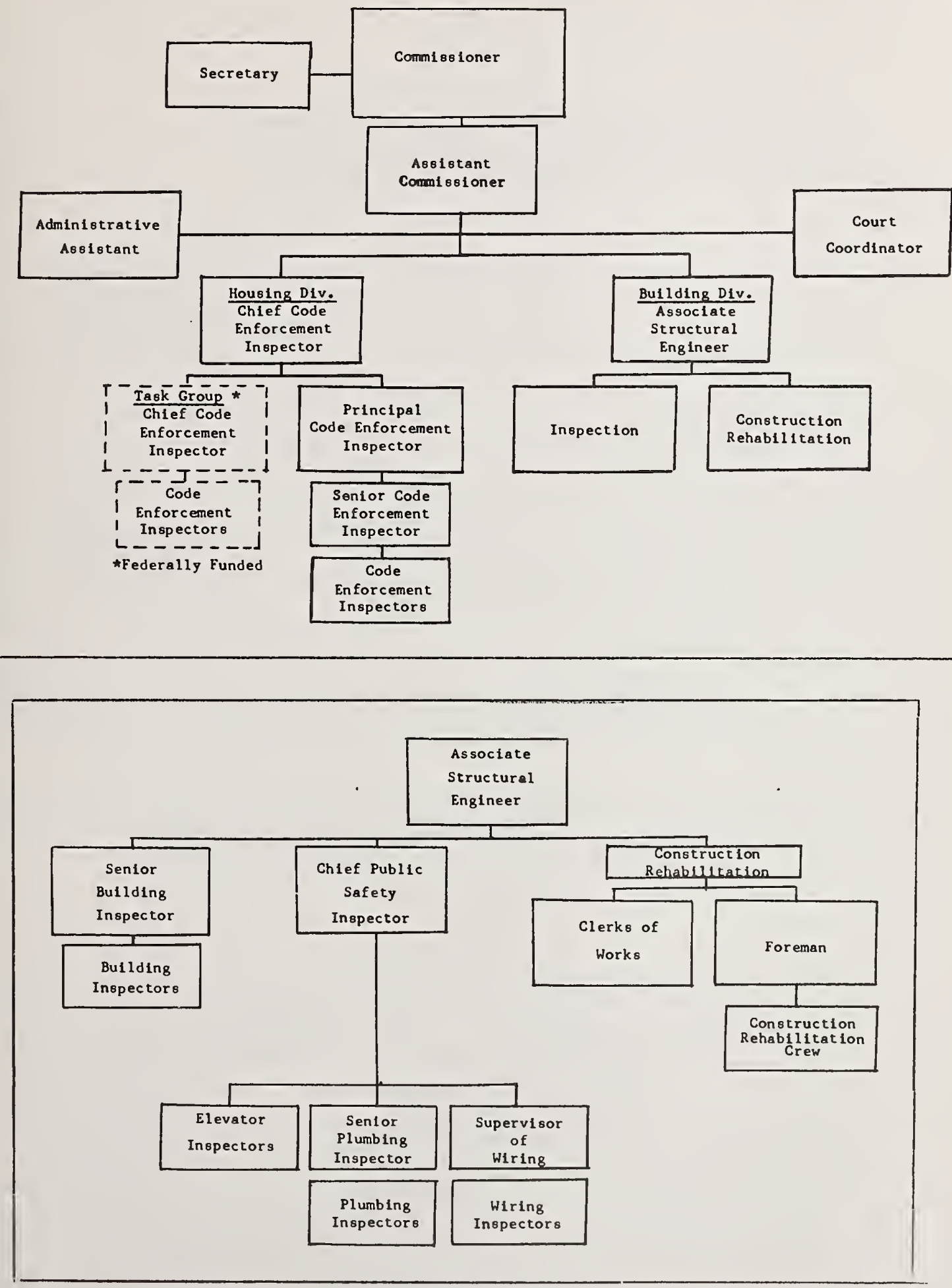

City of Worcester

Department of Code Inspection, As of $1 / 1 / 77$ 
Appendix 2-Figure 2

Table of Organization
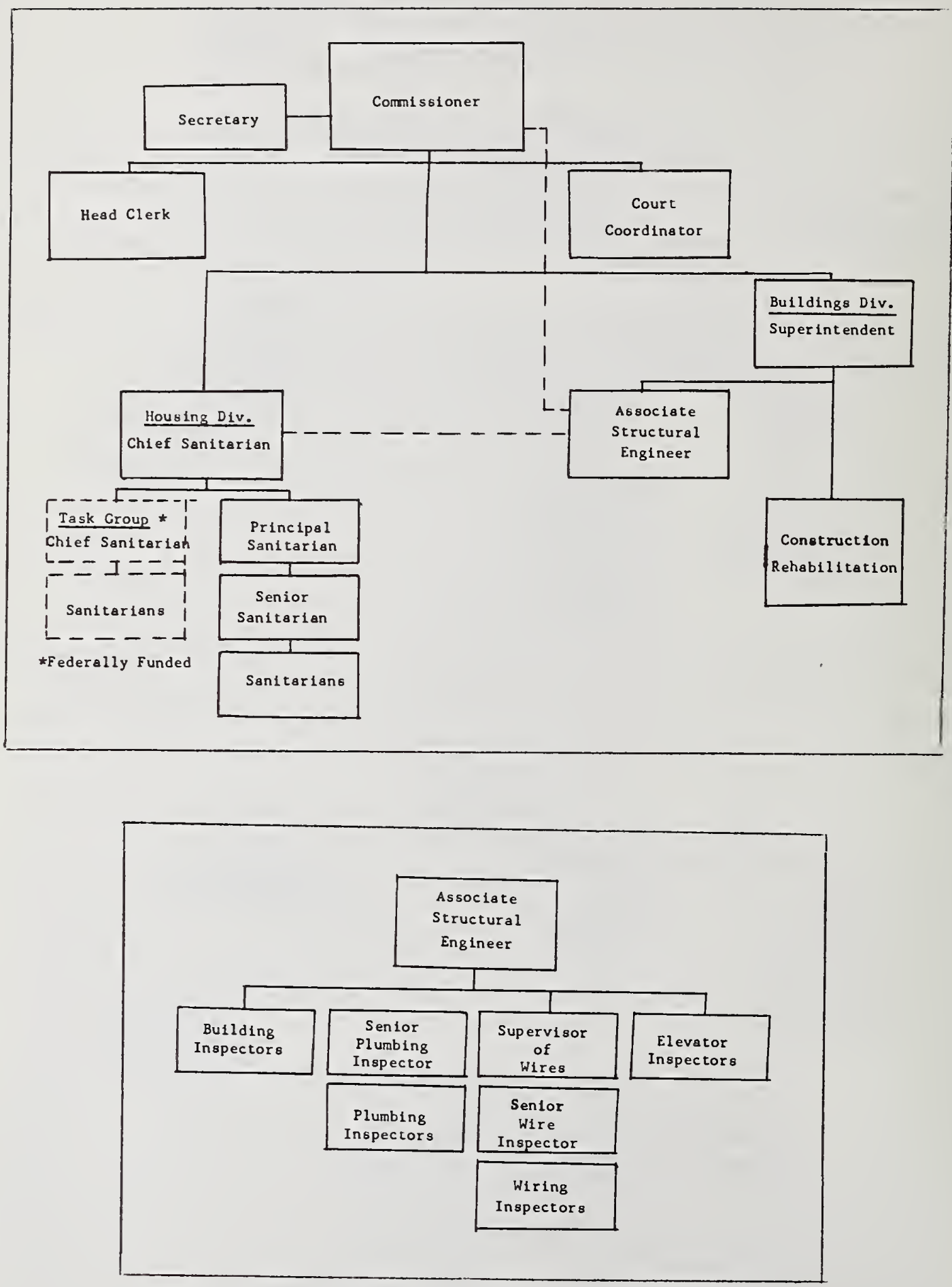

City of Worcester

Department of Code Inspection, As of 7/1/79 
LICENSING OF BUILDING CODE OFFICIALS:

THE EDUCATIONAL REQUIREMENTS

\author{
by \\ Kenneth Albert \\ Assistant Professor of Civil Engineering \\ New Jersey Institute of Technology \\ Newark, New Jersey
}

The State of New Jersey has recently adopted a statewide body of regulations known as the "New Jersey Uniform Construction Code." The code is designed to achieve innovation and economy in building construction and uniformity of standards throughout the State.

A unique set of standards and procedures for licensing code enforcement officials has been established along with the adoption of existing recognized standards as subcodes. The first part of this paper focuses on the problems associated with the development and the regulation of the specialized courses for building inspectors and code administrators which have been developed and implemented to meet the educational standards established by the code. The broader issues of licensing code officials and the establishment of educational criteria are discussed.

The second part of the paper proposes a model program for the implementation of the education component of the certification process.

Key Words: Building codes; building inspectors; code enforcement; course development; educational requirements; inspection; licensing; testing; training code officials 


\section{INTRODUCTION}

The State of New Jersey recently adopted a statewide body of regulations known as the "New Jersey Uniform Construction Code." The code is designed to achieve innovation and economy in building construction and uniformity of standards throughout the State.

A unique set of standards and procedures for licensing code enforcement officials has been established along with the adoption of nationally recognized standards as subcodes. This revised New Jersey Uniform Construction Code requires all inspectors and code administrators to be licensed by the State of New Jersey prior to January 1, 1981. In order to meet the educational requirements established by the code, specialized courses for building inspectors and code administrators have been developed and implemented.

The first part of this paper will focus on the problems associated with both curriculum development and the administration and regulation of the code official courses. The second part of the paper will propose solutions to the problem of developing and implementing the educational component of a program to upgrade the code enforcement process, which may assist New Jersey and other states adopting similar legislation.

\section{A NATIONAL TREND}

It is useful to view the certification of building officials as part of a national trend to improve the code enforcement process. High inflation and associated rising construction costs have provided a strong impetus to develop statewide codes and adopt nationally recognized subcodes. By eliminating the variation in regulations from town to town, the statewide code is expected to eliminate or at least minimize difficulties associated with the sometimes arbitrary plan review and inspection procedures.

A uniform construction code will have a direct impact on reducing construction costs. For example, due to inflation, the time element in construction projects has become an important cost factor. The statewide code would effectively reduce the time involved in plan review, thereby dramatically reducing the inflationary impact of a delay at this stage on the total cost of a project.

The adoption of statewide codes may also provide impetus for building systems development. It is expected that performance codes, such as the Building Officials and Code Administrators International, Inc. (BOCA) Basic Building Code, will allow for greater innovation and economy in the building systems area. Unfortunately, the expectations of programs such as Operation BREAKTHROUGH designed to increase building systems, in the late nineteen sixties, have not been realized. Although we are passing through a relatively dormant period in the building systems area, the utilization of performance codes would undoubtedly promote its development. 
It is reasonable to expect that more states will begin to regard their building regulatory practices as an influential factor in encouraging construction in their states. The adoption of the Uniform Construction Code in the State of New Jersey marks a progressive step in recognizing the relationship between the regulatory process and the level of construction activity.

Unfortunately, the reality of implementing the new code has not been consistent with the expectations just outlined. Since July 1, 1977, the effective date of the new code, New Jersey has been plagued by problems associated with its administration. Delays in granting permits appear to have increased dramatically. Permit fees have escalated, in some cases doubling, and a great deal of confusion and frustration on the part of architects, builders and administrators has been generated.

It should be noted that we are in a period of transition and this transition is a difficult one. It is clear that the success of the new code is almost entirely dependent on the code enforcement personnel who are responsible for carrying it out. The code requires a new level of sophistication and increased technical knowledge to interpret and administer the plan review and inspection process. An increased liability on the part of the code enforcement personnel may also exist, an area which will be explored in this paper.

\section{LICENSING OF CODE OFFICIALS}

Clearly an important part of the statewide code is the certification of building officials. The administration and enforcement of a statewide code must be carefully controlled if the desired uniformity is to occur. Recognition of the importance of this aspect of code enforcement has been occurring in Canada. The first province-wide certification of building officials began this year. A $\$ 45,000$ grant from the Council of Maritime Premiers was given to the Maritime Municipal Training and Development Board to develop a system to standardize qualifications and training for building inspectors which led to the certification of building inspectors in Nova Scotia.

The certification of building inspectors is a direct outcome of many years of work in Canada. In 1970, a report of the Committee on Uniform Building Standards for Ontario recommended the adoption of a provincewide code and called for training and certification of building inspectors. The BEAM program of the Department of Industry, Trade and Commerce called for the adoption of a single code throughout Canada, with certain area dependent modifications, and also addressed the need for training code enforcement personnel.

The intimate connection between the adoption of a statewide or national building code and the need for training and establishment of qualifications for code enforcement personnel has always been recognized. However, determining the specific qualifications for building inspectors is not a simple undertaking. 
Chapter 23, Title 5 of the New Jersey Administrative Code, the enacting legislation, established those qualifications. It provided for a combination of experience in construction and/or formal education in architecture and engineering with the additional requirement of successful completion of an approved educational program. Three levels of licensure were created: residential and commercial structures (R.C.S.), industrial and commercial structures (I.C.S.), and high-rise and hazardous structures (H.H.S.). Each classification of license required the completion of a different approved course.

The New Jersey Administrative Code includes a statement concerning the purpose of these courses:
"To carry out their responsibilities, code enforcement officials must be fully knowledgeable about code standards and adequately prepared to administer and enforce them properly. Code enforcement education programs must meet certain standards to ensure code enforcement officials have the necessary technical and administrative training to effectively enforce the Uniform Construction Code at the local level."

The Administrative Code goes on to say that:

\begin{abstract}
"Each institution is responsible for developing its code enforcement courses within the general policies relating to education and 1icensure of code enforcement officials in the state." 2
\end{abstract}

Creating minimum educational standards, in theory, is a relatively simple matter. However, developing courses for inspectors which will assist them in their work, and at the same time provide some guarantee that the participants will achieve the technical training necessary to "effectively enforce the Uniform Construction Code" is a very difficult task.

The New Jersey Administrative Code included a 1ist of subject headings for each of the licensing courses. Each college applying for course approval, submitted an outline to the Department of Community Affairs, (DCA). The DCA then compared these outlines with the subject heading list contained in the statute. Course approval was primarily based on the inclusion of all subjects in the statute by each college outline. The DCA's requirements were not detailed.

For example, one of the three subject requirements for the H.H.S. 1icense is "Advanced Structural Systems." The subject matter according to the law is as follows: 
"Structural design and analysis technique necessary to check compliance with code for heavily loaded and technically advanced structural systems which characterize class I buildings. Subjects covered should include pile and other foundation systems used to bear very heavy loads, analysis of high-rise framing systems including wind load and seismic considerations." 3

The above was to be covered in 30 contact hours of instruction. The description above, if taken literally, could be interpreted as a four-year program in structural engineering. A great deal of latitude is obviously given to the individual colleges in the implementation of this mandate.

When DCA officials were questioned about the lack of specific directions, their response was: "We (DCA) did not want to inhibit the creative development of courses by the various college teaching staff." In addition, they emphasized that curriculum development was not within their area of expertise while the colleges have had a great deal of experience in this area.

\section{CURRICULUM DEVELOPMENT}

When New Jersey Institute of Technology first entered into discussions with the Department of Community Affairs (DCA), we were fortunate to have on staff a number of faculty members who were very active in the construction industry. Following State guidelines, we were able to adopt a reasonable curriculum. However, during the first course, a number of serious problems began to emerge. In an effort to analyze some of these problems, a questionnaire was circulated among participants requesting some personal data as well as basic technical questions. The following became apparent:

1. Academic Background - There was a great variation with respect to academic background. The participants ranged from high school graduates to graduates of engineering programs. Two individuals held masters degrees in engineering.

2. Experimental Background - A large number of participants had some background in one or more of the construction trades, some with more than 20 years experience in construction. There were several architects and engineers. A number of individuals were novices, most of whom were attempting to become residential inspectors for private home owners or real estate agencies. The majority of participants were presently employed as inspectors or code administrators.

3. Technical Capabilities - The participants' technical capabilities varied from those who understood concepts of stress and force systems to those who were unable to answer questions concerning the nature of concrete. 
While we expected some diversity among the participants, the degree of variation in their technical capabilities was somewhat striking. We were reassured, however, by the fact that most of the participants were presently employed as building inspectors and, therefore, had a common basis of experience from which to work.

The information from this questionnaire forced us to re-think some of our original objectives. Several questions which were dealt with when we first developed our curriculum had to be reanswered. Presenting in a general way, what was actually done in a more specific fashion, we asked ourselves the following questions:

1. What does a building inspector do?

2. What technical information does he/she need to carry out their work?

3. What can we reasonably expect from their experience in the way of technical expertise?

4. What technical information is likely to be lacking which can be provided through a formal education experience?

It became evident that an evaluation of these questions is essential to the development of code official courses. The second part of this paper will focus on an analysis of these critical issues and their application to the development of code official courses.

An additional and more immediate problem also emerged; how do we translate the highly technical material mandated by law into a comprehendable framework which code officials could use in their decision-making process.

The need to translate highly technical concepts into practical terms will become clearer by way of an example. On May 16, 1968, in Canning Town, London, England, a relatively small gas explosion in a high-rise building known as Ronan Point blew out a single pre-cast panel on the eighteenth floor. This set up a chain reaction which led to the partial collapse of every floor of the structure. It was very much like building a house out of dominos and then removing one of the bottom dominos. This type of failure is known as progressive collapse. The Ronan Point collapse occured at a time when pre-casting and systems building in general, were in a growth period in Europe and the United States. A great deal of effort was directed at the study of this collapse. At that time, the expectations of the large-scale housing industry were invested, at least in part, in the pre-cast concrete industry. The Ronan Point disaster ultimately led to the abandonment of over 20 relatively new, high-rise structures in England. Today, we know why this failure occured and also how to prevent it. The solution effectively lies in tying the structural members together in such a way that the elimination of any one panel will not cause the adjacent panels to collapse. 
I use this example because in New Jersey, there is an active pre-cast concrete industry. It should be noted that this industry is in the forefront of technological development and has addressed this problem extensively. The solution to progressive collapse is highly sophisticated and is only offered on a graduate level to students working in this area. Therefore, many architects and engineers have not been exposed to this problem. With the exception of the Precast Concrete Institute, the applicable codes do not address this problem adequately. The enforcement of a performance code is particularly difficult in an area such as progressive collapse. For example the BocA code contains the following:
"701.2 Progressive Collapse: Buildings and structural systems shall provide such structural integrity that the hazards associated with progressive collapse, such as that due to local failure caused by severe overloads or abnormal loads not specifically covered herein, are reduced to a level consistent with good engineering practice."4

Although BOCA addresses progressive collapse in a manner consistent with a good performance code, it is evident that there is a lack of guidance for enforcement officials. Due to the existence of the precast industry in New Jersey it was felt that the problems associated with progressive collapse should be addressed in the high-rise seminar, one of the code official courses at the New Jersey Institute of Technology (N.J.I.T.). Our primary concern was how to translate the state-of-art technology related to progressive collapse into acceptable code enforcement practices.

The mathematics of pre-cast design are too sophisticated to be included in such a seminar. In addition, it is not the responsibility of the plan reviewer to either duplicate or verify the design work, of the engineer. However, a conceptual appreciation of technical problems such as progressive collapse, associated with a particular building system would assist code enforcement personnel to assess with confidence, those areas of high risk.

To facilitate pre-cast construction, the State has accepted responsibility for in-plant inspections and certification of building systems. It is the responsibility of the appropriate subcode official to ensure that the plans submitted for review are consistent with the certified system and that such plans meet all the constraints of the certification.

In the case of progressive collapse, there are two areas in need of special attention. Units delivered to the site must be inspected for defects. The second and more important aspect of the inspection process lies in the physical connections between concrete panels. It was decided to include in the high-rise seminar a description of the different types of connections and provide participants with actual guidelines for an inspection which would ensure consistency between the 
plans and the actual construction of these connections. Despite its complex nature, it is necessary to include this material in the seminar because of the degree of potential risk in this type of construction.

The primary point of this example is that a conceptual understanding of a complex problem is both possible and necessary if the code enforcement process is to be successful.

Typically, if an engineer were asked how he solved a particular problem, he or she would respond by simply reproducing the mathematical solution. In fact, much of engineering education today is based on an analytical approach. Application of such a theoretical approach to the code enforcement courses, most of which are taught by engineers, would be a disaster. A much broader perspective, with a reasonable combination of the analytical and the conceptual is needed if we are to adequately train code enforcement officials. The specific subject matter of these courses should always be presented as they relate to job related functions and actual decision-making.

Too often in an academic atmosphere, criticism by the participants occurs without a subsequent re-evaluation on the part of faculty. Thus, potentially useful feedback is lost. Training of code enforcement personnel must be accompanied by carefully thought out goals and objectives based on a realistic skills assessment. The following is an analysis of course evaluations submitted by participants in code official courses given at New Jersey Institute of Technology.

\section{COURSE EVALUATION}

Upon completion of each of the building inspector courses at the New Jersey Institute of Technology, the participants were asked to evaluate the course with respect to instructors, content, written materials and overall value. The results provided some insight into the needs of the participants.

Almost all of the participants enjoyed the course and welcomed the opportunity to take part in an academic process. It should be noted that our courses were offered during normal work hours and, therefore, most of those presently employed as code officials were excused from their normal work. The overall consensus was that the information provided by the course would assist them in their work. The sessions directly connected with plan review received the most enthusiastic response. Those sessions dealing with stress, force systems, and structural analysis were, according to the evaluation, the most difficult to understand. However, their comments indicated that they were intrigued by this material and had we employed a somewhat different approach to structural design and analysis, we might have been more successful. A conceptual approach similar to the one used in the progressive collapse example, would have been better received and of greater practical use. 
Lastly, there was criticism concerning the lack of a text or support material. The Uniform Construction Code, the appropriate energy subcode and the BOCA code were the only required texts. The instructors supplemented their lectures with some additional material, however, the students had no comprehensive text to refer to after each session. There were many comments concerning the need for more reference material.

\section{IMPLEMENTATION OF THE EDUCATIONAL COMPONENT}

Thus far, I have described some of the difficulties encountered at one institution in developing the specialized courses for building inspectors and code administrators. The problems faced at the New Jersey Institute of Technology are an indication of the magnitude of the much broader issue of the lack of uniformity in course development statewide.

At present, the code official courses are being developed and implemented independently by colleges and universities throughout the State and are approved by the Department of Community Affairs. The first courses were offered in 1978 and after one year of experience, it is evident that there is a wide variation in course content and testing among the different institutions. The participants, as well as the State, are aware of these variations which undermine the strength and potential of the certification process. Academic institutions are subject to the same variables encountered in other social agencies and private industry, therefore, uniformity cannot be expected to occur automatically.

The source of many of the problems can be attributed to the State's delegation of its responsibilities to the universities. Although the universities have much to offer in the area of curriculum development, the State must take responsibility for ensuring uniformity by developing control systems, specific guidelines for course content and universal testing procedures. The inclusion of some fundamental preparatory work in the program to implement the new code would have resulted in a more productive training and certification process.

The following is a multi-staged program for the implementation of a training program for code officials which, based on our experience, would avoid most of the difficulties we have encountered.

\section{Development of Job Descriptions for Code Enforcement Personnel}

Detailed job descriptions would include the technical functions, nontechnical functions, the responsibilities to the public as well as the legal responsibilities and liabilities. Job descriptions already exist in Civil Service classifications and within various public agencies. However, a much more detailed description must be created which would include, for example, not only plan review, but the technical functions which are inherent in plan review. The New Jersey Uniform Construction Code already contains much of the information needed for a detailed job description, however, this information must be revised and reorganized in order to establish a national skills assessment. 
An assessment must be made of the skills necessary to carry out the functions contained in the job descriptions developed in Stage I of this program. The term "skills" is used in its broadest sense to mean the analytical and technical capabilities and level of familiarity with the construction process which a code official should possess. Differentiation should be made between those skills which can be acquired from on-the-job experience and those skills requiring a basic technical background.

III. Curriculum Development

A job oriented curriculum must be developed. The basis for the curriculum should come from clearly stated goals and objectives which arise out of the skills assessment. A minimum level of the participants skills established in Stage II should be used in developing the curriculum. Those with insufficient background could upgrade their skills using the training manual which will be described in Stage IV.

The main thrust of the curriculum should be to supply information and background material, not ordinarily gained through field experience. Course content would relate directly to the functions outlined in the job description. The time in the classroom must be optimally used. Mandatory continuing education for code enforcement personnel, however desirable, is not a realistic possibility in the immediate future. Once an individual is licensed he or she will remain licensed, therefore, the classroom experience should instill an appreciation of code enforcement as a dynamic profession and should suggest the ways and means of updating professional skills. If the classroom experience is a positive one, participants may take a positive outlook towards future seminars, such as BOCA's Professional Development Series, the International Conference of Building Officials' (ICBO) Short Courses, the Southern Building Code Congress International, Inc.'s (SBCCI) Educatjon Program or the continuing education programs offered by various colleges.

\section{Training Manuals}

A comprehensive text must be developed and this overrides all other concerns. A manual would serve the dual purpose of providing a guidance document for the instructors as well as providing the necessary background and reference materials for the participants. The costs, and it should be noted that there are costs involved, of developing such manuals would not be exhorbitant and in most states, the costs could easily be offset by their purchase. The organization of the training manuals would be based on the information contained in the job descriptions, skills assessment and developed curriculum. 


\section{Faculty Selection}

Faculty selection is the key to the success of the training program. One of the primary criteria (with the exception of fire inspector) should be experience in construction. The bulk of the responsibilities of code enforcement personnel lies in the ensuring of consistency between plans and specifications and the construction process. The vast majority of building failures, with the exception of foundation failures, lies in the construction process, not in the design. Therefore, the orientation of faculty with regard to construction is critical.

State training sessions should be offered to instructors. These could be one-day sessions providing orientation and technical information.

In New Jersey, there is a reluctance on the part of the state to make demands on the colleges based on the false assumption that it would inhibit their interest and participation. My own experience indicates that most instructors would welcome the opportunity to be involved in an orientation program.

\section{Course Evaluation}

The state should review all written materials used in code enforcement seminars. Participant evaluations should be distributed and also reviewed by the state. At least one site visit by the state should be made to each seminar which would serve the dual purpose of reviewing the course and also give the reviewer the opportunity to speak directly to participants. An evaluation could then be made and sent to the college along with recommendations for improving the course.

\section{Testing}

Presently, for each seminar offered in New Jersey a different test is developed and administered by each institution. Participants taking the same seminar at different institutions, take different exams. Since these examinations are the only criteria for passing or failing a particular seminar, the examination content is critical.

A solution to this obvious lack of uniformity is the development and implementation of a single statewide examination for each seminar. The thrust of this program is the development of a uniform and relevant educational process which will be part of the overall certification program for code officials. There are some costs involved in the implementation of such a program. The costs should be more than offset by savings in the construction process, obtaining ratables earlier and by increased construction activity in the state. More important than any of these, however, is the increased protection of the public safety and welfare. 
Since the enactment of the new code in 1977, there have been many difficulties. Some are unavoidable during a period of transition. There have been numerous articles in the newspapers concerning legislative hearings, possible revocation of the new code, problems with unlicensed municipalities and pending law suits related to the code.

While there has been much criticism of the state govennment, I believe that the Department of Community Affairs has done remarkably well considering the enormity of the task. It should be stated that at least some of the criticism stems from the conflict between the code enforcement process and those individuals attempting to build. Most architects, engineers and builders view themselves as competent professionals who obey the law and wish to carry out their work in as smooth and easy fashion as possible. The code enforcement process is therefore often viewed as an enormous constraint which increases costs, delays construction and in general poses obstacles to the construction process.

This negative view of the code enforcement process might be greatly improved if code enforcement personnel were trained more effectively. The training experience, if administered properly and used to its fullest, can provide code officials with an appreciation of the concerns of the architect, engineer and owner while at the same time assist those officials in gaining confidence in carrying out their tasks. If an architect or engineer is confronted by a competent, know1edgeable code administrator, who presents valid, specific reasons for denying a permit, in essence that code administrator is acting as a consultant to the designer. When the plans are resubmitted and reviewed only in regard to the specified problem areas, as the New Jersey law provides, the designer will then gain a greater appreciation and respect for code enforcement. The need for an efficient code enforcement process with well trained personnel is more pressing than ever before. We have arrived at a point in the history of the United States in which large portions of our urban centers are filled with old and decaying buildings. At the same time the economics of new construction dictates that these buildings remain in service. Some of them undergo renovations while others are being recycled; when in former years, these buildings would simply be disposed of. In many cases, the owners of older buildings are not properly maintaining them and do not fully understand the implications inherent in such neglect. All of us are aware of the recent tragedies in New York City concerning the failure of lintels, ornamental work and in one case the collapse of an entire masonry wall.

In Newark, New Jersey the average age of a school building is over 50 years with many of the schools built in the late eighteen hundreds, yet these buildings must be preserved. The Newark Board of Education 
in conjunction with New Jersey Institute of Technology has just completed the development and implementation of an inspection, evaluation and rating system for the entire Newark school district. The inspection crews included architects and engineers and a11 personnel underwent an intensive training program. From this program, it is evident that inspection and code enforcement of these older structures, places an enormous burden on code enforcement personnel. Therefore, the training and certification of building officials has never been more needed.

It is not unrealistic to assume that certification may incur greater liabilities for code administrators. Although BOCA's Basic Building Code states that building officials are "relieved from all personal liability," the courts have already made exceptions to this general rule where negligence has occured. If building officials become entangled in legal actions to the extent that it interferes with their performance, then perhaps legislation in this area must be enacted. It is best to acknowledge and anticipate such a possibility. It is also clear that code enforcement personnel, to avoid serious liability, must thoroughly understand the codes. Therefore, certification, as long as it is accompanied by a sound educational program, can ultimately minimize the liabilities of building inspectors as well as ensure greater public safety.

The universities have a responsibility and have shown themselves to be willing to fulfill their designated role in the certification process. The success of the training programs, however, will be dependent on the implementation of the proper mandates, the necessary support and the required controls by the states.

\section{REFERENCES}

1. "New Jersey Administrative Code," 5:23-5.6, Division of Administrative Procedure, Department of State, Trenton, New Jersey, filed August 22, 1977.

2. Ibid.

3. Ibid.

4. "The BOCA Basic Building Code - 1978," Building Officials and Code Administrators International, Inc., Chicago, Illinois, 1978. 



\title{
SESSION 2A - STUDIES DEALING WITH HOUSING CODES
}

\author{
Moderator: Thomas K. Faison \\ Building Economics and Regulatory \\ Technology Division \\ Center for Building Technology, NEL \\ National Bureau of Standards \\ Washington, D.C.
}



HOUSING STANDARDS: OBJECTIVES AND AGENDAS

\author{
by \\ Danie1 L. Schodek \\ Associate Professor of Architectural Technology \\ Harvard University \\ Cambridge, Massachusetts
}

Housing standards imply a set of values and objectives that are rarely made explicit. In addition to stated goals of health and safety, standards also implement certain national policies and agendas relating to social planning. The nature of these objectives and their influence on the formulation of housing standards form the subject of this paper.

The paper traces the general development of national housing policies in the United States and briefly highlights those in other countries. It is argued that space and usability standards promote housing types responsive only to a limited set of biased objectives and mitigate against the development of housing responses to a broader range of lifestyles, cultural values and climatic conditions.

Key words: Housing standards, housing policies, building regulations; minimum property standards. 


\section{INTRODUCTION}

The idea of social planning is an anathema for most Americans. Yet the nature of much of current living environment--which many, but not all, of us find so comfortable--is largely a consequence of specific social planning agenda, primarily by virtue of the fact that housing standards are one way such agenda are translated into action.

The purpose of this paper is to examine the implied social planning objectives and biases in our prevalently used housing standards. Standards in this country are shown to promote an image of an "American House" derived largely from a limited set of social planning biases, even when this consequence may be detrimental to many segments of the population.

There is all too often a tendency to think of standards as measures that are objectively determined and thus implicitly have sacrosanct status. This status is hardly the case with respect to measures used in scientific or technical fields and patently untrue when it comes to measures used in connection with usability and living quality notions in housing. In the case of housing standards, it is argued in this paper that all measures in one way or another reflect larger socio-economic planning objectives and are consequently manifestations of particular biases. They are objective only with respect to the biased viewpoint assumed.

The assertion that housing standards reflect specific social planning biases could be explored in many ways. This paper chooses to do so by a quasi-historical review of the development of national housing policies and related standards and by contrasting major trends in the United States with those in other countries. Attention will be restricted to earlier events that have historically shaped our housing policies and standards. Current policies and standards will be only briefly addressed as a manifestation of further steps in a chain of continuing events. Since the history of these events is complex, no attempt will be made to do anything other than highlight primary milestones.

\section{EARLY DEVELOPMENT OF HOUSING STANDARDS}

Public measures related to housing have generally evolved along two different lines over the years. One set of measures relates almost exclusively to the safety of construction and protection of property. The second set relates more to the healthfulness and general living quality of housing.

The first set of measures have a long history, dating back to the well known provisions in the Codes of Hammurabi that deal with the adequacy of building construction. Through the years measures of this type have evolved into our current building codes. Efforts in the 19th century directed towards controlling conflagrations were particularly important in giving building codes their current form. An excellent treatise on this subject is contained elsewhere ( 1 ). 
The remainder of this paper will deal with the second set of measures that relate to the healthfulness and general usability and living quality of housing. These measures also date back into antiquity, with examples including the regulation of building lines in Nineveh during the reign of Sennacherib (705-681 B.C.) and the prohibition in the Campus Martius in fourth century Rome of huts and hovels. The Elizabethan Poor Laws of 1601 which provided for workhouses is yet another example.

Still it is during the industrial revolution that such measures began assuming their current form. The industrial revolution was a watershed in the development of housing measures for two primary reasons: (1) the rapid urbanization that took place in Europe and the U.S. in that era, and (2) the rapid development of new political ideologies and social consciousnesses.

As rapid urbanization took place in the 19 th century, existing housing stocks and means for constructing new dwellings proved incapable of providing adequate housing for the burgeoning urban populace. For many, housing conditions were appalling and unhealthful conditions existed in many cities (2).

Many private groups sought to relieve conditions. The New York Association for Improving the Condition of the Poor, started in 1843 for example, was a coalition of merchants and businessmen formed to combat slums. This organization was, of course, reflective of a larger social reform movement growing at the time which sought to ameloriate all of society's ills, not just poor housing.

In New York City, efforts of this type eventually led to some governmental intervention. In 1856, a panel of legislators investigated slum conditions in the city. The well known tenement House Act of 1867, with minimum standards for water, sanitation and repair, was enacted later. Competition for the design of a low cost residential structure to make housing available at low rent to all resulted in 1879 in one of the first social housing designs in history--the famous "dumbell" units. Interestingly, the awarding jury declared that requirements for "physical and moral health" could not be satisfied on the $25 \times 100$ foot lot size stipulated in the competition.

Another major tenement house law was passed in 1901 in New York that applied to New York City and Buffalo. This legislation came to be regarded as the nation's first housing code. It included requirements for light, sanitation, ventilation, occupancy, building and maintenance standards, and condemnation procedures for unfit buildings.

In addition to reform groups, other private organizations provided initiatives in the provision of housing. Industrial employers became active in providing housing for their workers--an initiative probably spawned as much by the failure of the market mechanism to provide housing as by more lofty goals, although the latter were present in many instances as well. Of central interest herein is that while much of the 
housing produced in this way was minimal in nature, some projects were carefully designed and regarded as model housing projects. Thinking about space and amenity standards was undoubtedly present, if not well documented in the literature of the day.

Other private groups promoting improved housing were various philanthropic organizations. An active movement was developed by these groups. Private initiatives in the form of housing corporations also developed, primarily in Europe. By and large, however, most private initiatives in the 19th century proved unequal to the task of assuring adequate housing. Many initiatives, such as housing provided by employers, engendered problems of their own. Government intervention, however, was still largely resisted. The influence of the laissez-faire philosophy that was so prevalent during the times reached into all quarters.

What extensive government interventions that did develop in the 19th century were largely initiated in other countries as a result of the need for improved sanitation and not housing per se. The Public Health Act in England in 1848, for example, followed a severe cholera epidemic. The Shaftsbury Act in 1851 became England's first significant housing legislation. The act allowed local governments to clear out slums by constructing new dwellings. Many other countries followed suit. Slum clearance and sanitation endeavors occured not only in cities such as London and Birmingham, but in Brussels, Paris and several German cities as well. Many of the slum clearance projects, unfortunately, merely displaced tenants. Several German cities imposed not only safety standards, but limited building heights and densities. Also stipulated were minimum requirements for ventilation, sunlight and ceiling heights.

In Europe, housing legislation concerned with the provision of adequate finance for the construction of low cost dwellings also appeared, e.g., in Belgium in 1889, an act made government funds available at low interest rates to finance the construction of dwellings for industrial workers.

By and large, however, most governmental efforts in the 19 th century were not able to meet the needs that existed.

\section{THE CITY BEAUTIFUL AND THE INNOVATIVE $1910^{\prime} \mathrm{S}$}

Towards the end of the 19 th century and beginning of the 20th century, a movement began occuring that was to have major significance on housing and housing standards later. This was the emergence of the "garden city" movement. The notion of the garden city with its departure from an intense urban fabric and back to the land ideals had almost instant appeal to many individuals of the day.

The year 1910 marked the approximate beginning of a really amazing period in the development of housing. With the 1907 depression over and a severe housing shortage present, the impetus for new housing was strong. By now urban reformers had much more of an image of the ideal city than ever before, an image influenced not only by the social 
reformers and those concerned with sanitation, but by the image of the city beautiful as well. In all spheres related to housing, there was much more of a consciousness about the role of housing in the city. The symbolic artifacts of a city; its centers, squares, monuments and boulevards, ceased to become the sole concern of the city planner and a wider spectrum of concerns emerged. In the United States, many remarkable projects were developed, such as those in Billerica, Forest Hills and Youngstown. Many aspects of the garden city movement was directly incorporated into many housing developments constructed at the time in this country and abroad.

The Russe11 Sage Foundation published in 1914, a landmark document in housing reform entitled, "A Model Housing Law." The document was authored by Lawrence Veiller who later did some very important work vis-a-vis the development of housing standards.

World War I caused a permanent change in the housing situation here and abroad. The Rent Restriction Act was passed in England in 1919 to curb rising prices. Similar acts were later passed in France and Germany. The Bolsheviks nationalized a11 urban housing in Russia in 1917. The destruction of life and property were unparalleled. Government actions were virtually mandated. The birth of massive public intervention in housing had taken place.

The entrance of the United States into the First World War caused the shortage of housing in this country to become even more acute. Certain1y housing near major war industry production centers was inadequate. A Council on National Defense in 1917 created a study that led to something that was unique in American history at the time--the construction and management of housing by a large central organization (the United States Housing Corporation). Also important was the creation of the Housing Division of the Emergency Fleet Corporation.

A fair number of units resembling English garden suburbs were completed by these organizations before their termination at the war's end.

Important1y, from the viewpoint of standards was the work of Lawrence Veiller, mentioned previously, who formulated standards for housing constructed by the United States Housing Corporation. Later these standards became the basis for many developed during the active years of the nineteen thirties in the U.S.

\section{THE INTER-WAR PERIOD}

The aftermath of the First World War strongly influenced the nature of the housing policies in this country and abroad. Certainly there was a housing shortage immediately following the Armistice. Many of the measures related to housing introduced in many countries during the war were initially mantained. 
Abroad, rent controls were often maintained well into the inter-war period. While serving some national aims, an effect of rent control was often to inhibit new housing construction by the private sector. The impetus for governmental intervention, a movement with pre-war roots, was thus strengthened. The changing nature of the political situations in many countries also influenced the housing policies pursued. Certainly the socialistic movements present also called for governmental intervention in housing.

As a consequence of these developments, there was in Europe a marked shift towards public rather than private initiatives in housing. Between 1924 and 1930, for example, over one half of all units built in Germany were publicly financed. Many other countries had comparable experiences. Many critical issues that are still of concern developed during this period which relate to the form of public support and the role of the private sector. A characteristic of housing efforts in Europe in the twenties was an upward adjustment or enforcement of minimum standards in implemented programs. This often resulted in higher costs to users who were in turn unable to afford them. Governmental subsidy programs were consequently required to maintain access to housing. Questions emerged of the type of subsidies offered and the target population, including whether "deep" subsidies to a relatively few individuals are more or less preferable to "shallow" subsidies to a great many. A mix of subsidies was usually used with the former often primarily undertaken by governmental authorities.

During this same period, a number of important studies were made in Europe which related to housing standards, e.g., Sven Reimer made surveys in Denmark in the nineteen-twenties on household possessions, attitudes and activities.

The nineteen-thirties saw a lessening of government support of housing in Europe as the housing shortage subsided. More emphasis was placed on slum clearance projects (Sweden was a major exception).

In the United States, there was relatively little activity in housing in the twenties--the period of significant developments in Europe. Undoubtedly, this is attributable to some extent to the lack of war damaged housing. Housing needs were thus different than in Europe. A surge in housing starts in 1922 reduced what demand there was present for governmental intervention in housing. Not until the thirties did the U.S. government intervene in a manner analogous to the public interventions that were so frequent in Europe in the twenties.

There remained in the twenties, however, an interest in housing on the part of many individuals in the United States. Several studies were made in the twenties about the amount of space needed by an average family and minimal furnishings required. At the national level, an organization entitled, "Better Homes in America" was created in 1922. Herbert Hoover, Secretary of Commerce, was its first President and Vice President Calvin Coolidge was Chairman of the advisory council. The 
able James Ford was its executive director. Franklin D. Roosevelt was on the advisory board. The goal of this organization is of central interest vis-a-vis the development of later U.S. housing policies and our current housing standards. The history of this organization and its influences are discussed in detail elsewhere (3).

Of central interest herein is that a goal of Better Homes in America was to encourage the construction of single family homes. This was done by a variety of means. Importantly, the organization primarily addressed the needs of middle-class Americans living in small communities, instead of being concerned with poor people in urban settings (the focus of many pre-war efforts). This conservative stance paid little attention to the housing of low-income groups. Many of the individuals involved with this group became active in forming policies and standards during the more active years of the thirties.

The U.S. Bureau of Standards produced a series of uniform codes dealing with building standards and zoning. Much of this work became the basis for legislation later enacted at State and local levels. The mood of these efforts was undoubtedly influenced by the Better Homes movement.

With the coming of the Great Depression, the government found itself with two great problems: (1) the need to generate jobs and (2) the almost complete collapse of mortgage credit and the system of home finance then in use. Mortgage foreclosures, for example, leaped from 68,000 in 1926 to 250,000 in 1932 .

In 1931, President Herbert Hoover convened the White House Conference on Homebuilding and Homeownership. Although opinion as to what to do was divided in the conference, several steps were soon taken. The Home Loan Bank system was created in 1932 and authorized to extend loans to its member institutions through Federal Home Loan Banks.

The Subsistence Homestead Program was developed in the early days of the Roosevelt Administration. The Home Owners Loan Corporation was set up in 1933 to further support the mortgage market.

The National Recovery Act of 1933 provided for a public housing program. The Public Works Administration began to grant low interest loans to non-profit and limited dividend corporations for the construction of inexpensive apartments in 1933, but the program generated little interest.

The Federal Housing Administration (FHA) was created by the National Housing Act of 1934 to provide a system of mortgage insurance. The major impetus was primarily that of creating jobs, but the FHA eventually caused major changes in the methods used in financing housing. The FHA was admired by many in this country and in Europe as a model of appropriate public intervention in housing. Others in this country wished for stronger action. 
The National Housing Act of 1937 created the Public Housing Program. A salient feature of this Program is that a subsidy program for lower rents was established--a practice already commonly experimented with in several European countries. The Program held that the development, ownership and management of projects were the domain of local governmental authorities. The Program was intended for low income families (families of fully employed blue-collar and semi-skilled workers were intended to be eligible). The total impact of the Program, however, was relatively small.

With the U.S. entry into World War II, many of the housing activities of the Federal government were coalesced into the National Housing Agency. The war years also saw the development in 1944 of the Influential Veteran's Mortgage Guarantee Program administered by the Veterans Administration (VA).

While many of the programs started in this era were related directly to housing, other agendas were also being served. One was that housing was being used as a level to get the overall economy (in a state of slump) moving again. Thus aid was primarily directed towards benefiting the housing sector as a whole, thereby improving the whole economy, rather than directly at the poor and/or under-housed.

As part of the renewed interest in housing assisted by public sector support, some housing standards were formulated. The Public Works Administration issued in 1935 a document containing spatial standards, construction specifications, and even prototypical plans for housing projects. The document engendered much public debate in the literature of the day concerning approaches to housing standards (4).

Also relevant were the works of specific individuals such as Walter Gropius, who propounded theories dealing with the heights and spacings of buildings with the objective of insuring environmental goals such as sunlight into apartments and so forth. These were later to influence directly the zoning laws of New York City.

The Housing Act of 1937 initiated new investigations of housing standards at the governmental level. As discussed in detail elsewhere, guidelines for this program were the outgrowth of research undertaken by the Committee on the Hygiene of Housing of the American Public Health Association (5). Many members of this committee had been a part of the Better Homes organization. Criteria for housing developed by the Committee were founded in principles of physical or mental health. This committee later joined with the Committee on Physical Standards of the National Association of Housing officials. The result was recommended minimal square footage for each room of a "home." These figures were accepted by the U.S. Housing Authority in its standards (6).

Efforts by the American Public Health Association in relation to housing standards continued in the late thirties and into the forties. A book was published by the Association entitled, Housing for Hea 1th (7). 
A 1942 report of a subcommittee chaired by James Ford, who headed the original Better Homes organization, introduced the concept of "usability" into standards, arguing that stipulation of square footage measures alone was inadequate. Systematic studies, largely sponsored by the John B. Pierce foundation, were later conducted on how Americans use their homes.

Interestingly, it has been observed by Handlin that these studies did not produce results that were substantially different from those prepared by Lawrence Veiller in connection with the original United States Housing Corporation in 1918 (8).

\section{POST-WAR EVENTS}

After the Second World War, housing was again in severe shortage in Europe. There was, of course, unprecedented destruction of housing in Europe during the war. In most countries, governments had to assume the primary responsibility of restoring depleted housing stocks. In Great Britain, for example, $85 \%$ of the new housing units completed between 1945 and 1951 were sponsored by local authorities. Some $56 \%$ of the housing built in West Germany in the fifties was what was termed "social housing." Other countries had similar experiences. With time the extent of governmental aid to housing in Europe has reduced. No longer do housing policies resemble those in the pre-war years. Programs were reformed to encourage private enterprise to a greater extent.

In the United States the demand for housing 1itera11y exploded after the war as eight million men and women were demobilized between September 1945 and June 1946. A Federal Housing Expeditor was appointed. Wartime housing legislation was reintroduced in the Veterans Emergency Housing Act of 1946. Constant housing activity brought pressure on interest rates and Congress struggled to maintain low rates through various supports, such as the Federal National Mortgage Association which was created in 1948. Interestingly, it has been observed that the Public Housing Program begun earlier was viewed at the time by many as a kind of creeping "socialism" (9).

The Housing Act of 1949 was a milestone. Its emphasis on "a decent home and suitable living environment" and that "private enterprise should be encouraged to serve more of the total need" still 1argely characterizes our current policies. Importantly, the act also took a stand on one of the more controversial issues of the day--was Public Housing to be the only Federal vehicle for slum clearance--by establishing a separate slum clearance and urban development program.

Although the 1949 Act appropriated large sums for public housing, the program was curtailed in the $1950^{\prime} \mathrm{s}$. With time public housing lost many of its working residents and more and more came to house large concentrations of the very poor. 
The Housing Act of 1954 made few major policy changes. "Workable program" requirements for community improvements were developed. In public housing, high density, minimum amenity designs, fostered by the Act led to some highly undesirable projects.

Throughout the fifties, a huge number of middle class families received support through the FHA program. Single family detached units were built by the droves.

The Housing Act of 1959 marked a major breakthrough for advocates of Federal subsidies in privately owned buildings. Section 202 of the act authorized direct Federal loans to non-profit private sponsors of rental projects for the elderly and handicapped. The well known 221(d)(3) program established by the Housing Act of 1961, expanded opportunities for private developers.

The move towards subsidies in privately owned buildings contained in the Housing Act of 1965 included the development of the controversial Rent Supplement Program. The cabinet level Department of Housing and Urban Development was created the same year.

The Housing Act of 1968 continued the emphasis on the use of housing subsidies in private housing through the Section 235 and 236 programs. It also made FHA mortgage insurance available for the first time in declining urban areas--thus marking a major policy shift--and for families with poor but defensible credit ratings. It also authorized large appropriations for new ownership and rental programs.

This era also saw the initiation of the Operation BREAKTHROUGH experiment in 1969. Originally conceived as a Federally sponsored program to foster the development of housing technologies, the program changed character with time and social objectives (10).

The we11-known housing moratorium imposed in 1972 during the Nixon administration sent a shock reeling through the housing market. By and large, however, the moratorium affected only the volume of housing produced and not policies as to what type of housing was encouraged.

The seventies did see a disenchantment with the subsidy policies of the late sixties. There was also a marked decrease in emphasis on urban housing and a shift towards suburban housing. The thrust of most programs was on enabling home ownership. The housing acts of the late seventies saw little innovative change in policy.

As has already been observed by Maisel and others, it is interesting to note that most national housing policies have built up with time as a series of ad hoc solutions to particular pressing needs or problems (11). As Burns and Grebler have noted, one looks in vain for a grand design in the history of the housing policies of any country(12). Yet, it is eviden that policies have been slowly but surely shaped by underlying socioeconomic attitudes and objectives, as well as by direct images of improved living environments. 
Insofar as specific housing standards are concerned, the measures used in later significant Federally sponsored programs that provided much of the housing in this country, e.g., the FHA programs, have not dramatically altered in intent and contents from their immediate predecessors.

The formalization of the FHA Minimum Property Standards with their extensive room requirements was a major point in the evolution in Federally sponsored standards related to housing. These standards were later refined and altered in many ways, but their basic structure was not radically changed for many years. The possibility of combining certain rooms that began to be allowed in the sixties was a small but important move towards flexibility.

Among the more important studies done anywhere in post-war years was the Parker Morris Report of 1961 in Great Britain, entitled, "Houses for Today and Tommorrow" (13). This report of a subcommittee of the Central Housing Advisory Committee stressed even further existing functionalist's approaches to standards. It states, for example that ". . the right approach to the design of a room is first to define what activities are likely to take place in it, then to assess the furniture and equipment necessary for these activities, and then to design around these needs - . " The thrust of these studies were reminiscent of earlier efforts, particularly in their orientation towards activities as the primary generator for standards.

The late sixties and early seventies saw a wealth of quasi-scientific studies on the use of buildings. The "performance concept" was very much in vogue at the time and explored in several studies, often relating to the technical development of components for building systems. Other studies were more broadly defined in scope and attempted to generate standards by detailed studies of "affectable characteristics," e.g., (physiological, psychological and sociological) in relation to a chain of performance requirements of increasing specificity that dealt with user needs and activities.

Specific programs, such as Operation BREAKTHROUGH, also fostered the development of specific standards, albeit most were more directed towards improvements in technical domains normally covered by building codes rather than use or spatial standards.

By and large, however, these later studies did not lead to dramatic changes in nationally applicable standards having broad impacts. The development of HUD Standards in the early seventies, by contrast, were significant. The provisions that dealt with room furnishing requirements as an alternative to dimensional requirements seemed at the time quite a significant change, again reflecting a strongly functionalistic viewpoint and very reminiscent of the Parker Morris study and recommendations. Perhaps because of the rather curious choices of the specific furnishings used as reference measures, however, the change has not proven as altogether productive as anticipated at the time. 
In sum total, housing standards dealing with general housing quality and liveability have not radically changed from those conceived years ago. The functionalistic viewpoint as reflected by minimum requirements for internal spaces and activities remains undiminished as are basic concepts of usability. The focus is thus still on defining units from the inward out and thus having the total unit or building result as a consequence of aggregating discrete requirements.

\section{MAJOR TRENDS IN U,S, HOUSING POLICIES: INFLUENCES ON STANDARDS}

It is clear from the preceeding discussion that the development of housing standards closely parallels the development of national housing policies which are in turn a manifestation of larger socio-economic goals. The remainder of this paper speculates on the consequences vis-a-vis housing standards of these larger relationships. The thrust of the argument is that housing standards tend to be both broadly applicable and reflective of specific biases about lifestyles and housing norms to a counter-productive extent.

An important characteristic of our national policies is that governmental intervention in housing has typically served multiple agenda. The policies begun in the thirties of using aid to housing as a way of affecting or balancing the overall economy are still very much in existence. Policies largely view housing in terms of its importance to the national economy (which undoubtedly is true) and its multiplier effects when intervention is made. Hence programs typically aid the housing sector as a whole rather than specific groups (some programs are, of course, more directed but their extent and impact has historically been minor). This general attitude is in marked contrast to many other countries, e.g., Great Britain, where policies have historically been more concerned with interventions directly at the source of the perceived housing problem. A consequence of the orientation assumed in the U.S. has been to reinforce subtly the notion and development of standards that are generally applicable to the whole housing sector rather than encourage the development of more specialized measures for groups at the actual perceived problem level, e.g., low-income minority groups.

A salient feature of our current policies is the continued emphasis on private enterprise as the primary mechanism for providing housing. This immediately casts the role of standards and methods for assuring they are met in a very different light than in situations where action directly by governmental authorities is the main vehicle for the provision of housing. Financial incentives of one type or another are consequently typically involved as well as withholding of funds if standards are not met. Again this tends to reinforce the development and use of broad universally applicable standards rather than ones responsive to specific needs.

Another factor that undoubtedly led to the emphasis in this country on universally applicable standards was the historical public health rationale for government intervention in housing. As has already been 
noted, public health issues were originally one of the dominant influences underlying minimum requirements for ventilation, sunlight, and sanitation, and later, minimum areas for functional spaces. The important contributions by the American Public Health Association in the thirties and early forties literally set the tone and content of housing standards for many years to come. Public health directives were obviously the primary focus of efforts rather than other possible criteria or objectives for standards, e.g., climatical, cultural (1ifestyles), or related to concepts of density or site planning. With time, needs springing from those other concerns have led to modifications of the developed standards, but their essential thrust and character remained largely the same.

The public health orientation also tended to foster universally applicable standards since they dealt largely with issues e.g., egonometric, not perceived to be dependent on the precise characteristics of different user groups but rather on common human needs.

Perhaps the most interesting of all influences in the development of our current standards are those of the Better Homes movement in the twenties and the earlier city beautiful movement. In particular, the goals and biases of the Better Homes in America movement directly influenced crucial standard development activities in the thirties. As noted earlier, many of the leaders of the Better Homes movement were involved with the development of housing policies in the thirties.

Of particular interest is the orientation of Better Homes towards single family housing and its concommitent focus on middle class values and 1ifestyles. As such, the objectives of this housing movement constituted a particular social planning objective, as did the more liberal movements in the $1910^{\prime} \mathrm{s}$ in other ways.

Many of the values and aspirations of the Better Homes movement evidently became part of the policies developed in the thirties and the standards originated then by a confluence with the public health movement, through the people involved if by no other mechanism. Specific family structures and ways of life, for example, were reflected and encouraged by the standards developed by their implication that dwelling units are, and must be, composed of individual defined-use rooms.

The Better Homes movement reflected an aspiration towards a certain way of 1 ife that was regarded as universally appropriate, hence associated standards were perceived to be universally appropriate as well. These biases were certainly reflected in post-war standards developed from those in the thirties. Since there is invariably an economic incentive to building housing conforming exactly to the minimum standards in force, the physical form of much of our current housing in a direct reflection of these biases and implied social planning agenda.

As a sidelight, it is interesting to observe that the Better Homes movement had an effect on other Federal agencies and organizations 
concerned with housing than just those already mentioned. It has been effectively argued by Handlin, for example, that the Division of Building and Housing, created as part of the National Bureau of Standards in 1921, implicitly took a similar conservative stance to the Better Homes organization by only assuming the role of gathering data for the construction industry and recommending construction codes primarily in relation to single family houses (14). This was at a crucial time in the fledgling development (that was tentatively begun in the 1910-1920 period) of building systems designed to meet the needs of urban housing. Many of these systems were technically unique and, vis-a-vis the type of housing provided, socially innovative (15). It is well known that the technical development of this type of housing stagnated in the inter-war period (16) It has been argued that the crucial role of leadership that could have been provided by the Division of Building with respect to this type of housing was not assumed.

It is also interesting to observe that standards only slowly respond to changes in policy directions. The liberalizing influences in the sixties, for example, did not immediately lead to significant commensurate changes in the intent and focus of applicable standards.

Another important point is that standards control, to a greater or lesser extent, the entry of individuals into the housing market. This is the same issue originally faced by housing reformers in Europe in the twenties. As standards increased, so did construction costs which in turn raised purchase and rental costs beyond the reach of many that desperately needed the housing, thereby complicating the issue enormous1y. Current standards implicitly take a strong position on this balance between standards and costs and thereby control who has access to housing. It can certainly be argued that there are those who would prefer not to have housing built according to standards responsive to middle class biases about what constitutes acceptable housing, but rather have more flexible standards more responsive to their own perceived needs and with greater accessibility.

\section{CONCLUSIONS}

The overall consequence of the influences discussed above is that housing standards in recent years have promoted the notion of an "American House" with its middle class biases, and, perhaps, mitigated against the development of other housing forms.

Housing built according to common standards generally tends to have the same spatial and functional characteristics no matter what climatic conditions are present or what specific housing needs are addressed. The form of housing provided in the deep south is not unlike that provided in the north despite obvious differences in local ways of life and customs (including specific differences such as the role of outdoor living). Obviously this is in marked contrast to the sharp regional differences that developed in housing not controlled by such standards. 
It is argued here that standards could advantageously be made more responsive to the needs and desires of a broader spectrum of people. Our current standards do not promote an adequate range of responses to differences in lifestyle, derived from personal preferences or as influenced by cultural values, or lifestyles as influenced by climatic conditions. Another paper argues this point in detail and recommends several fundamental changes in our standards (17). Housing need not be the same, only equal.

It should always be remembered that housing standards reflect one way in which implicit national social planning objectives are translated into action. An understanding and articulation of these objectives and principles can help to focus incremental improvements in housing standards by minimizing the risk of counter-productive changes. By the same token, conscious changes in national priorities and social planning objectives can be shown to imply corresponding changes in the make-up and technical content of housing standards. While the opportunities for constructive action are great, so are the possibilities that standards can promote counter-productive ends.

\section{REFERENCES}

1. Colling, H., and Colling, R., Modern Building Inspection, Building Standards Monthly Publishing Company, 2nd. Edition, Los Angeles, California, pp. 13-110.

2. See, for example, Lubove, R., The Progressives and the Slums, University of Pittsburgh Press, Pittsburgh, 1962; and Bowley, M., Housing and the State 1919-1944, Allen and Unwin, London, 1945.

3. Handlin, David P., "Housing and City Planning in the United States, 1910-1945," The Martin Centre for Architectura1 and Urban Studies, Cambridge, Great Britain, 1976.

4. Ibid., p. 318 .

5. Ibid., p. 328 .

6. Ibid., pp. 328-329.

7. Committee on the Hygiene of Housing of American Public Health Association, Housing for Health, Lancaster, Pennsylvania, 1949.

8. Handlin, op.cit., p. 330.

9. Pawley, Martin, Architecture Versus Housing, Praeger Publishers, New York, 1971.

10. See a discussion on this point in Schodek, D. L., "Operation BREAKTHROUGH: The Changing Image," Industrialization Forum, Vol. 4, No. 5, 1973, pp. 11-18. 
11. Nevitt (Ed.), The Economic Problems of Housing, pp. xi-xii.

12. Burns, L. S., and Grebler, L., The Housing of Nations, Halstead Press, John Wiley and Sons, New York, 1977, p. 94.

13. Central Housing Advisory Committee, "Homes for Today and Tomorrow," HMSO, London, 1961.

14. Handlin, op.cit., pp. 324-325.

15. See, for example, the discussion in Schodek, D. L., "Precast Concrete Housing," Journal of the Precast Concrete Institute, Vo1. 23, No. 6, Nov.-Dec., 1978, 00. 54-66.

16. Ibid., p. 64 .

17. Gauchat, Urs P., "Housing Standards: Their Derivation and Rationale 4th Annual NBS/NCSBCS Joint Conference on Research and Innovation in the Building Regulatory Process, St. Louis, Missouri, September 1979. 
HOUSING STANDARDS: THEIR DERIVATION AND RATIONALE

by

Urs P. Gauchat

Associate Professor or Architecture

Harvard University

Cambridge, Massachusetts

The quality of housing is mandated by minimum standards. The standards are based on egalitarian principles and on the assumption that housing anywhere in the United States would meet certain norms. Space standards, in particular, imply social planning objectives which apply throughout the country regardless of location, climate, or user group. These standards, perhaps unwittingly, promote the notion of an "American House."

Although fair in the sense of providing equality, the present system does not allow an adequate range of responses to different lifestyles and cultural backgrounds. It is the purpose of this paper to propose housing solutions that more adequately reflect regional characteristics and personal predilections. The proposals are based on the premise that housing standards should be based on the notion of equivalency rather than equality.

This paper first examines the key determinants of quality in housing; then analyzes the effects of current property standards; and finally, suggests modifications that would render housing standards more responsive and flexible.

Key Words: Equivalency; housing standards; minimum standards; space standards. 


\section{Background}

During the 19th century rapid urbanization, together with an influx of immigrants, created an unprecedented need for housing in the United States. Cities expanded rapidly and new subdivisions sprang up block by block. Construction of speculative buildings and rental property emphasized quantity rather than quality: much of the housing was substandard, overcrowded, unsanitary and devoid of natural light and ventilation. Until the old tenement law was enacted in 1867, housing construction proceeded unchecked. By stipulating minimum standards of construction and design, the law did much to curb the spreading fires and disease and represented the first deliberate public effort to maintain a modicum of housing quality regardless of occupants' income. A new tenement law, passed in 1901 , further raised the minimum standards for speculative and rental property.

The development of housing standards in this country was heavily indebted to the public health movement. Concern for disease and fire prevention became the major determinant of minimum requirements. The quality of housing and the quality of life it contains were thus primarily determined by a series of preventive measures designed to reduce the probability of unwanted events, such as the collapse of a building. Periodically these standards were revised based on empirical knowledge derived from specific events. The present standards are thus an accumulation of incremental changes rather than an extrapolation of a coherent set of principles.

It is interesting to look at the political climate which surrounds the governmental involvement in the control and sponsorship of housing. The control by government of the construction of housing increased gradually from the latter half of the 19 th century to the present level. In the beginning government sponsorship was only minimal. Although the Federal government declared "it was getting out of the business of housing" in 1919, the spectacular rise in foreclosures during the Depression demanded its intercession. In this context, the idea of a Federally guaranteed private loan program was conceived. Originally intended as a temporary measure, various forms of subsidized or minimum housing have since become a permanent segment of the housing economy. Because the program was conceived as a temporary measure during the Depression, people who became permanent residents were, and still are, viewed with suspicion. Housing standards, therefore, define minimal rather than optimal living conditions. Since housing built to minimum standards rarely becomes a valuable addition to the total inventory, it perpetuates the notion of a temporary abode from which to aspire to bigger and better things. 
The quest for acceptable minimum requirements has been pursued assiduously since the beginning of space standards. Based on economic motivations, the minimum standards were gradually refined to achieve the least initial cost. The implied policy seems to be to house the most people possible for a given amount of money, rather than provide optimum living conditions for a limited number of people.

As a contrast in philosophy, the English government has taken the stance that space standards ought to ensure a supply of new housing which is comparable to that provided by the private market regardless of the amount of subsidy or government sponsorship. As a result of this attitude the government has been forced to construct a much larger portion of the total housing stock than has been the case in this country.

The United States Housing and Urban Development Act of 1968 (as amended in 1977) declares that: "The Congress affirms the national goal, as set forth in Section 2 of the Housing Act of 1949, of a decent home and a suitable living environment for every American Family." The terms "decent" and "suitable" are as pliable as the lawyer's use of the word "reasonable." They are relative terms which reflect a level of aspiration rather than a well-defined standard. Housing that some consider decent and suitable, others will scorn as inadequate. Minimum standards, therefore, have not only relative values associated with a certain economic level, cultural background and region of the country, but they also have to be fair and equal, regardless of where and under what circumstances they apply.

\section{The Status Quo}

Like all other construction activities, housing is subject to a plethora of rules and regulations to ensure that the housing is technically sound and conducive to the health and safety of the occuparits. Minimum property standards generally consist of regulations that control the manner and method of building and space standards that stipulate minimum areas for human habitation. One of the major implications of space standards is the notion that in case of insufficient private incentives, the government provide the necessary means to construct minimum standard housing. Apart from protecting the public from unscrupulous speculators and landlords, space standards give physical dimensions to a national standard of living.

Particularly for middle and low-income families, minimum space standards have become the measure of quality to which market and non-market housing is built. The closer the margins for profit are, the lower the rental and sales price, the more the housing tends to be built to the absolute minimum allowed by law. As with any set of regulations, prescriptive space standards can be interpreted so that they are economically advantageous. These interpretations, by their sheer reputation, become the norm. The norm, in this case, is not defined in terms of explicit social objectives, but as an indirect result of the minimum space standards. 
Space standards depend on the jurisdiction and the form of financing. Each state, or in some cases each county, has its own standards. Federally funded projects have to follow guidelines set by the Department of Housing and Urban Development (HUD). Genera11y, all prevalent standards are based on the same premises and therefore only vary slightly, if at all.

Space standards typically stipulate minimum areas and dimensions for specific human activities; they also mandate access to common services such as water, sewer, gas and electricity. The inside of a dwelling is defined in terms of its major components, the size and dimension of which are related to the number of bedrooms. The living area, for example, increases in size in a three-bedroom unit as compared to a one-bedroom apartment. The assumption is that depending on the number of bedrooms a unit must conform to the same space standards regardless of how and by whom they are used. The edicts of fairness and egalitari policies are thus adhered to.

There are two methods of controlling minimum space standards: one is based on a definition of minimum areas and dimensions for living, dining, and bedrooms as well as kitchens and bathroom; the other stipulates minimum furnishings typical for each room and allows for adequate use and circulation space.* Both methods result in unit plans which are comparable in size and level of amenity. They are derived from the probable occupancy of a certain unit type: the requirements for an efficiency apartment are thus based on the expectation that it would contain a single occupant; the standards for a two-bedroom apartment are based on the probability that occupants would be a couple with a child, etc. Space standards, therefore, can result from extrapolating space requirements based on a number of bedrooms and presumably a corresponding number of occupants. Although this policy covers the majority of housing in the U.S., it does not achieve the stated objective of providing adequate housing in all cases.

\section{Standards Based on Parameters}

The present minimum property standards not only set some criteria for the quality of housing, but they also indirectly favor particular housing types. These housing types are found in great proliferations across the nation. Unit plans and aggregation types tend to be similar regardless of where and in what context the housing is built. If it is the intention to produce the largest number of similar housing units, then the present standards have fully succeeded. If the construction of housing is to proceed based on the egalitarian notion that they have to be literally the same, then this goal should be made explicit in terms of social goals and objectives. No such policy has been stated as part of a Housing Act, or in a preamble to the FHA or HUD standards. The absence of a policy statement gives rise to the suspicion that the proliferation of the same type of housing happens not by design but by default.

*See HUD Minimum Property Standards 4900, 4910, 4920 and 4930. 
The principle of space standards for housing is not in question; standards are absolutely necessary to protect the population (particularly those that have economic limits put on their choice of housing) from exploitation by speculators and landlords. The issue, therefore, is the particular form that the standards take. On the surface it seems that the new HUD standards, which offer a choice between minimum areas and dimensions for each activity and minimum furnishing requirements, allow sufficient scope for interpretation. It turns out, however, that both sets of HUD standards are based on the notion of a national norm. Although never explicitly stated, the norm defines an average user whose daily functions can be allocated to a number of specific rooms. The standards are substantially more prescriptive and specific than a cursory examination would indicate.

The systematic erosion of national origins and cultural differences stems from the idea of America as a melting pot; this idea is contradicted by the pride with which descendants of immigrants still refer to the "old country." Immigrants tended to settle in areas which then took on some of their ethnic and national characteristics. Many of these areas are still intact and often provide character and identity to an otherwise undistinguished urban fabric.

Some of the original ethnic neighborhoods are still intact and are considered as positive attributes to the life of a city. Much of the housing built in the nineteenth century reflects climatic and regional differences. The same housing type, such as a row house, can be found in a start].ing array of incarnations. Row houses in Boston and Philadelphia, for instance, are markedly different from those in New Orleans or Savannah. The differences manifest regional characteristics, establish local customs and provide a sense of place.

The question here is how to maintain and encourage regional variations without subverting the basic intentions of minimum space standards. To this end it is suggested that the existing standards be modified in format but not in intention, i.e., that the existing minimum requirements be replaced by a series of parameters to encourage local solutions which respond more closely to particular regional and cultural contexts. Using these parameters fully maintains the principle of equality while reducing the probability of all American families having the same housing.

There are a number of specific parameters which could take the place of the existing minimum space standards. The parameters not only give more scope and freedom to the design of housing, but they explicitly state the underlying objectives and principles.

1. Density is now controlled as a function of the number of bedrooms in a unit. All parts of a dwelling unit are scaled to the number of bedrooms and presumably the number of occupants. A direct correlation between the bedroom count and the number of occupants, however, is not a reliable presumption. An absolute minimum size 
for any dwelling unit, whether owner-occupied, leased or rented, is therefore proposed. The minimum unit would, however, be adequate for single occupancy; each additional occupant could require a proportional increase in the minimum space requirements. Space standards would thus reflect the maximum number of occupants for a given unit size or, conversely, the unit size would determine the maximum legal occupancy.

2. Space standards are expressed in terms of specific rooms for a normal range of human activities. Present requirements are based on the premise that certain human activities require the exclusive use of a space and others do not. It is assumed that bedrooms, for example, need to be separate from living areas (except in efficiency units) and that they be sized to accommodate the necessary furniture. The stipulation of specific rooms used exclusively for one function, therefore, precludes the use of a room for more than one purpose. A bedroom designed in accordance with minimum standards, for instance, cannot properly double up as a study or a workroom. It is thus suggested that beyond controlling the size and number of bathrooms (depending on the number of occupants) and a minimum amount of kitchen equipment, the division or non-division of the rest of the unit's space cannot be controlled. The tradeoffs of which rooms to increase or decrease would be left to the local market conditions and personal preferences. This does not mean, however, that the amount of space per person should be reduced; on the contrary, in order to increase the number of planning options a degree of redundancy has to be introduced.

This approach to space standards is also appropriate for the increasing number of buildings which are rehabilitated rather than replaced. The unit plan, with the planning constraints imposed by the location of the bathroom and kitchen, can be adapted to the preferences and living habits of each long term occupant. Apart from being less restrictive, this approach would encourage housing solutions which may be unorthodox but are better suited to local conditions. Extended, harsh winter months in the northeast call for ideal arrangements of space which differ from those for a southern climate which rarely gets uncomfortably cold. A number of types would evolve which best organize the disposition of spaces in keeping with preferences and contextural factors. Rather than standard minimum units, a number of locally acceptable interpretations would, over time, predominate in particular regions.

3. The specific area requirements could be supplemented by a series of non-binding design guidelines for particular user groups. Present requirements are based exclusively on living arrangements which fall within the expected life cycle from being single to raising a family to being elderly. Apart from the handicapped, no special provisions are made for user groups such as roommates, extended families and single parents. A closer fit between user requirements and the design of units can maintain the quality of housing without implying normative standards of behavior. 
4. The climatic and seasonal characteristics of an area should play an integral part in the development of housing. Housing in hot arid climates, for example, is likely to be used differently than housing in temperate zones. The present energy codes deal solely with the technical aspects of controlling natural temperature fluctuations in an efficient way; they do not, however, address the regional differences in life style and activities. The most energy-efficient housing will result from technical improvements such as insulation and heat pumps, combined with appropriate planning and design responses. It is therefore suggested that the minimum space requirements have sufficient flexibility to permit, for example, covered but unenclosed living spaces such as porches.

5. It is further suggested that the division between public and private could be more open to interpretation. Space standards would not be reduced, but the same area per person could be distributed differently. Thus, two or more units could contribute a proportion of the square footage to joint facilities such as libraries and workshops. These additional facilities would markedly increase the livability of minimum units yet not increase their size substantially. A formula could be devised to encourage experiments in this direction by allowing a reduction in the size of each unit (up to a reasonable limit) based on a proportion of the areas used for shared activities. Only those facilities would be counted which are designated for the exclusive use by two or more units. The particular function of a shared space, however, would not be subject to controls.

6. Compensatory factors should be built into the minimum standards for cases where the physical context affects the quality of the housing. Environmental conditions may not allow reasonable living conditions without some help in establishing neighborhood amenities such as recreation, schools and other community facilities. The establishment of compensatory factors recognizes that living conditions are not defined simply by the design and amenities within a unit, but also by the physical characteristics of the site and the availability of the essential amenities.

\section{Conclusion}

The present government-imposed criteria for housing, including the space standards, are working well in the sense of providing equal housing across the nation; they do not, however, allow sufficient scope for local customs, climatic conditions, and existing urban patterns. Current standards should, therefore, be modified in format rather than in intent.

The basic thesis of this paper is that instead of attempting to make a11 housing equal, standards should make housing equivalent. Rather than employ prescriptive standards based on specific rooms for each human activity, it might be possible to achieve the same ends without exerting as much control over the means. 
The mechanism described here consists of several design parameters which would control the size and amenities offered by various types of accommodation without prejudicing the solution. Specifically, these recommendations are:

- Space standards based on an absolute minimum area for any dwelling unit, with additional space increments for each occupant .

- Abolition of room designations for particular human activities in favor of overall area and service requirements.

- Non-binding guidelines addressing the functional requirements of specific user groups.

- Climate as a key determinant of house form.

- Limited reduction of minimum space requirements for individual units that share facilities.

- Compensatory factors for adverse contextural conditions.

Local and regional differences do not have to be at odds with egalitarianism. In fact, responsive regulation could be a major factor in assuring the survival of local and regional characteristics which are under threat of erosion. The result of uniformity and conformity, although in keeping with the letter of the law, would be incompatible with the self-determination of each community. Differences in terms of culture, ethnic make-up and climate can become a positive attribute of local distinctions in form and character; it can maintain the identity of a community, and help to strengthen an often fragile urban fabric.

Finally, the proposals suggested here are intended to promote discussion of how best to maintain the quality of housing without promoting a particular type of housing. The specific recommendations are thus offered in the spirit of encouraging a review of the present system of regulating housing quality rather than as a definitive answer. 


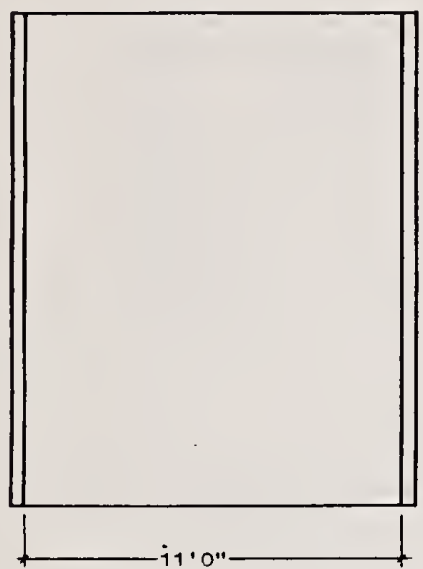

Living Room $120 \mathrm{SF}$

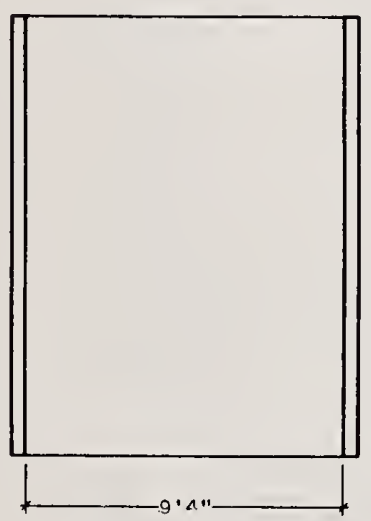

Master

Bedroom

$120 \mathrm{SF}$

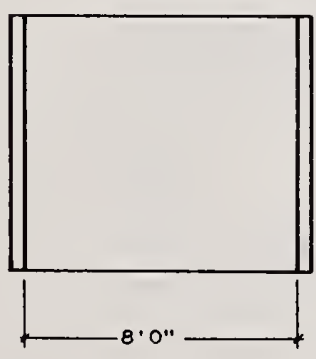

Kitchen $\quad 60$ SF

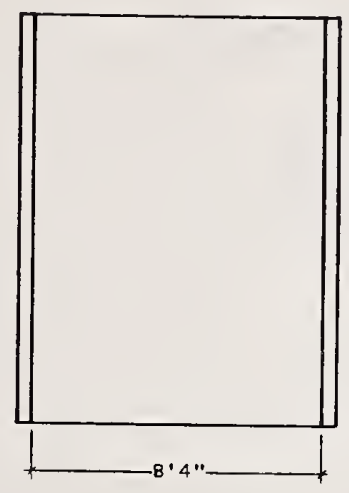

Dining Room 100 SF

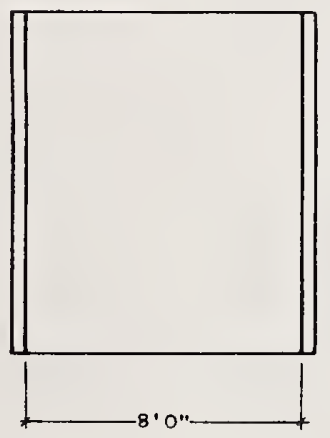

Secondary Bedroom $80 \mathrm{SF}$
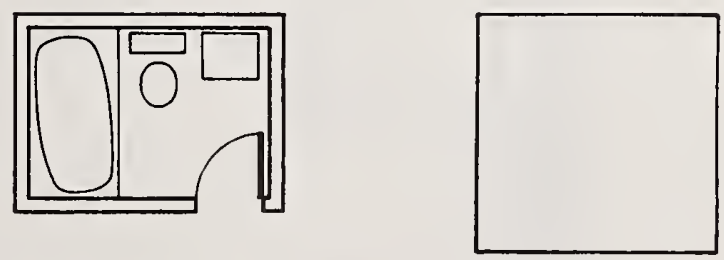

Bathroom $35 \mathrm{SF}$ 


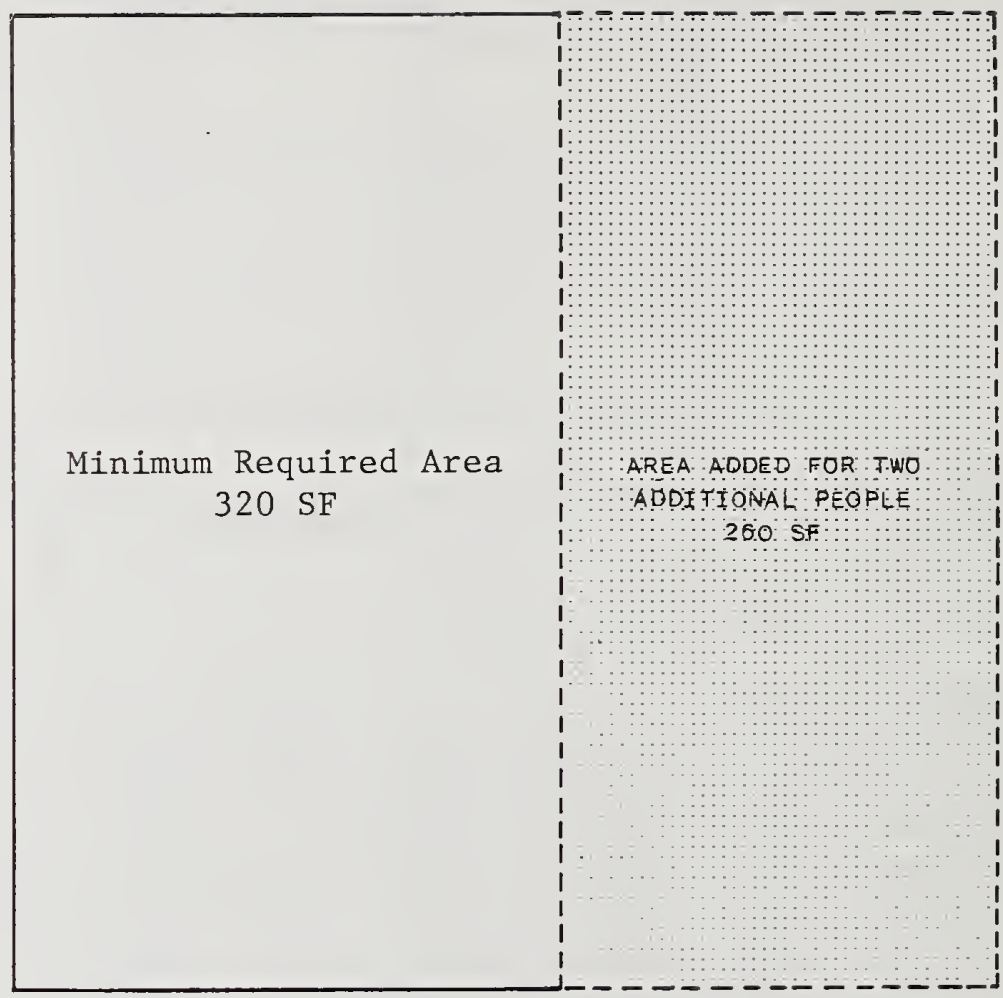

Total Area for Three Occupant Unit
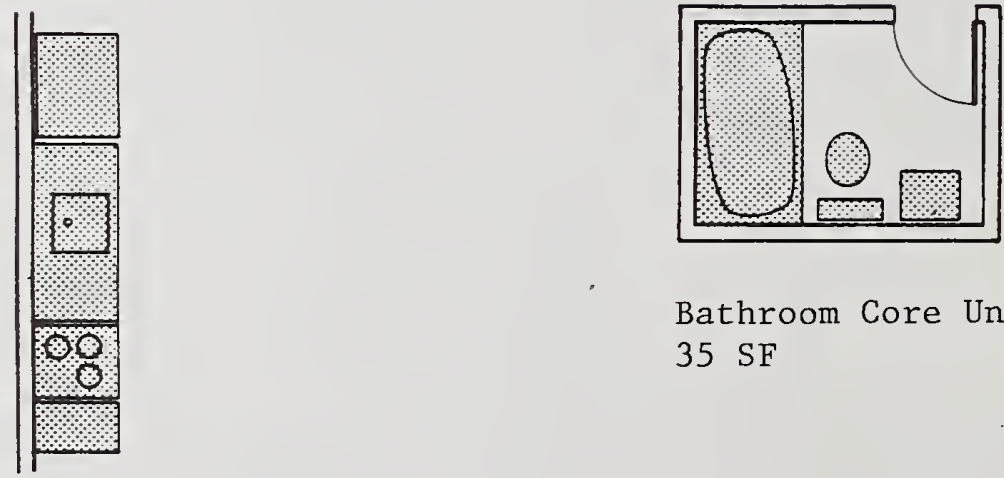

Bathroom Core Unit $35 \mathrm{SF}$

Minimum Kitchen Core Unit 


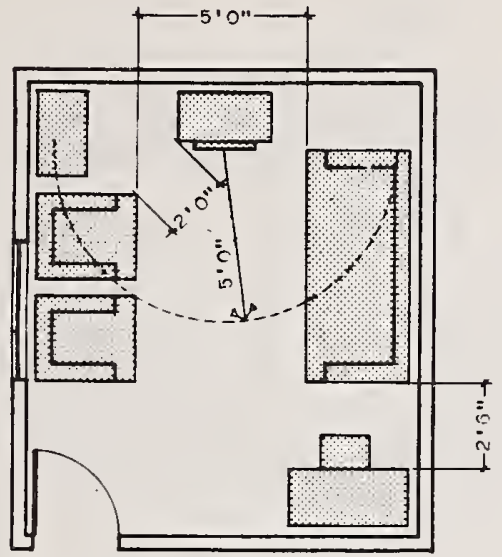

Living Room

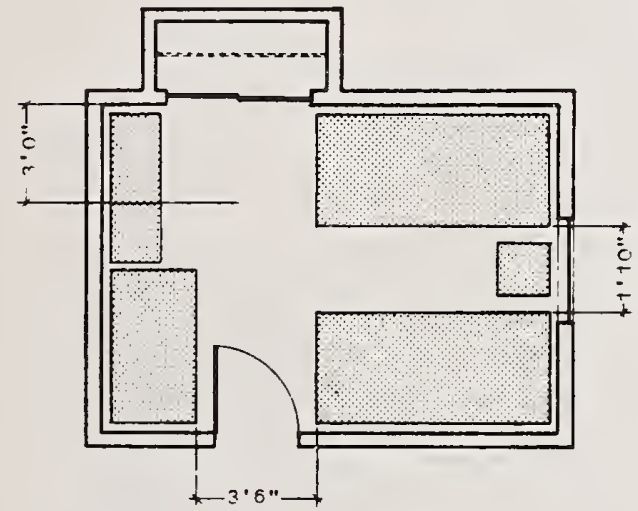

Master Bedroom

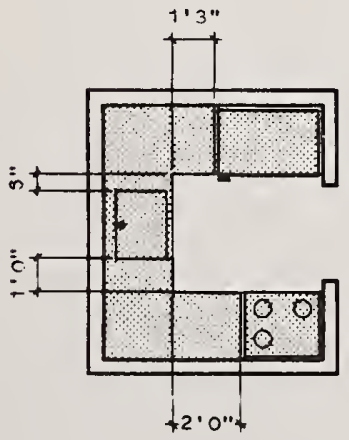

Kitchen
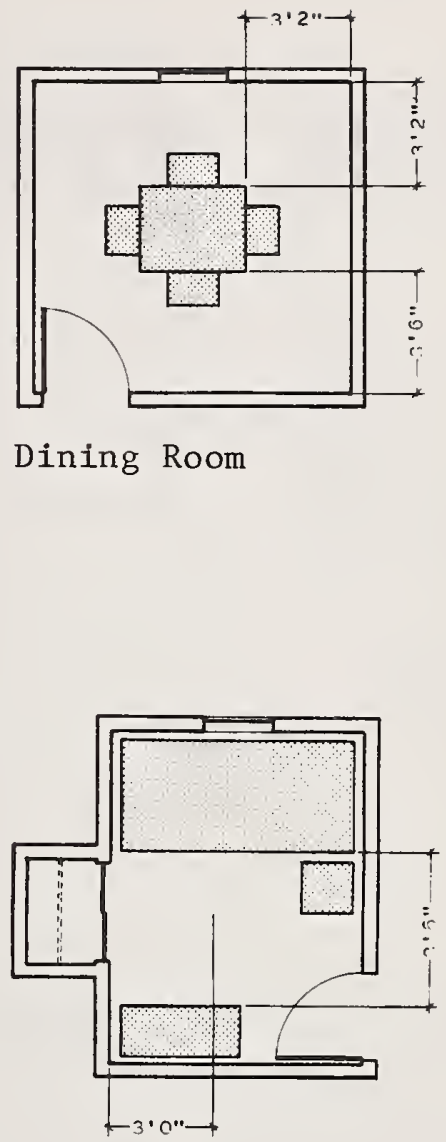

Secondary. Bedroom

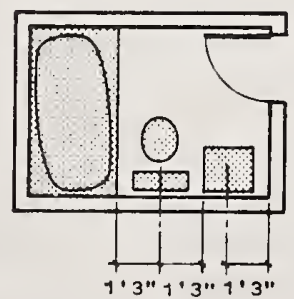

Bathroom 
TYPICAL HUD FURNITURE REQUIREMENTS

Couch

$3^{\prime} 0^{\prime \prime} \times 6^{\prime} 10^{\prime \prime}$

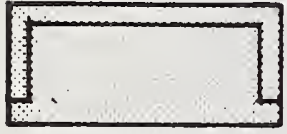

Easy Chairs

$2^{\prime} 6^{\prime \prime} \times 3^{\prime} 0^{\prime \prime}$

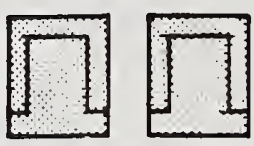

Television

Set

$1 ' 4 " \times 2 ' 6 "$

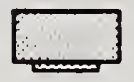

End Table

1'6" $\times 2$ '3"

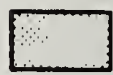

Table for Four

$2^{\prime} 6^{\prime \prime} \times 3^{\prime} 2^{\prime \prime}$

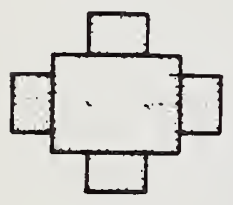

Twin Beds

$3^{\prime} 3^{\prime \prime} \times 6^{\prime} 10^{\prime \prime}$

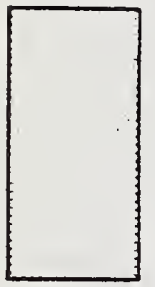

Dresser

1'6" $\times$ 4'4"

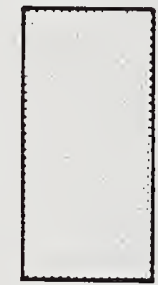

Chair

$1^{\prime} 6 " \times 1{ }^{\prime} 6 "$

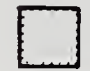

Crib

2'6" $\times 4^{\prime} 6^{\prime \prime}$

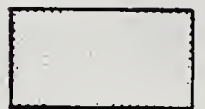

Twin Bed

Dresser
$1^{\prime} 6^{\prime \prime} \times 3^{\prime} 6^{\prime \prime}$

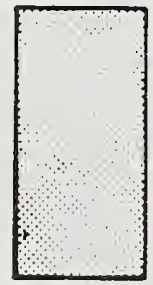

Chair

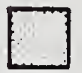


PROPOSED MINIMUM AREA REQUIREMENTS

\begin{tabular}{|c|c|c|c|c|c|c|c|c|c|}
\hline OCCUPANCY & $\begin{array}{l}\text { MINI } \\
\text { basi } \\
\text { unit } \\
\text { All }\end{array}$ & $\begin{array}{l}\text { UM NET } \\
\left|\begin{array}{ll}\text { plus } \\
1\end{array}\right| \\
\text { nits } \\
\text { | }\end{array}$ & $\begin{array}{l}T \text { SPAC } \\
\text { plus } \\
2 \\
\text { in squ }\end{array}$ & $\begin{array}{l}\text { CE. } \\
\text { plus } \\
3 \\
\text { uare }\end{array}$ & $\begin{array}{l}\mid \begin{array}{l}\text { plus } \\
4\end{array} \\
\text { feet }\end{array}$ & $\begin{array}{l}\text { TOTAL } \\
\text { NET SPACE. }\end{array}$ & $\begin{array}{l}\text { BATHROOM } \\
\text { AREA }\end{array}$ & $\begin{array}{l}\text { KITCHEN } \\
\text { AREA }\end{array}$ & $\begin{array}{l}\text { GRAND TOTAL } \\
\text { AREA PER UNIT }\end{array}$ \\
\hline 1 & 320 & & & & & 320 & 35 & 40 & 395 \\
\hline 2 & 320 & 130 & & & & 450 & 35 & 60 & 545 \\
\hline 3 & 320 & 130 & 130 & & & 580 & 35 & 60 & 675 \\
\hline 4 & 320 & 130 & 130 & 130 & & 710 & 55 & 70 & 835 \\
\hline 5 & 320 & 130 & 130 & 130 & 130 & 840 & 70 & 80 & 950 \\
\hline
\end{tabular}




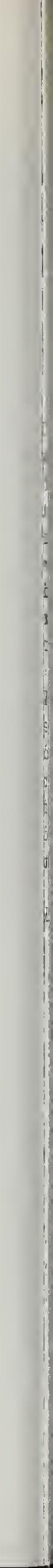




\title{
COMPARATIVE ANALYSIS OF PROVISIONS IN HOUSING CODES AND REHABILITATION GUIDES
}

by

\author{
Patrick W. Cooke \\ Building Economics and Regulatory Technology Division \\ Center for Building Technology, NEL \\ National Bureau of Standards \\ Washington, D.C.
}

The performance levels of existing buildings generally do not comply with the standards for safety or function that are required of new buildings. To have a solid base for regulatory authorities and others to use in establishing minimum requirements pertaining to life safety and health issues pertinent to the reuse of existing buildings and to assure an adequate level of acceptance in terms of the traditional intent of codes, it is essential to have a good understanding of the regulatory provisions for codes currently in place that address occupancy, maintenance and rehabilitation.

This paper highlights some of the more explicit comparisons that were available from a comprehensive analysis of the content of seven code documents that relate exclusively to the occupancy, maintenance or rehabilitation of existing residential buildings. This sampling of detailed comparisons indicates some of the inconsistencies among code documents with respect to uniformity as well as non-scientific approaches taken in the development of code provisions.

Key Words: Code provisions; comparison; existing buildings; housing codes; mode1 codes; performance levels; regulations; rehabilitation. 
This paper reports on a study undertaken to identify and compare the performance levels of selected code provisions contained in seven nodel codified documents which deal with the occupancy, maintenance and rehabilitation of existing residential buildings. While the primary regulatory intent of these documents, as a group, is to establish minimum standards essential to good health and which make existing dwellings safe, sanitary, and fit for human habitation, they individually take different approaches in attempting to achieve their defined goals and objectives. Aside from establishing minimum standards for what is claimed to be public health and safety, there is also a tendency to include provisions that establish various levels for housing amenities and arbitrary standards of liveability (i.e., comfort) for dwellings. In this regard, the performance levels of such regulatory criteria and their degree of enforcement can and do have significant economic and social impacts on our existing stock of housing, as well as on the directi and extent of upgrading when converting existing buildings of all types to residences through rehabilitation.

This comparison study was carried out with the following purposes in mind :

1. An analysis of this type will assist in identifying both implicit and explicit levels of performance currently required for existing residential buildings.

2. The summarized data, presented in a rational format for comparison, will provide a logical baseline from which selection of any revised compliance levels can be established by regulatory authorities.

3. The project could assist in the identification and definition of needed research study areas relative to the technical bases of regulations and development of priorities.

4. By consolidating similar provisions from the various code documents on a one-on-one basis, the degree of uniformity or non-uniformity among what are ostensibly model regulations promulgated for local adoption and enforcement on a national or regional basis can be demonstrated.

The study output relates to current and ongoing research programs at the National Bureau of Standards' (NBS) Center for Building Technology (CBT). Most significant of these research areas is the Building Rehabilitation Technology Program which has among its several goals the development of the technical basis of regulations [1]*. The regulatory strategy developed by the State of Massachusetts [2] for the rehabilitation of existing buildings suggests that the levels of performance may be less than that for new construction as long as minimum life-safety and health levels

* References are listed at end of paper. 
are maintained. The codes included in this comparison study have no direct effect on new construction, since existing buildings generally do not comply with the standards for safety and function that are required of new buildings. The study results, therefore, should give a good measure of what is perceived as minimum levels of acceptability regarding the performance of existing residential buildings. They will also be used in an ongoing CBT project on the development of a methodology for establishing the performance levels of existing buildings.

\section{CODE DOCUMENTS INCLUDED IN STUDY}

To obtain a realistic measure of current performance levels for existing housing, several model housing codes, as well as those available standards developed especially for rehabilitation of residential properties, were considered for detailed examination in the study. A total of seven code documents were finally selected; five model housing codes which have different spheres of influence or constituencies in various parts of the country and two guideline documents which have been developed at the national level and relate specifically to the physical rehabilitation of buildings for residential occupancy. The following is a brief description of each of the seven selected code documents.

1. APHA-CDC Recommended Housing Maintenance and Occupancy Ordinance, 1975 Revision [3] - This code was first published in 1952 by the Committee on the Hygiene of Housing of the American Public Health Association (APHA) to assist municipalities with the development of legislation necessary to regulate the quality of housing. It is considered by many to have been the first fundamental model housing code in this country. The first revision, in 1967, was drafted by APHA in collaboration with the Office of Urban Environmental Health Planning, U.S. Public Health Service. Additional revision was necessary as housing conditions changed resulting in the 1975 version, which is a cooperative effort of the APHA's Committee on Housing and Health and the Center for Disease Control (CDC) of the U.S. Department of Health, Education and Welfare.

2. New York State Model Housing Code, 1974 Edition [4] - This code is published as a guide to New York municipalities for voluntary adoption in meeting housing regulation requirements under Federal and State urban renewal and housing programs. The code is divided into four major parts covering: (1) conventional residential premises, (2) mobile homes, (3) migrant housing, and (4) administration and enforcement. The part on conventional residential buildings is designed to be consistent with the New York State Building Construction Code, which regulates new construction. 
3. Uniform Housing Code, 1979 Edition [5] - The International Conference of Building Officials (ICBO) promulgates the Uniform Housing Code for the conservation and rehabilitation of housing. It is intended to be compatible with the Uniform Building Code.

4. Standard Housing Code, 1979 Edition [6] - The Standard Housing Code is published and maintained by the Southern Building Code Congress International, Inc. (SBCCI) as a minimum code for the use, occupancy and maintenance of existing buildings.

5. The BOCA Basic Property Maintenance Code, 1978 Edition [7] - This code is published by the Building Officials and Code Administrators International, Inc. (BOCA) to establish minimum acceptable standards for the maintenance of existing buildings.

6. Code Enforcement Guidelines for Residential Rehabilitation [8] - BOCA developed a set of rehabilitation provisions and published them under the title "Code Enforcement Guidelines for Residential Rehabilitation" (First Edition, 1975). The studies that formed the basis for these guidelines were conducted under a contract with the U.S. Department of Housing and Urban Development (HUD). Although published by BOCA, the other three model code organizations cooperated in their development. The "Code Enforcement Guidelines" are also contained in the "BOCA Basic Property Maintenance Code," 1978 Edition, as a separate appendix.

7. HUD's Minimum Design Standard for Rehabilitation for Residential Properties [9] - Guidelines setting forth basic objectives and provisions specifically related to building rehabilitation have been issued by the U.S. Department of Housing and Urban Development-Federal Housing Administration (HUD-FHA) for use under various HUD-FHA mortgage insurance programs dealing with property rehabilitation. These HUD guidelines, contained in Handbook 4940.4 entitled, "Minimum Design Standards for Rehabilitation for Residential Properties," were originall issued in September 1973. Several additions (e.g., provisions for handicapped, elderly, lead-based paint hazards, thermal performance measures, and earthquake hazards) and certain changes (e.g., to fire protection and life safety provisions) were made to the Handbook and incorporated in later versions.

\section{COMPILATION OF MAJOR CODE AREAS FOR COMPARATIVE ANALYSIS}

As would be expected, the organizational approach, format of the content, and style of presentation for each code document deviated extensively. Also, the treatment and extent of coverage in the context of specific code provisions varied significantly from code to code. To make valid one-on-on comparisons, the code documents had to be dissected and rearranged in a format that would facilitate comparison. Sixteen major code areas were decided upon after studying the overall content of the seven documents. Not codes had provisions that addressed all of the major code areas. Similarly 
in those major code areas where provisions existed, the degree and extent of coverage fluctuated from code to code. Even though this unevenness with regard to the provisions and their extent of coverage exists among the seven code documents, no direct or indirect attempt has been made to rank or grade the codes. The sixteen major code areas decided upon for the study are as follows:

1. Structural Requirements

2. Space, Occupancy and Facility

Requirements

3. Windows and Doors

4. Stairs, Ramps, Landings, Porches, Balconies

5. Fire Protection/Fire Safety

6. Means of Egress/Exits

7. Light and Illumination
8. Ventilation Requirements

9. Mechanical Requirements

10. Electrical Requirements

11. Plumbing Requirements

12. Health and Sanitation

13. Elevators

14. Chimneys, Vents and Incinerators

15. Noise Abatement Requirements

16. Quality of Materials and Products

\section{SPECIFIC COMPARISONS OF SELECTED CODE PROVISIONS}

The following tables have been condensed from those contained in the full study report [10] to illustrate some of the more explicit requirements in the codes examined. The five housing code documents have been grouped first in the tables with the two rehabilitation guideline documents also grouped together below the housing codes.

\section{Space, Occupancy, and Facility Requirements}

Minimum floor area for habitable rooms - Room sizes based on floor area are used to set maximum density in terms of number of occupants in dwe11ing units and for defining what is or is not a habitable room. Table 1 summarizes the minimum required floor area for habitable rooms in the code documents examined.

The codes generally require at least one habitable room per dwelling unit and as indicated there is general agreement among the housing codes that for the first occupant the floor area should be at least 150 square feet. The APHA-CDC Ordinance, Standard Housing Code, and BOCA Housing Code agree on the 100 square feet requirement for each additional occupant, while the New York State and Uniform Housing Code do not address additional occupants. These latter codes do have minimum horizontal dimensions for the habitable room, but differ by three feet on the minimum length of the dimension. The BOCA Rehabilitation Guidelines defer to local codes and ordinances, while the HUD Rehabilitation Standards set its minimum room areas on the number of bedrooms in the living unit. 
Table 1: Minimum Floor Area for Habitable Rooms

\begin{tabular}{|c|c|c|c|}
\hline CODE/STANDARD & $\begin{array}{l}\text { First Occupant } \\
(\mathrm{Sq} . \mathrm{Ft} .)\end{array}$ & $\begin{array}{c}\text { Each Additional } \\
\text { Occupant (Sq. Ft.) }\end{array}$ & $\begin{array}{l}\text { Minimum Horizontal } \\
\text { Dimension (Ft.) }\end{array}$ \\
\hline APHA-CDC ORDINANCE & 150 & 100 & - \\
\hline N.Y. STATE MODEL & 150 & - & 10 \\
\hline UNIFORM (ICBO) & 150 & - & 7 \\
\hline STANDARD (SBCCI) & 150 & 100 & - \\
\hline BASIC (BOCA) & 150 & 100 & - \\
\hline $\begin{array}{l}\text { REHAB GUIDELINES } \\
\text { (BOCA) }\end{array}$ & \multicolumn{3}{|c|}{ As required by 1 ocal code or ordinance } \\
\hline $\begin{array}{l}\text { HUD/FHA MINIMUM } \\
\text { REHAB STANDARDS }\end{array}$ & \multicolumn{2}{|c|}{$\begin{array}{l}140 \text { for } 1 \text { and } 2 \text { bedroom units } \\
150 \text { for } 3 \text { or more bedroom units }\end{array}$} & 10 \\
\hline
\end{tabular}

Minimum floor area for sleeping purposes - Rooms to be used for sleeping purposes also have minimum floor area requirements. These floor areas are also prescribed on the basis of number of occupants as indicated in Table

Table 2: Minimum Floor Area for Sleeping Purposes

\begin{tabular}{|c|c|c|}
\hline CODE/STANDARD & $\begin{array}{c}\text { Floor Area Per Occupant } \\
\text { (Sq. Ft.) }\end{array}$ & $\begin{array}{l}\text { Minimum } \\
\text { Borizontal Dimension } \\
\text { (Ft.) }\end{array}$ \\
\hline APHA-CDC ORDINANCE & $\begin{array}{l}70 \text { for one occupant } \\
\text { so per occupant for more } \\
\text { than one occupant }\end{array}$ & - \\
\hline N.Y. STATE MODEI & 80 & 7 \\
\hline UNIFORM (ICBO) & $\begin{array}{l}70 \text { for one or two occupants } \\
\text { so per occupant for more than } \\
\text { two occupants }\end{array}$ & 7 \\
\hline STANDARD (SBCCI) & $\begin{array}{l}70 \text { for one occupant } \\
\text { so per occupant for more than } \\
\text { one occupant }\end{array}$ & - \\
\hline BASIC（BOCA） & $\begin{array}{l}70 \text { for one occupant } \\
50 \text { per occupant for more } \\
\text { than one occupant }\end{array}$ & - \\
\hline $\begin{array}{l}\text { REHAB GUIDEL INES } \\
\text { (BOCA) }\end{array}$ & - & - \\
\hline $\begin{array}{l}\text { BUD/FHA MINDMM } \\
\text { REHAB STANDARDS }\end{array}$ & $\begin{array}{l}70 \text { for single bedroom } \\
110 \text { for double bedroom }\end{array}$ & $\begin{array}{l}7 \\
82 / 3\end{array}$ \\
\hline
\end{tabular}


The 80 square feet given for the New York State Code is apparently not based on occupant density, however, the provision is not clear as presented in that code. The other housing codes specify an area of 70 square feet for the first occupant, except the Uniform Housing Code which allows two occupants in the same 70 square feet room. Minimum horizontal dimensions of seven feet for sleeping rooms are given by only two of the housing codes (New York State and Uniform) and the HUD Rehabilitation Standards, which sets its minimum room areas again on number of bedrooms in the unit. The BOCA Rehabilitation Guidelines have no specific requirements.

Minimum floor area for kitchens - The code documents examined treat minimum kitchen area requirements with some variation and in other cases do not have any specific requirements. Table 3 depicts the code requirements.

Table 3: Minimum Floor Area for Kitchens

\begin{tabular}{l|c|c}
\hline CODE/STANDARD & Kitchen Floor Area (Sq. Ft.) & $\begin{array}{c}\text { Minimum Horizontal } \\
\text { Dimension (Ft.) }\end{array}$ \\
\hline $\begin{array}{l}\text { APHA-CDC } \\
\text { ORDINANCE }\end{array}$ & $\begin{array}{l}\text { Area adequate for circulation and } \\
\text { required equipment }\end{array}$ & - \\
\hline $\begin{array}{l}\text { N.Y. STATE MODEL } \\
\text { UNIFORM (ICBO) }\end{array}$ & 60 & 7 \\
\hline $\begin{array}{l}\text { STANDARD (SBCCI) } \\
\text { BASIC (BOCA) }\end{array}$ & $\begin{array}{l}50 \text { for } 1 \text { to } 5 \text { occupants } \\
60 \text { for } 6 \text { or more occupants }\end{array}$ & - \\
\hline REHAB GUIDELINES \\
(BOCA)
\end{tabular}

The APHA-CDC Ordinance is a simply stated performance requirement, the New York State Model specifies a 60 square feet minimum area with a minimum horizontal dimension of seven feet and the BOCA Housing Code scales the requirement to the number of occupents. The HUD Rehabilitation Guidelines either do not address the requirement or leave it to local regulations.

Minimum ceiling height for habitable rooms - Ceiling requirements for habitable rooms also differ among the code provisions examined, as indicated in Table 4. 
Table 4: Minimum Ceiling Height for Habitable Rooms

\begin{tabular}{|c|c|c|c|}
\hline \multirow{2}{*}{ CODE/STANDARD } & \multirow{2}{*}{$\begin{array}{l}\text { Minimum Ceiling } \\
\text { Height ( } \mathrm{Ft.})\end{array}$} & \multicolumn{2}{|c|}{ Rooms With Sloping Ceilings } \\
\hline & & $\begin{array}{c}\text { Portion of Floor } \\
\text { Area Required for } \\
\text { Clear Ceiling }\end{array}$ & $\begin{array}{l}\text { Ceiling Height } \\
\text { Disallowed (Ft.) }\end{array}$ \\
\hline $\begin{array}{l}\text { APHA-CDC } \\
\text { ORDINANCE }\end{array}$ & 7 & $1 / 2$ & 5 \\
\hline N.Y. STATE MODEL & $71 / 2$ & $1 / 2$ & 5 \\
\hline UNIFORM（ICBO） & $\begin{array}{l}71 / 2 \\
7 \text { for kitchens, } \\
\text { halls and bathrooms }\end{array}$ & $1 / 2$ & 5 \\
\hline STANDARD (SBCCI) & 7 & $1 / 2$ & 5 \\
\hline BASIC (BOCA) & $71 / 3$ & $1 / 3$ & 5 \\
\hline $\begin{array}{l}\text { REHAB GUIDELINES } \\
\text { (BOCA) }\end{array}$ & 7 & $1 / 2$ & 5 \\
\hline $\begin{array}{l}\text { HUD/FHA MINIMUM } \\
\text { REHAB STANDARDS }\end{array}$ & $\begin{array}{l}\cdots \text { permit average } \\
\text { no unpleasant }\end{array}$ & $\begin{array}{l}\text { on to move about co } \\
\text { tion (Guide suggest }\end{array}$ & $\begin{array}{l}\text { fortably and create } \\
\left(71 / 2^{\prime}\right)\end{array}$ \\
\hline
\end{tabular}

Three codes have a seven feet minimum, two specify seven and one-half feet, and another requires seven and one-third feet. The HUD Rehabilitation Standards proposes that ceiling heights be such that they will permit the average person to move about comfortably and create no unpleasant sensa tion and suggests as a guide that minimum heights be seven and one-half feet. There is general agreement among five of the codes on the minimum fraction of floor area and clear ceiling height for rooms with sloping ceilings to qualify as habitable rooms. All specify that at least onehalf of the floor area of such rooms must meet the minimum ceiling height requirement; but the BOCA Housing Code reduces the fractional floor area requirement to one-third of the area. The codes are consistent in disallowing any portion of the room with ceiling heights less than five feet from being considered as part of the required area of habitable space.

\section{Natural Lighting}

Minimum requirements for natural lighting in habitable rooms - Daylighting of habitable rooms by means of windows or other glazed exterior openings is a minimum requirement of all seven codes reviewed. The following data is a tabulation of the salient requirements for natural lighting. 
Table 5: Minimum Requirement for Natural Light in Habitable Rooms

\begin{tabular}{l||c|c}
\hline CODE/STANDARD & $\begin{array}{c}\text { Window Area, \% of Floor } \\
\text { Area of Room }\end{array}$ & $\begin{array}{l}\text { Other Conditions } \\
\text { For Natural Light }\end{array}$ \\
\hline APHA-CDC ORDINANCE & $10 \%$ & $\begin{array}{l}\text { No structures closer } \\
\text { than } 3 \text { ft. to required } \\
\text { window }\end{array}$ \\
\hline $\begin{array}{l}\text { N.Y. STATE MODEL } \\
\text { UNIFORM (ICBO) }\end{array}$ & $10 \%$ & $\begin{array}{l}\text { Must face directly on } \\
\text { open space }\end{array}$ \\
\hline $\begin{array}{l}\text { STANDARD (SBCCI) } \\
\text { BASIC (BOCA) }\end{array}$ & $10 \%$ & $\begin{array}{l}\text { Min. glazed area of } \\
10 \text { sq. ft. required }\end{array}$ \\
\hline $\begin{array}{l}\text { REHAB STA MINIMUM } \\
\text { (BOCA) }\end{array}$ & $8 \%$ & $\begin{array}{l}\text { At least 15\% of floor } \\
\text { area for skylights }\end{array}$ \\
\hline \hline
\end{tabular}

The required minimum window area for admission of natural light to habitable rooms is 10 percent of the floor area for four of the codes and 8 percent for the remaining three. The Uniform Housing Code further specifies an absolute minimum glazed area of ten square feet and the Standard Housing Code requires the minimum daylighting area to be 15 percent of the floor area if the required opening is a skylight.

\section{Ventilation}

Minimum requirements for ventilation of habitable rooms - All of the code documents evaluated require natural ventilation of all habitable rooms. Practically all of the codes directly integrate their ventilation requirements with the provisions for natural light, since the natural ventilation requirements usually are a function of the window area reauirements for natural lighting. The specific requirements applicable to natural ventilation are summarized as follows. 
Table 6: Minimum Requirements for Ventilation of Habitable Rooms

\begin{tabular}{|c|c|c|}
\hline CODE/STANDARD & $\begin{array}{l}\text { Required Minimum Clear } \\
\text { Area Natural Ventilation }\end{array}$ & $\begin{array}{l}\text { Provisions for Alternate } \\
\text { Means of Ventilation }\end{array}$ \\
\hline $\begin{array}{l}\text { APHA-CDC } \\
\text { ORDINANCE }\end{array}$ & $45 \%$ of min. window area & $\begin{array}{l}\text { Other approved device } \\
\text { affording adequate } \\
\text { ventilation }\end{array}$ \\
\hline N.Y. STATE MODEL & $5 \%$ of floor area & $\begin{array}{l}\text { Mechanical ventilation } \\
\text { may be provided in } \\
\text { addition to natural } \\
\text { ventilation, but not as } \\
\text { a substitute }\end{array}$ \\
\hline UNIFORM (ICBO) & $\begin{array}{l}\quad 5 \% \text { of floor area } \\
\text { Min. area of } 5 \text { sq.ft. } \\
\text { required }\end{array}$ & $\begin{array}{l}\text { Mechanical ventilation } \\
\text { may be used as alternate, } \\
2 \text { alr changes/hour, } 20 \% \\
\text { fresh alr }\end{array}$ \\
\hline STANDARD (SBCCI) & $45 \%$ of min. window area & $\begin{array}{l}\text { Mechanical ventilation } \\
\text { may be used as alternate, } \\
\text { except in sleeping rooms }\end{array}$ \\
\hline BASIC (BOCA) & $45 \%$ of min. window area & $\begin{array}{l}\text { Mechanical ventilation } \\
\text { may be used as alternate }\end{array}$ \\
\hline $\begin{array}{l}\text { REHAB GUIDEL INES } \\
\text { (BOCA) }\end{array}$ & $5 \%$ of floor area & $\begin{array}{l}\text { Mechanical ventilation } \\
\text { may be used as alternate, } \\
2 \text { air changes/hour; } 80 \% \\
\text { maximum recirculation }\end{array}$ \\
\hline $\begin{array}{l}\text { HUD/FHA MINTMUM } \\
\text { REHAB STANDARDS }\end{array}$ & $5 \%$ of floor area & $\begin{array}{l}\text { Provides an exception for } \\
\text { interior rooms }\end{array}$ \\
\hline
\end{tabular}

Minimum natural ventilation criteria are based on 45 percent of the minimun glazed area of openable windows or other exterior openings (e.g., skylights, etc.) for three of the codes. "Minimum glazed area" is the requirs ment for natural light for habitable rooms and as indicated previously is normally 8 or 10 percent of the floor area.

The other four codes use 5 percent of the floor area of the room as the minimum requirement for openable area to allow for circulation of outside air. The Uniform Housing Code further stipulates an absolute minimum openable area of 5 square feet for natural ventilation. Overall, it appears that these two arbitrary 'rule of thumb' approaches (i.e., 45 percent of glazed area and 5 percent of floor area) to specifying ventilation provisions are for all practical purposes equivalent but more significantly appear to lack any rational technical basis for ensuring the attainment of an important health goal.

Minimum Requirements for ventilation of bathrooms - The code requirements for ventilation of bathrooms are summarized in Table 7 . 
Table 7: Minimum Requirements for Ventilation of Bathrooms

\begin{tabular}{l||l}
\hline CODE/STANDARD & Minimum Bathroom Ventilation Requirement \\
\hline APHA-CDC ORDINANCE & $\begin{array}{l}\text { Same as for Habitable Room, except no window required } \\
\text { if approved mechanical ventilation provided }\end{array}$ \\
\hline N.Y. STATE MODEL & $\begin{array}{l}\text { Natural Ventilation: Min, opening of 1 1/2 sq. ft. } \\
\text { Mechanical Ventilation: Exhausting min. of 25 cfm }\end{array}$ \\
\hline UNIFORM (ICBO) & $\begin{array}{l}\text { Natural Ventilation: 5\% of fin floor area; Min. } \\
\text { opening of 1 1/2 sq. ft. } \\
\text { Mechanical Ventilation: } 5 \text { alr changes/hour; 100\% } \\
\text { fresh air }\end{array}$ \\
\hline STANDARD (SBCCI) & $\begin{array}{l}\text { Same as for Habitable Room, except no window required } \\
\text { if approved mechanical ventilation provided }\end{array}$ \\
\hline BASIC (BOCA) & $\begin{array}{l}\text { Same as for Habitable Room, except no window required } \\
\text { if approved mechanical ventilation provided }\end{array}$ \\
\hline $\begin{array}{l}\text { REHAB GUIDELINES } \\
\text { RECA) }\end{array}$ & $\begin{array}{l}\text { Natural Ventilation: 5\% of floor area } \\
\text { Mechanical Ventilation: } 5 \text { air changes/hour, 100\% fresh } \\
\text { air }\end{array}$ \\
\hline
\end{tabular}

Overall, the code provisions are inconsistent or incomplete in defining mechanical ventilation air quantities in terms of air changes per hour and amount of recirculation allowed. In several cases the codes defer to an "approved" system of mechanical ventilation and in most cases the term approved means approved by local regulatory officials.

\section{Electrica1 Requirements}

Minimum electrical service and facilities - The following tabularized information provides a digest of the minimum code requirements for electrical service to a dwelling along with an indication of the electrical facilities required per habitable room. 
Table 8: Minimum Electrical Service Requirements

\begin{tabular}{|c|c|c|}
\hline CODE/STANDARD & $\begin{array}{l}\text { Minimum Requirements } \\
\text { For Electrical Service }\end{array}$ & $\begin{array}{l}\text { Electrical Outlets/Fixtures } \\
\text { Per Habitable Room }\end{array}$ \\
\hline APHA-CDC ORDINANCE & $\begin{array}{l}\text { 1- } 15 \text { amp circuit/dwelling } \\
\text { unit (No sharing with other } \\
\text { units) }\end{array}$ & $\begin{array}{l}2 \text { convenience outlets ( } 1 \text { may } \\
\text { be ceiling or wall fixture) }\end{array}$ \\
\hline N.Y. STATE MODEL & $\begin{array}{l}1-15 \text { anp circuit } / 400 \mathrm{sq} \text {. } \\
\mathrm{ft} \text {. of floor area or frac- } \\
\text { tion }\end{array}$ & $\begin{array}{l}1 \text { outlet } / 20 \mathrm{ft} \text {. or fraction } \\
\text { ( } 1 \text { fixture may be substituted } \\
\text { for outlet) }\end{array}$ \\
\hline UNIFORM (ICBO) & $\begin{array}{l}\text { (where available within } \\
300 \mathrm{ft} \text {. of building) }\end{array}$ & $\begin{array}{l}2 \text { convenience outlets ( } 1 \text { may } \\
\text { be ceiling or wall fixture) }\end{array}$ \\
\hline STANDARD (SBCCI) & $\begin{array}{l}\text { (where available to the } \\
\text { building) }\end{array}$ & $\begin{array}{l}2 \text { convenience outlets (in } \\
\text { addition, at least } 1 \text { wall } \\
\text { switch controlled fixture } \\
\text { in bedrooms }\end{array}$ \\
\hline BASIC (BOCA) & $\begin{array}{l}\text { (where available to the } \\
\text { building) }\end{array}$ & $\begin{array}{l}2 \text { convenience outlets ( } 1 \text { may } \\
\text { be ceiling or wall fixture) }\end{array}$ \\
\hline $\begin{array}{l}\text { REHAB GUIDELINES } \\
\text { (BOCA) }\end{array}$ & $\begin{array}{l}\text {...replace systems of } \\
\text { inadequate capacity or } \\
\text { that are potential } \\
\text { hazards }\end{array}$ & $\begin{array}{l}\text {..distribution of fixture } \\
\text { and/or outlets shall be so } \\
\text { as to provide satisfactory } \\
\text { illumination }\end{array}$ \\
\hline $\begin{array}{l}\text { HUD/FHA MINIMUM } \\
\text { REHAB STANDARDS }\end{array}$ & $\begin{array}{l}2 \text { - } 15 \text { amp general light- } \\
\text { ing circuits } \\
1-20 \text { amp appliance cir- } \\
\text { cuit (New electrical work) }\end{array}$ & $\begin{array}{l}\text {...system of wiring to safety } \\
\text { supply electrical energy }\end{array}$ \\
\hline
\end{tabular}

The three major model housing codes do not specify any minimum requirement for electrical service capacity in dwelling units but leave it subject to its' availability to the premises. On the other hand, the rehabilitation guideline documents are definite in their requirement for such service and assume that electrical service exists or will be install, in conjunction with the building rehabilitation process. The APHA-CDC Ordinance has a minimum requirement of at least one $15 \mathrm{amp}$ circuit per dwelling unit* which is quite low in contrast to the New York State Model Housing Code's requirement of one 15 amp branch circuit for each 400 square feet of total dwelling unit floor area and an additional 15 amp small appliance circuit in kitchens. With certain variations, four of the housing codes require a minimum of two convenience outlets per habitable room. In most cases, a ceiling or wall light fixture is allowed to fulfill the requirements for one of the convenience outlets, except for the Standard Housing Code, which requires that bedrooms have a wall switched light fixture in addition to the two convenience outlets.

* "Dwelling Unit" is defined as a room or group of rooms located within a dwelling forming a single habitable unit with facilities used or intended to be used by a single family for living, sleeping, cooking and eating purposes. 
The New York State Model Housing Code differs from the other codes by basing the number of convenience outlets on the perimeter of the room ( 1 outlet per every 20 feet or fraction thereof). In contrast to the housing codes as a group, the rehabilitation guideline documents do not prescribe any minimum distribution of convenience outlets or lighting fixtures throughout various rooms. For the most part, the requirement is stated in terms of "satisfactory illumination," "supply electrical energy for proper illumination," etc.

The minimum outlet and lighting requirements given for kitchens, bathrooms, and other spaces, when specified, vary from being the same as for a habitable room to as many as a combination of four outlets and fixtures. Table 9 summarizes the required minimum outlets and fixtures by type of dwelling space.

Table 9: Minimum Electrical Outlets/Lighting Fixtures *

\begin{tabular}{|c|c|c|c|c|c|c|}
\hline \multirow[t]{2}{*}{ CODE/STANDARD } & \multicolumn{2}{|c|}{$\begin{array}{l}\text { Habitable } \\
\text { Rooms }\end{array}$} & \multicolumn{2}{|c|}{$\begin{array}{c}\text { Kitchens } \\
\text { Kitchenettes }\end{array}$} & \multicolumn{2}{|c|}{$\begin{array}{l}\text { Bathrooms, Halls, } \\
\text { Laundry }\end{array}$} \\
\hline & Outlets & Fixtures & Outlets & Fixtures & Out lets & Fixtures \\
\hline $\begin{array}{l}\text { APHA-CDC } \\
\text { ORDINANCE }\end{array}$ & $-\frac{2}{1}--$ & $-\frac{0}{1}-$ & - & - & - & 1 \\
\hline N.Y. STATE MODEL & \multicolumn{2}{|c|}{$\begin{array}{l}1 \text { outlet } / 20 \mathrm{ft} \text {. or } \\
\text { fraction. ( } 1 \mathrm{fix}- \\
\text { ture may be sub- } \\
\text { stituted) }\end{array}$} & 2 & 1 & 1 & 1 \\
\hline UNIFORM（ICBO） & $-\frac{2}{1}--$ & $-\frac{0}{1}--$ & - & - & - & 1 \\
\hline STANDARD (SBCCI) & 2 & $\begin{array}{c}1 \text { in } \\
\text { bedrooms }\end{array}$ & 3 & 1 & 1 & 1 \\
\hline BASIC (BOCA) & $-\frac{2}{1}--$ & $-\frac{0}{1}-$ & $\begin{array}{r}3 \\
---\end{array}$ & $\frac{0}{1}--$ & 1 & 1 \\
\hline $\begin{array}{l}\text { REHAB GUIDEL INES } \\
\text { (BOCA) }\end{array}$ & \multicolumn{6}{|c|}{$\begin{array}{l}\text {...distribution of fixtures and/or outlets shall be so as to } \\
\text { provide satisfactory illumination }\end{array}$} \\
\hline $\begin{array}{l}\text { HUD/FHA MINTMUM } \\
\text { REHAB STANDARDS }\end{array}$ & \multicolumn{6}{|c|}{$\begin{array}{l}\text {...be provided and so distributed as to assure healthful con- } \\
\text { ditions and satisfactory illumination in all rooms }\end{array}$} \\
\hline
\end{tabular}

* "Outlet" refers to wall type duplex electric convenience outlets. "Fixture" refers to a wall or ceiling type electric light fixture. Where a code allows substitution of a lighting fixture for a convenience outlet, both alternatives are given in the table separated by a dashed line. 
Minimum comfort requirements for habitable rooms - The minimum indoor thermal standards for winter heating required by the code documents studied are given in Table 10. The room location or conditions for measurement of the required ambient indoor temperature are also given.

Table 10: Minimum Comfort Requirements for Habitable Rooms

\begin{tabular}{|c|c|c|}
\hline CODE/STANDARD & $\begin{array}{l}\text { Minimum Temperature To } \\
\left.\text { Be Maintained ( }{ }^{\circ} \mathrm{F}\right)\end{array}$ & Measurement Conditions \\
\hline APHA-CDC ORDINANCE & 68 & $\begin{array}{l}3 \mathrm{ft} \text {. above floor under } \\
\text { ordinary winter conditions }\end{array}$ \\
\hline N.Y. STATE MODER & $\begin{array}{l}\text { (55 from } 11: 00 \text { p.m. } \\
\text { to } 6: 00 \text { a.m.) }\end{array}$ & $\begin{array}{l}5 \mathrm{ft} \text {. above floor } \\
3 \mathrm{ft} \text {. from exterior wall }\end{array}$ \\
\hline UNIFORM (ICBO) & 70 & $3 \mathrm{ft}$. above floor \\
\hline STANDARD (SBCCI) & 70 & $\begin{array}{l}3 \mathrm{ft} \text {. above floor under } \\
\text { ordinary winter conditions }\end{array}$ \\
\hline BASIC (BOCA) & 65 & $\begin{array}{l}3 \mathrm{ft} \text {. above floor } \\
3 \mathrm{ft} \text {. from exterior wall }\end{array}$ \\
\hline $\begin{array}{l}\text { REHAB GUIDELINES } \\
(B O C A)\end{array}$ & As require & cal code or ordinance \\
\hline $\begin{array}{l}\text { HUD/FHA MINIMUM } \\
\text { REHAB STANDARDS }\end{array}$ & $\begin{array}{l}\text { (75 in housing for } \\
\text { the elderly) }\end{array}$ & $\begin{array}{l}\text {... when outside temperature } \\
\text { is at the design tempera- } \\
\text { ture }\end{array}$ \\
\hline
\end{tabular}

The minimum indoor temperature that the heating system must maintain ranges from $65^{\circ} \mathrm{F}$ to $70^{\circ} \mathrm{F}$ among the code documents, except that the BOCA Rehabilitation Guidelines defer the requirement to 1ocal regulations. Also, the New York State Model Housing Code is the only code to allow a night setback temperature of $55^{\circ} \mathrm{F}$ from 11:00 pm to 6:00 am, and the HUD Rehabilitation Standards specifies a temperature of $75^{\circ} \mathrm{F}$ in housing for the elderly.

As indicated by the data, the exact conditions for measurement of the room temperature varies to some extent among the codes. 
Minimum water heating and service requirements - All of the codes specify that "hot water" or "heated water" facilities be provided. Where a temperature is specified in the codes it varies considerably among the codes. Neither of the rehabilitation guideline documents specifies a minimum temperature level or range to be maintained for domestic hot water. Where given, the required temperatures varied from a low of $110^{\circ} \mathrm{F}$ (Uniform Housing Code) to a high of $130^{\circ} \mathrm{F}$ to $140^{\circ} \mathrm{F}$ from $6: 00$ am to midnight (New York State Model Housing Code). The three other housing codes were in apparent agreement with a minimum temperature requirement of $120^{\circ} \mathrm{F}$. The Standard Housing Code has a specific requirement of 30 gallons for the storage capacity of the water heater, as does the HUD Rehabilitation Standards. The comparative information on the specific code requirements for domestic hot water facilities are summarized in Table 11 .

Table 11: Minimum Water Heating and Service Requirements

\begin{tabular}{|c|c|c|}
\hline CODE/STANDARD & TEMPERATURE ${ }^{\circ} \mathrm{F}$ & STORAGE CAPACITY \\
\hline APHA-CDC ORDINANCE & 120 & $\begin{array}{l}\text {..pprovide supply } \\
\text { and distribu- } \\
\text { tion }\end{array}$ \\
\hline N.Y. STATE MODEL & $\begin{array}{l}130-140 \\
\text { from } 6: 00 \text { a.m. to } \\
\text { midnight }\end{array}$ & $\begin{array}{l}\text {...provide hot } \\
\text { water supply } \\
\text { system }\end{array}$ \\
\hline UNIFORM（ICBO） & 110 & $\begin{array}{l}\text {.. necessary for } \\
\text { normal opera- } \\
\text { tion }\end{array}$ \\
\hline STANDARD (SBCCI) & 120 & $30 \mathrm{gal}$. \\
\hline BASIC (BOCA) & 120 & $\begin{array}{l}\text {...adequate amount } \\
\text { for required } \\
\text { kitchen sink, } \\
\text { lavatory basin, } \\
\text { bathtub and } \\
\text { laundry facility }\end{array}$ \\
\hline $\begin{array}{l}\text { REHAB GUIDER INES } \\
\text { (BOCA) }\end{array}$ & Provide hot water & $\begin{array}{l}\ldots \text { provide supply } \\
\text { and distribution }\end{array}$ \\
\hline $\begin{array}{l}\text { HUD/FHA MINIMUM } \\
\text { REHAB STANDARDS }\end{array}$ & $\begin{array}{l}\text { Provide domestic hot } \\
\text { water and storage for } \\
\text { each unit }\end{array}$ & $\begin{array}{l}\text {.. in quantities } \\
\text { sufficient for } \\
\text { the needs of } \\
\text { occupants ( } 30 \\
\text { gal. for gas } \\
\text { or oil; } 52 \text { gal. } \\
\text { for electric) }\end{array}$ \\
\hline
\end{tabular}


The results of this evaluation, which in its final form will compare and analyze in detail all the technical provisions in the applicable code documents, should give a good profile of the performance levels expected, at least from a regulatory viewpoint, for existing residential buildings.

Based on preliminary results, as indicated by the comparisons presented in this paper, there exists significant variations in similar provisions among the several codes. For example, for natural ventilation in habitable rooms, the code requirements vary from fixed dimensions of five square feet to five percent of the floor area to forty-five percent of th glazed area. Another consideration is the perception that many of the code provisions have been developed empirically and are lacking in scientific merit. In this regard, a research agenda is needed to develop health, safety, and social well-being criteria from which meaningful provisions for housing codes and rehabilitation standards can be formulated.

\section{REFERENCES}

1. Berry, Sandra A., Editor, "Proceedings of the National Conference on Regulatory Aspects of Building Rehabilitation," NBS Special Publication 549, National Bureau of Standards, Washington, D.C., August 1979.

2. Gross, James G., James H. Pielert and Patrick W. Cooke, "Impact of Building Regulations on Rehabilitation - Status and Technical Needs," NBS Technical Note 998, National Bureau of Standards, Washington, D.C. May 1979.

3. APHA-CDC Recommended Housing Maintenance and Occupancy Ordinance, 1975 Revision; U.S. Department of Health, Education and Welfare, Public Health Service, Center for Disease Control, Atlanta, Georgia 30333 .

4. New York State Model Housing Code, 1974 Edition; New York State Division of Housing and Community Renewal, Housing and Building Codes Bureau, Two World Trade Center; New York, New York 10047.

5. Uniform Housing Code, 1979 Edition; International Conference of Building Officials (ICBO), 5360 South Workman Mill Road, Whittier, California 90601 .

6. Standard Housing Code, 1979 Edition; Southern Building Code Congress International, Inc. (SBCCI), 900 Montclair Road, Birmingham, Alabama 35213.

7. BOCA Basic Property Maintenance Code, 1978 Edition; Building Officials and Code Administrators International, Inc. (BOCA), 17926 South Halsted, Homewood, I11inois 60430. 
8. Code Enforcement Guidelines for Residential Rehabilitation, 1975 Edition; Building Officials and Code Administrators International Inc., (BOCA), 17926 South Halsted, Homewood, Illinois 60430. (Also printed as Appendix B in the BOCA Basic Property Maintenance Code, 1978 Edition.)

9. Minimum Design Standards for Rehabilitation for Residential Properties, HUD Circular 4940.4, February 1978 (revised through August $22,1978)$, U.S. Department of Housing and Urban Development, Washington, D.C. 20410.

10. Cooke, Patrick W., "Comparison of Selected Codes and Standards Relating to Existing Residential Buildings," National Bureau of Standards, Washington, D.C. (In review.) 



\section{PROBLEMS IN HOUSING CODE ENFORCEMENT:}

A FOCUS ON THE BUDGET

by

Carol B. Meeks, Ph.D.

Associate Professor

Dept. of Consumer Economics and Housing

NYS College of Human Ecology, Cornell University

Ithaca, New York

A housing code is one option available to communities concerned with maintenance of housing quality. Housing code administrators in New York State identified lack of financial and human resources as two key problems in code enforcement.

Primary attention in this paper is given to analysis of community housing code budgets which varied considerably among communities.

In a log-log regression equation, the size of per capita housing code budgets was significantly influenced by the number of housing code inspections conducted, the percent of revenues obtained from property taxes and the percent of owner occupied housing.

Practitioners can compare the results with their own situation.

Key words: Budgets; economic analysis; enforcement; housing codes; personnel. 
One of the major indicators of a community's viability is the quality of its housing stock. A housing code is one weapon that local communities can use to attack poor quality housing. However, that a community has a housing or building code is no guarantee that minimum standards of health, safety and welfare are being met, that blight is arrested or that the housing stock has improved. Effective code administration and enforcement are necessary to assure that minimum standards of housing quality are being achieved. A sample of 133 housing code administrators in New York State identified the following problems in order of priority in housing code enforcement:

1. lack of financial resources,

2. lack of human resources,

3. lack of public interest, and

4. lack of standard relocation housing.

Each of these problems will be discussed in this paper. However, primary attention is given to factors which have been found to influence the size of community housing code budgets, since financial concerns were identified both here and in previous work by Lieberman and Slavet and Levin as a primary problem in code administration. 1

\section{Housing Code Budget Mode1}

Obviously a city has a demand for a variety of goods and services, housing codes being only one of these items. 2 A city's preferences can be expressed as follows:

$$
\begin{aligned}
& \mathrm{U}_{\mathrm{C}}=\mathrm{U}_{\mathrm{C}}(\mathrm{E}, \mathrm{D}, \mathrm{C}, \mathrm{M}) \text { where } \\
& \mathrm{E}=\text { code enforcement } \\
& \mathrm{D}=\text { quality of housing } \\
& \mathrm{C}=\text { characteristics of a city and its residents } \\
& \mathrm{M}=\text { all other municipal goods and services }
\end{aligned}
$$

\footnotetext{
${ }^{1}$ Barnet Lieberman, "The Administrative Process--Housing Code Enforcement," The Urban Lawyer, 3: (1971), p. 45; and Joseph S. Slavet and Melvin R. Levin, New Approaches to Housing Code Administration, (NCUP Research Report No. 17), Washington, D.C.: U.S. Government Printing Office, 1969, p. 44 .
}

${ }^{2} \mathrm{~A}$ housing code is designed to preserve and protect existing structures, and set standards for facilities' conditions for use and occupancy for the health, safety and general welfare of the occupants. 
This equation states that a municipality's preferences depend on housing codes as well as all other municipal goods and services, characteristics of the city, housing code enforcement, and quality of housing.

The city attempts to maximize its preferences within the confines of its budget. The budget is allocated for code enforcement $\left(\mathrm{P}_{\mathrm{E}} \mathrm{E}\right)$ and all other goods and services $\left(\mathrm{P}_{\mathrm{M}} \mathrm{M}\right)$. The city's budget constraint can be expressed as:

$$
\begin{aligned}
& T R=P_{E} E+P_{M} M \\
& \text { where } T R=\text { tax revenues }
\end{aligned}
$$

Allocation of resources for housing codes will depend on the amount of resources or revenues, the cost of code enforcement relative to other goods and services, and the preference for housing codes relative to other goods and services.

Variables which contribute to a community's costs, resources, and preferences for housing codes account for the position of the community's budget line and the community's preference structure as represented by its indifference curve between housing code enforcement and all other goods (Figure 1). To the extent that these variables differ between cities, the position of the budget line will differ, assuming the price of housing codes relative to all other goods is the same in both communities.

Variables which contribute to the costs per unit of housing code enforcement will determine the slope of the budget line (Figure 2). To the extent that these variables differ between communities, the slope of the budget line will differ. Even if the preference structure as represented

A11

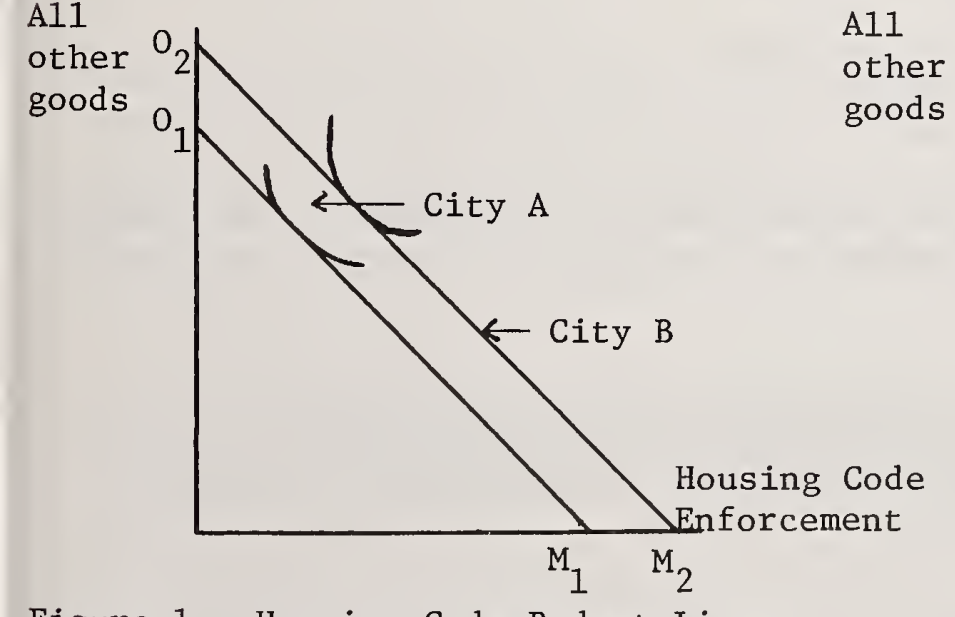

Figure 1. Housing Code Budget Lines for Two Cities

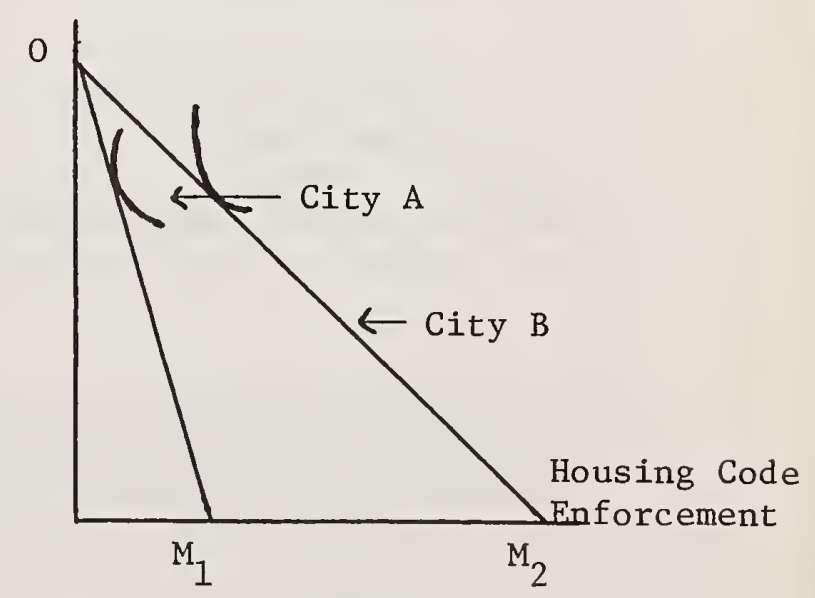

Figure 2. Costs Per Unit of Housing Code Enforcement Determine the Slope of the Housing Code Budget Line 
by its indifference curve is similar, less housing code enforcement will be purchased by the community with the higher costs.

Code enforcement has both a quantity and quality dimension. ${ }^{3}$ The effectiveness of code enforcement is determined to a great extent by factors which increase or decrease the quality and quantity. Therefore, housing code enforcement (E) can be expressed as:

$$
\begin{aligned}
& E=Q_{L} I \\
& \text { where } Q_{L}=\text { Quality of inspection } \\
& \qquad I=\text { Number of inspections }
\end{aligned}
$$

This breakdown implies that a given number of inspections in one municipality will not have the same effect as the same number of inspections in another city, to the extent that the quality of inspections varies between municipalities. 4 However, quality of inspections is not observable, only quantity is. Since quality is unobservable and there is a confounding between quality and price, this study examines housing code budgets to avoid trying to separate quality from price.

\section{Data}

This study analyzes a set of variables which are thought to represent city preferences and characteristics and resources available, as they relate to housing code enforcement expenditures.

Data used in this study were obtained from a mail questionnaire sent in 1975 to 198 housing code administrators in communities in New York State which were over 3000 in population and identified as having a housing code. 5 After additional mail and telephone follow-ups, the eight page questionnaire was completed by 133 officials or 67 percent of those contacted, representing 39 cities, 39 towns, 53 villages and 2 boroughs of New York City.

\section{Variables}

Housing Code Budgets

The measure of expenditures for housing code enforcement is the housing code budget as specified by survey respondents. The budget includes a11

3 Barbara Sherman, "Factors Related to the Probability that Municipalities in New York State Participate in Housing Rehabilitation Programs," M.S. Thesis, Cornell University, January 1979, p. 47.

${ }^{4}$ Sherman, p. 47 .

5 For more details on sample and data collection see Carol B. Meeks and Eleanor Oudekerk, A Review of Housing Codes in New York State, Research Paper 77-1, Department of Consumer Economics and Housing, Cornel1 University, Ithaca, New York, 1977. 
components of the housing code program since local officials could not separate enforcement expenditures from other expenditures. Housing code budgets for 1975 in New York State ranged from a low of zero to a high of $\$ 20$ million--the zero in smaller communities and the $\$ 20$ million in the boroughs of New York City (Table 1). About half the sample spent less than $\$ 20,000$. Villages spent the least and cities in general the most. Smaller communities had lower budgets than larger communities.

Mean and median budgets were examined by community size (Table 2). Within each group as well as between groups, there was a considerable range in the size of the budget. Places of 100,000 or less tended to have average budgets not too dissimilar from their medians. However, places over 100,000 exhibited considerable differences in the amount spent, so that the very high budgets of a few communities skewed the mean.

Since size of community played a key role in variance of housing code budgets, per capita expenditures were examined. It was found that expenditures for the majority of respondents were similar to the ranges reported by Slavet and Levin in 1967 in which communities under 100,000 averaged between $\$ 0.71$ and $\$ 1.31$ per capita. 6 The range of per capita expenditures in the New York State communities went from $\$ 0.86$ to $\$ 8.08$.

In describing the amount of variation in a population, a measure called the coefficient of variation is often used. 7 It is the standard deviation expressed as a fraction or percentage of the mean. It is a measure of the variation in a variable relative to the size of the variable. A knowledge of the relative variation allows for the evaluation of the variability in budgets or per capita budgets over population size. The coefficient of variations for both budget and per capita budget are large (Table 2).

Per capita budget is the measure used in the regression analysis. The measure of per capita budget is the housing code budget divided by number of year-round housing units. Number of year-round housing units is highly correlated with population $(r=.997)$. Year-round housing units was thought to be a more stable measure of a community's size and housing needs than population since household size is declining.

Independent Variables

A set of seven independent variables were chosen for empirical examination. These variables were thought to relate to community preferences and budget constraint.

${ }^{6}$ Slavet and Levin, p. 145.

${ }^{7}$ George W. Snedecor and William G. Cochran, Statistical Methods, Ames, Iowa: The Iowa State University Press, Sixth Printing, 1973, pp. 62-63. 
Table 1. Housing Code Enforcement Budgets, By Type and Size of Municipality.

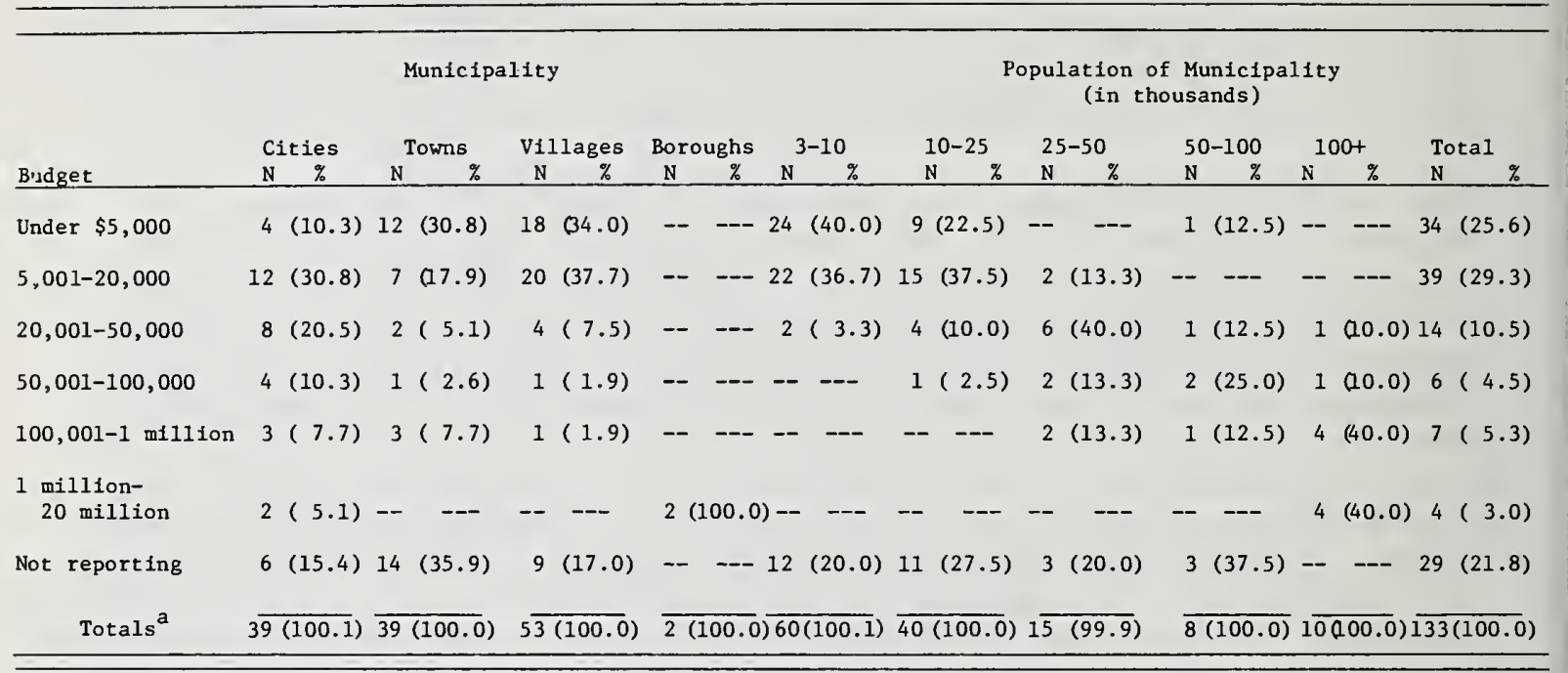

${ }^{a}$ Columens do not add up to $100 \%$ due to rounding.

Table 2. Description of Budget and Per Capita Budget Expenditures by Size of Municipality

\begin{tabular}{|c|c|c|c|c|c|}
\hline Population & $\mathrm{N}$ & Mean & $\begin{array}{l}\text { Standard } \\
\text { Deviation }\end{array}$ & $\begin{array}{l}\text { Coefficient } \\
\text { of Variation }\end{array}$ & Range \\
\hline & \multicolumn{5}{|c|}{ BUDGET (\$) } \\
\hline $3,00-10,000$ & 48 & 7,270 & 6,113 & .84 & 0 to 24,000 \\
\hline $10,001-25,000$ & 29 & 14,670 & 14,312 & .97 & 0 to 72,705 \\
\hline $25,001-50,000$ & 12 & 60,978 & 63,516 & 1.04 & 7,830 to 223,199 \\
\hline $50,001-100,000$ & 5 & 70,000 & 52,915 & .76 & 0 to 135,000 \\
\hline 100,001 and over & 10 & $4,276,797$ & $7,392,727$ & 1.72 & $\begin{array}{l}30,000 \text { to } \\
20,000,000\end{array}$ \\
\hline All places & 104 & 429,078 & $2,523,243$ & 5.88 & 0 to $20,000,000$ \\
\hline
\end{tabular}

\begin{tabular}{lccccc}
$3,000-10,000$ & 48 & 1.30 & 1.08 & .83 & 0 to 4.05 \\
$10,001-25,000$ & 29 & 0.86 & 0.70 & .81 & 0 to 3.36 \\
$25,001-50,000$ & 12 & 1.86 & 1.82 & .98 & .31 to 6.74 \\
$50,001-100,000$ & 5 & 1.20 & 1.00 & .83 & 0 to 2.68 \\
100,001 and over & 10 & 8.08 & 16.50 & 2.04 & .15 to 54.16 \\
A11 places & 104 & 1.89 & 5.39 & 2.85 & 0 to 54.16 \\
\hline
\end{tabular}


Number of Inspections. It is expected that economies of scale result as the number of inspections increases. "Not only will the average fixed costs of code enforcement decline as the number of inspections increases, but over some range, average variable costs are likely to decline as wel1."8 At any given time, one more inspection is not likely to require an additional inspector or more support staff.

However, number of inspections was highly correlated with number of complaints $(r=.813)$ and number of inspectors $(r=.852)$. So that as number of complaints increase, number of inspections increase so that number of inspectors needed increase. Because of multicollinearity concerns, only. number of inspections is used in the analysis.

Age of Housing Code. Effective code administration requires time for development and organization. Age of the housing code was thought to partially represent the institutionalization of the code and the experience of personnel and the municipality with it. To some extent it also represents a city's preference for housing codes and desire for quality housing.

More than 70 percent of the housing codes in the survey were less than 15 years old. Eight municipalities had housing codes prior to 1954; 49 more adopted them between 1955 and 1964 and 70 communities adopted one between 1965 and 1975 .

The condition of housing within a community reflects the city's preference for housing and the cost of maintaining or improving that stock. Several variables were selected to represent housing condition.

Age of Housing Stock. Cities with a higher percentage of older housing units are thought to have a greater percentage of poor quality housing. In addition, it is expected that newer housing units are built to the higher standards included in modern building codes. Municipalities with poorer quality housing are expected to require more resources for code administration to improve that stock. Thus, there would be a greater demand and larger budget for housing codes. However, code enforcement programs often avoid areas with the most serious problems so that budgets may not actually increase with age of the housing stock. The variable used to measure age of a city's housing stock is the percentage of housing units built before 1939 .

Plumbing Facilities. Housing lacking in plumbing facilities will not meet most housing codes so that a community may require a larger budget for inspection and enforcement. Plumbing facilities is measured as percent of housing lacking some or all plumbing.

Housing Tenure. Studies have found that poor quality housing tends to be concentrated among central units rather than owner occupied

${ }^{8}$ Sherman, p. 52 . 
units. 9 Rental housing often receives more attention from housing code officials than owned housing since tenants are likely to complain. In addition, owners may have more legal protection of their privacy. 10 Cities with a large percentage of owned units are thought to demand less housing code enforcement and thus, less money is needed for a housing code program.

Income. Low income households usually occupy poor quality housing. 11 If a community has a large number of low income households, their housing stock may be poorer. Property owners are not likely to make investments in areas in which there is little likelihood of return. Low income households may demand code enforcement whereas property owners may discourage its use. Household income was measured as percent of families below poverty.

Municipal Revenues. As a municipality's revenues increase, more funds become available for expenditures and hence, there are likely to be more funds available for housing codes. Although state and federal assistance could be provided for housing code programs, local revenue is the most important source. Slavet and Levin report that most financial support for housing code programs is generated via the local property tax. 12

Respondents in the present study relied heavily on general revenues for their housing code programs. Over one-half of the communities relied on general revenues exclusively and another 25 percent relied upon it for half to 95 percent of their code enforcement budget.

Special revenues were not specified as a financial source for code enforcement by 77 percent of the sample. However, for three communities less than 25,000 in population, this was their sole source of support. More than 60 percent of the communities did not use fees at all. Most

9 Michael A. Stegman, Housing Investment in the Inner City: The Dynamics of Decay, Cambridge, Massachusetts: The MIT Press, 1972, p. 34; William G. Grigsby and Louis Rosenburg, Urban Housing Policy, Rutgers University, N.J.: Center for Urban Policy Research, 1975, p. 62 .

${ }^{10}$ Kathleen L. Barber, "Inspecting the Castle: The Constitutionality of Municipal Housing Code Enforcement at Point of Sale." Loyola University of Chicago Law Journal, Vol. 10, No. 1 (Fall 1978), p. 1 .

${ }^{11}$ U.S. Department of Housing and Urban Development, Housing in the Seventies, Washington, D.C.: U.S. Government Printing Office, 1974, p. 169; David Birch, et al., America's Housing Needs: 1970 to 1980, Cambridge, Massachusetts: Joint Center for Urban Studies, 1973, p. 4, 12; Grigsby and Rosenburg, p. 67.

${ }^{12}$ Slavet and Levin, p. 153. 
of those communities which did cite fees as a source of funds stated that they were not intended to cover all costs of enforcement. In the analysis, percent of revenues derived from real property taxes and assessments was the variable used.

\section{Empirical Results}

Of the 133 communities with housing codes, complete data existed for 86. Table 3 contains means and standard deviations of the independent variables used in the equation. A log-log regression equation was estimated to determine the variables influencing per capita budget (Table 4).13

Multiple regression analysis is appropriate when examining the relationship between a continuous dependent variable and a set of independent variables. It allows for the examination of the net relationship between the dependent variable and each independent variable, holding a11 other variables in the equation constant. The regression coefficients for a log-log equation are interpreted as follows: for each one unit change in the independent variable, there is a percentage change in the dependent variable of the amount of the coefficient.

The regression equation had an $\mathrm{R}^{2}$ of .38 which indicates that 38 percent of the variation in housing code budgets was accounted for by the variables included (Table 4). The equation was significant at the .01 level.

Number of inspections performed significantly increased the budget. For each one percent increase on inspections conducted, the budget per capita increased by ten percent.

Percent of owner occupied housing had the expected effect. As percent of owner occupied housing increased, the per capita budget decreased by two percent.

As the percent of revenues a community received from property taxes increased, the amount allocated per capita for housing code budgets increased one percent.

${ }^{13}$ A linear regression equation was also run. The same variables were significant and in addition percent of families below poverty were significant at the .05 level. However, it was thought that given the small dollar changes made in per capita budgets, percentage changes were easier to understand. A regression equation was also estimated with budget as the dependent variable, the same independent variables were included as discussed here with the addition of year-round housing units. Only two variables, number of year-round housing units and number of inspections, were significant in the budget equation. It is thought that the effect of population overwhelmed the effect of the other variables. 
Table 3. Means and Standard Deviations of Variables Used in the Regression Analysis ( $N=86)$

\section{Variables}

Per Capita Budget

Number of inspections

Age of housing code (years)

Percent older than 1939

Percent lack of plumbing

Percent owner occupied

Percent below poverty

Percent revenues property taxes

$\begin{array}{rr}\text { Mean } & \text { S.D. } \\ 1.39 & 1.46 \\ , 572.59 & 11,386.20 \\ 11.58 & 6.32 \\ 60.78 \% & 20.82 \% \\ 2.99 \% & 1.84 \% \\ 61.68 \% & 16.37 \% \\ 6.78 \% & 2.98 \% \\ 39.75 \% & 17.33 \%\end{array}$

Table 4. Results of Log-Regression Analysis of Housing Code Budgets $(\mathrm{N}=86)$

\section{Variables}

Number of inspections

Percent lack of plumbing

Percent older than 1939

Percent owner occupied

Percent families below poverty

Percent revenues property taxes

Age of housing code

Constant

F

$\mathrm{R}^{2}$
B.

$$
\begin{aligned}
& 0.10786 * \\
& 0.00506
\end{aligned}
$$

0.00055

-0.02037 **

0.05436

0.01278 *

$-0.10184$

$-0.11092$

$6.84120 * *$

0.38040

\section{$\underline{\text { Standard error }}$}

0.04553

0.05701

0.00552

0.00685

0.03675

0.00552

0.12305

*significant at .05 level

**significant at .01 level 
Although only statistically significant at the ten percent level, as the percent of families below the poverty level increased, per capita housing code budgets increased by five percent. Sternlieb found that per capita municipal costs increase as the percent of families below the poverty level increases. 14

Neither plumbing, age of housing, nor age of housing code were significant.

\section{Human Resources}

The most comprehensive codes and the most ambitious housing goals will have no practical effect without adequate qualified staff to administer and enforce a program. Much of the criticism leveled at many communities for their failure to implement effective code enforcement programs identifies the problem of inadequate. poorly trained, underpaid personnel in a low status occupation. I5 This study reviewed the training, qualifications and selection process of housing code inspectors and administrators in the New York communities under study.

\section{Qualifications}

No clearcut picture merged regarding the basic qualifications needed for housing inspectors. This confirms Hale's findings that there is no agreed-upon job description nor clear definition of qualifications other than that of experience in construction. 16 In the current study respondents described basic qualifications consistently to include knowledge or experience in building and construction, often for a specified period of time. Most of the municipalities (77\%) required some combination of education, experience, and special knowledge. Nearly half also required some form of examination.

Perhaps indicative of a trend toward careful definition of staffing standards are the requirements listed by two of the municipalities. One

${ }^{14}$ George Sternlieb, Housing Development and Municipal Costs, Rutgers University, N.J.: Center for Urban Policy Research, p. 34 .

${ }^{15}$ Comptroller General of the United States, Enforcement of Housing Codes: How It Can Help to Achieve the Nation's Housing Goal, Report to the Congress, June 26, 1972, Washington, D.C.: U.S. General Accounting Office, p. 47; Slavet and Levin, pp. 118-119.

${ }^{16}$ Robert L. Hale, Jr. and Aliceann Fritschler, The Present State of Housing Code Enforcement, A Report to the U.S. National Commission on Urban Problems by the National Association of Housing and Redevelopment Officials, October 1968, p. 221. 
community which employed 17 inspectors required an associate degree, state certification as environmental health technician, completion of a 12 week training course, and a civil service examination. The other municipality employing 43 inspectors, which included "several different titles, graded by skill and responsibility," insisted on high school graduation plus three years experience in housing code enforcement, or two years college plus one year as a trainee, or an equivalent combination of training and experience.

\section{Size of Inspection Staff}

The literature suggests no single preferred method for determining the exact number of inspectors needed to carry out an effective housing program. Most analyses revolve around HUD guidelines for staffing ratios and workload formulae. These call for one inspector per 10,000 people or one per 1000 substandard dwelling units, based on the premise that one inspector can inspect, reinspect, and obtain compliance on an average of 200 substandard dwelling units, or 600 standard units over a five year period. 17 Both Hale and Taylor point out that the size of a community, the number of substandard dwellings, the age and type of dwellings all have a bearing on the number of inspections, hence, the number of inspectors needed. 18

The number of housing inspectors employed in communities in New York State reflected the size of the municipality. The widest range in the number of inspectors occurred among the largest communities. One place over 100,000 had only one inspector while two declared that over 400 were in their employ. Sixty percent of the sample met or exceeded the HUD suggested ratio of one inspector per 10,000 people. Twenty-four percent of the sample employed one inspector per 10,001 to 20,000 people.

Another way of viewing the adequacy of the inspection staff is to look at the relationship between the number of inspectors hired and the number of inspections conducted. Over half the communities with one inspector estimated that they did 250 or fewer inspections annually. Another 17 percent of the sample with a single inspector inspected an estimated 501 to 1500 places yearly.

Lieberman suggested that one full-time inspector should be able to conduct 1900 inspections annually. On this basis, the survey data indicated that 80 percent of the communities with one inspector were

\section{${ }^{17}$ Slavet and Levin, pp. 127-128.}

18Hale, pp. 218-219; Danie1 M. Taylor, A Guide for Codes Adoption and Enforcement, Birmingham, Alabama: Southern Building Code Congress International, Inc., n.d., pp. 29-30. 
adequately staffed. However, there is no information regarding the kind of inspection made, the average length of time needed to complete the job, or the amount of support staff available. Two other factors complicate the situation, the use of part-time inspection staff and the use of inspectional services of other departments or agencies.

Although only tentative conclusion can be made about housing code personnel, it is noteworthy that there is a trend toward more professionalism, with increasingly well-defined staffing standards, especially in areas employing large numbers of inspectors.

\section{Other Problems}

Two other problems identified in the survey were lack of public interest and lack of standard relocation housing. Citizens had little influence in the adoption of a code and only $40 \%$ of the communities had a citizen advisory or review board so that it is not surprising that there is a lack of public interest.

Relocation assistance may be offered to families forced to move because of housing code violations. Most relocation assistance is available from urban renewal, public housing or welfare agencies in the community. Over half the municipalities (58\%) did not give such aid. If assistance was given, it was most frequently available in cities (46\%) through public agencies; two thirds of the towns and villages had no relocation assistance programs.

\section{Summary and Conclusions}

Housing code administrators in New York State identified lack of financial resources as a key problem in housing code enforcement. Other problems identified included lack of human resources, lack of public interest and lack of standard relocation housing.

Primary attention was given to financial resources. Housing code budgets ranged from zero to $\$ 20$ million with a mean of $\$ 429,078$. The mean per capita budget was $\$ 1.89$.

Regression analysis indicated that number of inspections, percent of housing owner-occupied, and percent of revenues derived from property taxes all significantly influenced the size of housing code budgets in the expected manner.

In looking at their own communities, housing code administrators can use the data to compare their situation with other similar communities. In addition, administrators with knowledge about their community situation and changes which may take place can make some predictions about

19

Howard A. Schretter, Housing Code Enforcement Study Guide, Athens, Georgia: University of Georgia, 1971, p. 54. 
future needs and the budget necessary to finance the needs. For example, if rental units are being converted to owned units, the role of housing codes may decrease so that over time a smaller budget is needed or the kind of inspection program conducted could change.

Similarly, if a community is experiencing an economic decline so that family incomes are depressed, there may be a greater need for housing code enforcement and hence, a larger budget. Thus, this study enables practitioners to gain from the aggregated experiences of other housing code officials and indicates areas for comparison and possible improvement in their own agency's functioning and budgeting.

This research was supported through Hatch Funds, Project 411 "Implications of Housing Codes for Families and Rural Communities."

Special thanks is given to Jennifer Gerner, Assistant Professor, Department of Consumer Economics and Housing, New York State College of Human Ecology, Cornell University, Ithaca, New York for her helpful comments on the paper. 


\title{
SESSION 2B - ENERGY CONSERVATION AND \\ THE BUILT ENVIRONMENT
}

\author{
Moderator: Jack Kerin \\ Chief, Division of Codes and Standards \\ Department of Housing and Community \\ Development \\ 921 10th Street \\ Sacramento, California
}





\section{DEVELOPMENT AND EVALUATION \\ OF SOLAR STANDARDS AND CRITERIA}

\section{by}

Robert D. Dikkers

Group Leader, Solar Technology

Center for Building Technology

National Engineering Laboratory

National Bureau of Standards

Washington, D.C.

Many organizations, including the National Bureau of Standards (NBS), American Society of Heating, Refrigerating and Air-Conditioning Engineers and the American Society for Testing and Materials, have been very active during the past several years carrying out activities relating to the development of standards and performance criteria for solar heating and cooling applications. This paper, which describes various activities and accomplishments to date pertaining to the development and evaluation of solar heating and cooling standards and criteria, updates previous information presented by the author at the First NBS/NCSBCS Joint Conference held in 1976.

Key Words: Buildings; cooling; durability/reliability; performance criteria; safety; solar collectors; solar energy; standards; thermal performance 
Considerable progress is being made in the development of standards and criteria which will help provide a sound base for a viable solar heating and cooling industry. The purpose of this overview paper is to describe some of the major program efforts which are underway in both the public and private sectors to develop and evaluate such standards and criteria, and to outline some of the related accomplishments which have been achieved during the past few years.

A number of key objectives to help stimulate the use of solar energy are specified in the DoE National Program Plan for Solar Heating and Cooling of Buildings (DoE/CS-0007, July 1978). One of these objectives relates to the development of solar performance standards and criteria, with appropriate provisions for consumer protection. Another objective pertains to the availability of accredited private sector testing facilities. A major emphasis of National Bureau of Standards (NBS) efforts during the past five years has been working with the Department of Energy (DoE), the Department of Housing and Urban Development (HUD) and other members of the building community to help accomplish these objectives.

\section{STANDARDS DEVELOPMENT, EVALUATION AND IMPLEMENTATION}

Prior to examining specific standards activities, it is important to have some understanding and appreciation for the overall steps in the process of accelerating the development, evaluation and implementation of solar standards and criteria. The first step in this process

(Figure 1) is to identify needed standards and set priorities for their development. Plans to identify such needs and priorities have been developed by NBS in conjunction with the American National Standards Institute (ANSI) Steering Committee on Solar Energy Standards Development $[1,2]$.*

An important second step (Figure 1) to accelerate the development of standards is the preparation of proposed or draft standards for review and comments. Many of the NBS solar projects will result in the publication of proposed standards which are submitted to standardswriting organizations such as the American Society for Testing and Materials (ASTM) and the American Society of Heating, Refrigerating and Air-Conditioning Engineers (ASHRAE) for consideration and processing into national consensus standards. An example of this activity was the NBS work [3] which aided in the development of ASHRAE Standard 93-77, "Methods for Testing to Determine the Thermal Performance of Solar Collectors."

*Numbers in brackets [ ] refer to references at the end of this paper. 
The third step (Figure 1) is the development of consensus standards. Some consensus standards may take many months or several years to develop because of the lack of adequate technical data, the existence of sound but conflicting points of view, etc. Regardless of time delays, the consensus standards development process is an extremely important step because it permits direct input from all interested parties--designers, consumers, industry representatives, regulatory officials, etc.

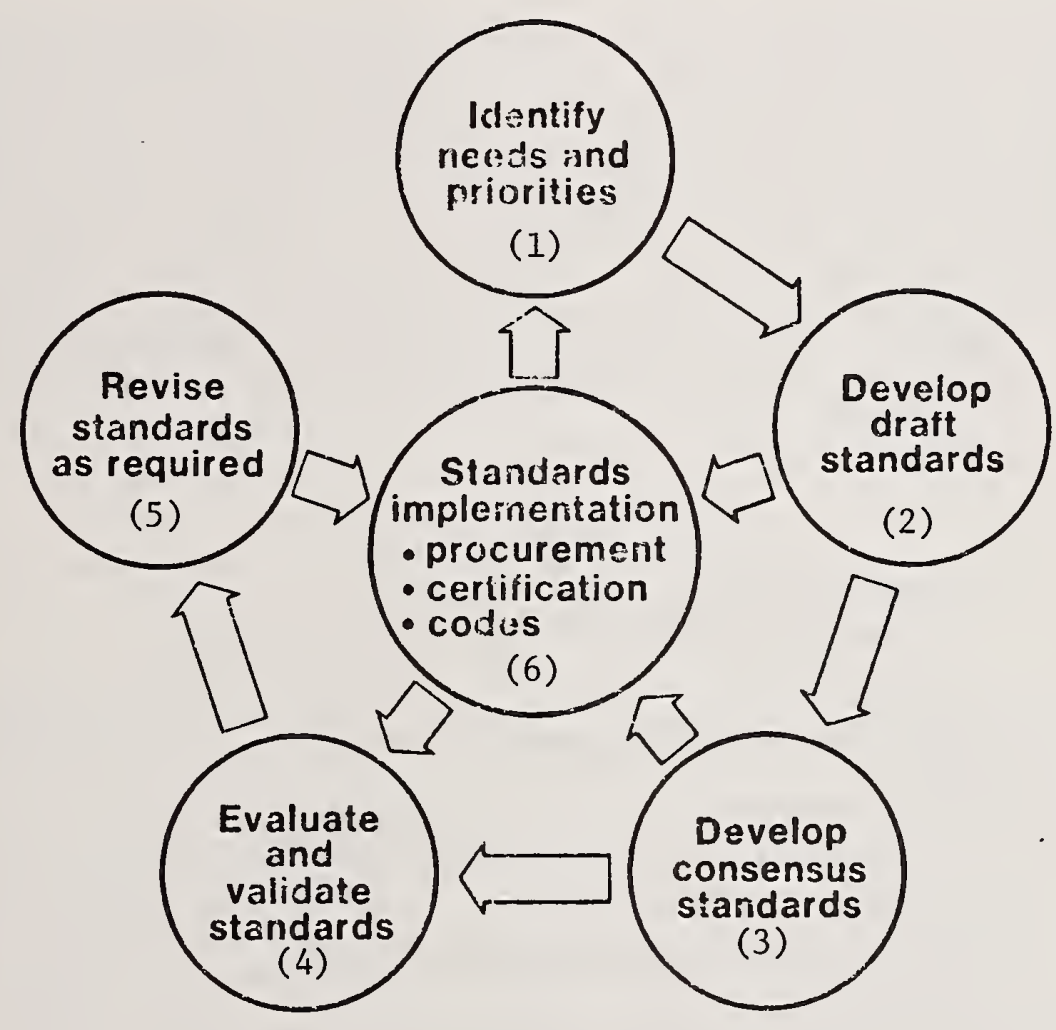

FIGURE 1 - Standards Development, Evaluation and Implementation

After draft or consensus standards are promulgated, the need for evaluating and validating such standards continues (Step 4). In the area of a new or rapidly growing and changing technology such as solar energy, the evaluation and validation process is vital. As necessary, such standards should be revised as better data and information becomes available (Step 5). Feedback from the DoE National Solar Data Program is being utilized by NBS and various standards-writing organizations to assist in the revision of standards and performance criteria. 
When voluntary standards are utilized in procurement specifications, certification programs and regulatory code documents, at the Federal, State and local level, the standards implementation step (Step 6) has been completed. However, the overall standards development, evaluation and implementation process is a continuous and interactive process and should receive the continued attention it deserves. In regard to solar heating and cooling applications, various activities are underway in all of these standards development, evaluation and implementation steps.

A matrix or list of needed solar standards can be developed from the general outline shown in Figure 2. It includes a consideration of various technologies, applications, performance areas, physical elements, etc. Although the emphasis in this paper is on heating and cooling, DoE, in cooperation with various organizations, is also developing standards and criteria for other solar technologies (i.e., photovoltaics, biomass). The remainder of this overview paper describes solar heating and cooling systems, components and materials standards activities from the standpoint of three performance attributes--thermal, durability/ reliability and safety.

- Technologies

- Heating/Cooling/Photovoltaics/Biomass

- Applications

- Residential/Commercial/Industrial

- Performance

- Thermal/Reliability/Durability/Safety

- Physical elements

- Materials/Components/Systems

- Procedural

- Design/Installation/Operation

- Acceptance

- Testing/ Lab accreditation/Certification

FIGURE 2 - General Outline of Needed Solar Standards

THERMAL PERFORMANCE STANDARDS

Collectors. As previously described, a test standard to measure the thermal performance of solar collectors has been developed. Since the publication of this standard (ASHRAE 93-77), the evaluation and development of thermal test standards has continued. ASHRAE has recently completed and approved ASHRAE Standard 96 which will contain procedures for the testing of unglazed solar collectors. NBS work on evaluating 
ASHRAE 93 in regard to concentrating collectors is also continuing. In conjunction with Wyle Laboratories, NBS has recently completed an experimental study in which various heat transfer fluids were examined to determine the effects of their properties and flow rates on the thermal performance of several different types of collectors. In 1978 and 1979, NBS completed and published results of continuing DoE sponsored collector research studies designed to improve and experimentally verify thermal performance test procecures $[4,5]$.

Earlier this year, NBS completed a study comparing experimental test results determined in accordance with the German BSE and ASHRAE procedures for five flat plate liquid collectors [6]. In the BSE procedures, the thermal loss characteristics of the collector are determined under indoor laboratory conditions. Such testing reduces the required test time by minimizing the dependence of testing upon outdoor weather conditions and also improves the reproducibility of test results because testing can be carried out under controlled laboratory conditions. For all five flat plate collectors tested, the differences between the efficiency curves determined by using the BSE and ASHRAE collector test procedures were less than the total uncertainty associated with the ASHRAE Standard 93-77 curves. Investigation of these collector test methods and the use of solar simulators is being conducted in support of International Energy Agency activities to develop acceptable worldwide test methods.

Collector Ratings. In November 1978, the ANSI Solar Standards Steering Committee established an ad hoc committee consisting of ASHRAE, Air-Conditioning and Refrigeration Institute (ARI), Solar Energy Institute Association (SEIA) and Solar Energy Research and Education Foundation (SEREF) to work toward the establishment of a national thermal performance rating standard for solar collectors. To the greatest extent possible, such a rating standard for solar collectors should apply to a broad range of use applications (i.e., hot water, heating, etc.) and climatic regions. It should also provide fair and reproducible rating values for use by designers, manufacturers, installers and consumers. The establishment of the previously mentioned ad hoc committee was prompted by the current existence of four different methods for rating solar collectors. All four methods--two developed by industry (ARI and SEIA) and two developed by States (Florida and California)--although somewhat different in their approach, utilize ASHRAE 93-77 as the basic test procedure. Because of the importance of this activity, NBS, with DoE support, is currently providing technical assistance to the ANSI ad hoc committee.

Testing Laboratory Evaluation. Another important activity being conducted in regard to solar collector thermal performance standards is the identification and evaluation of qualified testing laboratories. The initial effort to identify qualified testing laboratories was 
carried out by the Air-Conditioning and Refrigeration Institute Foundation (ARIF) and was summarized by NBS in a report published in November 1978 [7]. Subsequently, SEREF was given an additional contract task by DoE to conduct intercorrelation measurement checks (i.e., solar radiation, temperature, flow, data acquisition) at laboratories participating in the DoE interim collector testing program.

Storage Devices. A test standard to measure the thermal performance of storage devices has also been completed. The development of this standard, ASHRAE 94-77, was accelerated using a draft standard developed by NBS $[8,9]$. Studies to evaluate ASHRAE Standard 94 have also been completed. The results of these studies carried out on water storage tanks, pebble beds and phase-change devices were published by NBS in October 1978 and May 1979 [10,11].

Hot Water Systems. NBS has been conducting a solar hot water system testing program for DoE. One of the purposes of this program is to provide data for the validation of current, widely used computer programs and involves the collection of detailed performance data on six instrumented solar domestic hot water systems over a twelve-month period. Test results from this study, including data collected during the first eight months of operation of these systems, was recently presented at the International Solar Energy Society meeting held in Atlanta [12]. In general, the results to date indicate that the current computer programs (i.e., F-Chart, Solcost) predict long-term performance reasonably well.

The second objective of this hot water system test program is to assist ASHRAE Project Committee 95 in the development of a test standard for packaged residential solar hot water systems. The proposed ASHRAE test method allows for a separate test of a collector array and then inputting the appropriate thermal output of this collector array into the rest of the system through the use of a conventional energy source. This proposed ASHRAE standard will be available for public review and comments in September 1979.

Systems Evaluation. In conjunction with other government agencies, NBS developed a list of thermal performance factors with accompanying data requirements and measurement accuracies for use in the evaluation of systems and component performance [13]. This document has been used extensively in the National Solar Demonstration Program and an updated version has been accepted by the International Energy Agency Task Group for guidance in evaluating solar energy systems in Europe and Asia.

\section{DURABILITY/RELIABILITY STANDARDS}

Materials. In regard to durability/reliability standards, NBS completed a survey to assess materials performance in operating solar systems about 18 months ago [14]. This survey was very useful in 
identifying test standards which needed to be developed for a number of materials used in solar systems. The strategy to develop these materials standards is to identify approriate performance requirements and then to develop appropriate test methods to measure this performance. Draft standards which are being developed by NBS are being prepared in close cooperation with ASTM committees (E44 and D11). ASTM Committee D11 has approved two standard specifications covering rubber seals used in solar systems [15,16] based on NBS research [17] and has two other standards pertaining to rubber seals for use in solar systems under development. DoE sponsored materials standards projects currently underway at NBS pertain to cover plates, insulation, absorptive coatings, rubber hoses, and metallic and non-metallic containment materials.

NBS materials standards research work includes laboratory testing, and field testing in various containers designed to simulate the high stagnation temperatures and other exposure conditions that solar collector materials will experience under actual in-use conditions. Where possible, such field and laboratory testing is also being correlated with observations and data gathered from DoE and HUD solar demonstration projects.

Collectors. Work is also underway at NBS and ASTM to develop durability/ reliability standards for collectors. Test data from the DoE interim testing program, which involves approximately 150 collectors, will be very useful in validating a number of test procedures (i.e., ASHRAE 93-77, thermal shock, 30-day stagnation) which have been developed to date. It will also provide valuable information to assist in the development of industry rating and certification programs.. The current DoE collector testing program also includes various other provisional tests (i.e., rain, thermal cycling, structural, fire, hail) [18] which will be conducted on a smaller number (approximately 25) of collectors. Such data will provide a basis for developing other related durability/ reliability test standards.

Late last year, NBS initiated a comprehensive test program with DoE which will be very useful in evaluating current test procedures for predicting collector durability/reliability [19]. In this program, eight different collector types, along with associated small materials specimens, will be tested. Testing of these collectors and materials is now underway at test sites located in Arizona, California, Florida and Maryland. These sites were picked to examine a reasonably broad range of climatic factors. In the NBS durability/reliability test program, collector thermal performance will be determined after $3,15,30$, 60,120 and 240 days of stagnation. Currently, the 30-day stagnation test for solar collectors has been widely used. Test data collected in this program should be useful in determining collector thermal performance degradation relationships between field and laboratory tests and assessing the validity of the stagnation test exposure conditions. 
Collectors. Structural and fire tests of collectors wnich will be carried out in the DoE interim collector testing program will provide data for development of needed safety standards. In regard to collector Underwriters' Laboratories (UL) is also developing a product standard which will address safety. A draft of the proposed UL standard is expected to be available for public review and comment by September 1979 .

Heat Exchangers. The American Society of Mechanical Engineers (ASME) is currently developing a standard which will address safety requirements pertaining to residential liquid-to-liquid heat exchangers. Their current approach is to classify heat transfer fluids into different groups according to their toxicity and then to define the different heat exchanger designs which are required for these various fluid groups.

\section{PERFORMANCE CRITERIA}

The development of interim and definitive performance criteria for solar heating and cooling systems was mandated in the Solar Heating and Cooling Demonstration Act of 1974. The development of these criteria and related evaluation procedures, as well as the HUD Intermediate Minimum Property Standards for Solar Hot Water and Heating Systems and the Model Solar Code Document being prepared by the Council of American Building Officials ( $C A B O)$, are to a large extent dependent upon the availability of consensus standards.

The various performance criteria and intermediate standards developed by NBS for DoE and HUD have been used as a technical base for evaluating systems in the residential and commercial demonstration programs $[20,21,22]$. In developing definitive performance criteria for solar systems, NBS is, therefore, attempting to utilize all available data and information which are being collected from demonstration projects by DoE, HUD, NÁSA, Argonne National Laboratory and various DoE and HUD demonstration program support contractors. These data, and data from DoE research and development projects form an important data base for both solar standards and performance criteria development.

Definitive performance criteria documents for residential and commerical solar systems are scheduled to be completed by NBS in December 1979. It is recognized, however, that since all data will not be collected and all needed consensus standards will not be completed by December 1979, there is a vital need to continue active work on solar heating and cooling standards and performance criteria into the early $1980^{\prime} \mathrm{s}$. 


\section{CONCLUSION}

Since solar performance criteria and standards are and will continue to be used in a number of new and continuing Federa1, State and local solar programs, it is important to continue the development and evaluation of solar performance criteria and standards which will aid and accelerate the establishment of a viable solar heating and cooling industry.

\section{REFERENCES}

1. Waksman, D., Pielert, J., Dikkers, R., Streed, E., "Plan for the Development and Implementation of Standards for Solar Heating and Cooling Applications," NBS Report NBSIR 76-1143, August 1976.

2. Waksman, D., Pielert, J., Dikkers. R., Streed, E., Niessing, W., "Plan for the Development and Implementation of Standards for Solar Heating and Cooling Applications," NBS Report NBSIR 78-1143A, June 1978.

3. Hil1, J., Kusuda, T., "Method of Testing for Rating Solar Co1lectors Based on Thermal Performance," NBS Report NBSIR 74-635, December 1974 .

4. Streed, E., Thomas, W. C., Dawson III, A., Wood, B., Hill, J., "Results and Analysis of a Round-Robin Test Program for LiquidHeating, Flat-Plate Solar Collectors," NBS Technical. Note 975, August 1978 .

5. Hil1, J., Jenkins, J., Jones, D., "Experimental Verification of a Standard Test Procedure for Solar Collectors," NBS Building Science Series 117, January 1979.

6. Jenkins, J., "A Comparison of Test Results for Flat-Plate Water Heating Solar Collectors Using the BSE and ASHRAE Procedures," Proceedings of the 1979 International Congress of the International Solar Energy Society, Atlanta, GA, May 28-June 1, 1979.

7. Niessing, W., "Laboratories Technically Qualified to Test Solar Collectors in Accordance with ASHRAE Standard 93-77: A Summary Report," NBS Report NBSIR 78-1535, November 1978.

8. ASHRAE Standard 94-77, "Methods of Testing Therma1 Storage Devices Based on Thermal Performance."

9. Kelly, G., Hil1, J., "Method of Testing for Rating Thermal Storage Devices Based on Thermal Performance," NBS Report NBSIR 74-634, May 1975. 
10. Hunt, B., Richtmyer, T., Hil1, J., "An Evaluation of ASHRAE Standard 94-77 for Testing Water Tanks for Thermal Storage," NBS Report NBSIR 78-1548, October 1978.

11. Jones, D., Hill, J., "Testing of Pebble-Bed and Phase-Change Thermal Energy Storage Devices According to ASHRAE Standard 94-77," NBS Report NBSIR 79-1737, May 1979.

12. Fanney, A. H., Liu, S., "Experimental System Performance and Comparison with Computer Predictions for Six Solar Domestic Hot Water Systems," Proceedings of the 1979 International Congress of the International Solar Energy Society, Atlanta, GA, May 28June 1, 1979.

13. Streed, E., McCabe, M. , Waksman, D., Hebrank, J., Richtmyer, T., "Thermal Data Requirements and Performance Evaluation Procedures for the National Solar Heating and Cooling Demonstration Program," NBS Report NBSIR 76-1137, August 1976.

14. Skoda, L., Masters, L., "Solar Energy Systems - Survey of Materials Performance," NBS Report NBSIR 77-1314, October 1977.

15. ASTM Standard D3667-78, "Specification for Rubber Seals Used in Flat Plate Solar Collectors."

16. ASTM Standard D3832-79, "Specification for Rubber Sea1s Contacting Liquids in Solar Energy Systems."

17. Stiehler, R., Hockman, A., Embree, E., Masters, L., "Solar Energy Systems-Standards for Rubber Seals," NBS Report NBSIR 77-1437, March 1978.

18. Waksman, D., Streed, E., Reichard, T., Cattaneo, L., "Provisional Flat Plate Solar Collector Testing Procedures: First Revision," NBS Report NBSIR 78-1305A, June 1978.

19. Streed, E., Waksman, D., "The NBS Solar Collector Durability/ Reliability Program," First International Conference on Durability of Building Materials and Components, Ottawa, Canada, August 1978.

20. "Interim Performance Criteria for Solar Heating and Cooling Systems in Commercial Buildings," prepared for ERDA by NBS, NBS Report NBSIR 76-1187, November 1976.

21. Holton, J., et al, "Interim Performance Criteria for Solar Heating and Cooling Systems in Residential Buildings - Second Revision," NBS Report NBSIR 78-1562, November 1978.

22. "Intermediate Minimum Property Standards Supplement - Solar Heating and Domestic Hot Water Systems," 4930.2, U.S. Department of Housing and Urban Development, 1977. 


\title{
THERMAL MASS EFFECTS IN LOG HOMES
}

\author{
by \\ William Magruder \\ and \\ Steven Winter \\ Steven Winter Associates, Inc. \\ New York, New York
}

To improve thermal standards for log homes, certain adjustment factors must be established to account for the effects of thermal mass. Alternative definitions for these factors are presented as the "mass factor" and the " $\Delta \mathrm{R}$ effect." These factors will be a function of at least six parameters, which are discussed here in terms of their relevance to $10 \mathrm{~g}$ homes. The six parameters of concern are wall mass, wall color, location of mass, air infiltration, HVAC set-point schedule, and climate. The paper concludes with a summary of the results of a BLAST computer analysis of a $\log$ home in Des Moines.

Key words: BLAST; effective U-value; heat capacity; log home; mass factor; $\Delta \mathrm{R}$ effect; thermal mass. 
Log homes are enjoying increasing popularity as a result of the industrialization of their production. Their popularity makes it important to know how their thermal performance compares with conventional construction. To account for the possibility that heat storage in $\log$ walls significantly effects either peak or average thermal loads, it is necessary to consider dynamic rather than steady state conditions. A number of studies on what has come to be known as "thermal mass" provide suggestions for the thermal evaluation of log walls. Most of these studies have been focused on masonry and concrete buildings. Some masonry structures, built centuries ago, employ their thermal mass with such effectiveness and such economy, that we feel instructed by the sensibility of primitive builders working with indigenous materials. The success with which adobe has been used in desert regions is a famous example. Like adobe, log construction has an ancient history to recommend it. Log construction seems to have originated in pre-historic Sweden, where its popularity over many centuries attests to its viability in cold climates. The question is, can log homes still compete with alternative building systems in terms of thermal performance? This paper presents the beginnings of an answer to that question.

Log homes today bear only superficial resemblance to their ancestors. Before proceeding, it is necessary to establish what " 1 og home" now means. Most $\log$ homes are no longer made "by hand" but are pre-cut in a factory where their production is, to some extent, industrialized. The industrialized sector of the 1 og homes industry includes about 100 of the estimated $250 \mathrm{log}$ home producers in the country. The total number of units delivered by all log home producers in 1977 is estimated at over $30,000,80$ percent of which are used as primary residences. The largest log home manufacturer has produced as many as 2,200 homes in a single year. Neither production nor placement of log homes is concentrated in any single region of the country. Because producers are widely distributed across the United States, and because log home packages can be transported great distances without damage, it is now possible to place log homes in any city in the country. This means that $10 \mathrm{~g}$ homes are now going into a wide variety of climates, including extremes of hot-dry and hot-humid as well as the colder climates in which 1 og homes first evolved. Just as "log home" does not connotate any place or climate, it is not associated with just one type of wall, but many. Log walls differ in species of wood, thickness, section profile, and joint detail. Some walls are intended to look very rustic, others very finished.

In spite of differences in their products, log home manufacturers share a common problem: to meet stringent U-value prescriptions without compromising the "solid" character of the $\log$ wall, it may be necessary to beef up the thermal resistance of floors, ceilings, and windows. Many manufacturers feel that the extra insulation required has not proven cost-effective. Their surveys of energy use in log homes have tended to indicate that $\mathrm{R}$-values are not a good basis of predicting $1 \mathrm{og}$ home thermal performance. Two years ago, the Log Homes Council, the 
industry's main trade association and a branch of the National Association of Home Manufacturers, resolved to find better ways to evaluate the thermal performance of $10 \mathrm{~g}$ homes. This led them into participation with two major research organizations: ASHRAE and NBS.

ASHRAE Standard Project Committee 104P was formed at the request of the Log Homes Council. The objective of this committee is to produce a standard compatible with ASHRAE Standard 90-75, which will determine appropriate U-value adjustment factors for $\log$ homes. The scope of the Committee has been enlarged to include all heavyweight wall materials. Committee $104 \mathrm{P}$ proposes to develop its standard through a comprehensive computer study.

At the National Bureau of Standards, the Log Homes Council will participate in field tests of six $20 \mathrm{ft}$. x $20 \mathrm{ft}$. structures, one of which will have log walls. The log walls will be designed to be as nearly "typical" as possible. The energy requirements of the test structures will be monitored over a one year period. These will be the most extensive thermal tests of a log building ever carried out.

The ASHRAE and NBS studies share the same goals and face similar problems. Both studies seek to generate factors that have previously been defined as "Effective U-values," "mass factors," and " $\Delta \mathrm{R}$ effects." Some clarification of these terms is called for. Mass factors and Effective U-values are generally defined in terms of a ratio of the energy consumption associated with a certain U-value and certain thermal mass effects, divided by the energy consumption associated with the same U-value but with thermal mass neglected. The " $\Delta \mathrm{R}$ effect" refers to the change in $\mathrm{R}$-value that must accompany a change in thermal mass, in order to hold energy consumption constant. It is important to note that the $\Delta \mathrm{R}$ effect can be relatively large, even when the mass factor is considered to be small. This is apparent in curves generated by the Portland Cement Association that plot the energy consumption of heavy and lightweight walls over a range of R-values (Figure 1). Energy codes that equate "acceptable" levels of thermal performance with U-value or R-value prescriptions can use the $\Delta \mathrm{R}$ factor to account for thermal mass effects. In addition to the improvement of codes and standards, thermal mass research should also contribute to the development of passive solar design tools.

Mass and $\Delta \mathrm{R}$ factors have been difficult to put into widespread use because they tend to be sensitive to changes in a number of variables. Not only does a wall have one $\Delta \mathrm{R}$ in $\mathrm{St}$. Louis and another in Los Angeles, it is also likely that this factor will change with its color, orientation, and other variables that will be reviewed here. The mass factors developed by the Masonry Industry Committee in 1976 constitute a "first generation" of results that are presented as a function of on $1 y$ two variables: wall-weight and degree days (Figure 2). The next generation of mass factors will require a more complicated format for selection, as they will be tied to more detailed information about the building envelope and climate. Based on past research, we can predict with some confidence what variables will most influence thermal mass effects. 

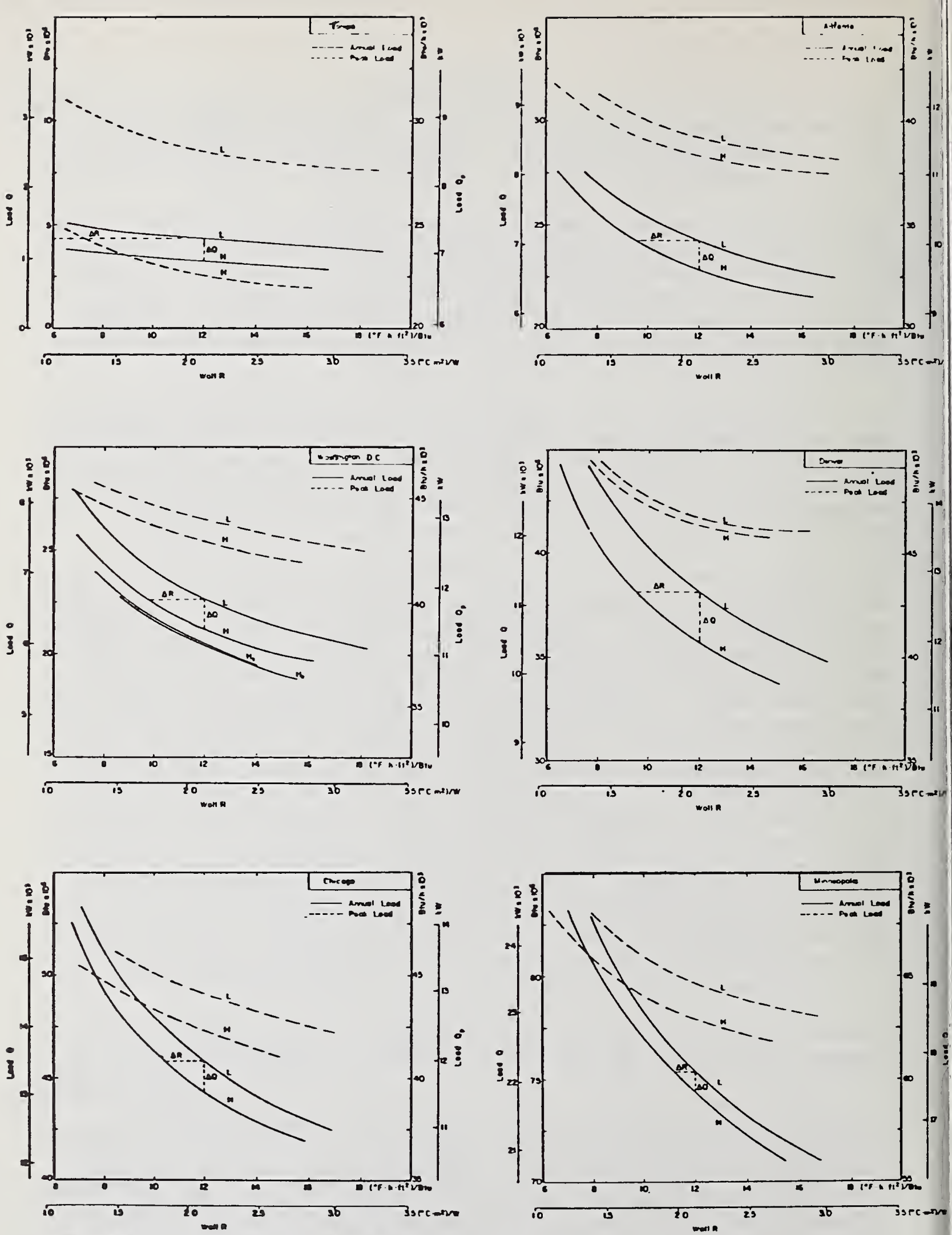

The effect of wall $\mathrm{R}$ values on peak and annual heating loads. L (lightweight) walls are compared with $\mathrm{H}$ (heavyweight) walls at six cities, representative of the results from all studies made.

Figure 1 


\section{Capacity Insulation Correction Graph}

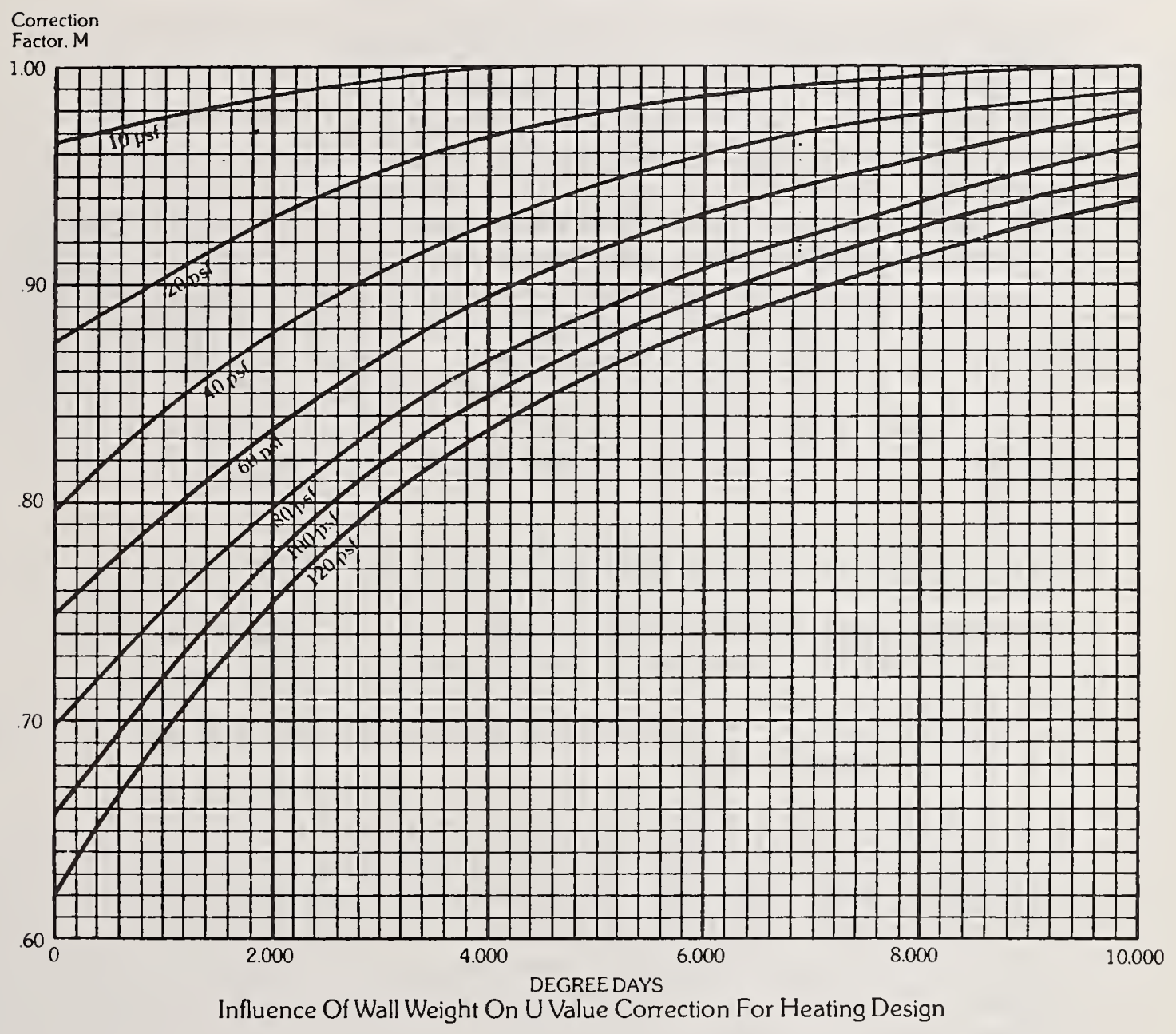

Figure 2 
Each of these shall be discussed here in terms of its impact on 1 g home thermal performance.

\section{REVIEW OF THERMAL MASS PARAMETERS}

\section{Wall Mass}

As a factor influencing thermal performance, the "massiveness" of a wall can be measured in many different ways. Typical measures of massiveness are presented here (Figure 3) in order to show that wall weight (in $1 \mathrm{bs} / \mathrm{ft}^{2}$ ) and wall heat capacity (in BTU/ft ${ }^{\circ}{ }^{\circ} \mathrm{F}$ ) are not necessarily a good indicator of thermal mass. A wall's thermal performance depends not only on its mass and heat capacity, but also on its conductance, so thermal mass is perhaps best measured by a quality like "time lag," which combines all three of these. Comparing solid wood walls to concrete walls of the same thickness, we find that wood walls have over twice the time lag even though they appear to be much less massive in terms of weight and heat capacity. Even when $l o g$ walls are very light and thin, such as a 4 inch cedar wall weighing $7 \mathrm{lbs} / \mathrm{ft}^{2}$, they can be shown to have over twice the time $1 \mathrm{ag}$ of 2 × 4 frame walls of approximately equal weight.

If we focus just on the wood walls of Figure 3, we see that:

1. Large differences in wall weight and heat capacity do not correspond to equally large differences in time lag;

2. the log wall with the highest $\mathrm{R}$-value is the 1 og wall with the lowest thermal mass.

The species and moisture contents of Figure 3 were selected to establish the widest range of values possible for a particular wall thickness. More typically, the in-service moisture content of $10 \mathrm{~g}$ walls will average between 9 and 12 percent, depending on geographic location.* Seasonal or short-term deviation from the average moisture content is not great enough to significantly change properties like conductivity and time lag. For these reasons, it will probably be sufficient to calculate the thermal performance of all 1 og species at a constant moisture content. At 12 percent moisture content, for example, time lag changes little from species to species, ranging from 8.4 hours, for 6 inches of Northern White Cedar, to 8.9 hours for the same thickness of Southern Yellow Pine. We can summarize all of this by saying that all species of wall-1ogs have about the same thermal mass.

* Moisture content of wood is defined as the weight of the water in the wood expressed as a fraction of the weight of ovendry wood. 


\section{COMPARATIVE THERMAL MASS INDICES}

\begin{tabular}{|c|c|c|c|c|c|c|c|}
\hline & $\underset{k}{\text { Conductivity }}$ & $\begin{array}{l}\text { Density, } \\
\text { D }\end{array}$ & $D(.5 \mathrm{ft})$. & $\begin{array}{c}\text { Heat } \\
\text { Capacity, } \\
\text { C }\end{array}$ & $D(.5 f t) c$ & $\begin{array}{c}\text { Diffusivity } \\
\mathrm{d}=\frac{\mathrm{k}}{\mathrm{D} c}\end{array}$ & $\begin{array}{l}\text { Time Lag } \\
t=\frac{(.5 \mathrm{ft})}{2} \sqrt{\frac{24}{\pi \mathrm{d}}}\end{array}$ \\
\hline & $\frac{B T U}{h r f t \cdot 2\left(\frac{O F}{f t}\right)}$ & $\frac{1 \mathrm{bs} .}{\mathrm{ft} .3}$ & $\frac{1 \mathrm{bg} .}{\mathrm{ft} \cdot \mathrm{g}^{2}}$ & $\frac{\mathrm{BTU}}{1 \mathrm{~b} . \mathrm{OF}_{\mathrm{F}}}$ & $\mathrm{ft} \cdot \frac{\mathrm{BTU}}{2 \mathrm{OF}}$ & $\frac{\mathrm{ft} .2}{\mathrm{hr} .}$ & \\
\hline $\begin{array}{l}\text { Northern White Cedar } \\
\text { (at os moisture content) }\end{array}$ & 0.050 & 20 & 10.0 & 0.30 & 3.0 & 0.00833 & 7.57 \\
\hline $\begin{array}{l}\text { Lodgepole Pine } \\
\text { (at } 16 \text { moisture content) }\end{array}$ & 0.075 & 29 & 14.5 & 0.42 & 6.1 & 0.00616 & 8.81 \\
\hline $\begin{array}{l}\text { Southern Yellow Pine } \\
\text { (at } 30 \text { molsture content) }\end{array}$ & 0.114 & 44 & 22.0 & 0.50 & 11.0 & 0.00518 & 9.60 \\
\hline Concrete & 1.0 & 140 & 70.0 & 0.2 & 14.0 & 0.0357 & 3.66 \\
\hline
\end{tabular}

Figure 3 
The effect of color on the thermal performance of 1 og walls has been investigated by Bickle, using a computer program to generate "Effective U-values" at three different solar absorbtivities (Figures 4, 5, 6, 7). Since the importance of color is expected to vary with the amount of available sunlight, Bickle has reported on a number of climates.

For each of the climates studied, the results show that heating loads associated with 1 og walls will be greatly affected by their color. The effects of color appear most dramatic in a place like Albuquerque, which has lots of sun; but they are also significant in very cold places like Bismarck, and very cloudy places like Seattle. Bickle finds that a we11-insulated frame wall is not influenced by color to the extent that the 1 og wall is. Those points where a curve for the $10 \mathrm{~g}$ wall (about R10) crosses a corresponding curve for the frame wal1 (about R16) establish the magnitude of the $\Delta R$ effect at a specific color and orientation. For example, in Seattle, the R $1010 \mathrm{~g}$ wall facing south, with an absorbtivity of 0.85 , will contribute the same heating 1 oad as the $\mathrm{R} 16$ frame wall with the same orientation and absorbtivity. In Albuquerque, this point of equivalent performance occurs at an absorbtivity of 0.25 . These findings apply only to heating loads, however, and the effect of color on total heating and cooling loads has yet to be determined. Further research is also required to establish the range of solar absorbtivities characteristic of 1 og walls.

3. Location of Mass Relative to Sun and Wall Insulation

We see from Bickle's graphs that a wall's location relative to the sun may strongly influence its thermal behavior (Figures 5, 6, 7). As would be expected, the heating load is lowest for those walls that see the most sun. Where the performance (i.e., "equivalent U-value") of the south facing log wall equals the performance of the south facing frame wall, we do not find the other orientations similarly related. This implies that the $\Delta \mathrm{R}$ effect changes with a wall's orientation. Bickle does not provide enough data to quantify the $\Delta \mathrm{R}$ for all orientations. Also, Bickle's approach yields a $\Delta R$ that is somewhat special. In order to isolate the performance of one particular orientation, the internal surface temperature of all other walls has been assumed to be constant, as though only the one orientation was "exposed." This means that Bickle's results may not accurately predict a wall's performance when it is one of many exposed surfaces, each with a different orientation. However, Bickle reports good correlation between his effective U-values and field measurements of in-service frame walls.

The location of mass is also important in terms of the amount of "internal mass." The internal mass of $10 \mathrm{~g}$ homes may be somewhat higher, on an average, than conventional homes, since their roofs 


\section{HEATING EFFECTIVE U-VALUES}

\begin{tabular}{|c|c|c|c|c|c|c|c|c|c|c|c|c|c|}
\hline \multirow[b]{3}{*}{ Location } & \multirow[b]{3}{*}{$\begin{array}{l}\text { Wall } \\
\text { Type** }\end{array}$} & \multicolumn{12}{|c|}{ wall Orientation } \\
\hline & & \multicolumn{3}{|c|}{ North } & \multicolumn{3}{|c|}{ East } & \multicolumn{3}{|c|}{ South } & \multicolumn{3}{|c|}{ West } \\
\hline & & $L^{*}$ & $M$ & $D$ & L & $M$ & $D$ & I & $M$ & $D$ & L & $M$ & $D$ \\
\hline Albuquerque & Erame & 0.066 & 0.062 & 0.057 & 0.063 & 0.055 & 0.046 & 0.060 & 0.045 & 0.031 & 0.064 & 0.057 & 0.049 \\
\hline Albuquerque & $\log$ & 0.094 & 0.076 & 0.057 & 0.082 & 0.047 & .0 .013 & 0.065 & 0.005 & -0.053 & 0.084 & 0.052 & 0.020 \\
\hline B1smarck & Frame & 0.062 & 0.060 & 0.058 & 0.061 & 0.057 & 0.053 & 0.059 & 0.053 & 0.048 & 0.061 & 0.058 & 0.054 \\
\hline Blomarck & Iog & 0.100 & 0.093 & 0.087 & 0.094 & 0.081 & 0.067 & 0.090 & 0.068 : & 0.053 & 0.095 & 0.033 & 0.070 \\
\hline Seattle & Frame & 0.069 & 0.067 & 0.064 & 0.069 & 0.065 & 0.061 & 0.067 & 0.062 & 0.056 & 0.069 & 0.065 & 0.060 \\
\hline Seattle & Log & 0.103 & 0.093 & 0.084 & 0.101 & 0.088 & 0.076 & 0.097 & 0.077 & 0.058 & 0.100 & 0.087 & 0.073 \\
\hline
\end{tabular}

"WALl corors, L - Light, solar Abgorptivity $=0.2$

M - Madium, Solar Absorptivity =0.5

D Dark, Solar Absorptivity =0.8

"WNLl TYPes, Frame - l" stucco, 1" Technifoam, 3-1/2" Batt, 1/2" Gypbd U = 0.062 BTU/hr. 9F ft. 2

Log - 7-1/4" Pine $U=0.099$ BTU/hr. ${ }^{\circ} \mathrm{F}$ ft. 2 


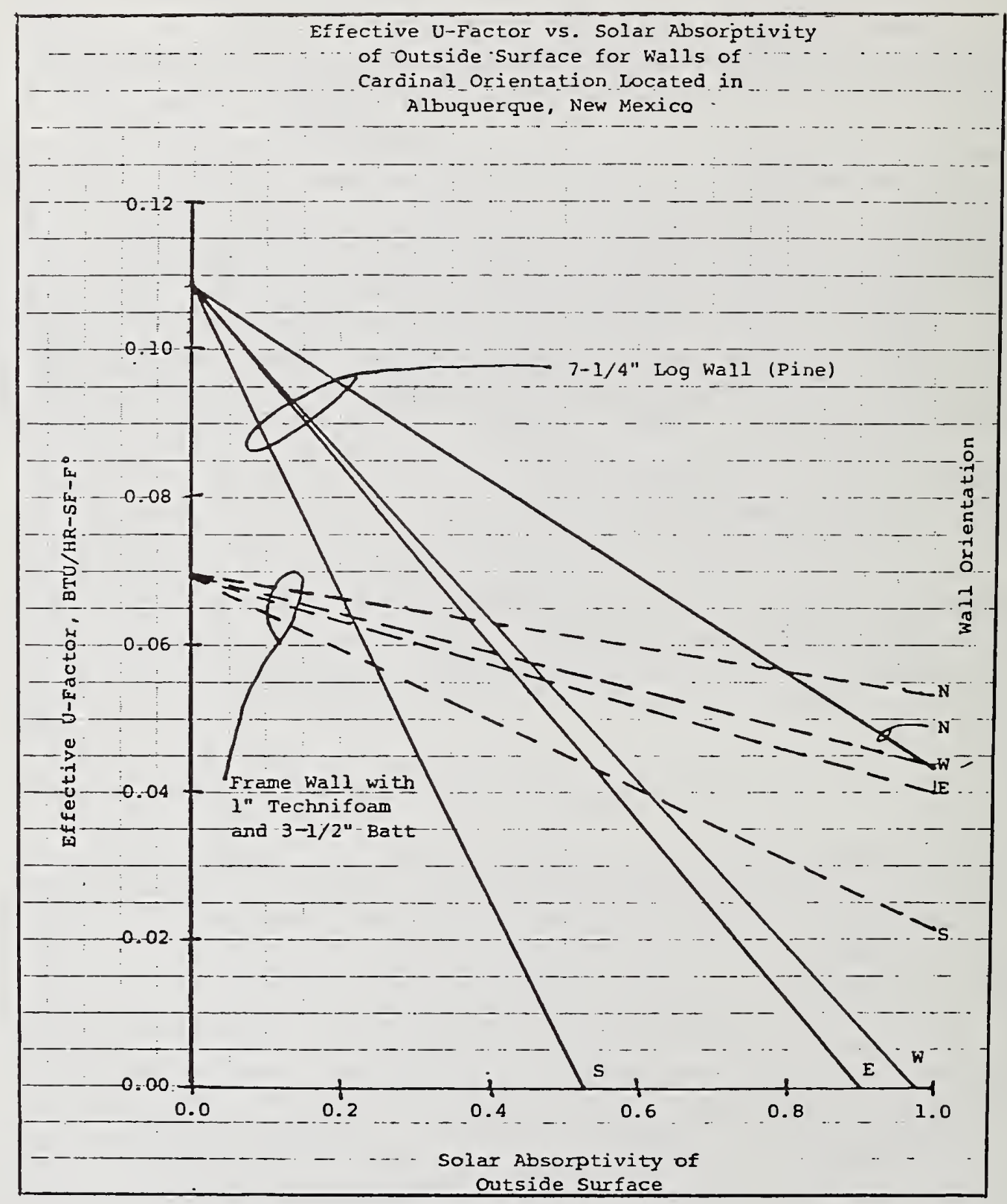

Figure 5 


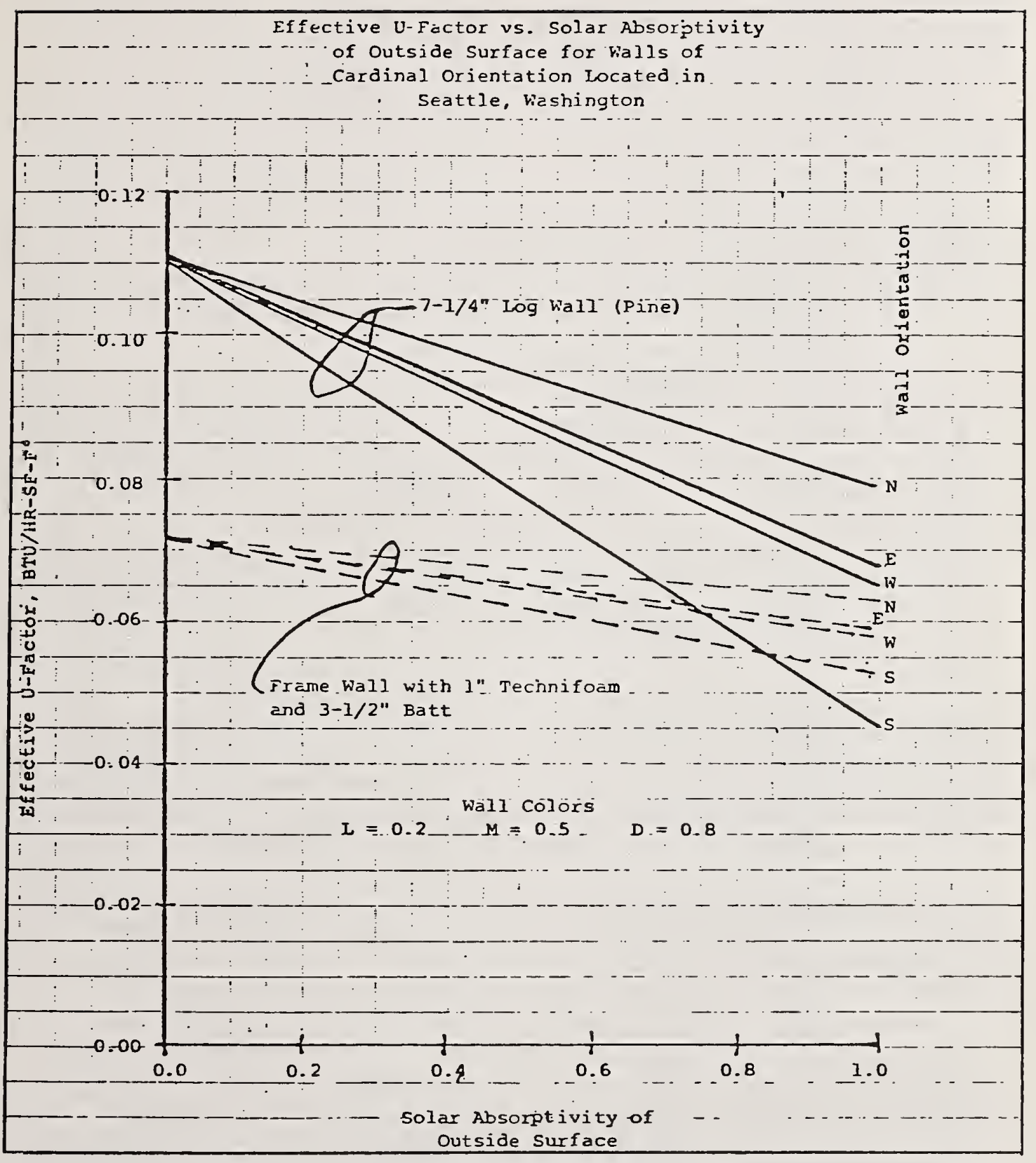

Figure 6 


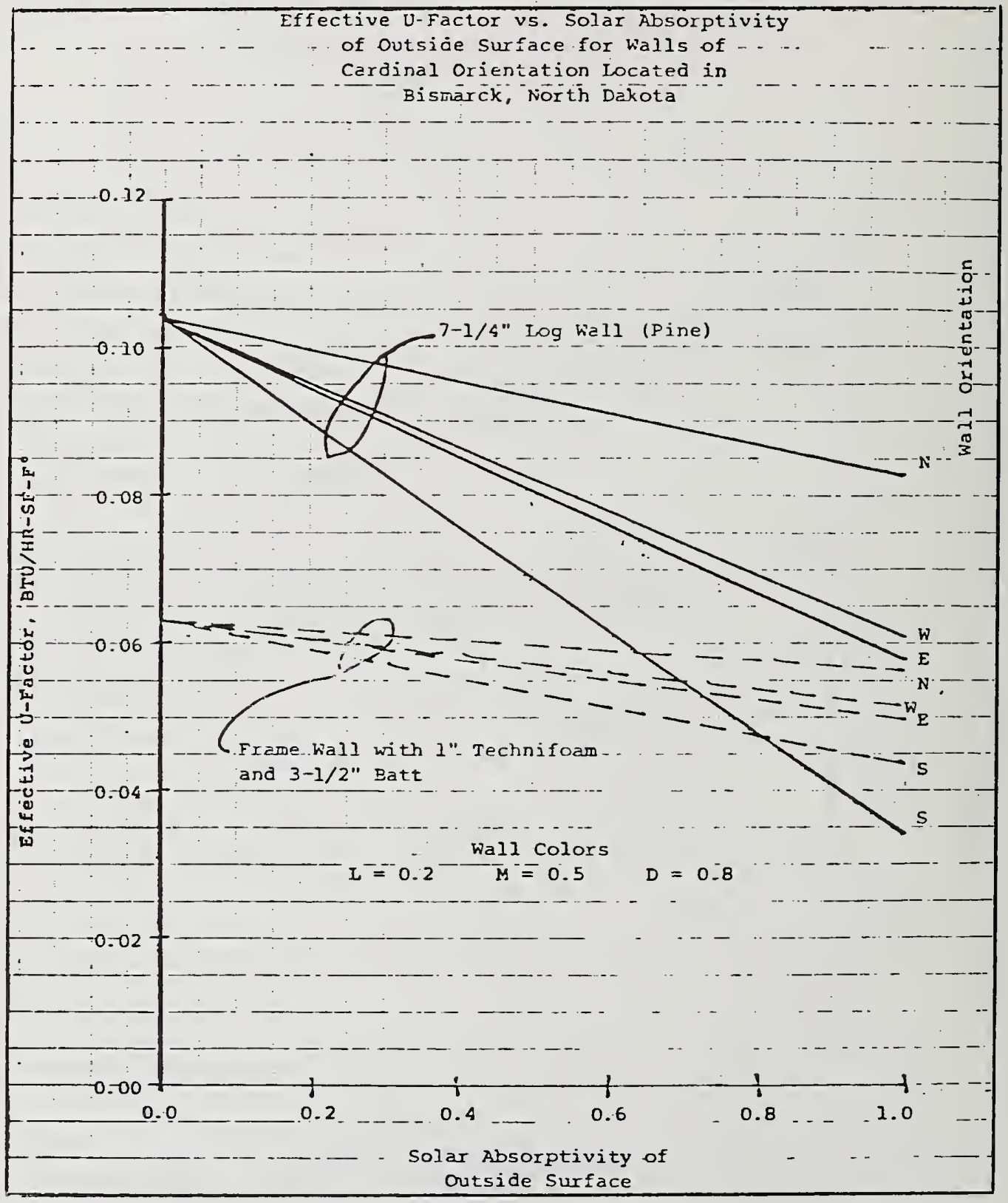

Figure 7 
and floors are often composed of heavy timbers supporting structural wood decking. In a timber frame house studied by the Bookhaven National Laboratory, the exposed post, beam, and deck structure was found to have a thermal storage capacity equal to that of the floor slab and chimney combined. Mitalas, in Canada, has identified the mass of the interior as one of the most important influences on the $\Delta \mathrm{R}$ effect. According to Mitalas, the buildings like log homes, where the wall-mass is in direct contact with the interior space, the $\Delta \mathrm{R}$ effect is found by adding the wall mass to the mass of the floor, partitions, furniture, etc. His graphs (Figure 8) predict that the $\Delta \mathrm{R}$ effect will be negligible at the low R-values of $10 \mathrm{~g}$ walls. However, it appears doubtful that these results can be applied to $10 \mathrm{~g}$ walls, since the mass of the wa11s is on 1 y characterized by its weight in $1 \mathrm{bs} . / \mathrm{ft}^{2}$. Another limitation of this study is that it is based on an average of Canadian climates only.

It may be that different climates call for different strategies in the location of thermal mass. 0lgyay formulated recommendations for arranging massive walls, lightweight walls, and internal masses to suit four different climate types (Figure 9). Log homes could be designed with such recommendations in mind. Where internal mass is desirable, log homes could replace conventional $2 \times 4$ interior partitions with solid log partitions. Thin 1 og walls could be used for some orientations, thick log walls could be used for others. These kinds of options have yet to be fully explored.

\section{Air-infiltration}

Very little is known about air-infiltration in log homes. Apparently, ful1-scale log homes have yet to be tested for air-tightness. Small one-space log structures and 1 og panels have been tested "in-house," but all data is proprietary and remains unpublished. The preliminary results of these tests have been summarized as follows:

1. The air-tightness of a $10 g$ wall relative to a $2 \times 4$ frame wall depends almost entirely on the care with which joints in the $10 \mathrm{~g}$ wall are caulked. A well caulked 1 og wall may be somewhat more air-tight than a frame wall, while a poorly caulked log wall can have twice the air-leakage of a frame wall.

2. Most air infiltration occurs at the corners of the 1 og wall. During one set of tests of a log structure, sealing the corner joints lowered infiltration by about $25 \%$.

3. Very little infiltration occurs through the vertical joint where two logs butt together.

In spite of a lack of test data, there is some reason to believe that air-infiltration is important to the determination of the $\Delta R$ of $10 \mathrm{~g}$ walls. The infiltration load is quite possibly independent of the R-value of the wall. If this is true, then as we increase 


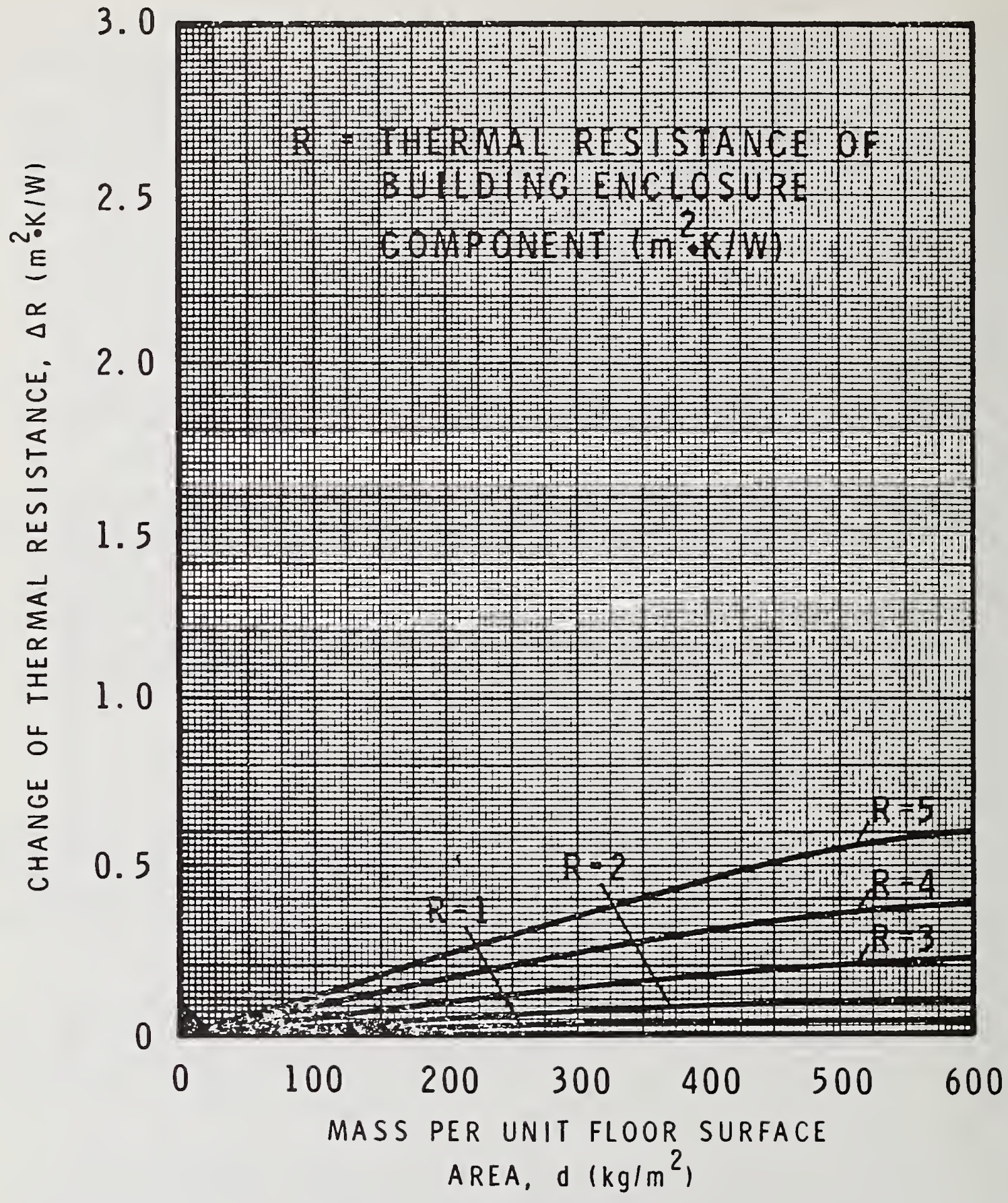

RELATION BETWEEN THERMAL RESISTANCE AND MASS OF BUILDING ENCLOSURE COMPONENT MASS LAYER IN DIRECT CONTACT WITH INTERIOR SPACE AIR TYPE OF ENCLOSURE: ENCLOSURE FOR BUILDING WITH A HIGH RATE OF HEAT LOSS RELATIVE TO INTERNAL HEAT GAIN

Figure 8 
CALE FOP. INSULATION VALUES

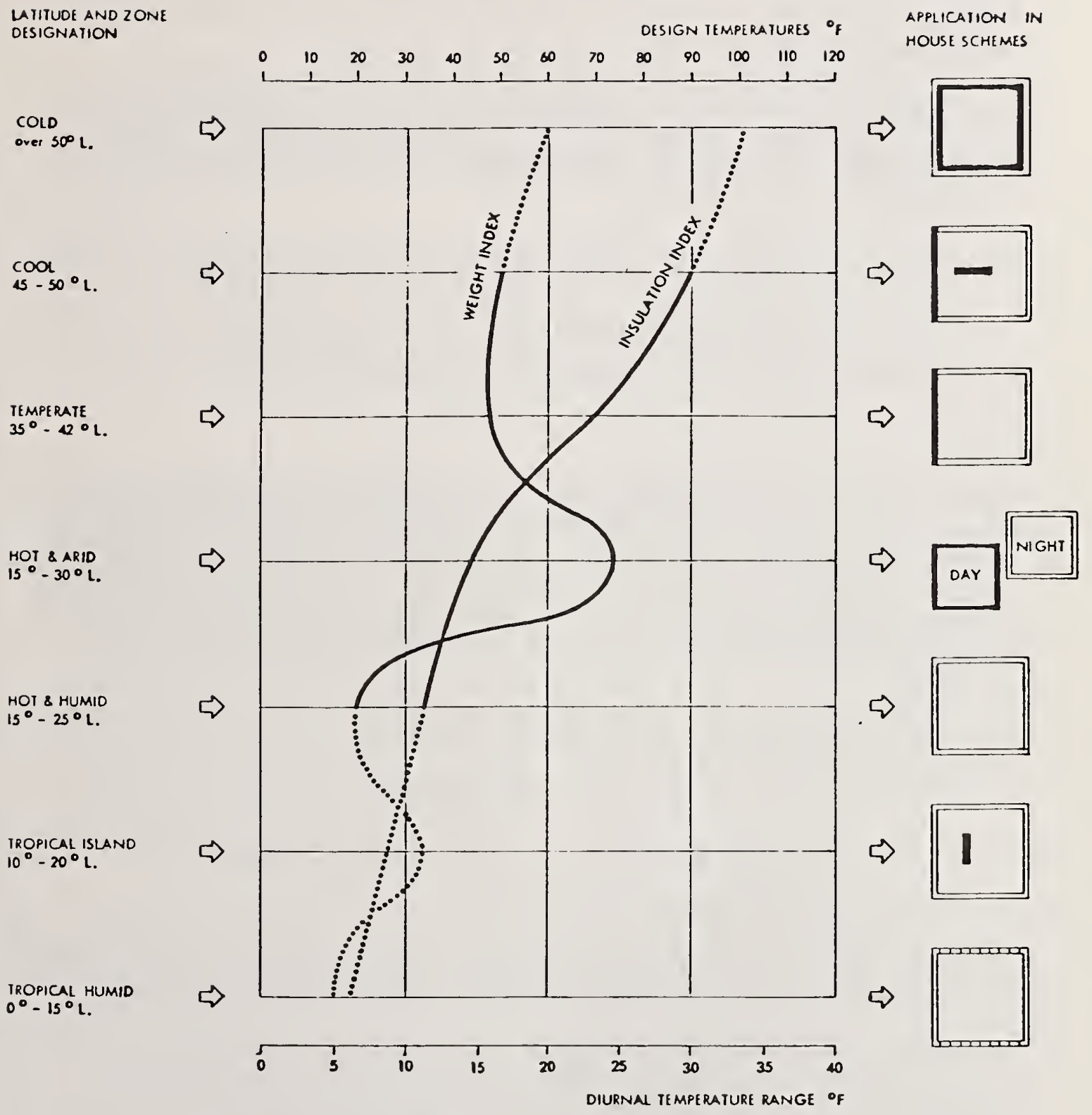

SCALE For LAG VALUES

Figure 9: Proper Location of Massive Walls (shown in black). 
or decrease the infiltration load, the total load will increase or decrease by the same amount, no matter what the R-value of the wall. Refering to the graphs of Figure 1, a change in the infiltration load would raise or lower the curves without changing their shape. Since these curves all have a decreasing slope with increasing $R$, these results are implied:

1. The $\Delta \mathrm{R}$ associated with a certain total load, will decrease as infiltration decreases. That is, as the curves of Figure 1 are lowered, they become closer together when measured along a line of constant total load.

2. The $\Delta R$ attributed to a wall of given $R$-value should not change as the infiltration load is varied. If, for example, we find that a "heavyweight" wall of R10 has the same load as a "lightweight" wall of R12, then the loads of these walls will still be equal if we add or subtract a constant infiltration load.

5. HVAC Set-Point Schedule

Certain operating characteristics are critical to the determination of $\Delta R$ values. These include the thermostat set-point schedule and the use of natural ventilation. Natural ventilation is of proven value, expecially in hot-arid regions, but it is difficult to model and control, so its effect on $\Delta R$ values has not yet been quantified. The thermostat set-point schedule is commonly specified by the following:

1. Temperature at which heating is supplied

2. Temperature at which cooling is supplied

3. Hours of the day during which heating or cooling is supplied

4. Night-time temperature "set-back"

With respect to these variables, there is no reason to believe that log homes will be operated differently than conventional homes.

The importance of the set-point schedule has been established by past research. By means of computer simulation, Leslie has determined that thermal mass is much more beneficial under a continuous heating regime than it is under an intermittent one. In the case of continuous heating, Leslie found that the removal of heat capacity from the walls and roof could increase the heating energy requirement by $16 \%$. Under the intermittent regime, which allowed heating from $4 \mathrm{p} . \mathrm{m}$. to $11 \mathrm{p} . \mathrm{m}$. on $1 \mathrm{y}$, this increase was on $1 \mathrm{y}$ $6 \%$. For some climates, Leslie found that increasing the wall-mass under intermittent heating actually increased the heating load. This raises the possibility of negative $\Delta R$ factors. The selection of a "typical" set-point schedule of an "average" $\Delta R$ is problematic, 
even when all variables except the set-point schedule are held constant. A set-point schedule that is chosen to minimize total loads will probably not also maximize the $\Delta R$ effect.

6. Climate

It is generally assumed that thermal mass becomes significant only where the daily temperature swing is relatively high and the mean daily temperature is not extremely high or low. A rule of thumb has been formulated by Francisco Arumi in terms of a "temperature ratio," $r$, which is defined for the heating season by the formula:

$$
\begin{aligned}
\mathrm{r}=\left(\mathrm{T}_{\mathrm{h}}-\mathrm{T}_{\mathrm{m}}\right) / \Delta \mathrm{T}, \text { where } \mathrm{T}_{\mathrm{h}} & =\text { thermostat set-point } \\
\mathrm{T}_{\mathrm{m}} & =\text { mean annual temperature } \\
\text { and, } \Delta \mathrm{T} & =\begin{array}{l}
\text { amplitude of daily temperature } \\
\text { swing }
\end{array}
\end{aligned}
$$

Arumi finds that the thermal mass of masonry walls is only significant when the temperature ratio is less than unity. When the temperature ratio is greater than one, thermal mass is not expected to reduce the wall's load by more than $5 \%$. Judging from Bickle's findings, log walls do not conform to this rule. The "effective U-values" found for log walls in Seattle and Bismarck show significant deviation from the steady state value, even though these climates have temperature ratios greater than 2 . It is possible that Arumi's rule was developed for walls with time-lags that are low compared to that of Bickle's log wall. Further research is required to establish the temperature ratio value that signifies a "good" climate for log walls.

\section{BLAST ANALYSIS OF LOG HOME IN DES MOINES}

The results of our use of the BLAST computer program to model a log home in Des Moines, Iowa, are only in partial agreement with the findings presented above. The log home used in this study is a typical ranch model which sits on a heated basement that is partially exposed on the south side. The walls of the house face the cardinal directions, with the longitudinal axis of the house running East-West. We were able to systematically vary some of the thermal mass parameters previously described, but not all of them. The wall mass, the mass of the rest of the house, and the climate were taken as a given, while the wall color, infiltration rate, and HVAC set-points were assigned a range of values. Properties of the log walls that were held constant are as follows:

$\begin{array}{ll}\text { Thickness: } & 0.634 \mathrm{ft} .(7.61 \text { inches }) \\ \text { Density: } & 27.65 \mathrm{lbs} / \mathrm{ft} .{ }^{3} \\ \text { Wall weight: } & 17.54 \mathrm{lbs} / \mathrm{ft} .{ }^{2} \\ \text { Conductivity: } & 0.0689 \mathrm{BTU} / 1 \mathrm{~b} .{ }^{2} \mathrm{hr} .\left({ }^{\circ} \mathrm{f} / \mathrm{ft} .\right) \\ \text { Heat capacity: } & 0.335 \mathrm{BTU} / 1 \mathrm{~b} .{ }^{\circ} \mathrm{F} \\ \text { Time lag: } & 10.17 \mathrm{hr}\end{array}$


For purposes of comparison, thermal loads were also calculated for the same house with $2 \times 4$ frame walls in place of the 1 og walls. Two frame versions were used, one at about R7, and one at about R11. These are the results of computer runs using 1977 weather data (Figure 10).

1. The $\Delta \mathrm{R}$ effect can be estimated here for only one set-point schedule, one color, and one air infiltration rate, at which point the $\mathrm{R} 9 \mathrm{log}$ wall results in a slightly lower total load than the R11 wa11.

2. Contrary to Bickle's findings, the color of the log wall does not appear to be an important influence on either heating or cooling loads. Because color changes have opposite effects on heating and cooling loads, the total load appears to be completely indifferent to color.

3. Changes in the set-point schedule considered here altered total loads slightly, but did not magnify or diminish thermal mass effects.

\section{REFERENCES}

1. Arumi, E., Thermal Inertia in Architectural Walls, National Concrete Masonry Association, 1977.

2. Bickle, L., Effective U-values for Log Walls, Log Homes Council, National Association of Home Manufacturers, 1978.

3. Goodwin, S. E., and Catani, M. J., The Effect of Mass on Heating and Cooling Loads and on Insulation Requirements of Buildings in Different Climates, ASHRAE Transactions, Volume 85, Part 1, 1979.

4. Jones, R., Krajewski, R., and Dennehy, G., Case Study of the Brownel1 Low Energy Requirement House (Thermal Storage Analysis), Bookhaven National Laboratory, Associated Universities, Inc., 1978.

5. Leslie, S. F., Annual Heating Energy Demand of Heavy Domestic Buildings, Building Research Association of New Zealand, 1976.

6. Mitlas, G. P., Relation Between Thermal Resistance and Heat Storage in Building Enclosures, ISSM 0701-5232, Division of Building Research, National Research Council of Canada, 1978.

7. 0lgyay, V., Design with Climate, Princeton University Press, 1963. 


\section{ANALYSIS OF CODE RELATED RESPONSES \\ FROM THE SOLAR DEMONSTRATION PROGRAM}

by

Joseph Greenberg

Project Leader

National Bureau of Standards

Washington, D.C.

This paper is based on a report prepared jointly for the Department of Housing and Urban Development (HUD) and the Department of Energy (DoE) under activities carried out by the National Bureau of Standards (NBS) relative to the Solar Heating and Cooling Demonstration Program. The report documents and analyzes building regulatory information gathered by HUD Contractor personnel during the course of the Solar Residential Demonstration Program--from inception of the program (late 1975) through September 30,1978 .

Although not all builders and local code officials participating in the demonstration program were interviewed for the study, the total number of participants interviewed was of sufficient size to postulate trends and draw reasonable conclusions regarding the building regulatory aspects of the program. The report concludes that existing codes do not present a barrier to the installation and acceptance of solar systems; however, code officials need additional training and better back-up material to properly evaluate solar systems.

This paper summarizes and presents the major findings included in the report.

Key Words: Building code; code officia1; demonstration program; institutional constraints; solar builder/developer; solar energy . 


\section{INTRODUCTION}

The objective of the project reviewed by this paper is the analysis of data collected for the HUD Solar Residential Demonstration Program to provide an insight into those aspects of the building regulatory process that inhibit, impede, or otherwise adversely affect the installation and use of solar hot water and space heating and/or cooling systems. The project was designed to provide:

An analysis of the response by the participants in the demonstration program as to real or perceived regulatory problems encountered during the conduct of the program.

An analysis of the adverse impacts, if any, resulting from differences in various regulatory statutes.

A recommended course of action, as articulated by the participants in the demonstration program, regarding current and future regulatory needs.

An assessment of the documentation and training needed to assure an orderly and efficient system for the evaluation and acceptance of solar systems.

The HUD Demonstration Program is structured in cycles; each takes place sequentially in a different time frame with various projects awarded for each cycle. Although the HUD Solar Residential Demonstration Program is expected to have a total of five cycles, the report was limited to data gathered during the first three cycles and includes data collected from late 1975 to September 30, 1978--the cutoff date of the report.

\section{DATA SOURCES}

To assure an orderly and systematic method of identifying and collecting the pertinent data associated with the regulatory aspects of the HUD Solar Residential Demonstration Program, each organization having responsibility for the collection of data was identified. The data collection instruments (questionnaires and reports) were collected and a review made of each document to assess its value as a data source for regulatory information. Those valuable to the project were then singled out for study and the appropriate mechanisms established to collect the data; either through the NBS Solar Data Base or through direct contact with the custodial organization. To facilitate the handling and analysis of the information, special computer print-outs were developed using the information stored in the NBS Solar Data Base.

Organizations collecting data for the Solar Residential Demonstration Program were: 
Real Estate Research Corporation - RERC

American Institute of Architects Research Corporation - AIA/RC

U.S. Department of Housing and Urban Development/Boeing - HUD/Boeing

The RERC data are by far the most pertinent to the study and are used to generate most of the conclusions and trends presented. The broad scope of the questions asked and the variety of respondents (demonstration builders, non-demonstration comparative builders, and loca1 building code officials) allow for comparisons to be made and differences in responses to be analyzed.

\section{SAMPLE SIZE}

Regulatory questions were responded to by fifty percent (50\%) of the single family builder/developers engaged in constructing solar equipped demonstration houses, and approximately ten percent (10\%) of the multifamily builders/developers. In addition, RERC interviewed non-demonstration, non-solar comparative single family builders at approximately fifty percent $(50 \%)$ of the locational areas where solar demonstration programs are being conducted. The demonstration builder data, both single family and multi-family, approximately reflected the number of site locations visited; the usual scheme is to generally interview only a single demonstration builder/developer per location. However, the number of comparative builders varied from one to four. In addition, responses were received from eighty-seven (87) local building code officials, which represents responses from approximately thirty-two percent (32\%) of the two hundred seventy-two (272) site locations, comprising the demonstration program during that time frame.

\section{FINDINGS}

The major findings that are detailed and analyzed in the report are summarized below:

A. Constraints/Technical Issues

1. Approximately eighty percent (80\%) of the local building code officials indicated that there are no major barriers in building codes at present which would impede the installation of solar energy systems in their jurisdictions, while a smaller percentage (approximately 64\%) foresaw no future problems. Those officials identifying current problems specified administrative difficulties as the most frequent reason for these problems. Anticipated new code requirements and structural concerns were identified by those officials who expected future problems.

2. Some local building code officials reported that the codes used in their jurisdictions contain provisions for solar systems. There was no indication that the processing and acceptance of solar energy installations was affected adversely or advantageously by a jurisdiction's adoption or lack of adoption of solar energy provisions. 
3. Approximately one-quarter of the local building code officials indicated that their departments had studied the question of potential impact of solar energy systems on building codes and of these, one-third indicated a need for standards for solar systems and components.

\section{B. Approval and Inspection of Solar Systems}

1. The solar demonstration builder/developer faces no greater or lesser difficulty than that routinely faced by non-solar builders in obtaining approval from building inspectors during the planning and construction phases of their projects. From the builder/developer perspective, it appears that regulatory issues have not impeded the acceptance of solar systems on the Solar Residential Demonstration Program.

2. Approximately one-quarter of the local building code officials indicated that solar applications presently require additional processing time and approximately one-half of these local building code officials expect that the need for this increased processing time will continue.

3. The number of waivers requested for solar installation is low. However, if a waiver is requested, the chance of having the waiver granted is excellent. In addition, approximately onequarter of the local building code officials required design changes to be made on solar systems installed in their jurisdictions.

4. System approvals and site inspections normally were handled in a routine manner; however, approximately one-quarter of the local building code officials reported that additional site inspections were required for them to become familiar with the solar installations or to run plumbing or other physical tests.

5. The greatest concern of the local building code officials identifying problems with solar systems meeting code requirements are the toxic fluids used in these systems.

6. Approximately two-thirds of the local building code officials indicated building code problems in the installation of a solar system in an older structure; citing an overwhelming concern with structural adequacy of the buildings. In addition, approximately one-quarter of the local building code officials indicated that multi-family solar installations would entail unique considerations from an approval point of view because of the inherent complexity of these larger installations.

7. Certification of solar equipment, with approved testing conducted by any qualified testing institution, was desired by one-third of 
the local building code officials prior to their issuing a building permit.

C. Code Official Training and Technical Support

1. Genera1ly, the knowledge and educational background of the local building code official and the sources of solar energy information available to him varied greatly from jurisdiction to jurisdiction. If the processing of solar applications is to be accomplished more effectively, the code official's knowledge of solar energy systems must be upgraded by education, training and actual experience.

2. Areas of assistance identified by the local building code official include: the training of evaluators and inspectors; the development of manuals of accepted practice and inspection guidelines; development of feasibility data; development of efficiency data for different solar systems; certification of equipment and systems; and, need for standards.

3. The sources most often used by the local building code official for information related to solar energy are trade publications, manufacturer's data, national and local associations, and government agencies. Other important sources are universities and independent agencies. Developers and financial institutions were rated low as sources for solar information. 

SESSION 3A - DESIGN CONSIDERATIONS AND

THEIR IMPACT ON CODE ENFORCEMENT

Moderator: Joseph A. Cirillo

State Building Commissioner

12 Humbert Street

North Providence, Rhode Island 

by

\author{
Donald E. Parker \\ Director, Value Management Division \\ Office of Construction Management \\ Public Buildings Service \\ General Services Administration \\ Washington, D. C.
}

This paper describes the content and application of the General Services Administration (GSA) Value Management (VM) Program requirements incorporated by regulation in all architect-engineer (A-E) contracts.

The objective of this VM Program is to control the cost of construction by performing VM studies at various points in the design process with the objective of recommending changes to design work in progress.

The VM process requires the understanding and agreement of two parties the client and the designer. VM study forces the enhancement of communication between these two parties. It provides the freedom to challenge codes, criteria, needs, desires, and specifications in a professional atmosphere.

Because the economic measure of value is life cycle cost, the program controls life cycle cost as well as initial cost. Thus, it has been effective in reducing maintenance and energy cost in addition to ensuring the project budget is met.

Required VM service design contracts can be expected to provide an average $\$ 10$ return for every dollar invested in cost of the service.

Key Words: Economic analysis; life cycle cost; value management;

value study. 
The General Services Administration (GSA) Public Buildings Service (PBS) incorporates a Value Management (VM) Services Contract Clause in each of its professional services contracts with architect-engineer $(A-E)$ and construction managers (CM) involving the design of buildings, extensions, alterations, and improvement projects with estimated construction costs (ECC) over $\$ 200,000$. This clause establishes minimum contractor performance and scope of service concerning Value Management during design.

Our intent in requiring the use of VM principals and techniques is that their application will result in:

1. Reduced overall costs without degradation of the essential performance of the project.

2. Reduced potential for design deficiencies as reflected in reduced numbers of change orders during construction.

3. Positive control of costs.

4. Savings in time for design by eliminating unnecessary design work, adding to a clarification of the design scope, reducing false starts, and preventing the loss of time that occurs when budgets are exceeded.

The simple reason we require the designer to perform VM is, besides the client, the A-E's decisions have the most influence over expenditure of funds during a facility's life. (See figure 1.)

For example, the client, through the code or criteria he uses, may prescri the quantity of plumbing fixtures to be provided. This does restrict the A-E's influence on what it will cost to provide and operate the plumbing system. However, he does retain the next greatest influence on these cost because he does determine layout, arrangements, materials, colors, etc.

By the time the construction contractor enters the scene, he can influence the cost of materials and installation by only a few percent. Maintenance and operations personnel are left with the least influence because they must live with that given them.

Clearly, the greatest potential for savings is to provide a way for the A-E to perform VM during design and at the same time permit him to questio client criteria. 


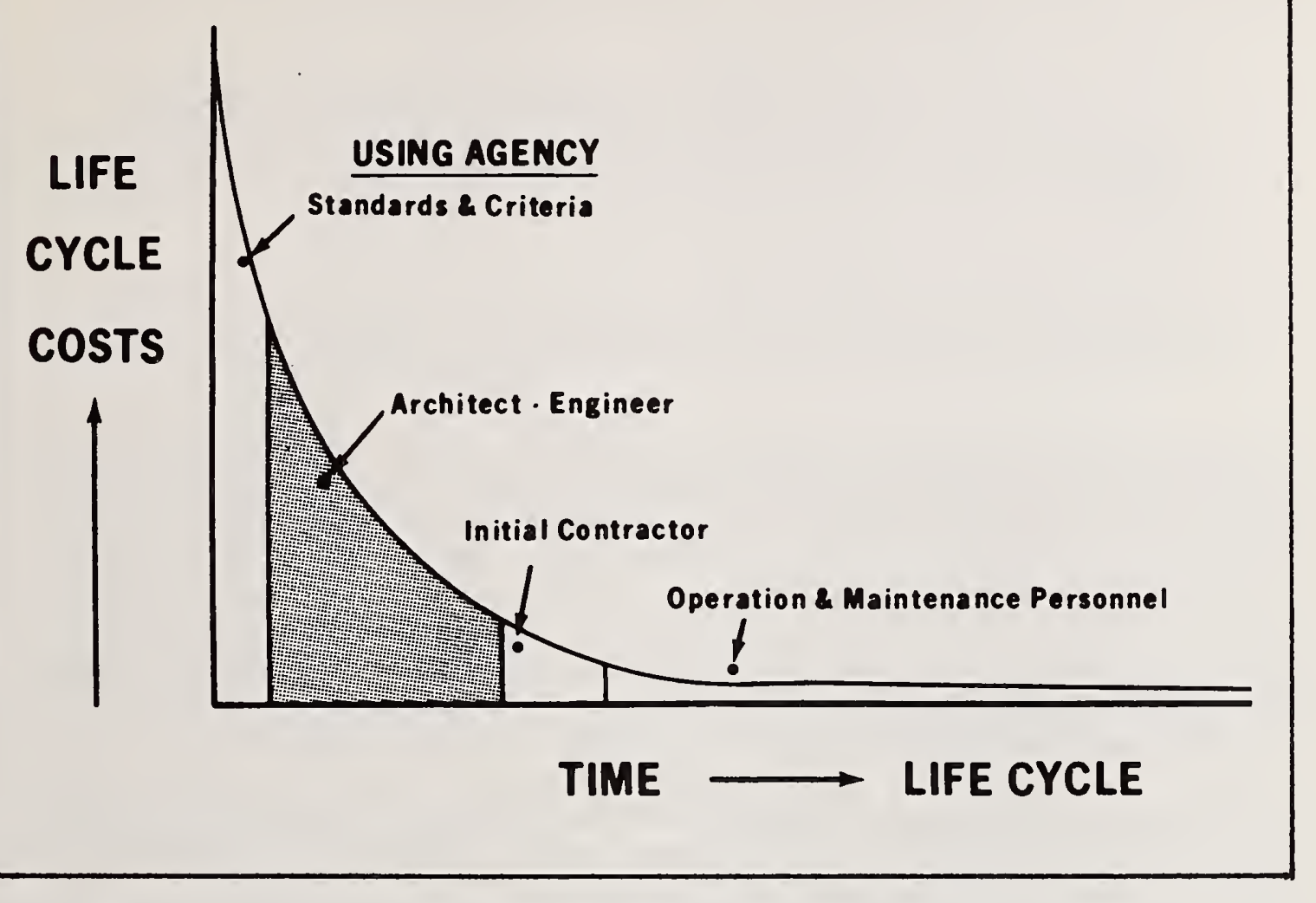

Figure 1: Decision Maker's Influence on Cost

\section{DEFINITION}

At this point it is important to emphasize that contracting for VM is not contracting for just cost reduction services or economic analysis to determine which is the cheapest system. In fact, our VM requirements are not a substitute for economic analysis or life cycle costing services which are still required in our A-E contracts.

Then it is important to state the formal definition of VM to understand what the service is and how it relates to other A-E contract requirements:

"VM is an organized effort directed at analyzing the function of goals and services for the purpose of achieving necessary functions at the lowest overall cost, consistent with achieving necessary operational, maintenance, safety, reliability and other performance features."

Analyzing the above definition with regard to our contract services, one will see the full implication of VM as a specific process which requires application of a specific methodology. 
For example, the term "organized effort" in the definition translates into:

* identifying and dedicating resources to perform VM (the contract sets these aside for VM use)

* deliberately investing these resources in potential areas of savings (rather than spending the resources to see what will happen)

* using multidiscipline teams

* formally following through on ideas until resolution is reached.

Of course, this process is aimed at identifying and eliminating all unnecessary costs without sacrificing required performance. The methodology takes over here. Value is enhanced by improving the relationship of worth (amount you are willing to pay for a function) to cost through the study of function (purpose for which an item or practice exists or is being considered). Identification of unnecessary costs is established by analyzing the functions of the design or item under review. Elimination of unnecessary costs is the result of implementing alternative means to achieve the required function.

Now, the cost referred to above is not just initial construction cost. Rather, it is life cycle cost ("lowest overall cost" in the definition). Life cycle cost (LCC) of any item (building, system, component) is the total cost to the owner or user for acquiring it plus operating, supporting, maintaining, repairing and/or replacing it over the full life span it is needed.

VM uses LCC as the economic measure of value. Doing this ensures that required performance is maintained when changes are adopted. More often than not, VM enhances the performance reliability of the service or products to which it is applied.

\section{VALUE SERVICE REQUIREMENTS}

GSA's handbook, A-E/CM Value Management Services (PBS P 8010.1), is the document referenced in A-E contracts which specifies the requirements for these services.

During negotiation of fee for the basic design work, a separately identified fee is negotiated for doing VM work. However, GSA requirements do not provide for incentive sharing, with A-E or CM, of savings achieved during design or construction.

The amount of VM effort we require increases as the dollar value of construction increases per the levels of service briefly described below: 
Leve1 1 - Projects between $\$ 200,000$ to $\$ 1,000,000$ require development of cost models and A-E consideration of client generated value study proposals.

Leve1 2 - Projects between $\$ 1,000,000$ to $\$ 5,000,000$ require the A-E to perform VM studies of criteria and systems.

Level 3 - Projects between $\$ 5,000,000$ to $\$ 30,000,000$ require the conduct of a VM workshop for the project in addition to the studies.

Level 4 - Projects over $\$ 30,000,000$ require assignment of a project manager to oversee and coordinate all the VM services under contract.

It is not enough, however, to simply require VM to be performed during design without the client being prepared to support the effort. In our case, GSA has issued written guidance to respond to issues that can be anticipated to arise from requiring VM services during design. These involve:

Design schedule. We require that all design schedules include provisions for performing value studies and time to implement expected results. A tight design schedule and an urgent need for design completion is not cause to permit VM services to be deleted from the contract. Such situations intensify the need for increasing value services. The faster the project is issued, the more susceptible to poor value it is.

Changes to codes, criteria. Because the VM program encourages innovation and initiative, changes are an expected product. In GSA Regional Commissioners and Assistant Commissioners are authorized to consider requirements in all PBS publications as general guidance rather than rigid standards in order to approve and implement results from VM efforts. Where definite advantages can be expected, deviations are authorized provided that a professional judgment has been made that a safe, adequate, more economical, or better design or procedure will result. This authorization for worthwhile deviations does not apply to deviations from statutory and similar requirements included in Public Laws, Federal Procurement Regulations, Executive Orders and similar regulations, such as - statutory requirements include provisions for the handicapped, air and water pollution abatement and control, and the use of specifications which are non-proprietary.

Compensation for changes. Assuming A-E's perform their professional responsibility during design, the client should be prepared to provide additional compensation to implement changes when necessary. GSA permits A-E's to be compensated for implemented changes resulting from value studies when they affect completed and approved design work to date. The 
entitlement and the amount of compensation is determined by the Contracting Officer before the A-E is authorized to proceed with any changes. Such compensation is limited to the additional costs of redesign. Value Management changes intended to bring the project, as designed by the A-E, back within the budget are expected to be accomplished by the A-E without additional compensation.

\section{SCOPE OF APPLICATION}

Our VM service requirements provide for repetitive consideration of VM at all stages of design. We know that the highest return on investment from VM application can be expected early in the design process, before the cost of redesign in order to implement a change adversely affects the savings potential.

But design is not a simple, straight forward process. It is an interactive process. Each step in programming or design of a project represents a known baseline that starts out broad in content and becomes more and more definitive as the time goes on. The heart of our VM requirements is to work against a given baseline in order to change or redirect the baseline and arrive at an end result that will satisfy the original functions. For this reason, VM is applied repeatedly as various points or phases during the design process.

Concept stage. The purpose of the conceptual phase is to translate requirements and program directives into feasible concepts which will result in defining future operational and support requirements. During this stage a VM criteria review is performed. The designer is requested to question, study, or recommend changes to Government-imposed restrictions whether they be performance criteria, scope requirements, standard prescriptive specifications or special instructions.

At this stage, a cost/worth model with parameter cost is developed and reconciled with the project budget to set a cost baseline to control initial costs through design.

Similarly, this is the time to establish LCC goals for the entire facility. Very often, the VM activity during this stage identifies issues for further detailed study and consideration for the next VM study.

Tentative stage. During the design tentative stage of design, approved concepts are definitized, preliminary drawings and outline specifications are started, and sufficient detailed information is developed to substantiate all quantity and cost that have been presented in the program 
directive. This is the most opportune time to question performance characteristics. VM effort at this stage is directed toward creating value indexes of function, cost, and worth of each system as a whole, and its major subsystem.

VM task team studies are conducted at this stage, often in the form of workshop, with the objective of generating changes to the design. We require that task team reviews be performed by individuals not responsible for the original design. This is intended to prevent extensive interruption of the design process as well as provide a less prejudicial value review.

VM studies at this stage of design are directed toward system studies. The studies concentrate on system selections as expressed by single line drawings and calculations for foundation, superstructure, mechanical, electrical, fire protection, and vertical transportation. In addition, system relationships, design configurations, space efficiencies and scope requirements are reviewed. Information derived from independently performed economic analysis on alternate systems by each engineering discipline is also used to arrive at recommendations for improving project value.

Working drawing stage. It is during the working drawings phase that specific (final) design details are formulated. Materials are selected and specifications created. VM effort at this stage is concentrated on elfminating unnecessarily restrictive detail for requirements, ensuring standards for details, minimizing the different types of quantities, and eliminating items not necessary.

VM study activity deals with components of the various building systems rather than the systems themselves. Effort is made to study areas where the cost to make a change (redesign) is minimal compared to the potential savings. Schedules for equipment, hardware, windows, doors, finishes and materials fill in this category as do specification requirements.

When projects are phased or fast tracked into bid-packages, VM study is conducted on each package prior to release for bids. The VM studies concentrate on all items of procurement in the bid-package as well as the interface with items that might influence cost savings on subsequent bidpackages.

\section{CONCLUSION}

Since the inception in 1973 of the VM Service Contract Clause in A-E/CM professional services contracts, studies by designers as well as GSA's own in-house staff, have resulted in elimination of more than $\$ 32$ million 
of unnecessary cost in facility designs. This represents a return of some $\$ 10.20$ for every dollar spent on the program. Many A-E's have accepted the methods and procedures of VM as proposed by GSA and view this approach as an opportunity to enhance the capability of their practice for the present and future benefit of their clients.

Value Management encourages innovativeness, ingenuity, and imagination in reducing cost without sacrificing required quality or function. It can serve as a beneficial tool to address the problems of scarce resources while maintaining sound quality construction. The Value Management Program in GSA continues to promote teamwork, enhance communication, improve productivity, reduce waste, increase cost consciousness, and encourage personal development because Value Management provides a definite avenue of change. 
BUILDING RECERTIFICATION AND DADE COUNTY, FLORIDA

by

Ralph Warburton, AIA, AICP, PE

Professor of Architecture and Planning

University of Miami

Coral Gables, Florida

One of the major problems in maintaining environmental quality is the need for continual routine monitoring of existing private-sector construction to ensure structural integrity over time. Dade County, Florida has an operating ordinance which provides a model deserving significant consideration in this regard, so that extensive loss of life and property can be minimized.

On May 21, 1975, the Dade County, Florida Commission adopted Ordinance 75-34, providing for routine examination by private-sector architects and engineers of structures over 40 years old (and re-examination at 10 year intervals thereafter) to verify their continued eligibility for a Certificate of Occupancy. The ordinance covers all private-sector buildings providing facilities for over 10 persons and having over $2,000 \mathrm{sq}$. ft. of floor area, except for 1 and 2 family residential structures.

At present, about 6,000 buildings have felt the effects of this ordinance, with about $75 \%$ receiving immediate recertification and about $10 \%$ requiring enforcement measures. Buildings are currently coming under the ordinance provisions at the rate of about 700 per year.

Evaluation of potential generic issues, considering the program development to date, indicates no serious defects in the program and the immense benefits to the public from such an ordinance covering privatesector buildings.

In fact, the Dade County Ordinance presents a model worthy of national attention and adoption as appropriate as part of new state/local building code legislation as well as through revisions to professional established standards and policies.

Key Words: Architects; codes; earthquake; engineers; Florida; inspection; legislation; recertification. 


\section{Introduction}

One of the major problems in maintaining environmental quality is the lack of procedures for the continual routine monitoring of existing private-sector construction to ensure maintenance of design quality over time. It has been recognized that our significant building stock must be maintained at an appropriate level of quality to ensure maximum livability as well as minimal catastrophic losses from such causes as fire, hurricanes, earthquakes, etc. This recognition at the federal, state and local level is outlined in this paper, together with material on the Dade County, Florida, recertification program which provides for periodic inspections and certifications of existing privatesector buildings utilizing private-sector design professionals.

\section{Background Overview}

Apparently, the first United States law for the inspection of existing buildings was adopted in New Orleans in 1856. It stated: "The Mayor and Surveyor shall examine theatres and places of public resort for structural stability, and take suitable measures to prevent accidents that might result from any negligence in the construction of the building or from any mismanagement of the proprietors." (Ref. 1, italics added.)

From this has developed, principally in the 20th century, the "system" of model codes, local codes and state codes which often encompass elements intended to ensure from the outset the safe continuance of the use for which the building was constructed. Maintenance of housing quality is provided for through housing codes. As late as 1969, a survey of the building code field included little material on building quality maintenance - covering only housing codes and use violations. (Ref. 2.)

This survey also covers the transition from specification codes to performance codes; the latter allowing broad leeway to designers in selected materials and methods to achieve desired results, within established engineering and architectural parameters. Performance orientation in building codes has been widely advocated since its benefits are many (Ref. 3), but it requires an increasingly greater degree of technical sophistication on the part of the code enforcement personnel.

The increasing extension of the building code responsibilities toward maintenance and performance-orientation areas, simultaneously, can be illustrated in regard to the developing national concern about earthquakes. 
In 1975, a panel of the National Academy of Science stated that the "...modification of and even demolition of unsafe structures must be included in the goals of structural design and maintenance to be pursued by public and private officials." (Ref. 4.) The evaluation of the long term performance of repaired buildings was called for in 1977 (Ref. 5). Also in 1977, the American Institute of Architects Research Corporation called for the generation of problem solving strategies in maintenance procedures and techniques (Ref. 6). The issue was discussed further in the 1978 report of Earthquake Hazards Reduction, prepared by the Executive Office of the President, which outlines some state measures taken to review structures (principally publicly assisted and/or licensed hospitals and schools) for their soundness with respect to potential earthquake damage (Ref. 7). Washington publications sponsored by the Veterans Administration, the General Services Administration, and the Department of Defense within the past decade have identified vital nonstructural as well as structural systems, and advanced evaluation systems for existing buildings which have potential application to recertification approaches (see Ref. 8 for summary). And, guidelines for the repair and strengthening of existing buildings and for emergency post-earthquake inspections have been proposed in the Applied Technology Council recommended tentative provisions. (Ref.9.)

\section{Local Government Background}

Are local government code procedures available to cope with the outlined subject matter? The key tool would be development of the certificate of occupancy concept, requiring periodic re-inspection for maintenance of the right to continue to occupy a structure. A recent national pilot survey by mail, carried out by researcher Philip Martin under the author's direction, strongly suggests that this tool is in its initial evolving stages of development.

Several quotes from response letters by local building officials are illustrative. In Boston, "The Building Department does not have a recertification program...," although voluntary recertifications are possible (Ref. 10). "The City and County of Denver has no program for recertifying buildings after their initial construction." (Ref. 11.) "Recertification of existing buildings is not required by the (Los Angeles) code." (Ref. 12.)

The response from San Francisco was more positive: "In apartment houses and hotels, we have a triennial inspection of the public areas for maintenance and to ensure compliance with the Housing Code, including retroactive provisions, and a program in which the worst 1000 apartment or hotel buildings each year are completely inspected including all rooms of all the dwelling units. That is the extent of the Bureau of Building Inspection's recertification program. The Fire Department has programs for inspection of public assembly, and a general program, when personnel are available, for maintenance of office buildings." (Ref. 13, italics added.) 


\section{Local Government Reliance on Private Sector Architects/Engineers}

While the term "recertification of buildings" is not in the Chicago vernacular, its Department of Buildings is required to inspect many types of buildings annully for code compliance, with fines being assessed for non-compliance. In addition, jointly recognizing problems connected with technical sophistication and manpower, the City Council enacted a 1978 ordinance requiring that a registered private-sector architect or structural engineer inspect "...every exterior wall and enclosure of or part of a building five stories or more in height..." at least once every ten years; every five years when the building reaches the age of 35 years. If deficiencies are found, "...repairs, reinforcements or precautionary measures..." are required. (Ref. 14.)

The metropolitan area of Dade County, Florida has an operating recertification ordinance, using private-sector architects and engineers, that is far in advance of those indicated above. (Ref. 15.) (The ordinance was adopted primarily to address problems connected with early building when no building code was in force. This resulted in, among other things, the use of sea sand and water in some concrete mixes.) Thus, the Dade County ordinance provides a procedural model deserving significant consideration in earthquake prone areas so that extensive loss of life and property can be minimized.

\section{THE DADE COUNTY ORDINANCE}

\section{Coverage}

On May 21, 1975, the Dade County, Florida Commission adopted Ordinance 75-34, providing for routine examination of structures over 40 years old (and re-examination at 10 year intervals thereafter) to verify their continued eligibility for a Certificate of Occupancy. The ordinance covers all private-sector buildings providing facilities for over 10 persons and having over $2,000 \mathrm{sq}$. ft. of floor area; except for 1 and 2 family residential structures.

"Recertification" is construed to mean "...the requirement for specific inspection of existing buildings and structures and furnishing the Building Official with a written report of such inspection as prescribed..." conforming, in general, with a 7-page guidelines form issued by the Building Official. (Ref. 16.)

As buildings reach the initial 40 years of age, or the 10 year renewal age, a "Notice of Required Inspection" is sent to the owner of record giving him 90 days to file an inspection report prepared by a licensed private-sector architect or engineer of his choosing. According to the ordinance, "such engineer or architect shall undertake such assignments only where qualified by training and experience in the specific technical field involved in the inspection and report." (Ref. 15.) 


\section{Inspection Report}

The inspection report form encompasses structural elements in some detail, but mechanical and electrical systems are not included. A review of some main topical headings is illustrative: Present Condition of Structure, Masonry Bearing Walls, Floor and Roof Systems, Steel Framing Systems, Concrete Framing Systems, Wood Framing, Windows. Under the Concrete Framing Systems heading for example, the inspecting engineer or architect is asked to give a full description of the structural system, analyze any cracking with regard to significance, estimate the general condition of the system, evaluate the extent of rebar corrosion and recommend repairs, and analyze any samples of concrete obtained from spall areas.

If any defects are noted in such report, the owner has 150 days after the date of the "Notice of Required Inspection" to correct the situation - if it is not corrected, as attested to by the certification of the inspecting architect or engineer bearing his seal and signature, the originally issued certificate of occupancy for that building may be revoked.

\section{Application}

At present, about 6,000 buildings have felt the effects of this ordinance, with about $75 \%$ receiving immediate recertification, $15 \%$ undergoing expeditious repairs, and about $10 \%$ requiring enforcement measures. Buildings are currently coming under the ordinance provisions at the rate of about 700 per year. As a consulting architect and engineer, the author has directly participated in this recertification program on behalf of a private-sector owner, and was able to discharge these responsibilities in a non-problematic manner. From inception, and during the five years since adoption, the program has had wide professional and political acceptance among all facets of the community.

\section{EVALUATION}

While the Dade County ordinance is evidently a landmark law which could have major impact, some prospective problem areas can be identified with regard to owners, a/e's and local governments.

Owner related issues include time requirements, a/e qualifications, equitable enforcement, effect on real estate capital and rental values, ability to secure repair loans, and effect on insurance costs. Architect and engineer related issues include contract standards, fees, professional liability, and threshold for minimum repairs. Local government related issues include enforcement organization structure and personnel, and unrepairable defects. 
However, evaluation of these potential generic issues, considering the program development to date, indicates no serious problems with the program as well as the immense benefits to the public from such an ordinance covering private-sector buildings.

The 6,000 building operational scale of the Dade County program is comparable to the magnitude of the problem in many cities, such as earthquake prone San Francisco. There, for example, it has been estimated that 4,200 potentially hazardous buildings are located within a 200 block area where severe damage may happen in the event of a 1906-type earthquake. (Ref.17.)

In fact, the Dade County ordinance presents a model worthy of national attention, including further research, and adoption as appropriate as a part of new state/local building code legislation as well as through revisions to established professional standards and policies and so that the desired environmental quality of our urban areas is maintained.

\section{REFERENCES}

1. Colling, R. C. and H., editors; Modern Building Inspection; Building Standards Monthly Publishing Company, Los Angeles, California; 1950.

2. Sanderson, R.; Codes and Code Administration; Building Officials Conference of America, Inc.; Chicago, Illinois; 1969.

3. Warburton, R.; "A Progressive Approach to Zoning and Building Codes;" Systems Building News, W. R. C. Smith Publishing Company, Atlanta, Georgia; July 1971.

4. Panel on the Public Policy Implications of Earthquake Prediction; Earthquake Prediction and Public Policy; the National Academy of Science, Washington, D. C.; 1975.

5. Hanson, R. D.; Repair, Strengthening and Rehabilitation of Buildings...; University of Michigan Department of Civil Engineering; Ann Arbor, Michigan; October 1977.

6. American Institute of Architects Research Corporation; Architects and Earthquakes: Research Needs; The Corporation, Washington, D. C.; 1977.

7. Working Group on Earthquake Hazards Reduction, Office of Science and Technology Policy, Executive Office of the President; Earthquake Hazards Reduction; the Office, Washington, D. C.; 1978 . 
8. Yancey, C. W. C. and A. A. Camacho; Aseismic Design of Building Service Systems: The State of the Art; U.S. Government Printing Office, Washington, D. C.; 1978.

9. Applied Technology Council; Tentative Provisions for the Development of Seismic Regulations for Buildings; U.S. Government Printing office, Washington, D. C.; 1978.

10. Letter dated 27 September 1978 from R. L. Granara, Assistant Building Commissioner, Boston, Massachusetts.

11. Letter dated 27 September 1978 from W. J. Miller, Director, Building Inspection Division, Denver, Colorado.

12. Letter dated 2 October 1978 from B. R. Whitson, Chief, Special Projects Division, Conservation Bureau, Department of Building and Safety, Los Angeles, California.

13. Letter dated September 1978 from R. C. Levy, Superintendent, Bureau of Building Inspection, San Francisco, California.

14. Letter dated 26 September 1978 from John F. Connelly, Coordinator, Special Projects, Department of Buildings, Chicago, Illinois, and attached documentation.

15. Ordinance No. 75-34 by the Board of County Commissioners of Dade County, Florida, amending the South Florida Building Code adopted by Ordinance No. 57-22, as amended, adding.a new subsection 104.9 Recertification. Adopted 21 May 1975.

16. Dade County, Florida, "Recommended Procedural Guidelines for Building Recertification," 21 May 1975.

17. Department of City Planning; "A Community Safety Plan for the Comprehensive Plan of San Francisco;" City of San Francisco, California; July 1974. Discussed, with other background in: American Institute of Architects Research Corporation; Summer Seismic Institute for Architectural Faculty; The Corporation, Washington, D.C.; 1977. 



\author{
COMPUTER-AIDED DESIGN REVIEW: \\ PREDICTING THE EMERGENCY EGRESS POTENTIAL \\ OF PROPOSED BUILDINGS ${ }^{1}$ \\ Fred I. Stah1, Ph.D. \\ Environmental Design Research Division \\ Center for Building Technology, NEL \\ National Bureau of Standards \\ Washington, D. C.
}

This paper discusses the potential use of computer simulation techniques by building code officials, as tools which aid in the prediction of building performance. As a case in point, the BFIRES program for simulating emergency egress during building fires, developed at NBS, is presented. The program is described from the user's viewpoint, and a specific example of its application in assessing building design is treated.

Key words: Building codes; building fires; computer-aided design; computer simulation; fire research; human performance; modeling; regulatory process; simulation

1 The research reported here was funded by the Center for Fire Research, NBS, through its NBS-HEW Fire/Life Safety Program, and by the Center for Building Technology, NBS. 


\section{Goals and Objectives}

Since 1977, the Environmental Design Research Division of the Center for Building Technology, National Bureau of Standards (NBS) has been actively developing a technique for simulating the emergency egress behavior of building occupants via computer $[1,2,3]^{1}$. Long range goals of this ongoing activity have been (a) to develop a deeper understanding of human behavior during fire situations, and (b) to develop a standardized technique for analyzing alternative building designs from an emergency egress viewpont. The latter aim provides the focal point of this paper.

The principal technical product of this research activity is BFIRES, a dynamic stochastic computer simulation of emergency egress behavior by building occupants during fires. The objectives of this paper are to acquaint the'reader with the purpose and structure of BFIRES, to suggest the utility of computer-aided design review by building designers and code officials, and to present an example illustrating an application of the BFIRES program. This paper should not, however, be construed as a "user's manual"2

\section{Computer-aided Design Review: Why?}

Regulatory mechanisms in current use usually require the compliance official to determine whether a given building design conforms to applicable regulations. When the building under review deviates little from local or accepted standards the review process is often straightforward. But when the regulatory official is confronted by a novel or highly specialized building program or design solution, he may be forced to exercise considerable discretion without the benefit of either past experience or reliable analytical tools. When considering life safety from fire for example, there currently exist no standardized tools with which to predict the emergency egress potential of specific building designs in relation to various fire or emergency scenarios.

A simple example illustrates this point. According to section 5-1201 of the Life Safety Code (1973 edition),

Exits shall be so located and exit access shall be so arranged that exits are readily accessible at all times. Where exits are not immediately accessible from an open floor area, safe and continuous passageways, aisles, or corridors leading directly to every exit

1 Numbers in brackets indicate references which appear at the end of this paper.

2 Preparation of a BFIRES user's manual is currently in progress. Researchers wishing to use the program should contact the author. 
shall be maintained and shall be so arranged as to provide convenient access for each occupant to at least 2 exits by separate ways of travel, except as a single exit or limited dead ends are permitted by other provisions of this Code.

This section, and in general Chapter 5 of the Life Safety Code, prescribes ready access to exits in the hope that during a fire, alternative egress pathways will protect occupants from the blocking of any single exit or path. However, the Code provides designers and building officials with neither a method for testing the adequacy of any given design, nor a means for comparing design alternatives in terms of life safety costs and benefits (e.g., time required to evacuate a floor, potential number of persons trapped on the floor, etc.). Without standardized tests and evaluative methods, how is the building official to determine the adequacy of a proposed egress scheme for those buildings too complex for straightforward code review?

\section{"BFIRES:" A COMPUTER MODEL FOR PREDICTING EMERGENCY EGRESS BEHAVIOR}

\section{Purpose}

BFIRES was specifically designed to simulate--by digital computer--the movement of people within building enclosures in response to life threatening stimuli (i.e., fire and smoke). Originally planned for use in evaluating health care facility designs, the program permits users to simulate such special activities as rescuing nonambulatory persons, in addition to simulating more frequent and general categories of emergency response (e.g., exit seeking, threat evasion, the deterioration of emergency responses resulting from inhabiting a toxic environment, etc.). In its current form BFIRES is applicable to a broad range of building occupancies.

\section{A Cautionary Note}

To date, considerable effort has been devoted to developing BFIRES $[1,2]$ and to analyzing the program's sensitivity to important parameters [2]. However, extremely little research has yet been undertaken regarding the predictive validity of BFIRES (i.e., the ability of the program to predict the performance of real human beings during actual fire emergencies). Although a recent investigation of the predictive capabilities of BFIRES yielded positive results [3], that study was extremely narrow in scope ${ }^{1}$ and the findings do not readily generalize to other

1 Fires in two-bedroom dwelling units were studied, in which the kitchen was the room of fire origin. BFIRES simulated fire outcomes were found to agree, in most respects, to results of real fires reported in the National Fire Protection Association Fire Incident Data Organization (NFPA-FIDO) data base. 
occupancies or fire conditions. Consequently, the reader is cautioned that BFIRES--in its present form--is not advocated for practical application by the building design and regulatory communities. Thus, references in this paper to the program's use are hypothetical. It is hoped, of course that future versions of the program will prove to be valid and reliable for practical applications.

\section{Concept and Structure of BFIRES}

BFIRES simulates the perceptual and behavioral responses of building occupants involved in fire emergencies. As in real fires, simulated occupants may respond to a fire alert although they are quite distant from actual fire products which may have been confined in some distant part of the building. Or their behavior may result from a direct confrontation with toxic agents. The program can simulate a wide variety of emergency scenarios, primarily because it deals with human behavior at a very fundamental level. Specifically, the basic unit of occupant behavior generated by BFIRES is the individual momentary response to the state of the environment at a discrete point in time, $t$. BFIRES conceptualizes a building fire event as a chain of discrete "time frames" $\left(t_{1}, t_{2}, \ldots, t_{n}\right)$ and for each such frame, it generates a behavioral response for every occupant in the simulated building. If each "frame" could be replayed sequentially as in the case of a movie or animated film, a complete "picture" of the building fire event would be seen (i.e., the simultaneous egress performance of all occupants in response to a migrating fire threat). See Figure 1.

The response generating capability of BFIRES is based upon an information processing explanation of human behavior, and suggests that building occupants act in accordance with their perceptions of a constantly changing environment. Between any two time frames $t_{i}$ and $t_{i \cdot r}$, the environment undergos change; e.g., people have altered thelr locations in space, smoke has advanced to new locations, and the building itself may have undergone physical changes. When preparing a behavioral response at $t_{i+1}$, a simulated occupant first gathers information which describes the state of the environment at this point in time. Next, he interprets this information, relating it to the emergency egress goals guiding his overall behavior. This is accomplished by comparing current with previous distances between the occupant, the fire threat, and the exit goal, and by comparing "knowledge" about threat and goal locations possessed by the occupant, with amounts possessed by other nearby simulated persons. Current locations of physical barriers (e.g., walls or doors) and of other occupants are also taken into account. Finally, he evaluates alternative responses and selects an action as his response for time $t_{i}$. The selection of a behavioral response (i.e., the decision to move in a particular direction) results from the comparison of available move alternatives against the occupant's current move criteria. For example, an occupant who knows the locations of both the fire threat and of a safe exit will favor moves which minimize his distance to the exit goal and/or maximize his distance from the threat. This response is likely 

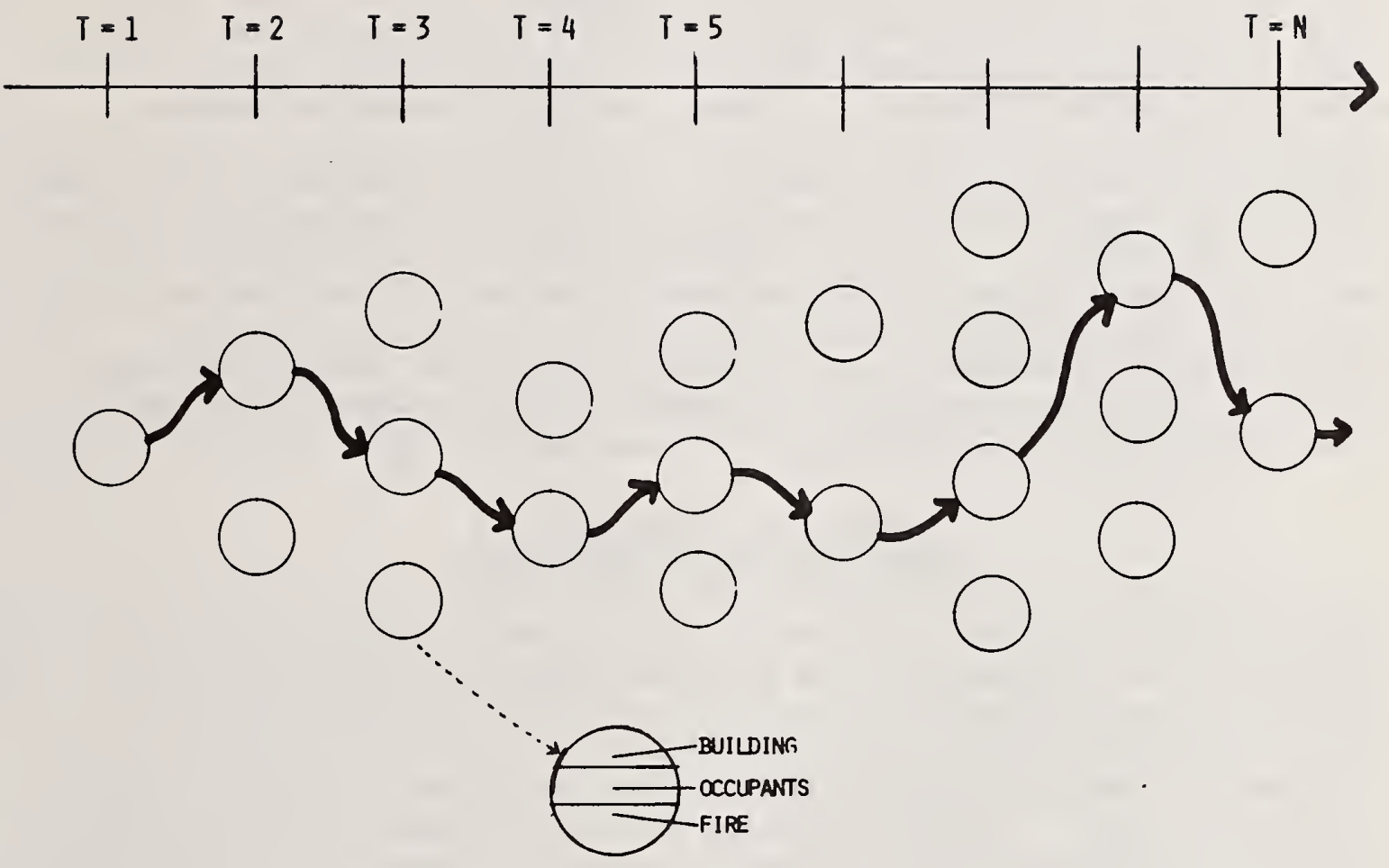

As the event unfolds, the state of the environment at time $t$ suggests several alternative states for time $t+1$. BFIRES probabilistically routes the event through time by constructing a logical sequence of states in Markovian fashion.

Figure 1: The Building Fire as a Sequence of Discrete Events 
to change his physical position within the building, and hence to create a new environmental information field to which all occupants must respond during the next time frame in the chain, $t_{i+1} \cdot$ This cycle continues until the fire event is completed.

In order to simulate information processing and behavior, BFIRES assumes that people possess "libraries of response programs" within their brains [4]. In broad terms these programs are thought to be acquired through learning and experience, and are also assumed to undergo change over time. The simulation program makes use of a simplified version of this mode1, as is shown in Figure 2. Thus, the BFIRES executive program routes simulated occupants through the perception (information gathering), interpretion, and response processes. Each of these processes calls upon a library of computer subroutines, each of which is responsible for producing some aspect of simulated occupant behavior (see Figure 2). Of course, several additional "nonbehavioral" subroutines are required which enable the user to communicate with BFIRES, i.e., to input initial scenarios and to retrieve from the computer data describing fire event outcomes. BFIRES was written in FORTRAN-V, and is currently operating on the UNIVAC 1108 and INTERDATA $7 / 32$ computers at NBS.

\section{A Technical Approach to Computer-aided Design Review}

Because BFIRES recreates fire events as they unfold over time, it is possible to use the program as a building design and regulatory tool. This may be accomplished by creating a building fire scenario (which depicts anticipated real world conditions), entering this scenario into the computer, executing the BFIRES program, and finally interpreting the computer's output. As more scenarios are executed for a given design, the more thoroughly will the design be tested. Comparisons between test results for several design alternatives could substantially aid the process of selecting the best scheme from a life safety viewpoint. A flow chart illustrating the technical approach to computer-aided design review is presented in Figure 3. An example is discussed below.

\section{AN EXAMPLE ILLUSTRATING THE APPLICATION OF "BFIRES"}

\section{Scenarios}

An example illustrating the possible uses of BFIRES involves the floor plans shown in Figures 4 and 5. These represent typical designs for a wing of a health care or nursing facility. The two plans are identical in most respects, and differ only in the location of the exit stairs. In Figure 4 the exits are remotely located at opposite ends of the floor, while in Figure 5 they are centrally located. At the moment of fire ignition, 12 occupants are assumed to be spatially distributed as shown in the figures.

In addition to considering differences in floor plan design, differences in occupant distribution are also compared. Figure 4 illustrates the situation in which all occupants are fully ambulatory, and may be assumed 

ANALYSIS OF CODE RELATED RESPONSES

FROM THE SOLAR DEMONSTRATION PROGRAM

\author{
by \\ Joseph Greenberg \\ Project Leader \\ National Bureau of Standards \\ Washington, D.C.
}

This paper is based on a report prepared jointly for the Department of Housing and Urban Development (HUD) and the Department of Energy (DoE) under activities carried out by the National Bureau of Standards (NBS) relative to the Solar Heating and Cooling Demonstration Program. The report documents and analyzes building regulatory information gathered by HUD Contractor personnel during the course of the Solar Residential Demonstration Program--from inception of the program (late 1975) through September 30, 1978.

Although not all builders and local code officials participating in the demonstration program were interviewed for the study, the total number of participants interviewed was of sufficient size to postulate trends and draw reasonable conclusions regarding the building regulatory aspects of the program. The report concludes that existing codes do not present a barrier to the installation and acceptance of solar systems; however, code officials need additional training and better back-up material to properly evaluate solar systems.

This paper summarizes and presents the major findings included in the report.

Key Words: Building code; code official; demonstration program; institutional constraints; solar builder/developer; solar energy . 


\section{INTRODUCTION}

The objective of the project reviewed by this paper is the analysis of data collected for the HUD Solar Residential Demonstration Program to provide an insight into those aspects of the building regulatory process that inhibit, impede, or otherwise adversely affect the installation and use of solar hot water and space heating and/or cooling systems. The project was designed to provide:

An analysis of the response by the participants in the demonstration program as to real or perceived regulatory problems encountered during the conduct of the program.

An analysis of the adverse impacts, if any, resulting from differences in various regulatory statutes.

A recommended course of action, as articulated by the participants in the demonstration program, regarding current and future regulatory needs.

An assessment of the documentation and training needed to assure an orderly and efficient system for the evaluation and acceptance of solar systems.

The HUD Demonstration Program is structured in cycles; each takes place sequentially in a different time frame with various projects awarded for each cycle. Although the HUD Solar Residential Demonstration Program is expected to have a total of five cycles, the report was limited to data gathered during the first three cycles and includes data collected from late 1975 to September 30, 1978--the cutoff date of the report.

\section{DATA SOURCES}

To assure an orderly and systematic method of identifying and collecting the pertinent data associated with the regulatory aspects of the HUD Solar Residential Demonstration Program, each organization having responsibility for the collection of data was identified. The data collection instruments (questionnaires and reports) were collected and a review made of each document to assess its value as a data source for regulatory information. Those valuable to the project were then singled out for study and the appropriate mechanisms established to collect the data; either through the NBS Solar Data Base or through direct contact with the custodial organization. To facilitate the handling and analysis of the information, special computer print-outs were developed using the information stored in the NBS Solar Data Base.

Organizations collecting data for the Solar Residential Demonstration Program were: 
Rea1 Estate Research Corporation - RERC

American Institute of Architects Research Corporation - AIA/RC

U.S. Department of Housing and Urban Development/Boeing - HUD/Boeing

The RERC data are by far the most pertinent to the study and are used to generate most of the conclusions and trends presented. The broad scope of the questions asked and the variety of respondents (demonstration builders, non-demonstration comparative builders, and local building code officials) allow for comparisons to be made and differences in responses to be analyzed.

\section{SAMPLE SIZE}

Regulatory questions were responded to by fifty percent (50\%) of the single family builder/developers engaged in constructing solar equipped demonstration houses, and approximately ten percent (10\%) of the multifamily builders/developers. In addition, RERC interviewed non-demonstration, non-solar comparative single family builders at approximately fifty percent ( $50 \%)$ of the locational areas where solar demonstration programs are being conducted. The demonstration builder data, both single family and multi-family, approximately reflected the number of site locations visited; the usual scheme is to generally interview only a single demonstration builder/developer per location. However, the number of comparative builders varied from one to four. In addition, responses were received from eighty-seven (87) local building code officials, which represents responses from approximately thirty-two percent (32\%) of the two hundred seventy-two (272) site locations, comprising the demonstration program during that time frame.

\section{FINDINGS}

The major findings that are detailed and analyzed in the report are summarized below:

A. Constraints/Technical Issues

1. Approximately eighty percent ( $80 \%$ ) of the local building code officials indicated that there are no major barriers in building codes at present which would impede the installation of solar energy systems in their jurisdictions, while a smaller percentage (approximately 64\%) foresaw no future problems. Those officials identifying current problems specified administrative difficulties as the most frequent reason for these problems. Anticipated new code requirements and structural concerns were identified by those officials who expected future problems.

2. Some local building code officials reported that the codes used in their jurisdictions contain provisions for solar systems. There was no indication that the processing and acceptance of solar energy installations was affected adversely or advantageously by a jurisdiction's adoption or lack of adoption of solar energy provisions. 
3. Approximately one-quarter of the local building code officials indicated that their departments had studied the question of potential impact of solar energy systems on building codes and of these, one-third indicated a need for standards for solar systems and components.

\section{B. Approval and Inspection of Solar Systems}

1. The solar demonstration builder/developer faces no greater or lesser difficulty than that routinely faced by non-solar builders in obtaining approval from building inspectors during the planning and construction phases of their projects. From the builder/developer perspective, it appears that regulatory issues have not impeded the acceptance of solar systems on the Solar Residential Demonstration Program.

2. Approximately one-quarter of the local building code officials indicated that solar applications presently require additional processing time and approximately one-half of these local building code officials expect that the need for this increased processing time will continue.

3. The number of waivers requested for solar installation is low. However, if a waiver is requested, the chance of having the waiver granted is excellent. In addition, approximately onequarter of the local building code officials required design changes to be made on solar systems installed in their jurisdictions.

4. System approvals and site inspections normally were handled in a routine manner; however, approximately one-quarter of the local building code officials reported that additional site inspections were required for them to become familiar with the solar installations or to run plumbing or other physical tests.

5. The greatest concern of the local building code officials identifying problems with solar systems meeting code requirements are the toxic fluids used in these systems.

6. Approximately two-thirds of the local building code officials indicated building code problems in the installation of a solar system in an older structure; citing an overwhelming concern with structural adequacy of the buildings. In addition, approximately one-quarter of the local building code officials indicated that multi-family solar installations would entail unique considerations from an approval point of view because of the inherent complexity of these larger installations.

7. Certification of solar equipment, with approved testing conducted by any qualified testing institution, was desired by one-third of 
the local building code officials prior to their issuing a building permit.

\section{Code Official Training and Technical Support}

1. Generally, the knowledge and educational background of the local building code official and the sources of solar energy information available to him varied greatly from jurisdiction to jurisdiction. If the processing of solar applications is to be accomplished more effectively, the code official's knowledge of solar energy systems must be upgraded by education, training and actual experience.

2. Areas of assistance identified by the local building code official include: the training of evaluators and inspectors; the development of manuals of accepted practice and inspection guidelines; development of feasibility data; development of efficiency data for different solar systems; certification of equipment and systems; and, need for standards.

3. The sources most often used by the local building code official for information related to solar energy are trade publications, manufacturer's data, national and local associations, and government agencies. Other important sources are universities and independent agencies. Developers and financial institutions were rated low as sources for solar information. 

SESSION 3A - DESIGN CONSIDERATIONS AND

THEIR IMPACT ON CODE ENFORCEMENT

Moderator: Joseph A. Cirillo

State Building Commissioner

12 Humbert Street

North Providence, Rhode Island 

CONTRACTING FOR VALUE MANAGEMENT DURING DESIGN

by

\author{
Donald E. Parker \\ Director, Value Management Division \\ Office of Construction Management \\ Public Buildings Service \\ General Services Administration \\ Washington, D. C.
}

This paper describes the content and application of the General Services Administration (GSA) Value Management (VM) Program requirements incorporated by regulation in a11 architect-engineer (A-E) contracts.

The objective of this VM Program is to control the cost of construction by performing VM studies at various points in the design process with the objective of recommending changes to design work in progress.

The VM process requires the understanding and agreement of two parties the client and the designer. VM study forces the enhancement of communication between these two parties. It provides the freedom to challenge codes, criteria, needs, desires, and specifications in a professional atmosphere.

Because the economic measure of value is life cycle cost, the program controls life cycle cost as well as initial cost. Thus, it has been effective in reducing maintenance and energy cost in addition to ensuring the project budget is met.

Required VM service design contracts can be expected to provide an average \$10 return for every dollar invested in cost of the service.

Key Words: Economic analysis; life cycle cost; value management;

value study. 
The General Services Administration (GSA) Public Buildings Service (PBS) incorporates a Value Management (VM) Services Contract Clause in each of its professional services contracts with architect-engineer (A-E) and construction managers (CM) involving the design of buildings, extensions, alterations, and improvement projects with estimated construction costs (ECC) over $\$ 200,000$. This clause establishes minimum contractor performance and scope of service concerning Value Management during design.

Our intent in requiring the use of VM principals and techniques is that their application will result in:

1. Reduced overall costs without degradation of the essential performance of the project.

2. Reduced potential for design deficiencies as reflected in reduced numbers of change orders during construction.

3. Positive control of costs.

4. Savings in time for design by eliminating unnecessary design work, adding to a clarification of the design scope, reducing false starts, and preventing the loss of time that occurs when budgets are exceeded.

The simple reason we require the designer to perform VM is, besides the client, the A-E's decisions have the most influence over expenditure of funds during a facility's life. (See figure 1.)

For example, the client, through the code or criteria he uses, may prescri the quantity of plumbing fixtures to be provided. This does restrict the A-E's influence on what it will cost to provide and operate the plumbing system. However, he does retain the next greatest influence on these cost because he does determine layout, arrangements, materials, colors, etc.

By the time the construction contractor enters the scene, he can influence the cost of materials and installation by only a few percent. Maintenance and operations personnel are left with the least influence because they must live with that given them.

Clearly, the greatest potential for savings is to provide a way for the A-E to perform VM during design and at the same time permit him to questio client criteria. 


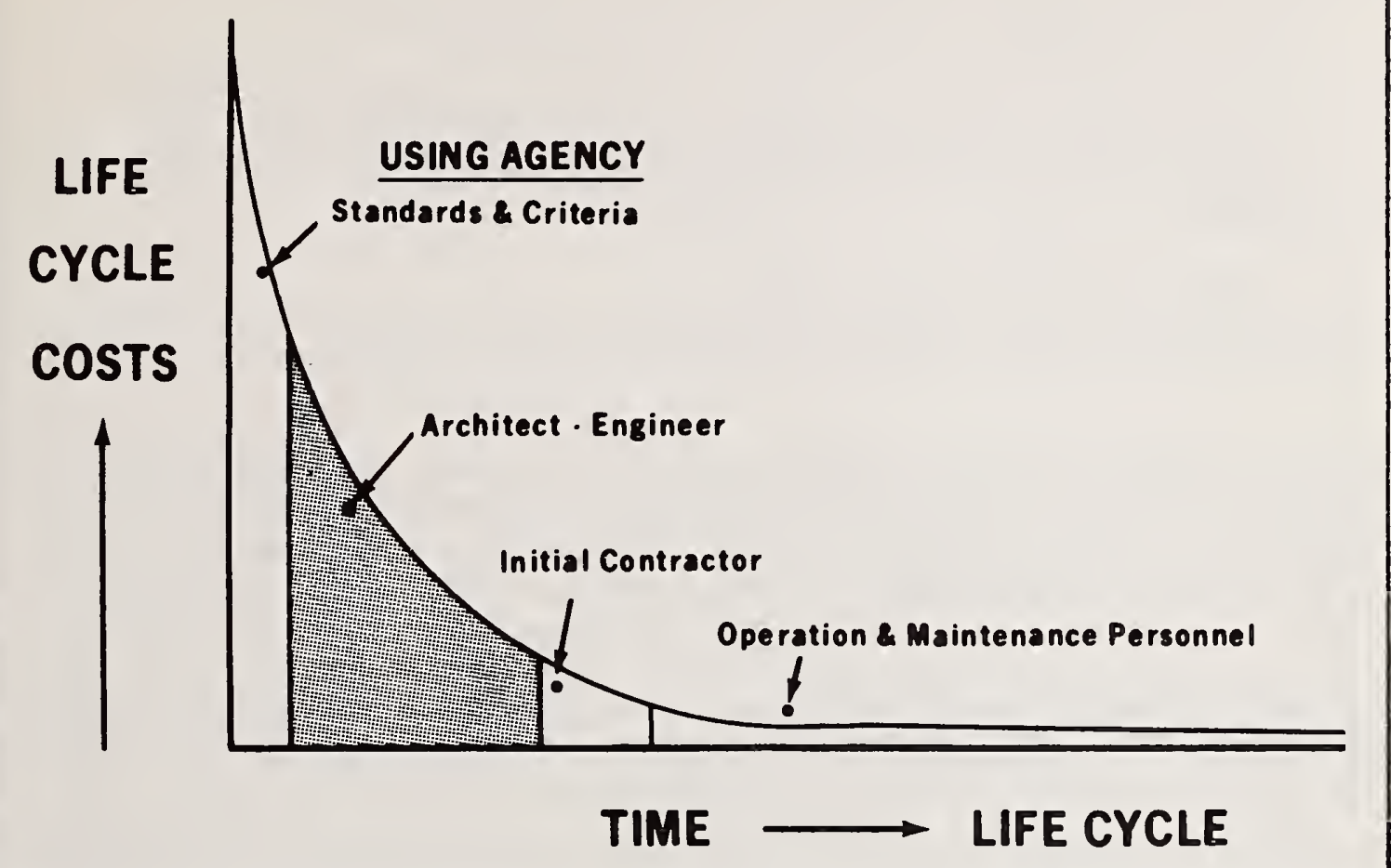

Figure 1: Decision Maker's Influence on Cost

\section{DEFINITION}

At this point it is important to emphasize that contracting for VM is not contracting for just cost reduction services or economic analysis to determine which is the cheapest system. In fact, our VM requirements are not a substitute for economic analysis or life cycle costing services which are still required in our A-E contracts.

Then it is important to state the formal definition of VM to understand what the service is and how it relates to other A-E contract requirements:

"VM is an organized effort directed at analyzing the function of goals and services for the purpose of achieving necessary functions at the lowest overall cost, consistent with achieving necessary operationa1, maintenance, safety, reliability and other performance features."

Analyzing the above definition with regard to our contract services, one will see the full implication of VM as a specific process which requires application of a specific methodology. 
For example, the term "organized effort" in the definition translates into:

* identifying and dedicating resources to perform VM (the contract sets these aside for VM use)

* deliberately investing these resources in potential areas of savings (rather than spending the resources to see what will happen)

* using multidiscipline teams

* formally following through on ideas until resolution is reached.

Of course, this process is aimed at identifying and eliminating all unnecessary costs without sacrificing required performance. The methodology takes over here. Value is enhanced by improving the relationship of worth (amount you are willing to pay for a function) to cost through the study of function (purpose for which an item or practice exists or is being considered). Identification of unnecessary costs is established by analyzing the functions of the design or item under review. Elimination of unnecessary costs is the result of implementing alternative means to achieve the required function.

Now, the cost referred to above is not just initial construction cost. Rather, it is life cycle cost ("lowest overall cost" in the definition). Life cycle cost (LCC) of any item (building, system, component) is the total cost to the owner or user for acquiring it plus operating, supporting, maintaining, repairing and/or replacing it over the full life span it is needed.

VM uses LCC as the economic measure of value. Doing this ensures that required performance is maintained when changes are adopted. More often than not, VM enhances the performance reliability of the service or products to which it is applied.

\section{VALUE SERVICE REQUIREMENTS}

GSA's handbook, A-E/CM Value Management Services (PBS P 8010.1), is the document referenced in A-E contracts which specifies the requirements for these services.

During negotiation of fee for the basic design work, a separately identified fee is negotiated for doing VM work. However, GSA requirements do not provide for incentive sharing, with A-E or CM, of savings achieved during design or construction.

The amount of VM effort we require increases as the dollar value of construction increases per the levels of service briefly described below: 
Leve1 1 - Projects between $\$ 200,000$ to $\$ 1,000,000$ require development of cost models and A-E consideration of client generated value study proposals.

Leve1 2 - Projects between $\$ 1,000,000$ to $\$ 5,000,000$ require the A-E to perform VM studies of criteria and systems.

Level 3 - Projects between $\$ 5,000,000$ to $\$ 30,000,000$ require the conduct of a VM workshop for the project in addition to the studies.

Leve1 4 - Projects over $\$ 30,000,000$ require assignment of a project manager to oversee and coordinate all the VM services under contract.

It is not enough, however, to simply require VM to be performed during design without the client being prepared to support the effort. In our case, GSA has issued written guidance to respond to issues that can be anticipated to arise from requiring VM services during design. These involve:

Design schedule. We require that all design schedules include provisions for performing value studies and time to implement expected results. A tight design schedule and an urgent need for design completion is not cause to permit VM services to be deleted from the contract. Such situations intensify the need for increasing value services. The faster the project is issued, the more susceptible to poor value it is.

Changes to codes, criteria. Because the VM program encourages innovation and initiative, changes are an expected product. In GSA Regional Commissioners and Assistant Commissioners are authorized to consider requirements in a11 PBS publications as general guidance rather than rigid standards in order to approve and implement results from VM efforts. Where definite advantages can be expected, deviations are authorized provided that a professional judgment has been made that a safe, adequate, more economical, or better design or procedure will result. This authorization for worthwhile deviations does not apply to deviations from statutory and similar requirements included in Public Laws, Federal Procurement Regulations, Executive Orders and similar regulations, such as - statutory requirements include provisions for the handicapped, air and water pollution abatement and control, and the use of specifications which are non-proprietary.

Compensation for changes. Assuming A-E's perform their professional responsibility during design, the client should be prepared to provide additional compensation to implement changes when necessary. GSA permits A-E's to be compensated for implemented changes resulting from value studies when they affect completed and approved design work to date. The 
entitlement and the amount of compensation is determined by the Contracting Officer before the A-E is authorized to proceed with any changes. Such compensation is limited to the additional costs of redesign. Value Management changes intended to bring the project, as designed by the $A-E$, back within the budget are expected to be accomplished by the A-E without additional compensation.

\section{SCOPE OF APPLICATION}

Our VM service requirements provide for repetitive consideration of VM at all stages of design. We know that the highest return on investment from VM application can be expected early in the design process, before the cost of redesign in order to implement a change adversely affects the savings potential.

But design is not a simple, straight forward process. It is an interactive process. Each step in programming or design of a project represents a known baseline that starts out broad in content and becomes more and more definitive as the time goes on. The heart of our VM requirements is to work against a given baseline in order to change or redirect the baseline and arrive at an end result that will satisfy the original functions. For this reason, VM is applied repeatedly as various points or phases during the design process.

Concept stage. The purpose of the conceptual phase is to translate requirements and program directives into feasible concepts which will result in defining future operational and support requirements. During this stage a VM criteria review is performed. The designer is requested to question, study, or recommend changes to Government-imposed restrictions whether they be performance criteria, scope requirements, standard prescriptive specifications or special instructions.

At this stage, a cost/worth model with parameter cost is developed and reconciled with the project budget to set a cost baseline to control initial costs through design.

Similarly, this is the time to establish LCC goals for the entire facility. Very often, the VM activity during this stage identifies issues for further detailed study and consideration for the next VM study.

Tentative stage. During the design tentative stage of design, approved concepts are definitized, preliminary drawings and outline specifications are started, and sufficient detailed information is developed to substantiate all quantity and cost that have been presented in the program 
directive. This is the most opportune time to question performance characteristics. VM effort at this stage is directed toward creating value indexes of function, cost, and worth of each system as a whole, and its major subsystem.

VM task team studies are conducted at this stage, often in the form of workshop, with the objective of generating changes to the design. We require that task team reviews be performed by individuals not responsible for the original design. This is intended to prevent extensive interruption of the design process as well as provide a less prejudicial value review.

VM studies at this stage of design are directed toward system studies. The studies concentrate on system selections as expressed by single line drawings and calculations for foundation, superstructure, mechanical, electrical, fire protection, and vertical transportation. In addition, system relationships, design configurations, space efficiencies and scope requirements are reviewed. Information derived from independently performed economic analysis on alternate systems by each engineering discipline is also used to arrive at recommendations for improving project value.

Working drawing stage. It is during the working drawings phase that specific (final) design details are formulated. Materials are selected and specifications created. VM effort at this stage is concentrated on eliminating unnecessarily restrictive detail for requirements, ensuring standards for details, minimizing the different types of quantities, and eliminating items not necessary.

VM study activity deals with components of the various building systems rather than the systems themselves. Effort is made to study areas where the cost to make a change (redesign) is minimal compared to the potential savings. Schedules for equipment, hardware, windows, doors, finishes and materials fill in this category as do specification requirements.

When projects are phased or fast tracked into bid-packages, VM study is conducted on each package prior to release for bids. The VM studies concentrate on all items of procurement in the bid-package as well as the interface with items that might influence cost savings on subsequent bidpackages.

\section{CONCLUSION}

Since the inception in 1973 of the VM Service Contract Clause in A-E/CM professional services contracts, studies by designers as well as GSA's own in-house staff, have resulted in elimination of more than $\$ 32$ million 
of unnecessary cost in facility designs. This represents a return of some $\$ 10.20$ for every dollar spent on the program. Many A-E's have accepted the methods and procedures of VM as proposed by GSA and view this approach as an opportunity to enhance the capability of their practice for the present and future benefit of their clients.

Value Management encourages innovativeness, ingenuity, and imagination in reducing cost without sacrificing required quality or function. It can serve as a beneficial tool to address the problems of scarce resources while maintaining sound quality construction. The Value Management Program in GSA continues to promote teamwork, enhance communication, improve productivity, reduce waste, increase cost consciousness, and encourage personal development because Value Management provides a definite avenue of change. 
BUILDING RECERTIFICATION AND DADE COUNTY, FLORIDA

\author{
by \\ Ralph Warburton, AIA, AICP, PE \\ Professor of Architecture and Planning \\ University of Miami \\ Coral Gables, Florida
}

One of the major problems in maintaining environmental quality is the need for continual routine monitoring of existing private-sector construction to ensure structural integrity over time. Dade County, Florida has an operating ordinance which provides a model deserving significant consideration in this regard, so that extensive loss of life and property can be minimized.

On May 21, 1975, the Dade County, Florida Commission adopted Ordinance 75-34, providing for routine examination by private-sector architects and engineers of structures over 40 years old (and re-examination at 10 year intervals thereafter) to verify their continued eligibility for a Certificate of Occupancy. The ordinance covers all private-sector buildings providing facilities for over 10 persons and having over $2,000 \mathrm{sq}$. ft. of floor area, except for 1 and 2 family residential structures.

At present, about 6,000 buildings have felt the effects of this ordinance, with about $75 \%$ receiving immediate recertification and about $10 \%$ requiring enforcement measures. Buildings are currently coming under the ordinance provisions at the rate of about 700 per year.

Evaluation of potential generic issues, considering the program development to date, indicates no serious defects in the program and the immense benefits to the public from such an ordinance covering privatesector buildings.

In fact, the Dade County Ordinance presents a model worthy of national attention and adoption as appropriate as part of new state/local building code legislation as well as through revisions to professional established standards and policies.

Key Words: Architects; codes; earthquake; engineers; Florida; inspection; legislation; recertification. 


\section{Introduction}

One of the major problems in maintaining environmental quality is the lack of procedures for the continual routine monitoring of existing private-sector construction to ensure maintenance of design quality over time. It has been recognized that our significant building stock must be maintained at an appropriate level of quality to ensure maximum livability as well as minimal catastrophic losses from such causes as fire, hurricanes, earthquakes, etc. This recognition at the federal, state and local level is outlined in this paper, together with material on the Dade County, Florida, recertification program which provides for periodic inspections and certifications of existing privatesector buildings utilizing private-sector design professionals.

\section{Background Overview}

Apparent1y, the first United States law for the inspection of existing buildings was adopted in New Orleans in 1856. It stated: "The Mayor and Surveyor shall examine theatres and places of public resort for structural stability, and take suitable measures to prevent accidents that might result from any negligence in the construction of the building or from any mismanagement of the proprietors." (Ref. 1, italics added.)

From this has developed, principally in the 20th century, the "system" of model codes, local codes and state codes which of ten encompass elements intended to ensure from the outset the safe continuance of the use for which the building was constructed. Maintenance of housing quality is provided for through housing codes. As late as 1969, a survey of the building code field included little material on building quality maintenance - covering only housing codes and use violations. (Ref. 2.)

This survey also covers the transition from specification codes to performance codes; the latter allowing broad leeway to designers in selected materials and methods to achieve desired results, within established engineering and architectural parameters. Performance orientation in building codes has been widely advocated since its benefits are many (Ref. 3), but it requires an increasingly greater degree of technical sophistication on the part of the code enforcement personnel.

The increasing extension of the building code responsibilities toward maintenance and performance-orientation areas, simultaneously, can be illustrated in regard to the developing national concern about earthquakes. 


\section{Earthquake Hazard Mitigation Developments}

In 1975, a panel of the National Academy of Science stated that the "...modification of and even demolition of unsafe structures must be included in the goals of structural design and maintenance to be pursued by public and private officials." (Ref.4.) The evaluation of the long term performance of repaired buildings was called for in 1977 (Ref. 5). Also in 1977, the American Institute of Architects Research Corporation called for the generation of problem solving strategies in maintenance procedures and techniques (Ref. 6). The issue was discussed further in the 1978 report of Earthquake Hazards Reduction, prepared by the Executive Office of the President, which outlines some state measures taken to review structures (principally publicly assisted and/or licensed hospitals and schools) for their soundness with respect to potential earthquake damage (Ref. 7). Washington publications sponsored by the Veterans Administration, the General Services Administration, and the Department of Defense within the past decade have identified vital nonstructural as well as structural systems, and advanced evaluation systems for existing buildings which have potential application to recertification approaches (see Ref. 8 for summary). And, guidelines for the repair and strengthening of existing buildings and for emergency post-earthquake inspections have been proposed in the Applied Technology Council recommended tentative provisions. (Ref. 9.)

\section{Local Government Background}

Are local government code procedures available to cope with the outlined subject matter? The key tool would be development of the certificate of occupancy concept, requiring periodic re-inspection for maintenance of the right to continue to occupy a structure. A recent national pilot survey by mail, carried out by researcher Philip Martin under the author's direction, strongly suggests that this tool is in its initial evolving stages of development.

Several quotes from response letters by local building officials are illustrative. In Boston, "The Building Department does not have a recertification program...," although voluntary recertifications are possible (Ref. 10). "The City and County of Denver has no program for recertifying buildings after their initial construction." (Ref. 11.) "Recertification of existing buildings is not required by the (Los Angeles) code." (Ref. 12.)

The response from San Francisco was more positive: "In apartment houses and hotels, we have a triennial inspection of the public areas for maintenance and to ensure compliance with the Housing Code, including retroactive provisions, and a program in which the worst 1000 apartment or hotel buildings each year are completely inspected including all rooms of all the dwelling units. That is the extent of the Bureau of Building Inspection's recertification program. The Fire Department has programs for inspection of public assembly, and a general program, when personnel are avaizable, for maintenance of office buildings." (Ref. 13, italics added.) 


\section{Local Government Reliance on Private Sector Architects/Engineers}

While the term "recertification of buildings" is not in the Chicago vernacular, its Department of Buildings is required to inspect many types of buildings annually for code compliance, with fines being assessed for non-compliance. In addition, jointly recognizing problems connected with technical sophistication and manpower, the City Council enacted a 1978 ordinance requiring that a registered private-sector architect or structural engineer inspect "...every exterior wall and enclosure of or part of a building five stories or more in height..." at least once every ten years; every five years when the building reaches the age of 35 years. If deficiencies are found, "...repairs, reinforcements or precautionary measures..." are required. (Ref.14.)

The metropolitan area of Dade County, Florida has an operating recertification ordinance, using private-sector architects and engineers, that is $f a r$ in advance of those indicated above. (Ref. 15.) (The ordinance was adopted primarily to address problems connected with early building when no building code was in force. This resulted in, among other things the use of sea sand and water in some concrete mixes.) Thus, the Dade County ordinance provides a procedural model deserving significant consideration in earthquake prone areas so that extensive loss of life and property can be minimized.

\section{THE DADE COUNTY ORDINANCE}

\section{Coverage}

On May 21, 1975, the Dade County, Florida Commission adopted Ordinance 75-34, providing for routine examination of structures over 40 years old (and re-examination at 10 year intervals thereafter) to verify their continued eligibility for a Certificate of Occupancy. The ordinance covers all private-sector buildings providing facilities for over 10 persons and having over 2,000 sq. ft. of floor area; except for 1 and 2 family residential structures.

\footnotetext{
"Recertification" is construed to mean "...the requirement for specific inspection of existing buildings and structures and furnishing the Building Official with a written report of such inspection as prescribed..." conforming, in general, with a 7-page guidelines form issued by the Building Official. (Ref. 16.)
}

As buildings reach the initial 40 years of age, or the 10 year renewal age, a "Notice of Required Inspection" is sent to the owner of record giving him 90 days to file an inspection report prepared by a licensed private-sector architect or engineer of his choosing. According to the ordinance, "such engineer or architect shall undertake such assignments only where qualified by training and experience in the specific technical field involved in the inspection and report." (Ref. 15.) 


\section{Inspection Report}

The inspection report form encompasses structural elements in some detail, but mechanical and electrical systems are not included. A review of some main topical headings is illustrative: Present Condition of Structure, Masonry Bearing Wa11s, Floor and Roof Systems, Steel Framing Systems, Concrete Framing Systems, Wood Framing, Windows. Under the Concrete Framing Systems heading for example, the inspecting engineer or architect is asked to give a full description of the structural system, analyze any cracking with regard to significance, estimate the general condition of the system, evaluate the extent of rebar corrosion and recommend repairs, and analyze any samples of concrete obtained from spall areas.

If any defects are noted in such report, the owner has 150 days after the date of the "Notice of Required Inspection" to correct the situation - if it is not corrected, as attested to by the certification of the inspecting architect or engineer bearing his seal and signature, the originally issued certificate of occupancy for that building may be revoked.

\section{Application}

At present, about 6,000 buildings have felt the effects of this ordinance, with about $75 \%$ receiving immediate recertification, $15 \%$ undergoing expeditious repairs, and about $10 \%$ requiring enforcement measures. Buildings are currently coming under the ordinance provisions at the rate of about 700 per year. As a consulting architect and engineer, the author has directly participated in this recertification program on behalf of a private-sector owner, and was able to discharge these responsibilities in a non-problematic manner. From inception, and during the five years since adoption, the program has had wide professional and political acceptance among all facets of the community.

\section{EVALUATION}

While the Dade County ordinance is evidently a landmark law which could have major impact, some prospective problem areas can be identified with regard to owners, a/e's and local governments.

Owner related issues include time requirements, a/e qualifications, equitable enforcement, effect on real estate capital and rental values, ability to secure repair loans, and effect on insurance costs. Architect and engineer related issues include contract standards, fees, professional liability, and threshold for minimum repairs. Local government related issues include enforcement organization structure and personnel, and unrepairable defects. 
However, evaluation of these potential generic issues, considering the program development to date, indicates no serious problems with the program as well as the immense benefits to the public from such an ordinance covering private-sector buildings.

The 6,000 building operational scale of the Dade County program is comparable to the magnitude of the problem in many cities, such as earthquake prone San Francisco. There, for example, it has been estimated that 4,200 potentially hazardous buildings are located within a 200 block area where severe damage may happen in the event of a 1906-type earthquake. (Ref. 17.)

In fact, the Dade County ordinance presents a model worthy of national attention, including further research, and adoption as appropriate as a part of new state/local building code legislation as well as through revisions to established professional standards and policies and so that the desired environmental quality of our urban areas is maintained.

\section{REFERENCES}

1. Colling, R. C. and H., editors; Modern Building Inspection; Building Standards Monthly Publishing Company, Los Angeles, California; 1950 .

2. Sanderson, R.; Codes and Code Administration; Building Officials Conference of America, Inc.; Chicago, Illinois; 1969.

3. Warburton, R.; "A Progressive Approach to Zoning and Building Codes;" Systems Building News, W. R. C. Smith Publishing Company, Atlanta, Georgia; July 1971.

4. Panel on the Public Policy Implications of Earthquake Prediction; Earthquake Prediction and Public Policy; the National Academy of Science, Washington, D. C.; 1975.

5. Hanson, R. D.; Repair, Strengthening and Rehabilitation of Buildings...; University of Michigan Department of Civil Engineering; Ann Arbor, Michigan; October 1977.

6. American Institute of Architects Research Corporation; Architects and Earthquakes: Research Needs; The Corporation, Washington, D. C.; 1977.

7. Working Group on Earthquake Hazards Reduction, Office of Science and Technology Policy, Executive Office of the President; Earthquake Hazards Reduction; the Office, Washington, D. C.; 1978 . 
8. Yancey, C. W. C. and A. A. Camacho; Aseismic Design of Building Service Systems: The State of the Art; U.S. Government Printing Office, Washington, D. C.; 1978.

9. Applied Technology Council; Tentative Provisions for the Development of Seismic Regulations for Buildings; U.S. Government Printing Office, Washington, D. C.; 1978.

10. Letter dated 27 September 1978 from R. L. Granara, Assistant Building Commissioner, Boston, Massachusetts.

11. Letter dated 27 September 1978 from W. J. Miller, Director, Building Inspection Division, Denver, Colorado.

12. Letter dated 2 October 1978 from B. R. Whitson, Chief, Special Projects Division, Conservation Bureau, Department of Building and Safety, Los Angeles, California.

13. Letter dated September 1978 from R. C. Levy, Superintendent, Bureau of Building Inspection, San Francisco, California.

14. Letter dated 26 September 1978 from John F. Connelly, Coordinator, Special Projects, Department of Buildings, Chicago, Illinois, and attached documentation.

15. Ordinance No. $75-34$ by the Board of County Commissioners of Dade County, Florida, amending the South Florida Building Code adopted by Ordinance No. 57-22, as amended, adding a new subsection 104.9 Recertification. Adopted 21 May 1975.

16. Dade County, Florida, "Recommended Procedural Guidelines for Building Recertification," 21 May 1975.

17. Department of City Planning; "A Community Safety Plan for the Comprehensive Plan of San Francisco;" City of San Francisco, California; July 1974. Discussed, with other background in: American Institute of Architects Research Corporation; Summer Seismic Institute for Architectural Faculty; The Corporation, Washington, D.C.; 1977. 



\author{
COMPUTER-AIDED DESIGN REVIEW: \\ PREDICTING THE EMERGENCY EGRESS POTENTIAL \\ OF PROPOSED BUILDINGS ${ }^{1}$ \\ Fred I. Stah1, Ph.D. \\ Environmental Design Research Division \\ Center for Building Technology, NEL \\ National Bureau of Standards \\ Washington, D. C.
}

This paper discusses the potential use of computer simulation techniques by building code officials, as tools which aid in the prediction of building performance. As a case in point, the BFIRES program for simulating emergency egress during building fires, developed at NBS, is presented. The program is described from the user's viewpoint, and a specific example of its application in assessing building design is treated.

Key words: Building codes; building fires; computer-aided design; computer simulation; fire research; human performance; modeling; regulatory process; simulation

1 The research reported here was funded by the Center for Fire Research, NBS, through its NBS-HEW Fire/Life Safety Program, and by the Center for Building Technology, NBS. 


\section{INTRODUCTION}

\section{Goals and Objectives}

Since 1977, the Environmental Design Research Division of the Center for Building Technology, National Bureau of Standards (NBS) has been actively developing a technique for simulating the emergency egress behavior of building occupants via computer $[1,2,3]^{1}$. Long range goals of this ongoing activity have been (a) to develop a deeper understanding of human behavior during fire situations, and (b) to develop a standardized technique for analyzing alternative building designs from an emergency egress viewpont. The latter aim provides the focal point of this paper.

The principal technical product of this research activity is BFIRES, a dynamic stochastic computer simulation of emergency egress behavior by building occupants during fires. The objectives of this paper are to acquaint the'reader with the purpose and structure of BFIRES, to suggest the utility of computer-aided design review by building designers and code officials, and to present an example illustrating an application of the BFIRES program. This paper should not, however, be construed as a "user's manual"2

\section{Computer-aided Design Review: Why?}

Regulatory mechanisms in current use usually require the compliance official to determine whether a given building design conforms to applicable regulations. When the building under review deviates little from local or accepted standards the review process is often straightforward. But when the regulatory official is confronted by a novel or highly specialized building program or design solution, he may be forced to exercise considerable discretion without the benefit of either past experience or reliable analytical tools. When considering life safety from fire for example, there currently exist no standardized tools with which to predict the emergency egress potential of specific building designs in relation to various fire or emergency scenarios.

A simple example illustrates this point. According to section 5-1201 of the Life Safety Code (1973 edition),

Exits shall be so located and exit access shall be so arranged that exits are readily accessible at all times. Where exits are not immediately accessible from an open floor area, safe and continuous passageways, aisles, or corridors leading directly to every exit

1 Numbers in brackets indicate references which appear at the end of this paper.

2 Preparation of a BFIRES user's manual is currently in progress. Researchers wishing to use the program should contact the author. 
shall be maintained and shall be so arranged as to provide convenient access for each occupant to at least 2 exits by separate ways of travel, except as a single exit or limited dead ends are permitted by other provisions of this Code.

This section, and in general Chapter 5 of the Life Safety Code, prescribes ready access to exits in the hope that during a fire, alternative egress pathways will protect occupants from the blocking of any single exit or path. However, the Code provides designers and building officials with neither a method for testing the adequacy of any given design, nor a means for comparing design alternatives in terms of life safety costs and benefits (e.g., time required to evacuate a floor, potential number of persons trapped on the floor, etc.). Without standardized tests and evaluative methods, how is the building official to determine the adequacy of a proposed egress scheme for those buildings too complex for straightforward code review?

\section{"BFIRES:" A COMPUTER MODEL FOR PREDICTING EMERGENCY EGRESS BEHAVIOR}

\section{Purpose}

BFIRES was specifically designed to simulate--by digital computer--the movement of people within building enclosures in response to life threatening stimuli (i.e., fire and smoke). Originally planned for use in evaluating health care facility designs, the program permits users to simulate such special activities as rescuing nonambulatory persons, in addition to simulating more frequent and general categories of emergency response (e.g., exit seeking, threat evasion, the deterioration of emergency responses resulting from inhabiting a toxic environment, etc.). In its current form BFIRES is applicable to a broad range of building occupancies.

\section{A Cautionary Note}

To date, considerable effort has been devoted to developing BFIRES $[1,2]$ and to analyzing the program's sensitivity to important parameters [2]. However, extremely little research has yet been undertaken regarding the predictive validity of BFIRES (i.e., the ability of the program to predict the performance of real human beings during actual fire emergencies). Although a recent investigation of the predictive capabilities of BFIRES yielded positive results [3], that study was extremely narrow in scope ${ }^{1}$ and the findings do not readily generalize to other

1 Fires in two-bedroom dwelling units were studied, in which the kitchen was the room of fire origin. BFIRES simulated fire outcomes were found to agree, in most respects, to results of real fires reported in the National Fire Protection Association Fire Incident Data Organization (NFPA-FIDO) data base. 
occupancies or fire conditions. Consequently, the reader is cautioned that BFIRES--in its present form--is not advocated for practical application by the building design and regulatory communities. Thus, references in this paper to the program's use are hypothetical. It is hoped, of course that future versions of the program will prove to be valid and reliable for practical applications.

\section{Concept and Structure of BFIRES}

BFIRES simulates the perceptual and behavioral responses of building occupants involved in fire emergencies. As in real fires, simulated occupants may respond to a fire alert although they are quite distant from actual fire products which may have been confined in some distant part of the building. Or their behavior may result from a direct confrontation with toxic agents. The program can simulate a wide variety of emergency scenarios, primarily because it deals with human behavior at a very fundamental level. Specifically, the basic unit of occupant behavior generated by BFIRES is the individual momentary response to the state of the environment at a discrete point in time, $t$. BFIRES conceptualizes a building fire event as a chain of discrete "time frames" $\left(t_{1}, t_{2}, \ldots, t_{n}\right)$ and for each such frame, it generates a behavioral response for every occupant in the simulated building. If each "frame" could be replayed sequentially as in the case of a movie or animated film, a complete "picture" of the building fire event would be seen (i.e., the simultaneous egress performance of all occupants in response to a migrating fire threat). See Figure 1.

The response generating capability of BFIRES is based upon an information processing explanation of human behavior, and suggests that building occupants act in accordance with their perceptions of a constantly changing environment. Between any two time frames $t_{i}$ and $t_{i \cdot r}$, the environment undergos change; e.g., people have altered thelr locations in space, smoke has advanced to new locations, and the building itself may have undergone physical changes. When preparing a behavioral response at $t_{i+1}$, a simulated occupant first gathers information which describes the state of the environment at this point in time. Next, he interprets this information, relating it to the emergency egress goals guiding his overall behavior. This is accomplished by comparing current with previous distances between the occupant, the fire threat, and the exit goal, and by comparing "knowledge" about threat and goal locations possessed by the occupant, with amounts possessed by other nearby simulated persons. Current locations of physical barriers (e.g., walls or doors) and of other occupants are also taken into account. Finally, he evaluates alternative responses and selects an action as his response for time $t_{i}$. The selection of a behavioral response (i.e., the decision to move in a particular direction) results from the comparison of available move alternatives against the occupant's current move criteria. For example, an occupant who knows the locations of both the fire threat and of a safe exit will favor moves which minimize his distance to the exit goal and/or maximize his distance from the threat. This response is likely 

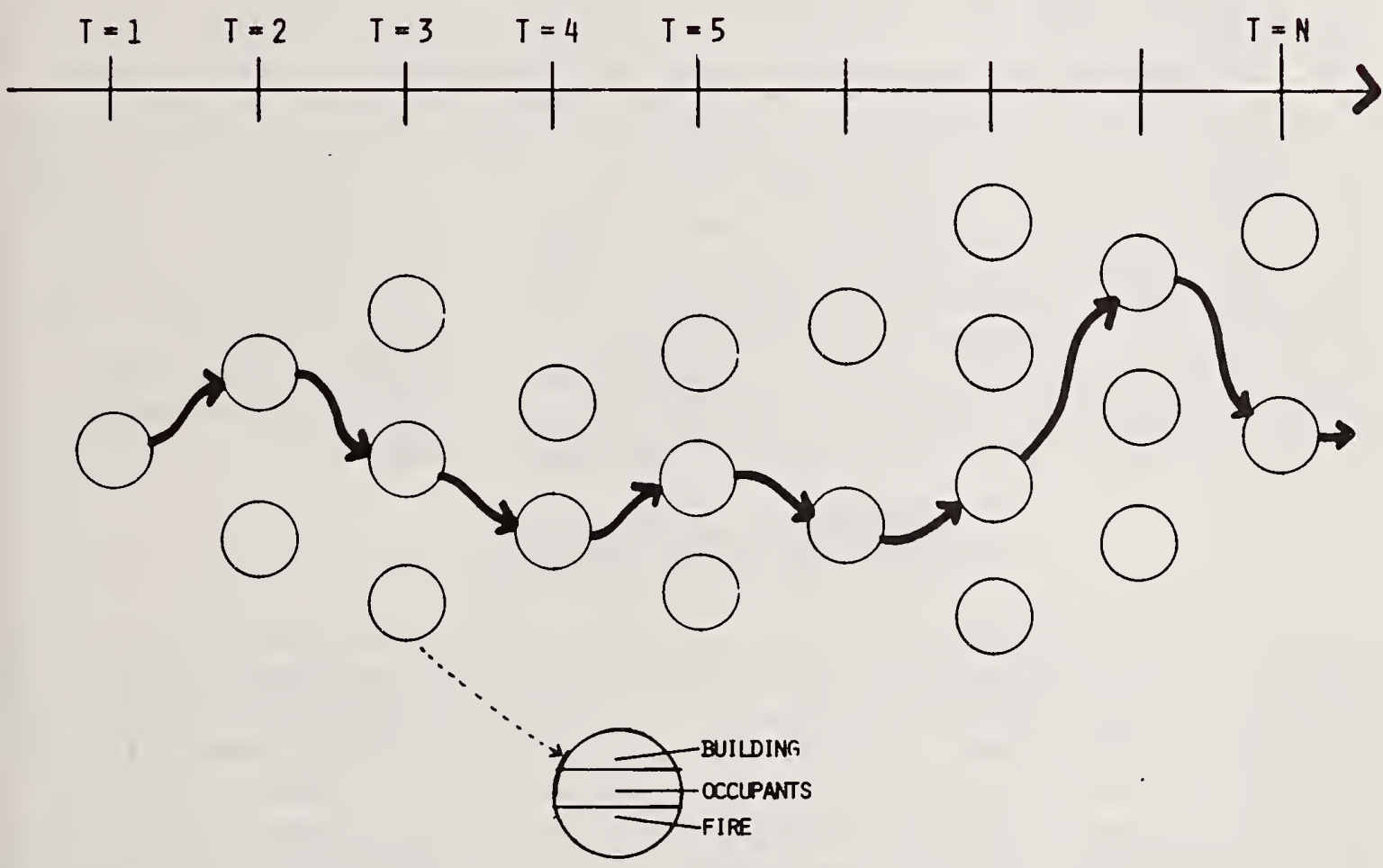

As the event unfolds, the state of the environment at time $t$ suggests several alternative states for time $t+1$. BFIRES probabilistically routes the event through time by constructing a logical sequence of states in Markovian fashion.

Figure 1: The Building Fire as a Sequence of Discrete Events 
to change his physical position within the building, and hence to create a new environmental information field to which all occupants must respond during the next time frame in the chain, $t_{i+1}$. This cycle continues until the fire event is completed.

In order to simulate information processing and behavior, BFIRES assumes that people possess "libraries of response programs" within their brains [4]. In broad terms these programs are thought to be acquired through learning and experience, and are also assumed to undergo change over time. The simulation program makes use of a simplified version of this mode1, as is shown in Figure 2. Thus, the BFIRES executive program routes simulated occupants through the perception (information gathering), interpretion, and response processes. Each of these processes calls upon a library of computer subroutines, each of which is responsible for producing some aspect of simulated occupant behavior (see Figure 2). of course, several additional "nonbehavioral" subroutines are required which enable the user to communicate with BFIRES, i.e., to input initial scenarios and to retrieve from the computer data describing fire event outcomes. BFIRES was written in FORTRAN-V, and is currently operating on the UNIVAC 1108 and INTERDATA 7/32 computers at NBS.

\section{A Technical Approach to Computer-aided Design Review}

Because BFIRES recreates fire events as they unfold over time, it is possible to use the program as a building design and regulatory tool. This may be accomplished by creating a building fire scenario (which depicts anticipated real world conditions), entering this scenario into the computer, executing the BFIRES program, and finally interpreting the computer's output. As more scenarios are executed for a given design, the more thoroughly will the design be tested. Comparisons between test results for several design alternatives could substantially aid the process of selecting the best scheme from a life safety viewpoint. A flow chart illustrating the technical approach to computer-aided design review is presented in Figure 3. An example is discussed below.

\section{AN EXAMPLE ILLUSTRATING THE APPLICATION OF "BFIRES"}

\section{Scenarios}

An example illustrating the possible uses of BFIRES involves the floor plans shown in Figures 4 and 5 . These represent typical designs for a wing of a health care or nursing facility. The two plans are identical in most respects, and differ only in the location of the exit stairs. In Figure 4 the exits are remotely located at opposite ends of the floor, while in Figure 5 they are centrally located. At the moment of fire ignition, 12 occupants are assumed to be spatially distributed as shown in the figures.

In addition to considering differences in floor plan design, differences in occupant distribution are also compared. Figure 4 illustrates the situation in which all occupants are fully ambulatory, and may be assumed 
One possible answer to these questions is that it is the right of a democracy to have different approaches and solutions to the same issue, regardless of their effects. But, there is also the clear demonstration in the history of democracies that the greatest achievements have occurred in periods of crisis or external impact that provided a "common purpose" to all segments and groups. In such instances, the influence or power of individuals or organizations becomes subordinate to common goals, thus making it very difficult to defend hard-won positions that are not in the interest of the general community.

The likely conversion during the $1980^{\prime}$ 's to the International (Metric) System of Units--SI--becomes the first major common cause in the construction community, in which all sectors will need to cooperate to achieve a cost-effective transition. This "common cause" of metrication becomes a powerful catalyst for review, simplification, harmonization and rationalization. Rational solutions will surface and be accepted under the very weight of the unpalatable alternative: needless cost and confusion. In some instances, metrication will require bold and courageous vision to overcome the natural tendencies to stick with the past, regardless of the scientific or technological rationale of other and, generally, better alternatives. Precedent has already shown that "soft conversion" --the do-nothing alternative--is generally no more than a temporary and inefficient solution because it is nearly always followed by a later, second change to more sensible metric values. By contrast, a "hard conversion"--the change to new and preferred values--brings with it the one-time opportunity for an overhaul of known suboptimal aspects of building and building technology and the adoption of harmonized measurement values.

In the field of U.S. building codes, one alternative would be the preparation of an "American Metric Model Code," by involving the most knowledgeable and capable individuals in the industry in its development. This task should be given careful consideration by the model code writing organizations. In the age of data processing and information technology, a metric model code should have considerable appeal, economically as well as technologically, because it would link right at the outset the processes of design, production and construction with regulatory compliance and, therefore, could save a lot of time and money all around. In addition, it would facilitate metric familiarization and activities for all parties to the building process.

Another approach would be to harmonize those differences that are both unnecessary and indefensible, and to retain those differences that have a specific merit in the regions that are served. For many years there have been attempts to unify definitions, format, building occupancy classifications, and type of construction classifications, to facilitate interchangeability between code requirements for the benefit of users with activities throughout the nation, or in areas served by differing codes. While these efforts have born some fruit, the change to metric presents an opportunity for additional work and constitutes an almost "ideal" point in time to harmonize general functional parameters. 
A third approach with high payoff and minor disruption would be to adopt uniform test methods for verification purposes. This would still allow the adoption of differing acceptance levels in line with variations in the climatic or economic environment; however, the assessment of suitability would have to be made only once rather than again and again for each differing requirement in different localities or regions.

These then are the key technical challenges for harmonization "in tandem' with the change to metric. To let the metric opportunity pass without some degree of accomplishment of much needed reforms would be shortsighted and detrimental to all parties in the largest activity sector of the economy--the building and construction industries.

Therefore, when you hear the word "metric," try to think of it as a modern, efficient, technically-based, rational, international, and comprehensive measurement system, and, as an opportunity for the harmonization of American building codes.

244 
Appendix 1

Example 1

Dimensional Coordination in Building: Room Dimensions and Minimum Areas

in Residential Construction

BOCA Basic Building Code (1978) Section 506.5 Room Dimensions

SBCCI Standard Building Code (1979) Section 2001.1.1 Room Dimensions

ICBO Uniform Building Code (1979) Section 1207 Room Dimensions

\section{General}

Despite slightly different wording, the contents of the three model codes relating to minimum room dimensions and floor areas in residential construction are essentially the same, except that the Uniform Building Code introduces an additional criterion of exposed beam ceiling members and their spacing relative to the determination of minimum ceiling height.

\section{Metric Conversion Considerations}

To provide for metric preferred dimensions based on the international $100 \mathrm{~mm}$ building module, which has been recommended for use in the United States, metric dimensions that are multiples of $100 \mathrm{~mm}$ are preferred.

To give a precision similar to customary requirements expressed in multiples of 10 square feet, area requirements, desirably, should be expressed in multiples of whole square meters $\left(\mathrm{m}^{2}\right)$ or, at least, half square meters $\left(0.5 \mathrm{~m}^{2}\right)$.

Conversion Approach

\begin{tabular}{|c|c|c|c|c|c|}
\hline Item & $\begin{array}{c}\text { Existing } \\
\text { Requirements }\end{array}$ & $\begin{array}{c}\text { Soft } \\
\text { Conversion }\end{array}$ & $\begin{array}{c}\text { Hard } \\
\text { Conversion }\end{array}$ & $\begin{array}{l}\text { Actual } \\
\text { Change }\end{array}$ & $\begin{array}{c}\% \\
\text { Change }\end{array}$ \\
\hline \multirow[t]{4}{*}{ a. Ceiling Height } & $7^{\prime}-6^{\prime \prime}$ & $2286 \mathrm{~mm}$ & $\left(7^{\prime} \quad 69 / 16^{\prime \prime}\right)$ & $\begin{array}{c}+14 \mathrm{~mm} \\
\left(+9 / 16^{\prime \prime}\right)\end{array}$ & $+0.6 \%$ \\
\hline & $7^{\prime}-0^{\prime \prime}$ & $2134 \mathrm{~mm}$ & $\left(6^{\prime} 10011 / 16^{\prime \prime}\right)$ & $\begin{array}{c}-34 \mathrm{~mm} \\
\left(-15 / 16^{\prime \prime}\right)\end{array}$ & $-1.6 \%$ \\
\hline & $48^{\prime \prime}$ & $1219 \mathrm{~mm}$ & $\begin{array}{c}1200 \mathrm{~mm} \\
\left(47.25^{\prime \prime}\right)\end{array}$ & $\begin{array}{l}-19 \mathrm{~mm} \\
\left(-3 / 4^{\prime \prime}\right)\end{array}$ & $-1.6 \%$ \\
\hline & $5^{\prime}-0^{\prime \prime}$ & $1524 \mathrm{~mm}$ & 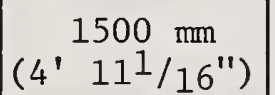 & $\begin{array}{c}-24 \mathrm{~mm} \\
\left(-15 / 16^{\prime \prime}\right)\end{array}$ & $-1.6 \%$ \\
\hline \multirow[t]{2}{*}{ b. Floor Area } & $150 \mathrm{ft}^{2}$ & $13.94 \mathrm{~m}^{2}$ & $\begin{array}{c}14 \mathrm{~m}^{2} \\
\left(150.7 \mathrm{ft}^{2}\right)\end{array}$ & $\begin{array}{c}+0.06 \mathrm{~m}^{2} \\
\left(+0.7 \mathrm{ft}^{2}\right)\end{array}$ & $+0.6 \%$ \\
\hline & $70 \mathrm{ft}^{2}$ & $6.50 \mathrm{~m}^{2}$ & $6.5 \mathrm{~m}^{2}$ & No change & -- \\
\hline c. Width & $7^{\prime}-0^{\prime \prime}$ & $2134 \mathrm{~mm}$ & $\begin{array}{c}2100 \mathrm{~mm} \\
\left(6^{\prime} 10^{7} / 16^{\prime \prime}\right)\end{array}$ & $\begin{array}{c}-34 \mathrm{~mm} \\
\left(-15 / 16^{\prime \prime}\right)\end{array}$ & $-1.6 \%$ \\
\hline
\end{tabular}

Underlined linear soft conversions are exact values. Others have been rounded to the nearest millimeter. 
Geometry of Stairs in Buildings: Treads and Risers

BOCA Basic Building Code (1978) Section 616.4 Treads and Risers SBCCI Standard Building Code (1979) Section 1115.3 Treads and Risers ICBO Uniform Building Code (1979) Section 3305.(c) Rise and Run

\section{Genera1}

The requirements for stair treads and risers differ in the three model codes and provide a good opportunity for harmonization during the change to metric (SI) measurement.

The first form of harmonization might be extended to the nontechnical matter of definitions: the BOCA and SBCCI codes use the terms "tread" and "riser," while ICBO uses "rise" and "run," even though in the text of Section 3305.(c) reference is made to "tread run" and "riser height." Since there is some benefit in providing the community with identical requirements for stair geometry, for safety as well as economic reasons, the change to metric might be utilized as an opportunity for technical harmonization of requirements.

\section{Metric Conversion Considerations}

It is anticipated that the change to metric preferred dimensions in the building industry will lead to much greater use of story heights (floorto-floor heights) that are whole multiples of $100 \mathrm{~mm}$. This move to metric preferences, in turn, will lead to some natural preferences for riser heights in the normal range from $150 \mathrm{~mm}$ to $200 \mathrm{~mm}$.

Another significant advantage of metric dimensions is that riser height and tread widths can be calculated and specified to the nearest millimeter thus leading to smaller variations in riser heights in any one stair flight and, therefore, to greater stair safety as uneven riser heights have been found to constitute a major stair safety hazard.

The matrix below for metric riser heights in stairs designed for preferred story heights, clearly illustrates some natura1 preferences, including a riser height of $200 \mathrm{~mm}\left(7^{7} / 8^{\prime \prime}\right)$. The matrix also shows the value of stairs with an even number of risers, which allows for two flights with an equal number of risers per flight.

\begin{tabular}{|c|c|c|c|c|c|c|c|c|c|}
\hline \multirow{2}{*}{$\begin{array}{l}\text { Story Height } \\
(\mathrm{mm})\end{array}$} & \multicolumn{9}{|c|}{ Number or Risers } \\
\hline & 12 & (13) & 14 & (15) & 16 & $(17)$ & 18 & (19) & $(21)$ \\
\hline 2400 & 200 & 185 & 171 & 160 & 150 & & & & Riser height in $\mathrm{mm}$ \\
\hline 2500 & $(\overline{208})$ & 192 & 179 & $\overline{167}$ & $\overline{156}$ & (147) & & & Underlined values \\
\hline 2600 & & 200 & 186 & 173 & 162 & 153 & (144) & & are exact. \\
\hline 2700 & & $(\overline{208)}$ & 193 & $\underline{180}$ & 169 & 158 & 150 & & \\
\hline 2800 & & & 200 & $\overline{187}$ & 175 & 165 & 156 & $(147)$ & \\
\hline 2900 & & & $(\overline{207})$ & 193 & $\overline{181}$ & 171 & 161 & 153 & $(145)$ \\
\hline 3000 & & & & 200 & 188 & 176 & 167 & 158 & $150(143)$ \\
\hline
\end{tabular}


Comparative Listing of Requirements in Existing Codes:

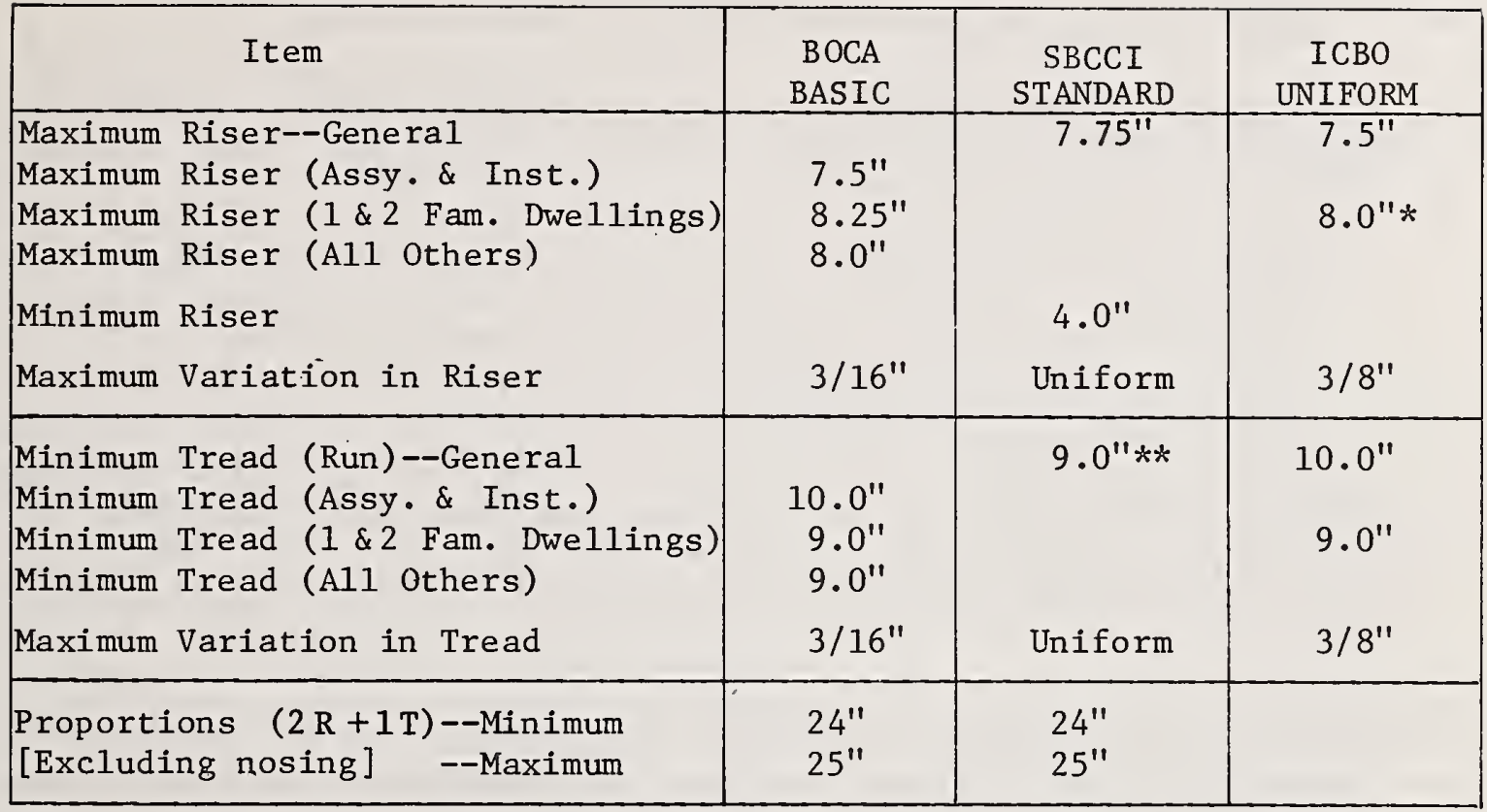

* Private stairways with occupant load less than 10 , or stairways to unoccupied roofs

** Treads less than 10" wide shall have nosing or projection of approx. $1^{\prime \prime}$ Conversion and Rationalization

\begin{tabular}{|c|c|c|c|c|c|c|}
\hline $\begin{array}{l}\text { Existing } \\
\text { Values } \\
\text { (Inches) }\end{array}$ & $\begin{array}{c}\text { Exact } \\
\text { Conversion } \\
(\mathrm{mm})\end{array}$ & $\begin{array}{c}\text { Soft } \\
\text { Conversion } \\
(\mathrm{mm})\end{array}$ & $\begin{array}{c}\text { Hard } \\
\text { Conversion } \\
(\mathrm{mm})\end{array}$ & $\begin{array}{c}\text { Actual } \\
\text { (In) }\end{array}$ & $\begin{array}{c}\text { Change } \\
\text { (mm) }\end{array}$ & $\begin{array}{c}\% \\
\text { Ch ange }\end{array}$ \\
\hline $\begin{array}{l}7.5 \\
7.75 \\
8.0 \\
8.25\end{array}$ & $\begin{array}{l}190.5 \\
196.85 \\
203.2 \\
209.55\end{array}$ & $\begin{array}{l}190 \\
197 \\
203 \\
210\end{array}$ & $\begin{array}{l}(190) * \\
200 \\
200 \\
(210) *\end{array}$ & $\begin{array}{r}* * \\
+1 / 8 \\
-1 / 8 \\
* *\end{array}$ & $\begin{array}{l}-0.5 \\
+3.2 \\
-3.2 \\
+0.45\end{array}$ & $\begin{array}{l}-0.3 \\
+1.6 \\
-1.6 \\
+0.2\end{array}$ \\
\hline 4.0 & 101.6 & 102 & 100 & $-1 / 16$ & -1.6 & -1.6 \\
\hline $\begin{array}{l}3 / 16 \\
3 / 8 * * *\end{array}$ & $\begin{array}{l}4.7625 \\
9.525\end{array}$ & $\begin{array}{l}5 \\
10 * * *\end{array}$ & $\begin{array}{c}5 \\
(10) * * *\end{array}$ & $\begin{array}{l}* * \\
* *\end{array}$ & $\begin{array}{l}+0.24 \\
+0.48\end{array}$ & $\begin{array}{l}+5.0 \\
+5.0\end{array}$ \\
\hline $\begin{array}{l}9.0 \\
10.0\end{array}$ & $\begin{array}{l}228.6 \\
254\end{array}$ & $\begin{array}{l}229 \\
254\end{array}$ & $\begin{array}{l}230 \\
250\end{array}$ & $\begin{array}{l}+1 / 16 \\
-5 / 32\end{array}$ & $\begin{array}{l}+1.4 \\
-4.0\end{array}$ & $\begin{array}{l}+0.6 \\
-1.6\end{array}$ \\
\hline $\begin{array}{l}24 \\
25\end{array}$ & $\begin{array}{l}609.6 \\
635\end{array}$ & $\begin{array}{l}610 \\
635\end{array}$ & $\begin{array}{l}610 \\
635\end{array}$ & $\begin{array}{l}* * \\
* *\end{array}$ & $\begin{array}{c}+0.4 \\
--\end{array}$ & $\begin{array}{c}+0.1 \\
--\end{array}$ \\
\hline
\end{tabular}

* For the purposes of rationalization, these values might be changed to $200 \mathrm{~mm}$, involving an actual change of $+3 / 8^{\prime \prime}: 9.5 \mathrm{~mm}:+5.0 \%$ for the existing value of $7.5^{\prime \prime}$; and $-3 / 8^{\prime \prime}:-9.5 \mathrm{~mm}:-5.0 \%$ for the existing value of $8.25^{\prime \prime}$. In this way, a singular maximum riser height in metric units would be established.

** The actual change is less than $1 / 32^{\prime \prime}$. *** Excessive variation for 
Possible Metric Model Code Clause for Treads and Risers in Exit Stairway:

xxx. 1 Risers and Treads in Stairways with Parallel Treads

(a) Dimensions of Risers: Risers in exit stairways shall have a minimun height of $100 \mathrm{~mm}$, and a maximum height of $200 \mathrm{~mm}$. (*)

Within any flight, the height of risers shall not vary by more than $5 \mathrm{~mm}$.

(*) Note: The maximum height requirement might altermatively be shown as: ".... maximum height of $200 \mathrm{~mm}$ in buildings accessible to the public, and $210 \mathrm{~mm}$ for private staimays in dwellings serving an occupant load of less than 10, and stairways to unoccupied roofs."

(b) Dimensions of Treads: Treads in exit stairways shall have a minimum width of $230 \mathrm{~mm}$ for private stairways, and $250 \mathrm{~mm}$ for stairways accessible to the public.

Within any flight, the width of treads shall not vary by more than $5 \mathrm{~mm}$.

(c) Proportions of Risers and Treads: For public stairways, the proportion of risers and treads shall be such that the sum of two (2) risers plus one (1) tread, exclusive of nosing or projection, falls between $610 \mathrm{~mm}$ and $635 \mathrm{~mm}$. 
Example 3

Minimum Uniformly Distributed Live Loads in Buildings

ANSI American National Standard A58.1-1972

ANSI A58.1, Proposed 1979 Revision

BOCA Basic Building Code (1978)

SBCCI Standard Building Code (1979)

ICBO Uniform Building Code (1979)
Section 3, Live Loads, Table 1

Table 4.1

Section 706.0, Table 706

Section 1203, Table on pages

$12-1$ to $12-3$

Chapter 23, Table No. 23.A

General

Despite the existence of a comprehensive national standard on "Building Code Requirements for Minimum Design Loads in Buildings and Other Structures (ANSI A58.1-1972)," the major model codes have introduced specific requirements and tables detailing the specification of design loads and, especially, uniformly distributed live loads. Although there is some agreement with the numerical values recommended in A58.1--most notably in the BOCA Basic Building Code--these values have been supplemented or altered to a certain extent.

The change to metric units provides a unique opportunity to review these differences and introduce greater harmony in design requirements.

Metric Conversion Considerations

For the purposes of this paper, discrepancies in code requirements are not discussed; rather, an approach to conversion and rationalization is shown which should facilitate technical harmonization decisions.

The change to metric (SI) units will require a fundamentai reappraisal of values now accepted for design loads in buildings. Existing requirements are stated to the nearest 10 or $251 \mathrm{bf} / \mathrm{ft}^{2}\left(0.48\right.$ or $\left.1.18 \mathrm{kN} / \mathrm{m}^{2}\right)$ and there seems to be little value in applying exaggerated conversion precision to arrive at metric equivalents. In fact, a soft conversion of existing requirements would complicate the design procedures rather than facilitate them. Thus, a similar degree of accuracy for computational purposes would be to select metric values to the nearest 0.5 or $1.0 \mathrm{kN} / \mathrm{m}^{2}$.

The other, significant change that occurs during the change to SI is the move from loads expressed in gravitational terms to loads expressed in absolute terms (force/area). The absolute unit, newton per square meter $\left(\mathrm{N} / \mathrm{m}^{2}\right)$, and the working unit, kilonewton per square meter $\left(\mathrm{kN} / \mathrm{m}^{2}\right)$, replace pounds-force per square foot (psf). While the $\mathrm{N} / \mathrm{m}^{2}$ is equal to the pascal $(\mathrm{Pa})$, it is preferable to show loads in the composite unit. The non-SI unit, kilogram-force per square meter $\left(\mathrm{kgf} / \mathrm{m}^{2}\right)$, is non-coherent and should not be used.

To visualize a load of $1 \mathrm{kN} / \mathrm{m}^{2}$, it would be caused by a mass of $102 \mathrm{~kg}$ distributed over an area of 1 square meter, at standard acceleration due to gravity.

The Table on page 250 shows the conversion and rationalization of existing building code values for uniformly distributed live loads. 
Uniformly Distributed Live Loads in Buildings: Conversion and Rounding (Basis: $1 \mathrm{lbf} / \mathrm{ft}^{2}$ [psf] $=47.8803 \mathrm{~N} / \mathrm{m}^{2}=47.8803 \mathrm{~Pa}$ )

Existing

Values $\left(1 \mathrm{bf} / \mathrm{ft}^{2}\right.$ )
Rounding to Conversion Nearest $0.1 \mathrm{kN} / \mathrm{m}^{2}$ $\left(\mathrm{kN} / \mathrm{m}^{2}\right)$
Rounding to Nearest $0.5 \mathrm{kN} / \mathrm{m}^{2}$ Value \% Change
Rounding to Nearest $1.0 \mathrm{kN} / \mathrm{m}^{2}$ Value \% Change

\begin{tabular}{rrrrrrrr}
\hline 20 & 0.96 & 1.0 & +4.4 & 1.0 & +4.4 & 1.0 & +4.4 \\
30 & 1.44 & 1.4 & -2.5 & 1.5 & +4.4 & 1.0 & -30.4 \\
40 & 1.92 & 1.9 & -0.8 & 2.0 & +4.4 & 2.0 & +4.4 \\
50 & 2.39 & 2.4 & +0.2 & 2.5 & +4.4 & 2.0 & -16.5 \\
60 & 2.87 & 2.9 & +0.9 & 3.0 & +4.4 & 3.0 & +4.4 \\
75 & 3.59 & 3.6 & +0.2 & 3.5 & -2.5 & 4.0 & +11.4 \\
80 & 3.83 & 3.8 & -0.8 & 4.0 & +4.4 & 4.0 & +4.4 \\
100 & 4.79 & 4.8 & +0.2 & 5.0 & +4.4 & 5.0 & +4.4 \\
125 & 5.99 & 6.0 & +0.2 & 6.0 & +0.2 & 6.0 & +0.2 \\
150 & 7.18 & 7.2 & +0.2 & 7.0 & -2.5 & 7.0 & -2.5 \\
$(200)$ & 9.58 & 9.6 & +0.2 & 9.5 & -0.8 & 10.0 & +4.4 \\
250 & 11.97 & 12.0 & +0.2 & 12.0 & +0.2 & 12.0 & +0.2 \\
\hline
\end{tabular}

The above table shows that within comparatively small percentages of rounding, metric values can be established that are multiples of $0.5 \mathrm{kN} / \mathrm{m}^{2}$ (10.44 $\left.\mathrm{lbf} / \mathrm{ft}^{2}\right)$, and lead to a rational progression of loads in a series.

Such a series might contain the following steps $\left(\mathrm{kN} / \mathrm{m}^{2}\right)$ :

$1,1.5,2,2.5,3,4,5,6,7,9,12$

Alternatively, a completely new series of values for uniformly distributed live loads in buildings in SI units may be developed to best reflect the likely live loading conditions encountered in building of various types. The relevant recommendations made at the international level by Technical Committee (TC) 98, Bases for Design of Structures, of the International Organization for Standardization (ISO)--especially by Subcommittee (SC) 3, Loads, Forces and Other Actions--may be considered in such a review. 
DUAL UNITS

EXACT CONVERSION

HARD CONVERSION

M-DAY

METRICATION

RATIONALIZATION

SI

SOFT CONVERSION

TRANSITIONAL PERIOD
A description in two measurement systems, one of which normally is a preferred value.

The conversion of measurement values to exact equivalents expressed in SI (e.g.: $3 / 4^{\prime \prime}=19.05 \mathrm{~mm}$; 1 quart $=0.946353 \mathrm{~L})$. The precision of an exact conversion is rarely, if ever, required.

A term used to describe a definite change to a metric alternative in preferred values, e.g.: $3 / 4^{\prime \prime}(20 \mathrm{~mm})$; 1 quart (1 L).

A key target date for a sector of the economy after which it is proposed that transactions will be carried out in metric units. In the construction industries, the M-Day signifies the date after which metric hardware (building materials and products) is expected to be used in metric construction.

The process and activities necessary to bring about the change from a customary system to SI (metric) units of measurement.

The modification of a range of values (requirements or products) to reduce or optimize the number in the range or the steps between values, or both, for better costeffectiveness or functional efficiency.

Abbreviation for the "International System of Units," the modern metric system agreed to by all member nations of the General Conference on Weights and Measures (CGPM) in 1960--including the United States--and adopted progressively by all countries as their national measurement system.

A term used to describe the change to a metric equivalent, within normal tolerances, rounded to give a convenient value (e.g.: $3 / 4^{\prime \prime}(19 \mathrm{~mm}) ; 1$ quart $(0.95 \mathrm{~L})$. A soft converted item generally remains interchangeable.

The period during which the change to metric (SI) units occurs and two measurement systems are in use, with metric usage increasing and customary usage diminishing. 



\author{
by \\ Richard L. Meyer, Architect \\ Lead Code Consultant \\ State of Wisconsin \\ Department of Industry, Labor and Human Relations \\ Division of Safety and Buildings \\ Code Development Unit \\ Madison, Wisconsin
}

Formaldehyde is utilized in the manufacture of a variety of products. The most significant use is in the production of phenolic, melamine and urea formaldehyde resins. It is also used in agriculture, for chemical analysis, concrete and plaster, cosmetics and deodorants, disinfectants and fumigants, dyes, hydrocarbon products, for leather tanning, paper manufacture, photography, rubber production, solvents and plasticizers, starch, wood, textiles, and embalming fluid. It is also a byproduct of combustion found in automotive exhaust and cigarette smoke.

There are an increasing number of complaints received from persons residing in mobile homes caused from the emission of formaldehyde vapor.

The department is developing standards for formaldehyde vapor.

While formaldehyde standards have been established to protect the worker from formaldehyde vapor, no standards have been set for formaldehyde in non-working environments.

The paper will deal with Wisconsin's experience in developing standards for formaldehyde vapor.

Key words: Formaldehyde; urea-formaldehyde resins; formaldehyde-based chemicals; formaldehyde level; concentration; standards; committee; department. 


\section{INTRODUCTION}

On October 17, 1973, most of the oil-producing countries in the Mid-East placed an embargo on oil shipments to the United States. The President of the U.S. declared that the U.S. was in a national emergency.

The energy crisis spurred improvements in construction and energy conservation research. As a result, mobile home construction has been getting physically tighter. Consequently, occupants are becoming more aware of indoor pollutants, the most noticeable being formaldehyde.

\section{SOURCES OF FORMALDEHYDE}

The formaldehyde concentration in a home is a product of many factors. Formaldehyde is commonly present in the outdoor air in urban communities and in large manufacturing centers. Areas around main traffic routes will have higher formaldehyde levels because it is also a product of gasoline and diesel engines. Formaldehyde is also a constituent of smog.

Formaldehyde is also produced in the home through the breakdown of cooking oil. It is also a combustion product of gas stoves and heaters. Tobacco smoke can contain up to $4 \mathrm{ppm}$ of formaldehyde.

Urea-formaldehyde resins and formaldehyde-based chemicals are constituents of many household substances. Urea-formaldehyde is the resin used in permanent press fabrics and the synthetic textiles used for rugs and drapery backings.

Certain cosmetics and some hair sprays are known to contain formaldehydebased chemicals.

Urea-formaldehyde resins are used as the bonding agent in particleboards and as adhesives for bonding together veneer layers to form plywood. Emission of formaldehyde from these products is due to the breakdown of urea-formaldehyde resins and is dependent on temperature, humidity, pressure and light exposure. There may also be free formaldehyde in the product.

The concentration of formaldehyde in a home is primarily dependent on three factors:

(1) The concentration of formaldehyde from the external environment and formaldehyde-emitting products used in the home, including cigarette smoking; 
(2) The contribution from urea-formaldehyde products used in the construction of the home; and

(3) The amount of air available for dilution of the internal environment.

\section{FORMALDEHYDE IN MOBILE HOMES}

The median formaldehyde concentration in 68 homes studied by the University of Washington was about $.4 \mathrm{ppm}$. The mean formaldehyde level for 20 homes tested by the Wisconsin Division of Health was about .9 ppm. The NIOSH (National Institute for Occupational Safety and Health) test method was used in both studies. The homes studied represented homes from which residents had complained of health problems.

Two classes of symptoms are reported by residents of mobile homes with detectable concentrations of formaldehyde: those which are characteristic of formaldehyde exposure (irritation to the eyes, nose and respiratory tract; headaches; nausea; and drowsiness) and another group which could occur in any population group without exposure to formaldehyde such as chronic respiratory problems, chronic ill feeling, constant cold symptoms, difficulty in breathing, heart attacks, pains in chest, chronic sore throat, low grade fever, asthma, emphysema, headache and chronic ear infection. There is no evidence indicating whether the conditions were subjective or actual, or whether they are due to formaldehyde, environmental conditions or diseases. There is demonstration of a relationship between the incidence of symptoms and the concentration of formaldehyde.

The only demonstrated effects of formaldehyde are irritation and sensitization. Human experiences indicate that formaldehyde is irritating to the eyes, nose and upper respiratory tract, can cause dermatitis (inflammation of the skin), is an allergen and may have an adverse effect on behavior. Some individuals are sensitive to a trace of formaldehyde while others can tolerate high concentrations.

Formaldehyde has shown mutagenicity in some tests and tests are being planned to establish a dose-response relationship. Animal tests have shown no teratorgenic effects (damage to fetus) with formaldehyde. Several studies have been done with animals which have attempted to assess the carcinogenic effects (cancer producing) of formaldehyde. These tests, which show that formaldehyde is not carcinogenic, are inadequate. Well documented tests are now being conducted by the Formaldehyde Institute which should determine if formaldehyde is a carcinogenic material. Tests are also being conducted to assess whether continuous low level exposure creates health effects. 


\section{STANDARDS}

Two alternatives exist to protect the consumer from toxic chemicals. One is to ban the use of certain toxic chemicals; the other is to set standards to limit exposure to these chemicals. In the industrial hygiene field, the latter course has been established as a national policy. The present OSHA standard for formaldehyde is 3 ppm for an average exposure over an eight-hour work shift. The American Conference of Governmental Industrial Hygienists (ACGIH) recommends 2 ppm as ceiling concentration for an eight-hour work shift and NIOSH has recommended 1 ppm as a means of protecting the more sensitive workers. There is no national ambient air standard for formaldehyde which could be used as a guide for exposure in residences.

European countries, however, are moving rapidly in establishing formaldehyde standards. The Netherlands have established a standard of .1 ppm and Denmark, Sweden and West Germany have recommended standards at approximately the same value. ASHRAE specifies that air used for indoor ventilation must not contain contaminants at concentrations greater than $1 / 10$ of the threshold limit value (TLV), or .2 ppm. The National Academy of Sciences has determined that .1 ppm would allow an adequate margin of safety for either 90-day or 1,000-day missions.

\section{WISCONSIN STANDARD-SETTING PROCESS}

The Wisconsin Statutes permit agencies to use public advisory committees in the standard-setting process. The structure of some of these committees is specifically established by law. The Wisconsin Statutes require the department's mobile home advisory committee to consist of two representatives of mobile home manufacturers, one public member, one representative of labor, and one department representative. The committee began studying the formaldehyde problem in late February, 1979.

After the committee recommends a standard to the department, the standard will be presented at public hearings for review and comment. The committee will review all hearing comments with the department and make changes based on those comments. The final rules will be sent to the legislature for review prior to being adopted.

Types of Standards

The committee is studying the possibility of setting one or more of the following types of standards: (1) air quality standard; (2) complaint procedure standard; (3) product standards; (4) warning to purchaser standard. 
Air quality standard. Formaldehyde vapor levels could be regulated by requiring mobile homes to meet a specific indoor air concentration. The committee is looking at concentration levels ranging from .1 to $.4 \mathrm{ppm}$. Under this concept, the mobile home would be required to be designed and constructed to meet the established concentration. The standard would require testing the air quality of the mobile home prior to sale. It would be necessary to consider the following in establishing uniform testing procedures and conditions: (1) acceptable test methods; (2) number and location of test samples; (3) indoor and outdoor temperature; (4) indoor and outdoor relative humidity; (5) burden of testing; and (6) number of mobile homes tested.

Complaint standard. A complaint standard would establish a procedure to assist the manufacturer and owner in resolving formaldehyde complaints. This type of standard would require the manufacturer or dealer to test for the formaldehyde concentration in the mobile home upon receipt of a complaint. The manufacturer would be responsible for reducing the formaldehyde concentration to the value prescribed in the standard. It would also be necessary to establish test methods and conditions similar to those outlined for the air quality standard.

Product standards. A product standard would establish minimum formaldehyde emission levels for building products used in the manufacture of mobile homes. It would be necessary to establish (1) which products to regulate; (2) appropriate test methods and conditions; and (3) emission levels for each product.

Warning to buyer standard. A warning or notice would be required to be posted on the mobile home or to be given to the purchaser prior to sale. The warning would inform the purchaser that the home contained formaldehyde, which is a known irritant. 
The committee is reviewing the four alternatives and discussing their advantages, disadvantages and cost/benefits. The air quality standard and the product standard control the product at the point of manufacture and will increase the cost of manufacturing. Also, establishing a material standard without an overall indoor air quality standard will not ensure that the home will meet a reasonable formaldehyde concentration. The warning standard and the complaint standard will have little impact on the manufacturing cost but may not adequately protect the purchaser who is affected but does not issue a complaint.

One of the difficulties in setting a standard at a specific concentration is the lack of scientific data of low level formaldehyde emissions and their effect on the population. Also, the formaldehyde emission rate of building products varies with time, temperature and humidity, making it difficult to set test conditions.

These are a few of the problems the department and the committee is facing in setting formaldehyde standards. It appears, at this point in time, that a combination of the various standards previously mentioned may be the best alternative. 


$$
\text { SNOW - WIND - ICE, }
$$

ITS CHANGING EFFECT ON BUILDING CONSTRUCTION

\title{
by
}

\author{
Charles V. Opdyke, Chief \\ Plan Review Division \\ Department of Labor \\ Lansing, Michigan
}

The impacts of the effects of "Weather" is being experienced across the nation as it relates to the destructive forces of snow, wind and ice on building construction.

In an effort to deal with these problems individually or collectively, we must re-evaluate all of our engineering principles, practices and theories that have been used through the years and have been accepted as gospel.

This paper deals with new and innovative design principles and methods of construction to overcome, wind loads, snow loads, icing conditions, freeze-thaw cycles, ventilation problems, roof leaks and structural failure. It also covers new types of roof designs and how to deal with them.

The report speaks to the many types of freezes, the wind pattern effect, the snow effect and the general combined effects of all three.

Finally, the paper speaks to a general lack of accurate local climatology recording on a uniform basis.

Key Words: Buildings collapse; ice; snow; wind. 
How. many of you remember Senator William Proxmire and his "Golden Fleece" award? Wel1, last winter the U.S..Department of Housing and Urban Development won the award for a community building north of Grand Rapids, Michigan, that collapsed due to the snow load. Fortunately the building was not occupied at the time. Unfortunately, no one knew about the roof collapse until several days later. Unfortunately the roof was designed for a total live and dead load of 30 pounds per square foot. Unfortunately, 30 pounds per square foot is the building code requirement for that area. The code was the 1975 Building Officials and Code Administrators International, Inc. (BOCA) Basic Building Code. The referenced standard was American National Standards Institute (ANSI) standard A58.1-1972, "Building Code Requirements for Minimum Design Loads in Buildings and Other Structures." Being an assembly building, the BOCA Code requires loads that correspond to the ground snow load in pound-force per square foot for 100 year mean recurrence intervals. When you multiply this on-the-ground snow load by the snow load coefficient $\left(C_{S}\right)$ of 0.8 , the result is a required snow load of only 24 pounds per square foot. The actual snow load for that area is 40 pounds per square foot. Shortly after the building collapse occured, Michigan's Bureau of Construction Codes was accused in the press of not enforcing the building codes. The truth of the matter was that the State of Michigan had no jurisdiction in that particular township because in accordance with Michigan's Statutes, the township had opted to administer and enforce the State Construction Code itself--which in the case of this building, it did not.

The Bureau of Construction Codes did, however, make an investigation into the matter. From the building plans, it was determined that there was a pitched roof supported by wood trussed rafters $2^{\prime}-0^{\prime \prime}$ on center. A structural analysis of the design was made and it was determined that the trussed rafters were good for a total live and dead load of only 30 pounds per square foot, whereas it should have been 50 pounds per square foot.

\section{INADEQUATE ROOF CONSTRUCTION}

I recall a case back in 1966 when I was in practice. I was retained by the State Girl Scout Council to investigate the structural capabilities of several assembly and dormitory type buildings at its camp in northern Michigan. Several of these buildings were home-made by the camp custodian and each fall he would have to brace the roof structure with poles from the inside because of the roof sag due to the snow load. Upon investigation I found that the roofs were about a 5/12 pitch with four inch round pole rafters spaced $3^{\prime}-0^{\prime \prime}$ on center; an eight inch round ridge beam and so-called trusses spaced $12^{\prime}-0^{\prime \prime}$ on center. The reason I call them so-called trusses is that they looked like trusses, but they were not performing like trusses--in fact, they were performing like roof rafters. 
The caretaker in all good faith was constructing buildings, without a permit, which he thought were structurally sound. Each four inch round pole rafter was supporting a total live and dead load of almost 4,000 pounds. The deflection under maximum loading conditions must have been astronomical. The actual design replacement for the four inch round pole was three $2 \times 12^{\prime}$ 's glue-nailed, and spaced $3^{\prime}-0^{\prime \prime}$ on center.

Construction contracts were let in the fall of 1966 for structural reinforcement of the roof system for ten buildings. The contractor completed the work on eight buildings and then one night there was an early heavy 16 inch snowfall. Two bunk buildings collapsed completely from the overload. Again, it was fortunate that the buildings were not occupied. It was also fortunate that the contractor's insurance paid for the reconstruction of both buildings. It is interesting to note that the 16 inch snowfall added only 12 pounds per square foot to the roof.

\section{BLIZZARD}

On January 27-28, 1967, the mid-west was paralyzed by a blizzard with on-the-ground snow depths up to 27 inches with drifts of several feet. During this period many roofs collapsed and my firm was commissioned for the design of the replacement of many roofs and structures. It is interesting to note that although many roofs collapsed during the blizzard, some did not collapse until several days afterwards. What happened was that after the storm had passed, there was a short period of colder weather, followed by a warming trend, and then later followed by gusting winds of about 25 miles per hour. First the colder temperatures stabilized the snow, next the warming trend gave the snow a firmer set into a homogenous mass, and finally the wind provided the added pressure, which was enough to cause collapse.

\section{STRUCTURAL THEORY}

I have a theory that many of these roof collapses are caused by previous overloadings in which the structural members have gone beyond the elastic limit and into the yield area. We know that any structural member when loaded will elongate, and when the load is removed it will return to its original length; however, if it is loaded beyond the elastic limit and the load is removed, it will not return to its original length. Therefore, the member has developed permanent camber or permanent set and even though not under any unusual loading, will appear to have a deflection bend in the direction of the applied load. (Figures 1 and 2.)

The factor of safety of a structural member is the ratio between the actual tensile stress and the ultimate tensile strength of the material. If the factor of safety is low, the resultant of over-loading is early failure. 


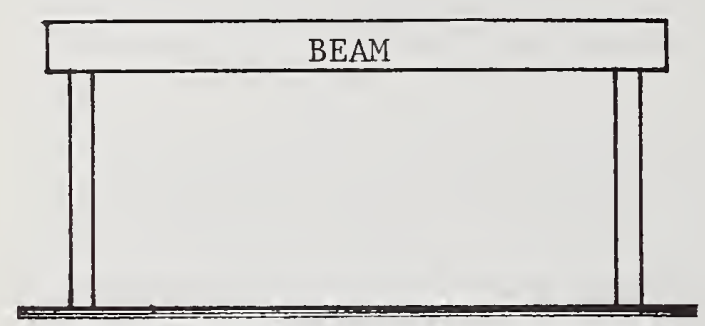

NO LOAD

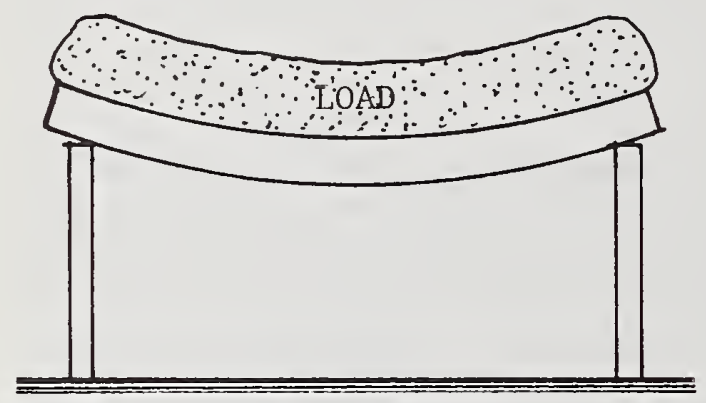

ELONGATED

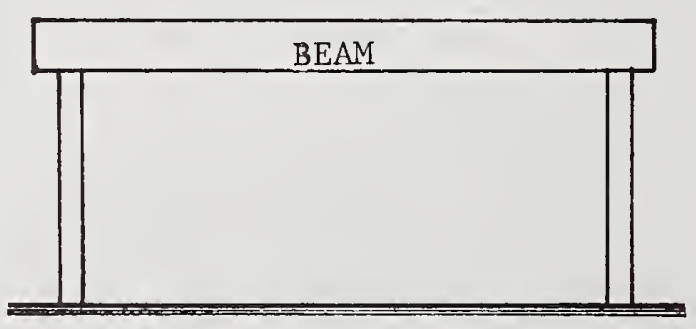

RETURNED TO NORMAL

Figure 1
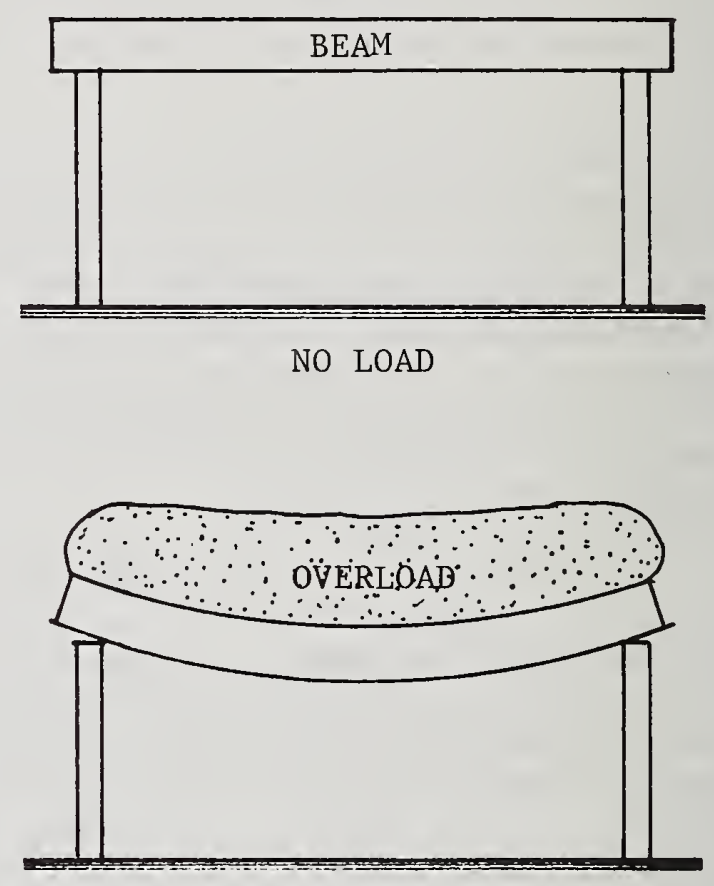

ELONGATED

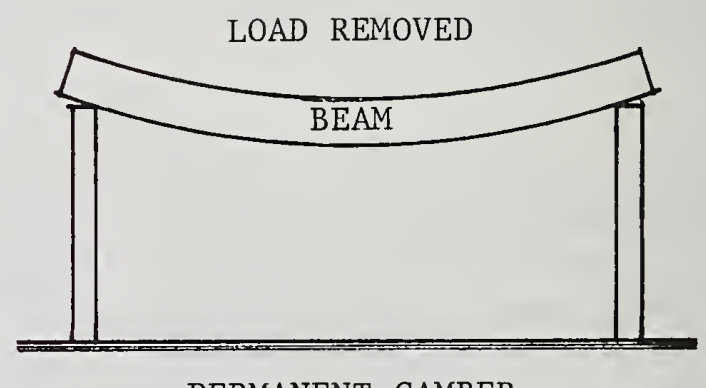

PERMANENT CAMBER

Figure 2 
In any composite structural assembly, the material with the lowest factor of safety will be the first to rupture, and when this occurs, there is an immediate transferral of stresses to the adjacent members. If these members fail, there is a domino effect and the result is structural collapse.

Now let us go back to the roof whose structural members have a permanent deflection bend in them--this means that the interal fibers have been pulled out of their original pattern which in turn has weakened the original integrity of the material. In this weakened state any applied load that is more than the load that caused the original damage will make the member more vulnerable to rupture.

Another cause for structural failure and which will produce the same results is a member that is exposed to a long-term overload. Most structural members under a normal loading situation can withstand shortterm impact loads, such as a sudden gust of wind, but when overloaded over a long period of time, they become very vulnerable when subjected to a heavy snow load or even from a gust of wind. Either situation could be enough to tip the delicate balance of its structural capacity.

\section{WEATHER EFFECTS}

There is a theory that wind and snow loads on roofs vary from the flat roof to the steeply pitched roof. I agree with this theory and admit that there may be some fluctuation according to the density of the snow and the external temperature, but I would like to add another element-ice, either formed from melted snow in a thaw-freeze cycle, or from a build-up of freezing rain.

I submit that any roof, flat or sloped, can receive a loading condition that is the resultant of progressive conditions as follows: (Figure 3)

\section{a. a heavy snowfall;}

a slight thaw; not enough to melt in a runoff, but enough to change the density of the original snow. On a pitched roof the snow would adhere better;

c. repeats of the above condition causing an adhesive build-up;

d. a freezing rain, followed by a drop in temperature considerably below freezing;

e. a strong wind.

There could be a repeat of any of the above conditions and in any combination. 


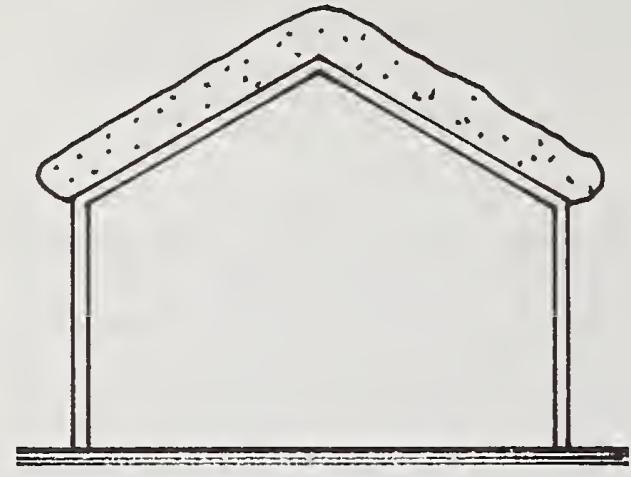

LIGHT SNOW
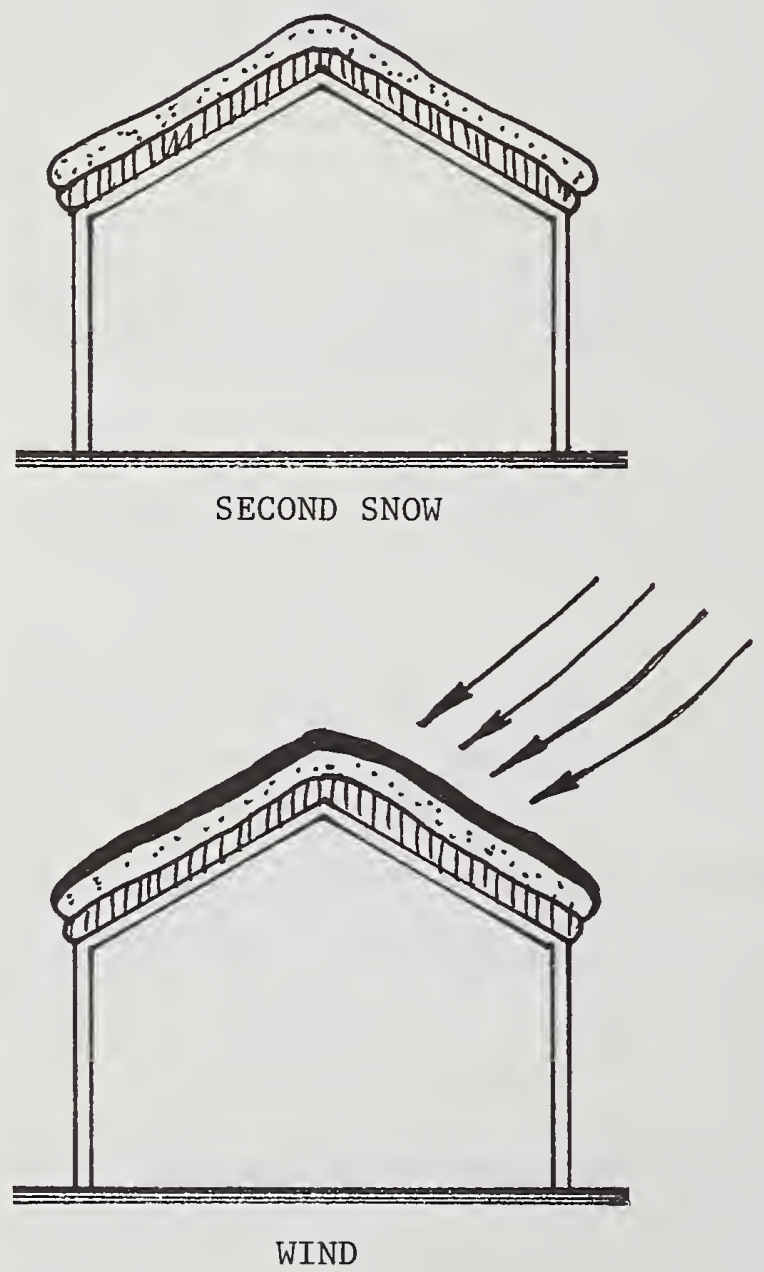
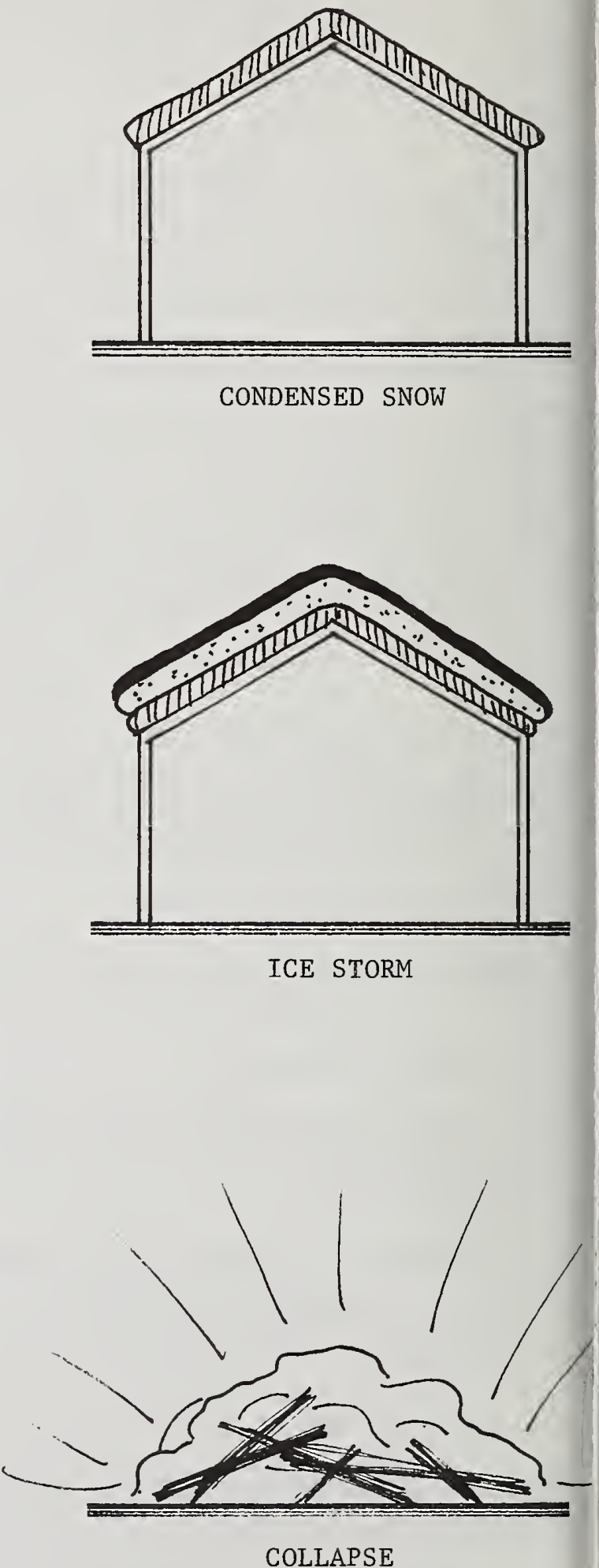

Figure 3 
During the winter of 1978-1979, there were 20 consecutive days in Michigan where there was some form of snow that fell.

The ice storm in Texas last spring developed icing up to one inch in thickness--that represents almost five pounds per square foot in weight.

Consider a pitched roof surface which has gone through several of the snow-thaw-freeze conditions with a 12 inch ice build-up at 56 pounds per square foot and a wind pressure of 30 pounds per square foot. The resultant load would be 86 pounds per square foot and that does not include the dead load that has to be added.

There is a very real probability of these conditions occurring during a 50 year recurrence.

\section{MOISTURE CONTROL}

The control of moisture seems to be an ever-surfacing problem, particularly in residential types of buildings during the winter months in cold climates. The problems are roof leaks, interior staining and water damage, interior sweating of windows, swelling of wood window construction, paint peeling, and sometimes structural damage.

It may seem strange to say that houses built 50 to 75 years ago never had these problems for the reason that they were well ventilated--not from a sophisticated exhaust and ventilation system, but from moisture permeation right through the walls. (Figure 4.)

The construction was usually wood studs covered with wood sheathing boards over which was put a layer of Kraft paper or roofer's felt and an exterior covering of lapped wood siding. The inside surface of the studs was covered with wood lath over which was placed plaster reinforced with animal hair. Over this was a coat of wallpaper. The moisture on these old homes moved right through the walls and dissipated to the exterior. Over the years a paint built-up of succeeding coats could establish a vapor barrier on the exterior. This is the worse thing that could happen as it traps the moisture behind the paint which will freeze and in turn force the paint film away from the wood surface. This is called blistering of the paint. The remedy is not to repaint as many millions of homeowners have done over the years and much to the joy of the paint manufacturers.

The remedy is to control the moisture. If the moisture is controlled, all of the devastating effects of moisture are controlled.

The rules are relatively simple: Make the house air tight by reducing all leakage of air from the inside to outside. Make it air tight in its construction and around the perimeter of all openings such as doors and windows. Do not forget electrical switch boxes, wall outlets, 
flashing at doors and windows. Seal off chases for entrance of piping, areas around exhaust fans and ventilators, plumbing vents and dryer exhaust vents, doors to attics or any place where air can move from the interior to the exterior via openings.

Make the building vapor tight from the inside or the high vapor side. By doing so will contain the moisture on the inside as well as to prevent the moisture from passing through the construction to the exterior. On interior plaster or drywall surfaces, thoroughly patch all cracks or holes and cover with a good coat of waterproof varnish such as a bartop or plastic finish, or any good vapor tight enamel. Then apply a good vapor tight or non-permeable finish. A vinyl wall covering would produce excellent results. Do not forget that the ceilings receive the same treatment as well as all interior walls and partitions.

Also do not forget the perimeters of all trimmed openings because moisture can travel through the cracks where wood trim is applied. Cover the rough opening with plastic sheeting and tape the edges under where wood casings will be applied.

Make the exterior of the house vapor permeable by using a vapor permeabl exterior finish. This will allow any moisture that does happen to get through from the interior a charice to escape. It is important that the dew point within the walls of the structure is such that it can be absorbed by the insulation without turning to liquid water. As you know, water turns to ice and then the damage starts.

The fourth phase is the extraction of the vapor from the interior to the exterior. Now that we have isolated the moisture on the interior, it must be exhausted to the exterior by a good exhaust system in areas where maximum moisture accumulates, namely, the kitchen, the bathroom, and the lanudry room. Manual exhaust fans in these areas will do the job if they are properly used.

It is possible that the house can be so air tight with the exhaust fans running that there is a pressure when opening the doors. This can be relieved by providing a fresh air supply duct to the furnace area. This would supply fresh air, combustion air for the furnace, and relieves the pressure.

The last phase of moisture control is in the roof and eave area. Previously mentioned were ice and snow build-ups on pitched roofs. Most of this ice is from the exterior, but in improperly treated houses, this moisture comes from the interior seeking its way out through the roof. Here we have to contend with a two-way problem. Let us handle the extraction of the interior moisture first. This can be done with proper ventilation. (Figure 5.)

The exterior situation is where ice will back-up under the shingles and cause roof leaks. Also, ice will build an ice dam at the eave line. During a thaw it will hold back water and at night it will freeze again. 


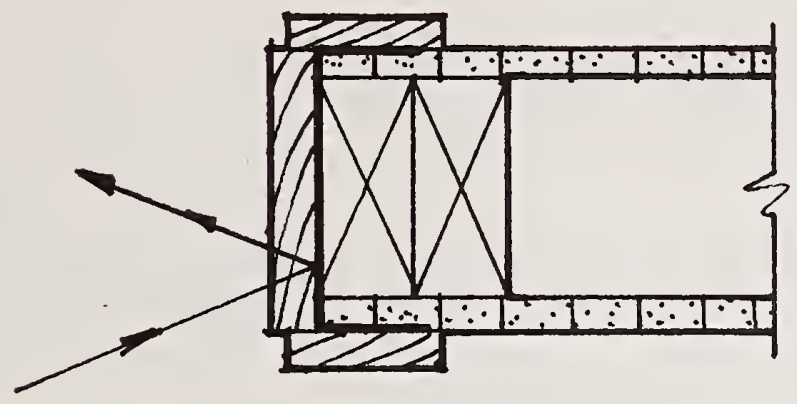

PROPOSED MOISTURE CONTROL

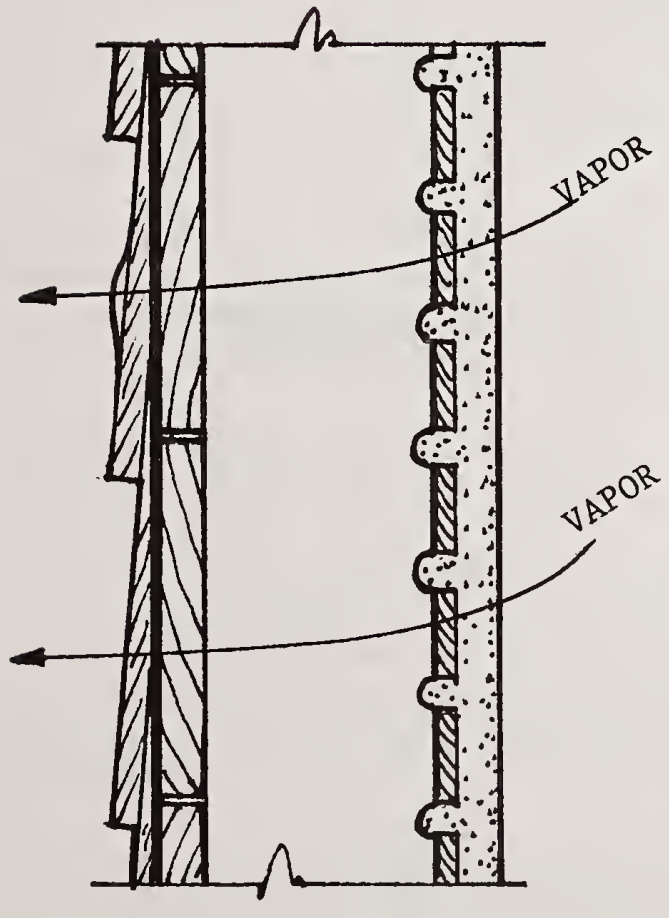

50-75 YEAR OLD HOME

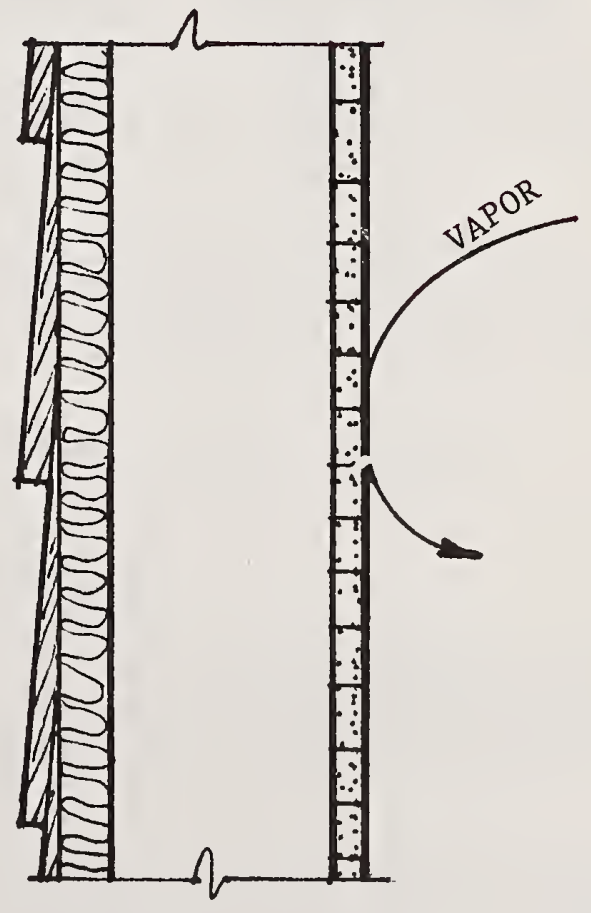

PROPOSED MOISTURE CONTROL

Figure 4

267 


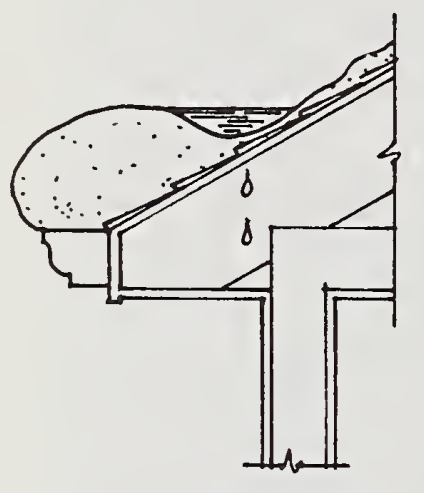

Figure 5

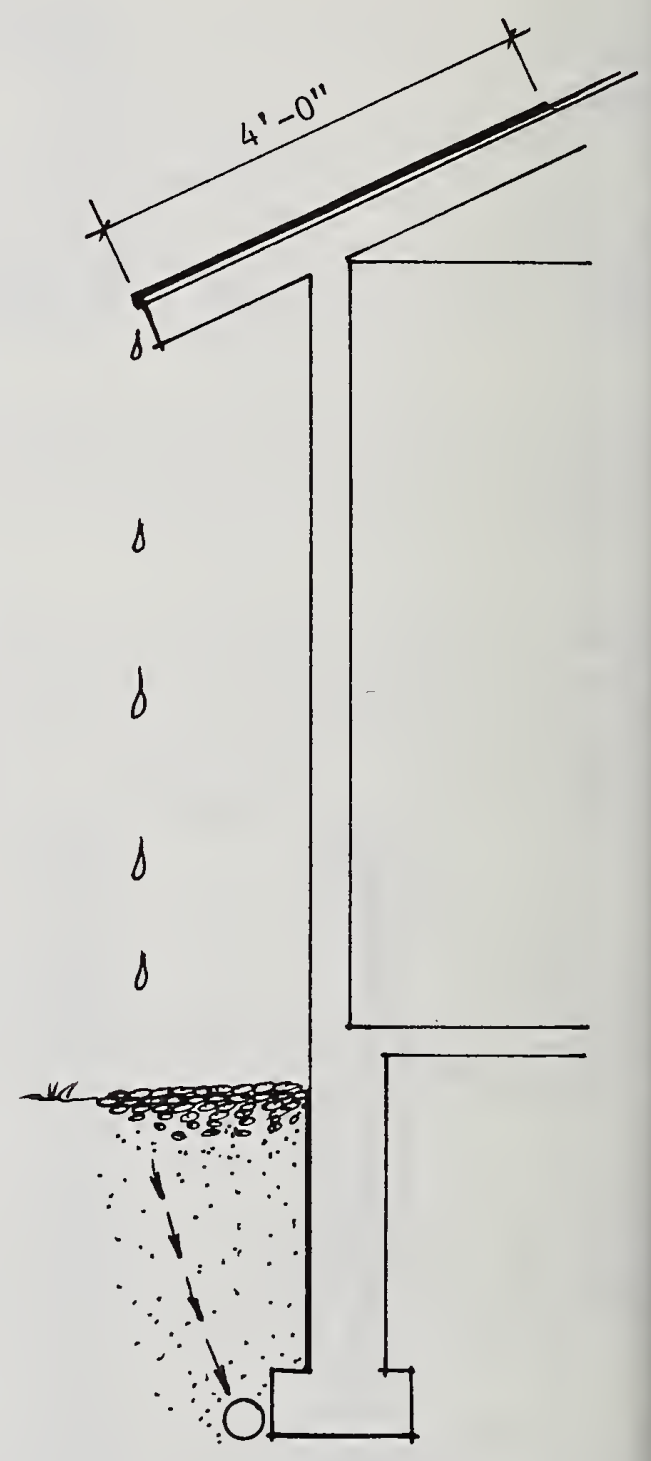

Figure 6 
This constant cycling of freeze-thaw may go on for several days, causing shingle damage, interior leaks and damage to the gutter and eave construction.

Have you ever noticed that in the northern parts of the country, particularly in the snow belt, most of the houses do not have eave-troughs? The reason is simply that the eave-troughs caused too many problems by contributing to the ice dam condition and in many cases the eave-troughs were damaged or destroyed by ice.

One solution is to use heat tapes laid in the trough but even this is not entirely satisfactory.

\section{ALTERNATIVES}

I would like to propose a few alternative remedies that would greatly reduce this problem: (Figure 6) Omit the eave-troughs and let roof water drip to a course gravel or stone bed at the grade level. If the house has a basement, the walls should be well waterproofed. A perimeter footing drain should be provided in all cases to run the roof water into the sewer. Eave-troughs may be used at points of entry for protection.

After roof felts have been applied, install metal edge strip around perimeter of roof line. Next install a $4^{\prime}-0^{\prime \prime}$ wide sheet of flashing metal or heavy vinyl flashing around all eave lines. This sheet will act as a water and ice barrier and will prevent roof leaks if ice backs up under the roof shingles. Then install the roof shingles.

Provide eave line ventilation into the attic area and out through the gable vents or roof vents. This must be vented from the cold side of any insulation. This system discourages a warm air build-up that might cause ice or snow on the roof to melt.

If further protection is desired, heat tape may be laid under the shingles parallel to the eaves.

\section{CONCLUSION AND RECOMMENDATIONS}

I have cited some examples of snow loadings, building collapses, structural theories relative to overloading, conditions that contribute to structural failure and proposed some recommendations relative to moisture control.

I propose that the American National Standards Institute make a restudy of ANSI A58.1-1972, and that each state be represented in order to more accurately depict and chart the weather conditions for those areas, and that this information be transposed to revised national charts and maps. (Considerable difference has been found between ANSI data and the Michigan Weather Service data.) 
I also propose that all nationally-recognized codes and standards organizations study these situations and include them in their next code or standard change cycle. I would like them to consider developing snow load tables that the layperson can understand and use. I would like to have consideration given to our changing climatology. I would like to see the building codes include definitions of vapor barrier, dew point, permeable, liquid water, ice dam, air tight, and snow load.

If we are going to dictate the minimum building requirements of today's buildings, we must also be aware of today's conditions. 


\begin{tabular}{|c|c|c|}
\hline $\begin{array}{l}\text { U.S. DEPT. OF COMM. } \\
\text { BIBLIOGRAPHIC DATA } \\
\text { SHEET }\end{array}$ & $\begin{array}{l}\text { 1. PUBLICATION OR REPORT NO. } \\
\text { NBS SP } 586\end{array}$ & 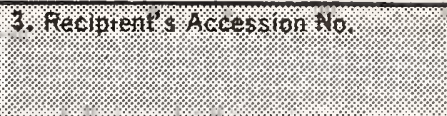 \\
\hline \multirow{2}{*}{\multicolumn{2}{|c|}{$\begin{array}{l}\text { 4. TITLE AND SUBTITLE } \\
\text { Research and Innovation in the Building Regulatory Process } \\
\text { Proceedings of the } 4 \text { th Annual Joint NBS-NCSBCS Conference }\end{array}$}} & $\begin{array}{l}\text { 5. Publication Date } \\
\text { June } 1980\end{array}$ \\
\hline & & 6. Performing Organization Code \\
\hline \multicolumn{2}{|c|}{$\begin{array}{l}\text { 7. AUTHOR(S) } \\
\text { Sandra A. Berry, Editor }\end{array}$} & 8. Performing Organ. Report No. \\
\hline \multirow{2}{*}{\multicolumn{2}{|c|}{$\begin{array}{l}\text { 9. PERFORMING ORGANIZATION NAME AND ADDRESS } \\
\text { NATIONAL BUREAU OF STANDARDS } \\
\text { DEPARTMENT OF COMMERCE } \\
\text { WASHINGTON, DC } 20234\end{array}$}} & 10. Project/Task/Work Unit No. \\
\hline & & 11. Contract/Grant No. \\
\hline \multirow{2}{*}{\multicolumn{2}{|c|}{$\begin{array}{l}\text { 12. SPONSORING ORGANIZATION NAME AND COMPLETE ADDRESS (Street, City, State, zIP) } \\
\text { U.S. Department of Commerce, National Bureau of Standards } \\
\text { and National Conference of States on Building Codes and } \\
\text { Standards (NCSBCS) }\end{array}$}} & $\begin{array}{l}\text { 13. Type of Report \& Period Covered } \\
\text { Final }\end{array}$ \\
\hline & & 14. Sponsoring Agency Code \\
\hline
\end{tabular}

\section{SUPPLEMENTARY NOTES}

Library of Congress Catalog Card Number: 80-600080

$\square$ Document describes a computer program; SF-185, FIPS Software Summary, is attached.

16. ABSTRACT (A 200-word or less factual summary of most sigrificant information. If document includes a significant bibliography of literature survey, mention it here.)

The Proceedings of the 4th Annual NBS/NCSBCS Joint Conference on Research and Innovation in the Building Regulatory Process contain nineteen technical papers, the opening remarks and Keynote Address. The subject matter covered in these Proceedings includes:

o Issues in Building Code Enforcement;

- Legal, Political and Educational Aspects of Code Enforcement;

o Studies Dealing with Housing Codes;

- Energy Conservation and the Built Environment;

- Design Considerations and Their Impact on Code Enforcement; and,

- Innovative Regulatory Approaches for Metrication, Insulation Standards, and Climatic Conditions

17. KEY WORDS (six to twelve entries; alphabetical order; capitalize only the first letter of the first key word unless a proper name; separated by semicolons)

Buildings; building code enforcement; design; energy conservation; housing codes; regulatory approaches.

\section{AVAILABILITY$$
\text { XXulimited }
$$

For Official Distribution. Do Hot Release to NTIS

XX Order From Sup. of Doc., U.S. Government Printing Office, Washington, DC 20402.

$\square$ Order From National Technical Information Service (NTIS), Springfield, VA. 22161

\begin{tabular}{|l|c|}
\hline $\begin{array}{l}\text { 19. SECURITY CLASS } \\
\text { (THIS REPORT) }\end{array}$ & $\begin{array}{c}\text { 21. NO. OF } \\
\text { PRINTED PAGES } \\
\text { UNCLASSIFIED }\end{array}$ \\
\hline $\begin{array}{l}\text { 20. SECURITY CLASS } \\
\text { (THIS PAGE) }\end{array}$ & 261 \\
L...CLASSIFIED & $\$ 7.00$ \\
\hline
\end{tabular}




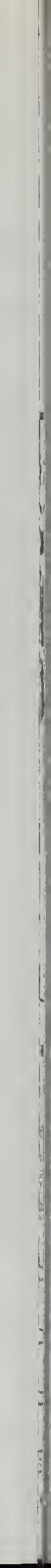




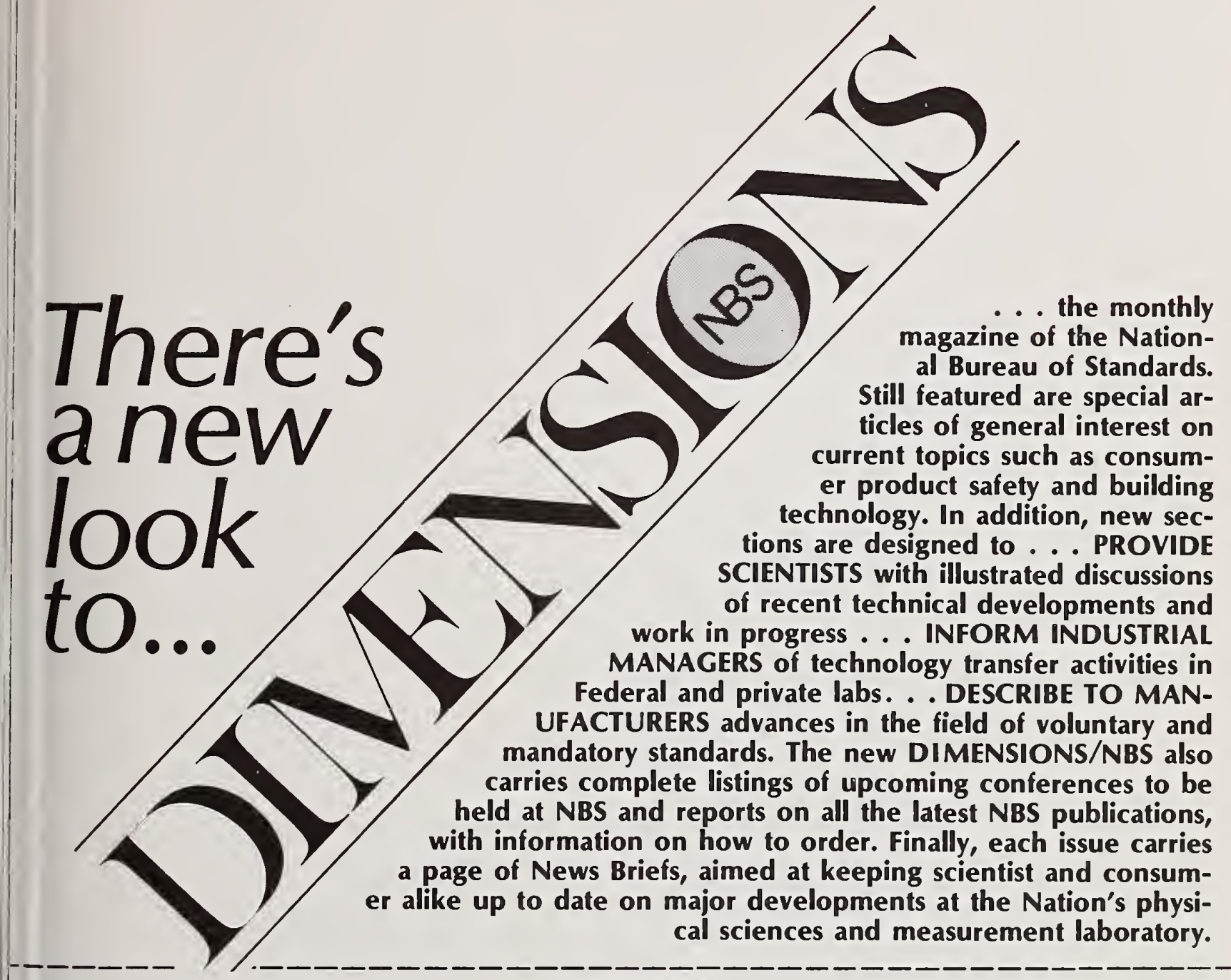

(please delach here)

JBSCRIPTION ORDER FORM

ter my Subscription To DIMENSIONS/NBS at $\$ 11.00$. Add $\$ 2.75$ for foreign mailing. No additional stage is required for mailing within the United States or its possessions. Domestic remittances ould be made either by postal money order, express money order, or check. Foreign remittances ould be made either by international money order, draft on an American bank, or by UNESCO upons.

end Subscription 10:

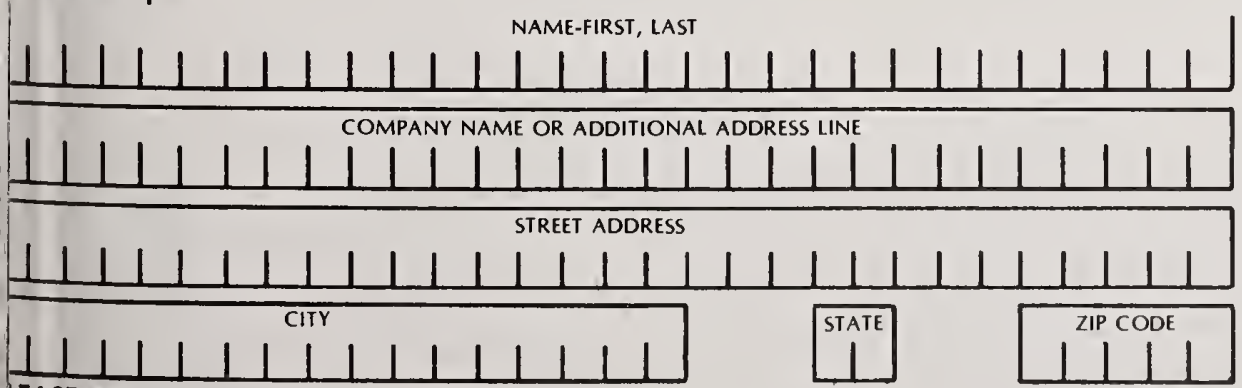

Remittance Enclosed (Make checks payable to Superintendent of Documents)

Charge to my Deposi Account No.

MAIL ORDER FORM TO:

Superintendent of Documents Government Printing Office Washington, D.C. 20402 


\section{NBS TECHNICAL PUBLICATIONS}

\section{PERIODICALS}

JOURNAL OF RESEARCH-The Journal of Research of the National Bureau of Standards reports NBS research and development in those disciplines of the physical and engineering sciences in which the Bureau is active. These include physics, chemistry, engineering, mathematics, and computer sciences. Papers cover a broad range of subjects, with major emphasis on measurement methodology and the basic technology underlying standardization. Also included from time to time are survey articles on topics closely related to the Bureau's technical and scientific programs. As a special service to subscribers each issue contains complete citations to all recent Bureau publications in both NBS and nonNBS media. Issued six times a year. Annual subscription: domestic $\$ 13$; foreign $\$ 16.25$. Single copy, $\$ 3$ domestic; $\$ 3.75$ foreign.

NOTE: The Journal was formerly published in two sections: Section A "Physics and Chemistry" and Section B "Mathematical Sciences."

DIMENSIONS/NBS-This monthly magazine is published to inform scientists, engineers, business and industry leaders, teachers, students, and consumers of the latest advances in science and technology, with primary emphasis on work at NBS. The magazine highlights and reviews such issues as energy research, fire protection, building technology, metric conversion, pollution abatement, health and safety, and consumer product performance. In addition, it reports the results of Bureau programs in measurement standards and techniques, properties of matter and materials, engineering standards and services, instrumentation, and automatic data processing. Annual subscription: domestic \$11; forcign $\$ 13.75$.

\section{NONPERIODICALS}

Monographs-Major contributions to the technical literature on various subjects related to the Bureau's scientific and technical activities,

Handbooks-Recommended codes of engineering and industrial practice (including safety codes) developed in cooperation with interested industries, professional organizations, and regulatory bodies.

Special Publications-Include proceedings of conferences sponsored by NBS, NBS annual reports, and other special publications appropriate to this grouping such as wall charts, pocket cards, and bibliographies.

Applied Mathematics Series-Mathematical tables, manuals, and studies of special interest to physicists, engineers, chemists, biologists, mathematicians, computer programmers, and others engaged in scientific and technical work.

National Standard Reference Data Series-Provides quantitative data on the physical and chemical properties of materials, compiled from the world's literature and critically evaluated. Developed under a worldwide program coordinated by NBS under the authority of the National Standard Data Act (Public Law 90-396).
NOTE: The principal publication outlet for the foregoing data is the Journal of Physical and Chemical Reference Data (JPCRD) published quarterly for NBS by the American Chemical Society (ACS) and the American Institute of Physics (AIP). Subscriptions, reprints, and supplements available from ACS, 1155 Sixteenth St., NW, Washington, DC 20056.

Building Science Series-Disseminates technical information developed at the Bureau on building materials, components, systems, and whole structures. The series presents research results, test methods, and performance criteria related to the structural and environmental functions and the durability and safety characteristics of building elements and systems.

Technical Notes-Studies or reports which are complete in themselves but restrictive in their treatment of a subject. Analogous to monographs but not so comprehensive in scope or definitive in treatment of the subject area. Often serve as a vehicle for final reports of work performed at NBS under the sponsorship of other government agencies.

Voluntary Product Standards-Developed under procedures published by the Department of Commerce in Part 10, Title 15, of the Code of Federal Regulations. The standards establish nationally recognized requirements for products, and provide all concerned interests with a basis for common understanding of the characteristics of the products. NBS administers this program as a supplement to the activities of the private sector standardizing organizations.

Consumer Information Series-Practical information, based on NBS research and experience, covering areas of interest to the consumer. Easily understandable language and illustrations provide useful background knowledge for shopping in today's technological marketplace.

Order the above NBS publications from: Superintendent of Documents, Government Printing Office; Washington, DC 20402.

Order the following NBS publications-FIPS and NBSIR's-from the National Technical Information Services, Springfield, VA 22161.

Federal Information Processing Standards Publications (FIPS PUB)-Publications in this series collectively constitute the Federal Information Processing Standards Register. The Register serves as the official source of information in the Federal Government regarding standards issued by NBS pursuant to the Federal Property and Administrative Services Act of 1949 as amended, Public Law 89-306 (79 Stat. 1127), and as implemented by Executive Order 11717 (38 FR 12315, dated May I1. 1973) and Part 6 of Title 15 CFR (Code of Federal Regulations).

NBS Interagency Reports (NBSIR)-A special series of interim or final reports on work performed by NBS lor outside sponsors (both government and non-government). In general, initial distribution is handled by the sponsor; public distribution is by the National Technical Information Services, Springfield, VA 22161. in paper copy or microfiche form.

\section{BIBLIOGRAPHIC SUBSCRIPTION SERVICES}

The following current-awareness and literature-survey bibliographies are issued periodically by the Bureau:

Cryogenic Data Center Current Awareness Service. A literature survey issured biweekly. Annual subscription: domestic $\$ 25$; foreign $\$ 30$.

Liquefied Natural Gas. A literature survey issued quarterly. Annual subscription: $\$ 20$.
Superconducting Devices and Materials. A literature survey issued quarterly. Annual subscription: \$30. Please send subscription orders and remittances for the preceding bibliographic services to the National Bureau of Standards, Cryogenic Data Center (736) Boulder, CO 80303. 
